Aus dem Max-Planck-Institüt für Biophysikalische Chemie in Göttingen

Abteilung Zelluläre Biochemie

Direktor: Prof. Dr. Reinhard Lührmann

\title{
Investigation of the higher order structure of the spliceosomal RNA network
}

\author{
Dissertation \\ zur Erlangung des Doktorgrades \\ der Mathematisch-Naturwissenschaftlichen Fakultäten \\ der Georg-August-Universität zu Göttingen
}

vorgelegt von

Gizem Dönmez

aus

Nazilli, Turkey

Göttingen, 2006 
D7

Referent: Prof. Dr. Ralf Ficner

Korreferent: Prof. Dr. Reinhard Jahn

Tag der mündlichen Prüfung: 17.01.07 


\section{TABLE OF CONTENTS}

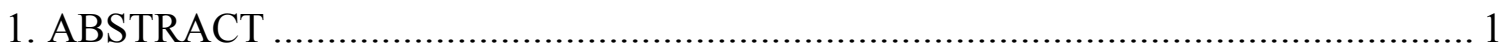

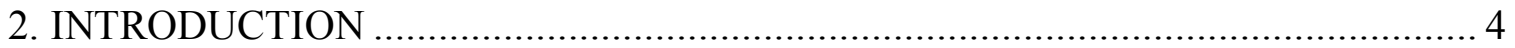

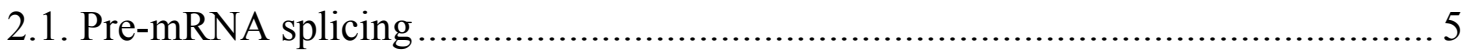

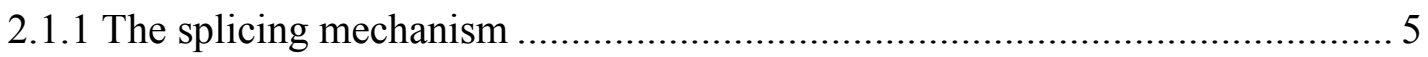

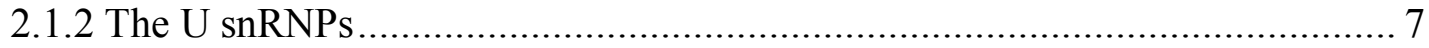

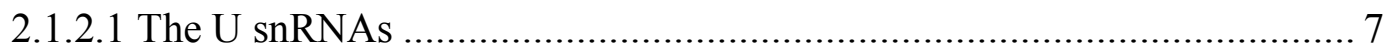

2.1.2.1.1 Internal modified nucleotides in snRNAs ......................................... 9

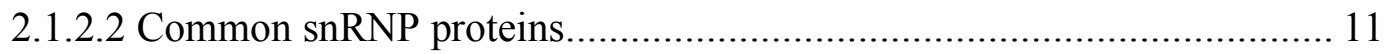

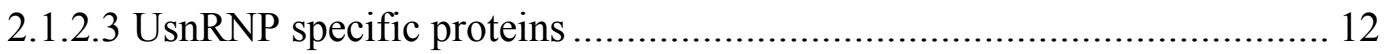

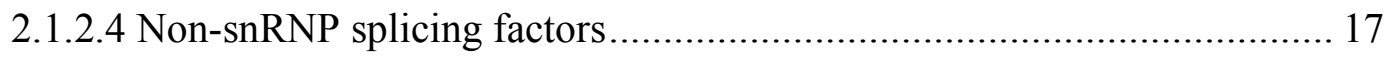

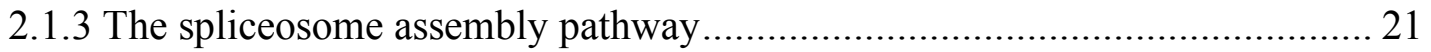

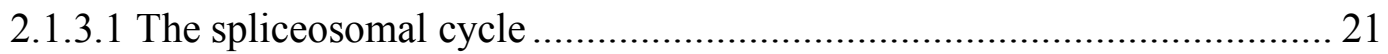

2.1.3.2 The RNA-RNA network in the spliceosome.......................................... 23

2.1.4 The recognition and pairing of the splice sites........................................... 25

2.1.4.1 Current knowledge on the interactions among the elements of early

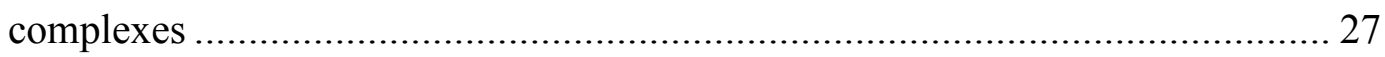

2.1.4.2 The site-directed hydroxyl radical probing as a method to investigate the higher order RNA structure in early spliceosomal complexes ............................ 30

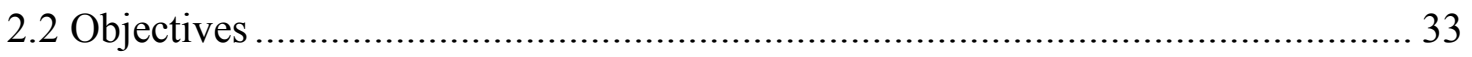

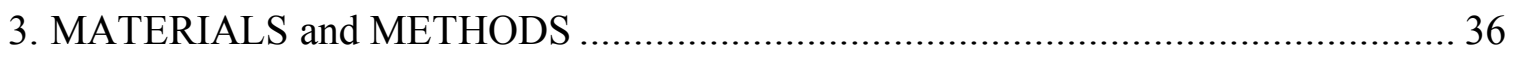

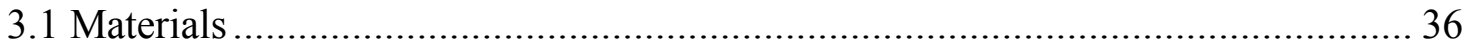

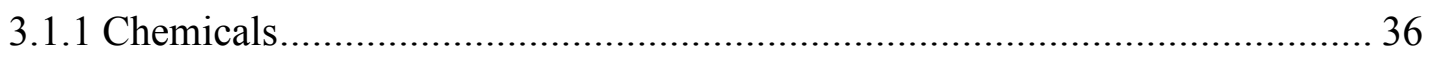

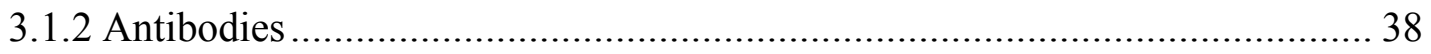

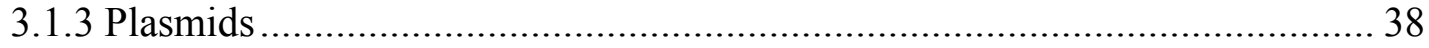

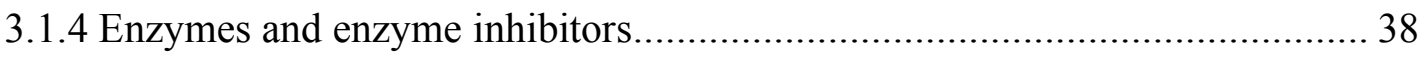

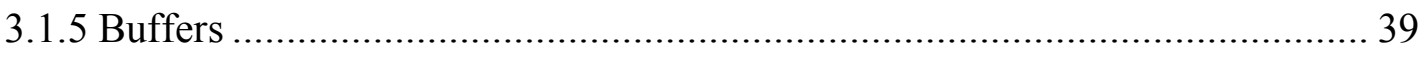

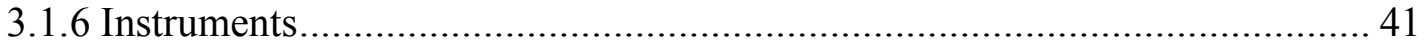

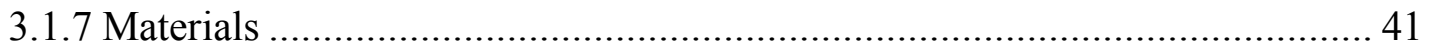




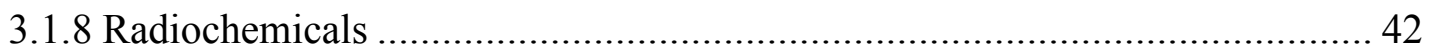

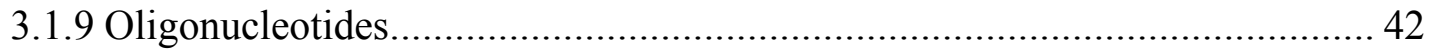

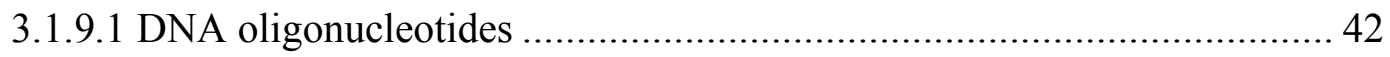

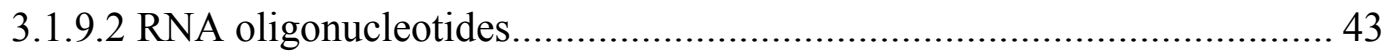

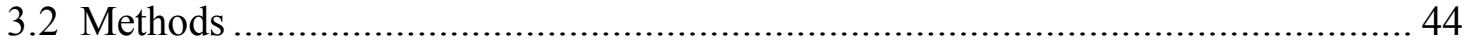

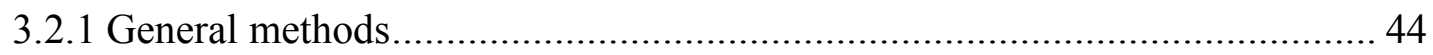

3.2.1.1 Phenol/chloroform extraction............................................................. 44

3.2.1.2 Ethanol precipitation of nucleic acids................................................ 45

3.2.1.3 Concentration determination of DNA or RNA ....................................... 45

3.2.1.4 Concentration determination of proteins................................................ 46

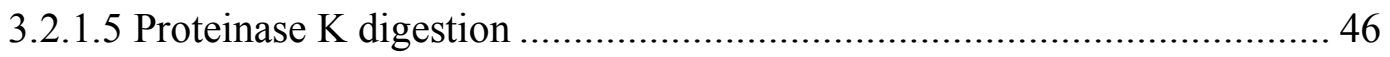

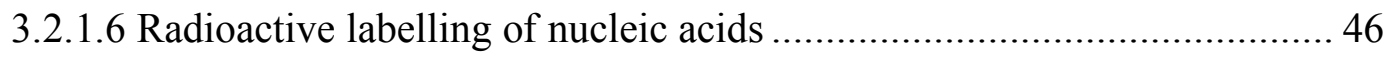

3.2.1.6.1 5'-End labeling with T4 Polynucleotide kinase and $\gamma^{3}{ }^{32} \mathrm{P}$ ATP ........ 46

3.2.1.6.2 3'-End labelling with T4-RNA-Ligase (pCp labeling) ...................... 47

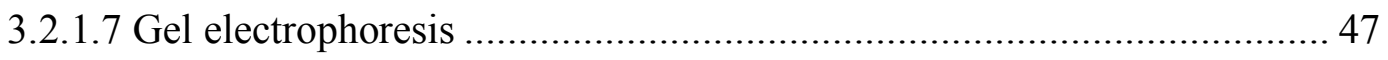

3.2.1.7.1 High-TEMED, SDS-polyacrylamide gel electrophoresis (PAGE).... 47

3.2.1.7.2 Denaturing polyacrylamide gel electrophoresis of RNA .................. 49

3.2.1.7.3 Agarose gel electrophoresis.......................................................... 50

3.2.1.7.4 Low-melting agarose gel electrophoresis for RNA complex gels..... 50

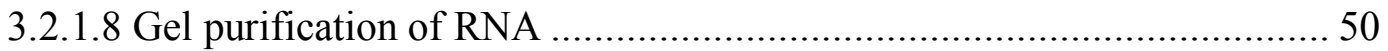

3.2.1.9 Autoradiography and Phosphor Imager Analysis................................... 51

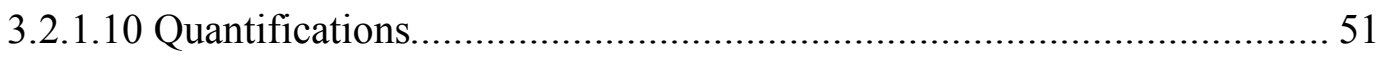

3.2.1.10.1 Quantification of a single RNA band........................................... 51

3.2.1.10.2 Densitometric analysis of primer extension gels .......................... 52

3.2.1.11 Preparation of competent E. coli bacteria and E. coli transformation .... 52

3.2.1.12 Preparative plasmid preparation ......................................................... 53

3.2.1.13 Standard polymerase chain reaction (PCR) ………………................ 53

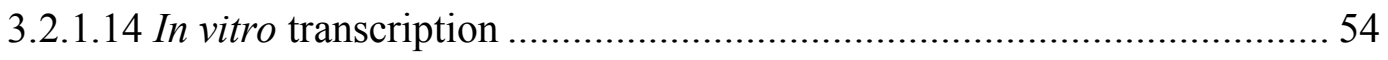

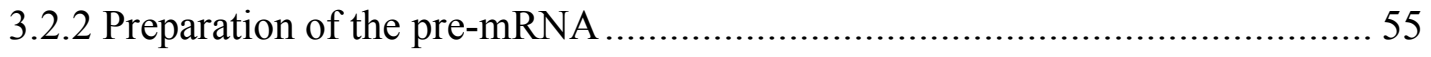

3.2.2.1 Generation of branchsite-deleted pre-mRNA........................................ 55

3.2.2.2 Generation of 5' ss-deleted pre-mRNA................................................. 56 


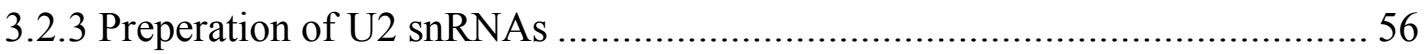

3.2.3.1 Preparation of U2 and U2G25 RNA transcripts................................... 56

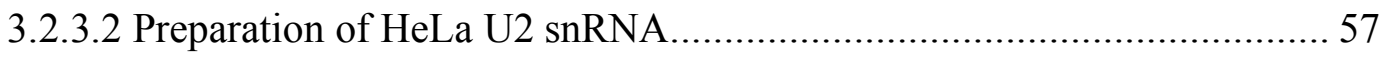

3.2.3.3 Preparation of chimaeric U2 snRNAs via ligations................................. 58

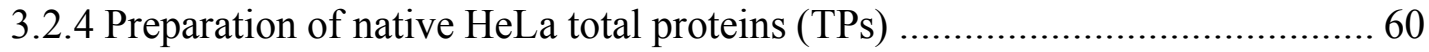

3.2.5 Preparation of U2 snRNP-depleted nuclear extract ....................................... 61

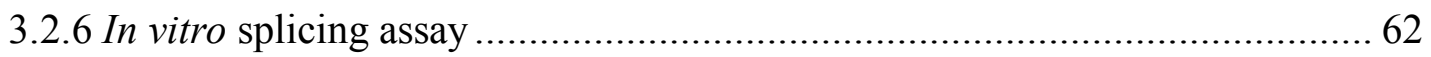

3.2.7 In vitro reconstitution/complementation assay .................................................. 63

3.2.8 Analysis of complex formation in nuclear extract ......................................... 63

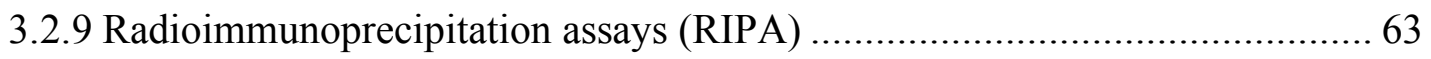

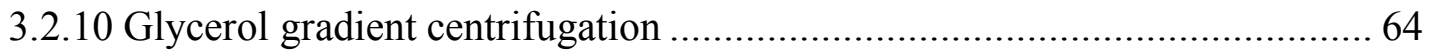

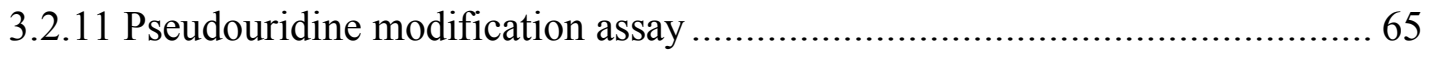

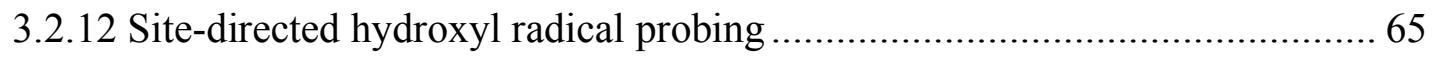

3.2.12.1 Synthesis of bromoacetamidobenzyl-EDTA (BABE) ........................... 65

3.2.12.2 Cysteine-test to control the reactivity of BABE ..................................... 67

3.2.12.3 Modification of the 5' U2 RNA oligo with Fe(II)-BABE...................... 67

3.2.12.4 Generation of functional Fe(II)-BABE modified U2 snRNPs ............... 69

3.2.12.5 Fe(II)-BABE induced hydroxyl radical formation ............................... 70

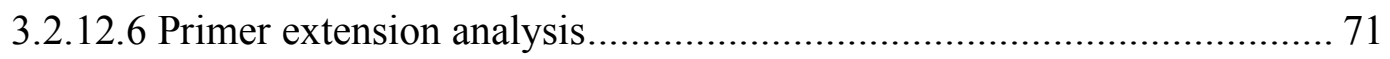

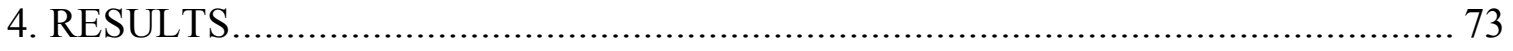

4.1 Modifications of U2 at the 5' end are required for splicing ................................ 73

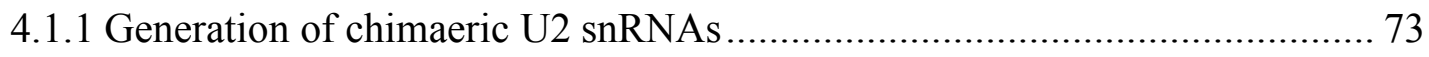

4.1.2 Native snRNP protein (total protein) preparations and in vitro reconstitution of

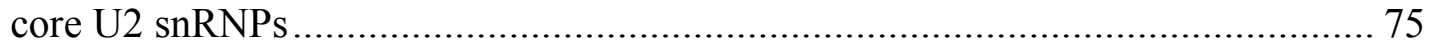

4.1.2.1 Native snRNP protein (total protein) preparations …………………........ 77

4.1.2.2 In vitro reconstitution of core U2 snRNP ............................................ 79

4.1.3 Depletion of U2 snRNP from HeLa nuclear extracts ..................................... 80

4.1.4 Splicing assay of the in vitro reconstituted chimaeric U2 snRNPs................. 81

4.1.4.1. Internal modifications at the 5 ' end of $\mathrm{U} 2$ snRNA, but not the $\mathrm{m}_{3} \mathrm{G}$ cap structure, are required for splicing in vitro 
4.1.4.2 The three pseudouridines within the first 24 nucleotides contribute to U2 snRNA function in pre-mRNA splicing..... 84

4.1.4.3 Four 5'-terminal 2'-O-methylations are essential for the function of U2 snRNA in pre-mRNA splicing. 85

4.1.5 Complex formation analysis of HeLa, in vitro transcribed and chimaeric U2 RNAs by using reconstitution/complementation system ............................... 85

4.1.6 Modifications are not required for 17S U2 snRNP assembly ...................... 88 4.1.7 Modifications are not required for the association of 17S U2-specific proteins 88

4.2 Site-directed hydroxyl radical probing in early complexes............................. 90

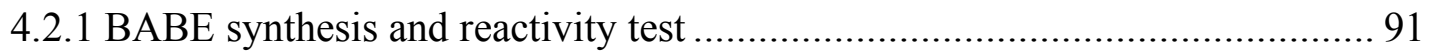

4.2.2 Modification of 5' U2 RNA oligo with Fe(II)-BABE ................................ 92

4.2.3 Formation of chimaeric Fe-BABE modified U2 snRNAs via ligation .......... 93 4.2.4 17S U2 snRNP assembly with Fe-BABE modified chimaeric U2 snRNAs ... 94 4.2.5 Analyzing the functionality of Fe-BABE modified chimaeric U2 snRNAs in complex formation and splicing.......................................................... 96

4.2.6 Site-directed hydroxyl radical probing of pre-mRNA in E complexes .......... 98

4.2.7 Site-directed hydroxyl radical probing of pre-mRNA in the A complex ...... 102

4.2.8 Proximity of the 5' end of U2 snRNA to U1 snRNA in early spliceosomal

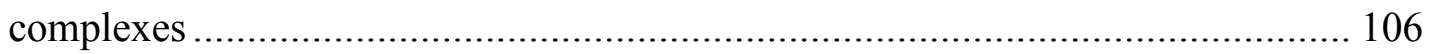

4.2.9 Densitometric analysis of the hydroxyl radical probing experiments ........... 114

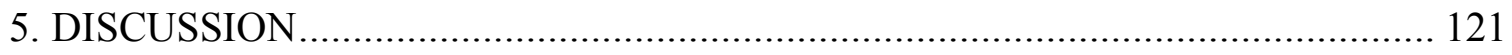

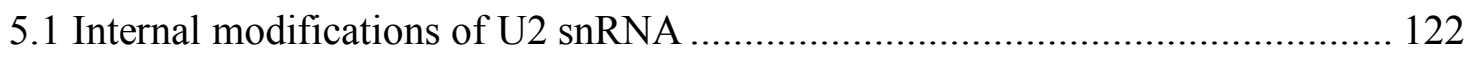

5.1.1 The three pseudouridines and five 2'-O-methylations at the 5' end of U2 snRNA are required for E complex formation and splicing in vitro................... 122

5.1.2 The $\mathrm{m}_{3} \mathrm{G}$ cap is not required for $\mathrm{U} 2$ function in splicing ......................... 124

5.1.3 The modifications are not required for the association of 17S U2-specific

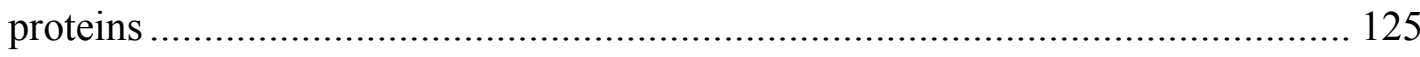

5.1.4 The role of modifications in E complex formation and splicing ................ 126

5.2 Hydroxyl radical probing in E and A complexes....................................... 128

5.2.1 Structural aspects of the E complex ................................................ 128 
5.2.2 Close spatial relationship of the U1 and U2 snRNPs .............................. 132

5.2.2.1 Mapping the cleavage data onto the 3D model of U1 snRNA............. 134

5.2.2.2 Mapping the cleavage data onto the 3D model of U1 snRNP .............. 134

5.2.3 The potential structural changes accompanying the E to A complex transition

5.2.4 Interactions among the components of the A complex

5.2.5 Conserved early spatial organization of snRNPs in the major and minor

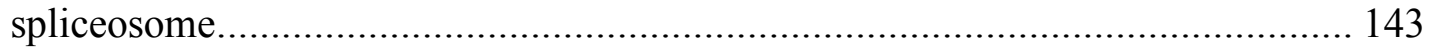

5.2.6 Pre-organization of U2 and its impact on subsequent assembly steps ......... 144

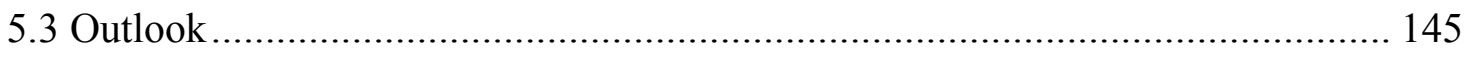

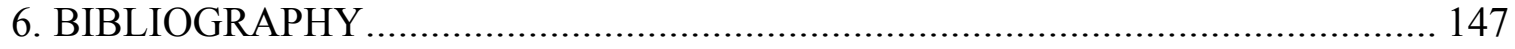

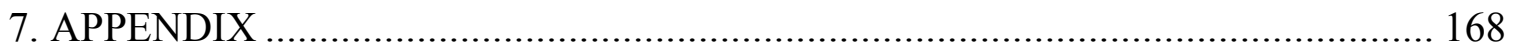

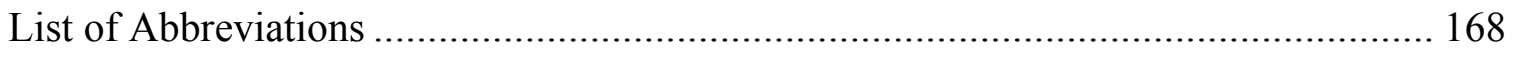

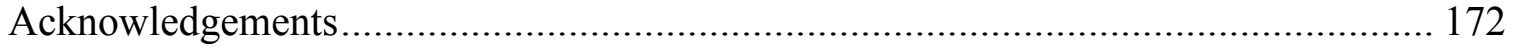

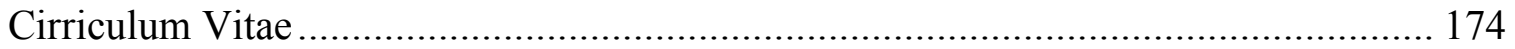

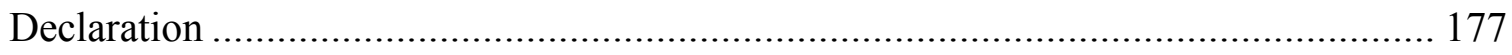




\section{ABSTRACT}

The removal of introns from pre-mRNA is achieved by a highly dynamic ribonucleoprotein complex termed the spliceosome. It is formed by the ordered association of the U1, U2, U4/U6 and U5 snRNPs (small nuclear ribonucleoproteins) and non-snRNP proteins with conserved regions of the pre-mRNA at the 5' and 3 ' splice sites, and the so-called branch site. Spliceosome assembly begins with the association of U1 and $\mathrm{U} 2$ to form the E complex. Subsequently, the A complex is formed upon stable integration of the U2 snRNP and is then converted to the B complex by association of the tri-snRNP (U4/U6.U5). After rearrangements, the catalytically active C complex is formed and the splicing reaction ensues.

Recognition and pairing of the correct $5^{\prime}$ and $3^{\prime}$ splice sites (ss) of a pre-mRNA are critical events that occur early during spliceosome assembly. Little is known about the spatial organization in early spliceosomal complexes of the U1 and U2 snRNPs, which together with several non-snRNP proteins, are involved in juxtapositioning the functional sites of the pre-mRNA. To better understand the molecular mechanisms of splice site recognition/pairing, we have examined the organization of $\mathrm{U} 2$ relative to $\mathrm{U} 1$ and premRNA in spliceosomal complexes via site-directed hydroxyl radical probing. For this purpose, the hydroxyl radical generator, Fe-BABE, was tethered to U2 snRNA and FeBABE modified U2 snRNPs were reconstituted in vitro, and used to complement splicing reactions lacking U2. To generate Fe-BABE modified U2 snRNAs active in splicing, we first determined which modifications of the U2 snRNA are essential and what role they play in U2 snRNP assembly and/or splicing.

U2 snRNA has a 5'-terminal $\mathrm{m}_{3} \mathrm{G}$ cap and many internal modifications including ten 2'O-methylated residues and thirteen pseudouridines. At the onset of this work, it was known that modifications within the first 27 nucleotides of U2 snRNA, including the $\mathrm{m}_{3} \mathrm{G}$ cap, are required for splicing and/or U2 snRNP biogenesis in Xenopus oocytes. 
However, precisely which modifications of U2 snRNA are essential and their role in snRNP and/or spliceosome assembly in HeLa nuclear extract was not clear. To address these questions, chimaeric U2 snRNAs were synthesized via Moore and Sharp ligation containing different numbers and types of modifications within the first 24 nucleotides of U2 snRNA and assayed for activity. It was shown that the three pseudouridines and five 2'-O-methyl groups within the first 24 nucleotides of U2 snRNA, but not the $\mathrm{m}_{3} \mathrm{G}$ cap, are required for efficient pre-mRNA splicing in vitro. The in vitro assembly of 17S U2 snRNPs was not dependent on the presence of modified U2 residues. However, spliceosomal complex formation assays demonstrated that internal modifications at the $5^{\prime}$ end of U2 snRNA are required for the formation of the ATP-independent, early spliceosomal E complex. This data suggested that modifications within the first 24 nucleotides of U2 snRNA might play a role in facilitating the interaction of U2 with U1 snRNP and/or other factors within the E complex.

In the second part of this work, RNA proximities within the $\mathrm{E}$ and $\mathrm{A}$ spliceosomal complexes were analyzed by site-directed generation of hydroxyl radicals from Fe-BABE covalently attached to the U2 snRNA. Fe-BABE was attached to the 5 'terminal nucleotide, which was inserted during the chemical synthesis of the 24 nucleotide long oligomer comprising the $5^{\prime}$ end of U2 snRNA with all required natural modifications. Significantly, 5' Fe-BABE-U2 snRNPs supported both spliceosomal assembly and splicing in vitro. Hydroxyl radical probing with 5' Fe-BABE U2 snRNPs demonstrated that the functional sites of the pre-mRNA (the 5' and $3^{\prime}$ splice sites, the anchoring sequence and the polypyrimidine tract) are in close proximity to the 5 ' end of U2 in the E complex, the earliest detectable splicing complex. In A complex, the proximities to the pre-mRNA were generally similar. Interestingly, U1 snRNA was found to be in close proximity to the $5^{\prime}$ end of $\mathrm{U} 2$ in both $\mathrm{E}$ and A complexes. Upon A complex formation, the relative orientation of U1 snRNP to U2 snRNP did not change. This work showed for the first time that, as early as in the E complex, the U2 and U1 snRNPs are in close proximity and in a fixed orientation relative to one another. As such, they "bridge" the 5' and $3^{\prime}$ ends of the pre-mRNA. This particular orientation of U1 relative to U2 is 
dependent on active spliceosomal complex formation on pre-mRNA, and on a functional 5 ' splice site.

By mapping the U1 snRNA cleavage data onto the protein-free 3D U1 snRNA structure, it was shown that the cleaved nucleotides are oriented such that they could face a single point source of hydroxyl radicals, consistent with the idea that the 5' end of U2 is located on one side of the U1 snRNA. When the cleavage data on U1 snRNA were mapped onto the U1 snRNA in the U1 snRNP model, cleaved nucleotides were still found on one side of the U1 snRNA at the "back" of the U1 snRNP. These data indicate that the U2 snRNP interaction domain is located predominantly at the "back" of the U1 snRNP and, furthermore, support the apparent structure/position of the U1 snRNA in the U1 snRNP 3D model. The detection of hydroxyl radical cleavages at the $5^{\prime}$ end of the U1 snRNA suggests that this functionally important region is also positioned on the same side of the U1 snRNP as the other cleaved nucleotides.

These studies reveal that functional sites of the pre-mRNA and U1 snRNA are located close to the $5^{\prime}$ end of $\mathrm{U} 2$ both in E and A complexes. U1 and U2 snRNPs may form a molecular bridge between the ends of the intron, much like the U11/U12 di-snRNP. The results of this work thus suggest that a major rearrangement in the 5 ' end of U2 relative to the reactive functionalities of the pre-mRNA might not be required to generate catalytically active spliceosomes in the subsequent steps leading to the first step of splicing. 


\section{INTRODUCTION}

One of the most exciting discoveries of the molecular biology is the finding that the majority of the genes of higher eukaryotes possess exons (short coding sequences) and introns (internal non-coding sequences) which have to be excised in order to generate translatable mRNAs. The transcripts of these genes (pre-mRNAs) undergo extensive posttranscriptional processing prior to their translation into functional proteins by ribosomes. Eukaryotic pre-mRNA processing takes place in the nucleus, and mature mRNA is subsequently exported through the nuclear pore complex into the cytoplasm. The eukaryotic pre-mRNA processing involves (i) covalent attachment of an N7methylguanosine ( $\mathrm{m}^{7} \mathrm{G}$-cap) to the $5^{\prime}$ end of pre-mRNA, (ii) $3^{\prime}$ end cleavage of the premRNA, (iii) addition of a poly(A) tail to the 3' end of the pre-mRNA and (iii) removal of the introns from the pre-mRNA.

The latter step, which ensures the precise excision of introns and exact ligation of exons, is known as pre-mRNA splicing. It is catalyzed by a large, dynamic macromolecular machinery, called the spliceosome, composed of four uridine-rich small nuclear ribonucleoprotein particles (U1, U2, U4/U6 and U5 snRNPs) and numerous non-snRNP protein splicing factors.

Alternative splicing, the process by which the exons of primary transcripts (pre-mRNAs) from genes can be spliced in different arrangements to produce structurally and functionally distinct mRNA and thus also protein variants, may be one of the most extensively used mechanisms that accounts for the greater macromolecular and cellular complexity of higher organisms. It is a central mode of genetic regulation in higher eukaryotes and major contributor to protein diversity in metazoan organisms. 


\subsection{Pre-mRNA splicing}

\subsubsection{The splicing mechanism}

Most of the eukaryotic genes are initially expressed as precursor messenger RNAs (premRNAs), which undergo a nuclear processing event called splicing in order to become functional messenger RNAs (mRNAs). Pre-mRNA splicing is the removal of non-coding regions, which are called introns, from the pre-mRNA, and the ligation of the coding regions which are called exons. This process is achieved by the spliceosome, a dynamic machinery composed of several snRNP particles and numerous non-snRNP splicing factors (Burge et al., 1999).

The splicing reaction proceeds by two consecutive transesterification steps (Moore et al., 1993). The phosphodiester bonds of the pre-mRNA that have to be cleaved and then ligated are precisely defined by consensus sequences which are located around the $5^{\prime}$ and 3' splice sites and the branch site (Fig. 2-1). In mammalian cells, the 5' and 3' splice sites consensus sequences in the majority of introns, which are called U2-type introns, are AG/GURAGU and Y $\underline{A G / G}$, respectively, while the branch site is YNYURAC (where / indicates the splice site, $\mathrm{R}=$ purine, $\mathrm{Y}=$ pyrimidine and $\mathrm{N}=$ any nucleotide) (Fig. 2-1). In the first step of splicing, the $2^{\prime} \mathrm{OH}$ group of the branch adenosine, which is usually located 18 to 40 nucleotides upstream of the $3^{\prime}$ splice site, attacks the phosphodiester bond at the $5^{\prime}$ splice site (Fig. 2-1). This results in cleavage of the 3',5' phosphodiester bond at the $5^{\prime}$ splice site and the concomitant formation of an unusual 2',5' phosphodiester bond between the first nucleotide of the intron and the branch site adenosine to produce two splicing intermediates which are the $5^{\prime}$ exon and a lariat containing the intron and $3^{\prime}$ exon. In the second step, the $3^{\prime} \mathrm{OH}$ of the $5^{\prime}$ exon, which is released by the first transesterification reaction, carries out a nucleophilic attack at the $3^{\prime}$ splice site. This results in ligation of exons via 3', 5' phosphodiester bond and excision of the intron in the form of lariat which is subsequently debranched and degraded. 

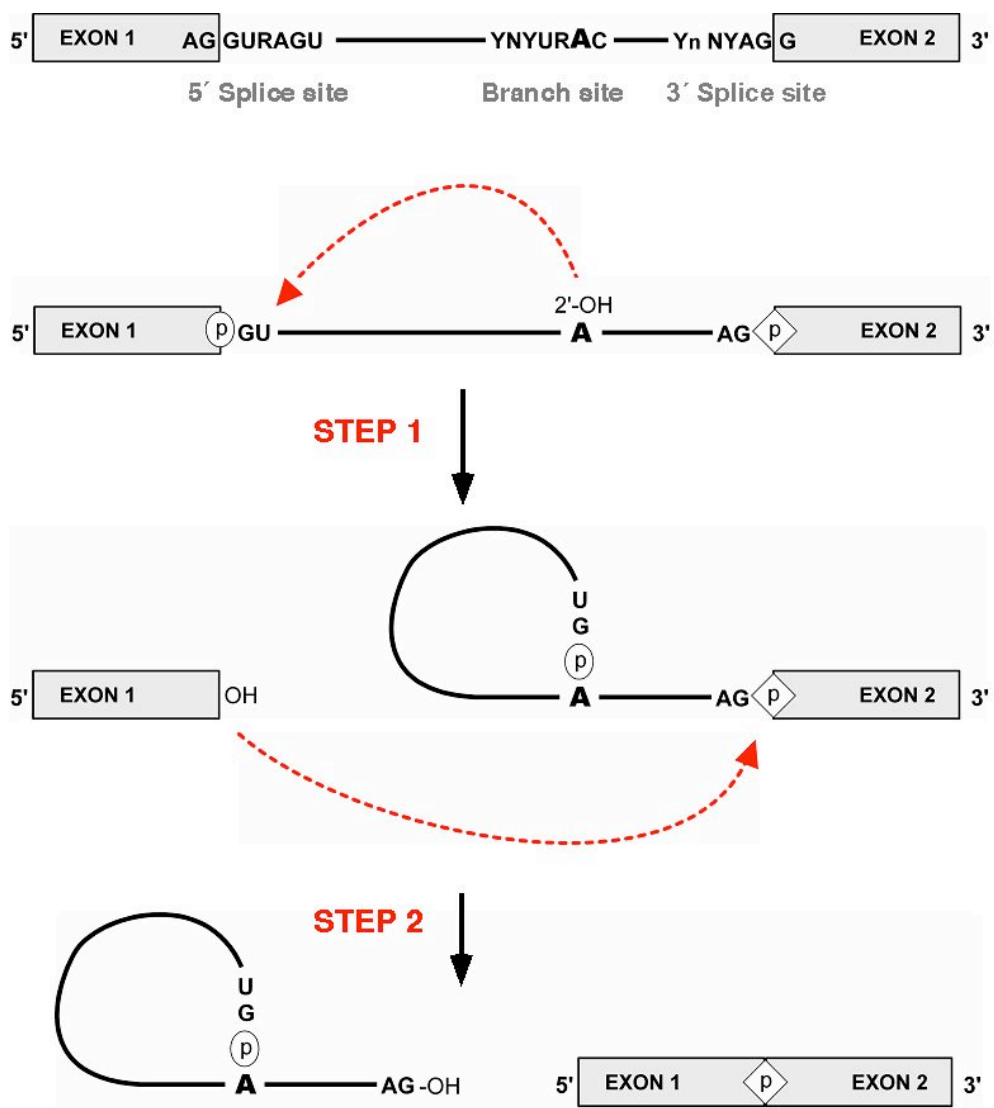

Intron

mRNA

Figure 2-1. Schematic representation of the two-step splicing pathway of pre-mRNAs. Boxes and solid lines indicate exon and intron sequences, respectively. The consensus sequences at the 5' and 3' splice sites, and branch site are shown, where $\mathrm{N}$ : any base, $\mathrm{Y}$ : pyrimidine, and R: purine. The branch site adenosine is written with bold letter, and the polypyrimidine tract is denoted by Yn. The nucleophilic attacks on the splice sites by the 2' OH of the branch site adenosine (step 1) and of the 3' $\mathrm{OH}$ of the cleaved 5' exon (step 2) are displayed by dashed arrows. The phosphate groups at the $5^{\prime}$ and $3^{\prime}$ splice sites, which are conserved in splicing products, are denoted by a circle and square, respectively. This figure is kindly provided by Berthold Kastner.

RNA splicing of nuclear pre-mRNA is catalyzed by spliceosome. Spliceosomes are assembled stepwise on pre-mRNA. The snRNPs U1, U2, U5 and U4/U6 are the main subunits of U2-dependent spliceosome and consist of one or two snRNA molecules together with a group of seven common Sm proteins B, B', D3, D2, D1, E, F, G plus particle-specific proteins (Will and Lührmann, 1997). 
The majority of nuclear pre-mRNA introns are removed by the major or U2-dependent spliceosome. U12-dependent introns, which represent less than $0.2 \%$ of all nuclear premRNAs, are excised by the minor or U12-dependent spliceosome. So far it was identified in only a limited number of eukaryotes. It is comprised of U11, U12 and U4atac/U6atac snRNPs (Will and Lührmann, 2005) which are functional analogues of U1, U2, U4/U6 snRNPs. The U5 snRNP is common to both spliceosomes. The consensus sequences delineating the U12-type 5' splice site -A(or G)UAUCCUUU- and branch siteUCCUUAACU- are longer and more tightly constrained compared to the U2-type introns. U12-type 3 ' splice sites are typically denoted by YAC/ or YAG/. U12-type introns are removed by an identical two-step mechanism of U2-type introns that involves two consecutive transesterification reactions.

\subsubsection{The U snRNPs}

Each of the U snRNPs are composed of one or two (in case of the U4/U6 and U4atac/U6atac snRNPs) uridine-rich small nuclear RNA molecules (U snRNAs), from which the name of the snRNPs is derived, a set of proteins common to all spliceosomal $\mathrm{U}$ snRNPs and a number of particle-specific proteins.

\subsubsection{The U snRNAs}

The spliceosomal snRNPs are comprised of uridyl-rich small nuclear RNAs (U snRNAs) associated with numerous proteins. Each of the U1, U2, U5, U11 and U12 snRNPs has one $\mathrm{U}$ snRNA while in the case of U4/U6 and U4atac/U6atac snRNPs, there are two $\mathrm{U}$ snRNAs which share sequence complementarities and stable base pairing. All U snRNAs have extensive secondary structures of stable double-stranded regions with stem-loops and bulges (Fig. 2-2). Except for U6 and U6atac, all U snRNAs are transcribed by RNA Polymerase II and obtain a $5^{\prime}$ N7-methyl guanosine cap $\left(\mathrm{m}^{7} \mathrm{G}\right)$ structure cotranscriptionally, which is modified in the cytoplasm to 2,2,7-trimethylguanosine cap $\left(\mathrm{m}_{3} \mathrm{G}\right)$. 

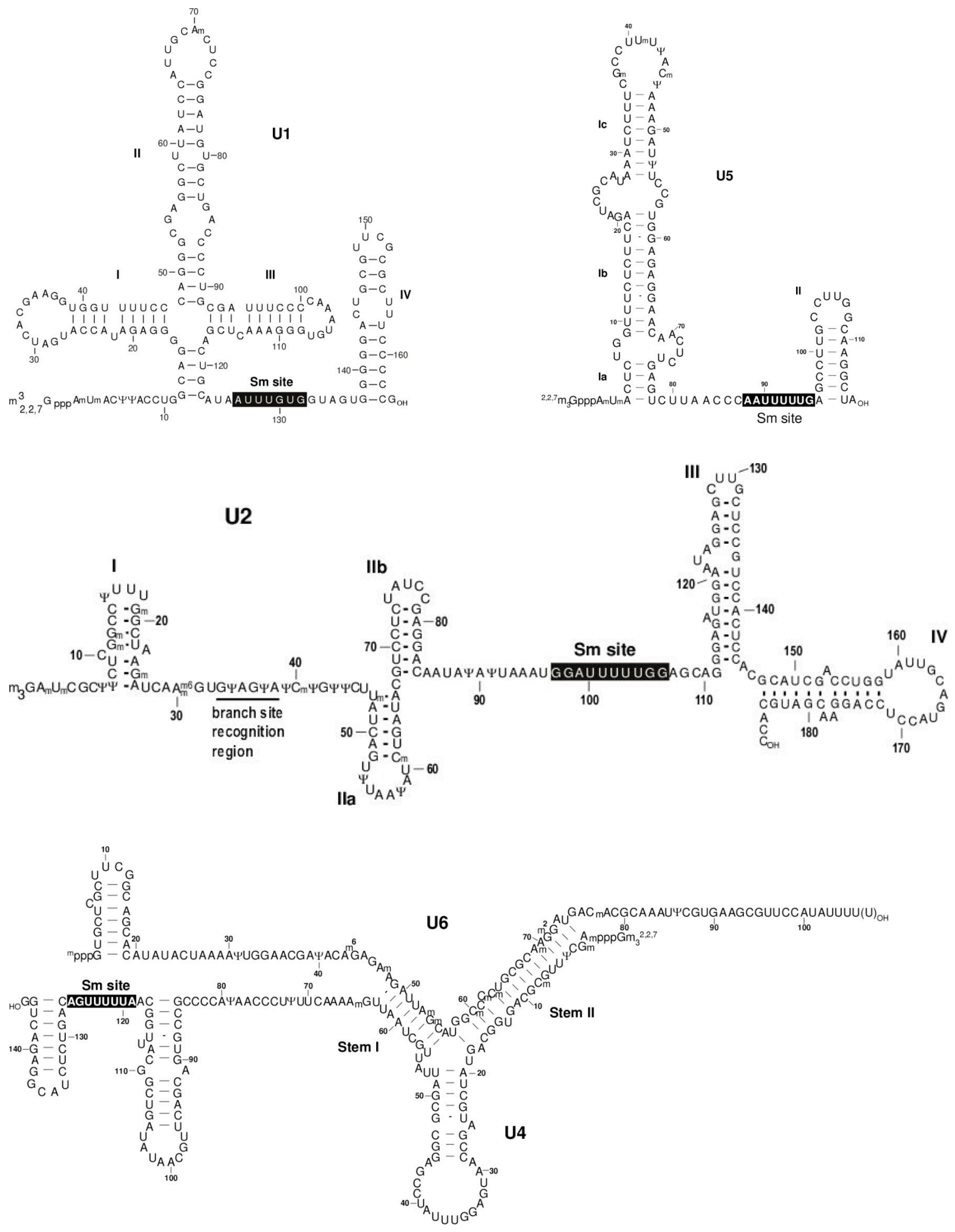

Figure 2-2. Primary and secondary structures of human U1, U2, U4/U6 and U5 snRNAs. Pseudouridines are indicated with $\psi$ and 2'-O-methylations are indicated with $\mathrm{m}$. The Sm site is shown in black (Burge et al., 1999). 
Another common feature of $U$ snRNAs is the presence of a short, conserved sequence of $\mathrm{PuAU}_{3-6} \mathrm{GPu}$, which is located within a single stranded region close to the 3 ' end of the snRNA (Branlant et al., 1982; Liautard et al., 1982). This was termed the Sm binding site, or the Sm site, because Sm proteins associate with this sequence element. U6 and U6atac do not have an Sm binding site, have a $\gamma$-methyl triphosphate cap, and are transcribed by RNA polymerase III (Reddy and Busch, 1988; Tarn and Steitz, 1996).

Newly synthesized spliceosomal snRNAs (except for U6) are transported into the cytoplasm where the Sm proteins associate with the Sm binding site (Lührmann, 1988; Mattaj, 1988). After this, the $5^{\prime}$-monomethylated guanosine cap $\left(\mathrm{m}^{7} \mathrm{G}\right)$ of each snRNA is hypermethylated to 2,2,7-trimethylguanosine cap $\left(\mathrm{m}_{3} \mathrm{G}\right)$ and it is transported back to the nucleus (Izaurralde and Mattaj, 1992; Mattaj, 1988). Once in the nucleus, the snRNP particles complete their biogenesis to a mature snRNP by addition of the particle specific proteins.

\subsection{Internal modified nucleotides in snRNAs}

RNA modification is a post-transcriptional process where certain nucleotides are altered after their initial incorporation into an RNA chain. Modified nucleotides occur in all organisms and in a variety of cellular RNAs. Among the most common internal modifications are 2'-O-methylation and the conversion of uridines to pseudouridines (5$\beta$-D-ribofuranosyluracil) (Fig. 2-3). These modified residues are identified in all three types of stable RNAs, namely, tRNAs (Auffinger and Westhof, 1998; Grosjean et al., 1995; Westhof and Michel, 1998), rRNAs (Maden, 1990; Ofengand and Bakin, 1997; Ofengand et al., 1995), and spliceosomal snRNAs (Massenet et al., 1998; Reddy and Busch, 1988). There are about ten times more sites of 2'-O-methylation and $\Psi$ formation in eukaryotes than in bacteria (Maden, 1990; Ofengand et al., 1995). The pseudouridylation of eukaryotic rRNAs and snRNAs is achieved by H/ACA snoRNPs. In all tRNAs and in eubacterial rRNAs, pseudouridines are synthesized by pseudouridine synthases. In eukaryotic rRNAs and in snRNAs, the 2'-O-methylations are achieved by 
C/D box snoRNPs and in tRNAs, ribose methylations are achieved exclusively with methyltransferases (Massenet et al., 1998).

$\Psi$ is unique among modified nucleosides in possessing a C-C rather than the usual N-C glycosyl bond that links base and sugar (Fig. 2-3). Because of the enhanced rotational freedom in C-C compared with N-C glycosyl bonds, $\Psi$ exhibits greater conformational flexibility than U. Modifications of the $2^{\prime}-\mathrm{OH}$ to a 2'-O-methyl is one of the most powerful biological strategies for stabilizing helical RNA structure. The modified nucleotide preferentially adopts the 3 '-endo, axial conformation to minimize steric interactions between the large methyl group and the base.

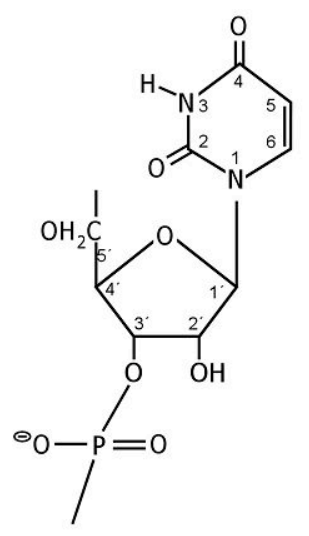

Uridine

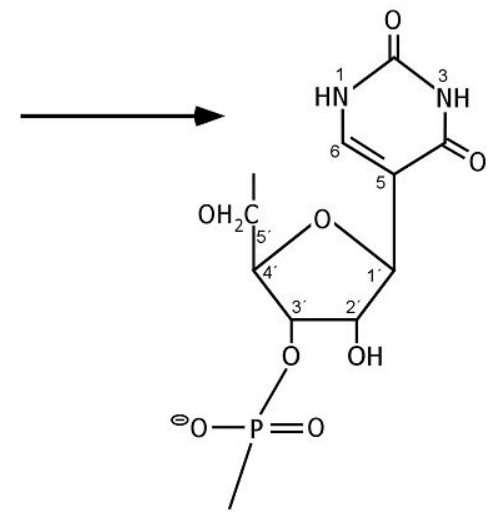

Pseudouridine

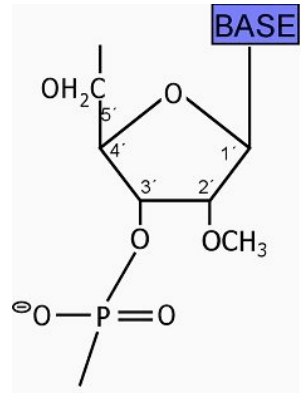

2'-O-Me

Figure 2-3. Uridine, pseudouridine $(\psi)$ and 2'-O-methylation are indicated.

A number of nucleotides of the $\mathrm{U}$ snRNAs are post-transcriptionally modified. The pseudouridines and 2'-O-methylations are the most common modifications observed in $\mathrm{U}$ snRNAs. In the major spliceosomal snRNAs (U1, U2, U4, U5 and U6), 23 pseudouridines and 30 2'-O-methylated nucleotides have been detected (Reddy and 
Busch, 1988). Compared with the major snRNAs, the U11, U12, U4atac and U6atac snRNAs contain notably fewer internal nucleotide modifications.

Among the U snRNAs, U2 has the most extensive modifications, including ten 2'-Omethylations and thirteen pseudouridines (Fig. 2-2). The posttranscriptional modifications identified in spliceosomal RNAs are mainly concentrated in the U snRNA segments that are shown to be involved in intermolecular RNA-RNA interactions, in U snRNA segments showing alternative secondary structures and in regions of functional importance ( $\mathrm{Gu}$ et al., 1996). Although their exact function is not known, the modifications are thought to play a role in stabilization of the U snRNA structure. This idea is based on the data obtained from biochemical and physical studies performed on pseudouridines of tRNAs (Auffinger and Westhof, 1998; Sampson et al., 1987). Consequently, it would not be surprising that pseudouridines would stabilize the snRNA in a similar manner as in tRNA. In snRNA, the occurrence of pseudouridines in singlestranded regions may be required to improve their recognition features.

The observations in several reconstitution systems showed that in vitro transcribed U1 snRNA (Will et al., 1996), U5 snRNA (Ségault et al., 1995), U4 snRNA (Wersig and Bindereif, 1992) and U6 snRNA (Fabrizio et al., 1989; Pikielny et al., 1989) supported splicing, whereas in vitro transcribed U2 snRNA did not complement splicing in U2depleted Xenopus oocytes (Pan et al., 1989) or in U2-depleted HeLa nuclear extracts (Segault et al., 1995). In Xenopus oocytes, it was demonstrated that the modifications within the first 27 nucleotides of $\mathrm{U} 2$ snRNA and the $\mathrm{m}_{3} \mathrm{G}$ cap at the 5 ' end are required for splicing (Yu et al., 1998).

\subsubsection{Common snRNP proteins}

All spliceosomal snRNAs, with the exception of U6 and U6atac, associate with a common set of seven Sm proteins to form core RNPs. Sm proteins, named G, F, E, D1, D2, D3, B and B', have molecular weights ranging from 8.5 to $24.6 \mathrm{kDa}$. The $\mathrm{B}^{\prime}$ and $\mathrm{B}$ proteins are isoforms created by alternative splicing that differ only in their C-terminal 11 
amino acids (van Dam et al., 1989). All Sm proteins contain a conserved bipartite sequence motif, Sm1 and Sm2 (Hermann et al., 1995). Sm proteins interact in vitro to form three stable subcomplexes F-E-G, D1-D2 and B-D3. They are able to bind spliceosomal snRNAs or an oligonucleotide containing the Sm site to form so called Sm core RNPs (Raker et al., 1999; Raker et al., 1996; Urlaub et al., 2001). Even though Sm core formation in vitro is a self-organizing, energy-independent process, in vivo it requires ATP and is mediated by the multiprotein SMN-complex, providing a critical checkpoint in the U snRNP maturation pathway (Meister and Fischer, 2002). NMR and $\mathrm{X}$-ray crystallographic studies revealed that Sm proteins exhibit a common characteristic fold, a bended $\beta$-sheet comprised of 5 antiparallel $\beta$-strands. A combination of structural and biochemical data led to the proposal of a model of the Sm core, in which a sevenmembered ring is formed by a single copy of each Sm protein, in the order G-E-F-D2D1-B-D3. The RNA-protein contacts are assumed to occur at the inner surface of the ring (Kambach et al., 1999; Nagai et al., 2001)

The U6 and U6atac associate with a group of related proteins, also containing a conserved Sm motif, called the Sm-like proteins (LSm-proteins): LSm2-8 (Seraphin, 1995). They bind to U-rich sequences at the 3' end of the U6 and U6atac snRNAs and, like Sm proteins, form a heptameric ring (Achsel et al., 1999). Interestingly, the exchange of one subunit in this complex (LSm8 for LSm1) dramatically changes the function of the whole complex, targeting it to the mRNA degradation machinery (Ingelfinger et al., 2002).

\subsubsection{U snRNP specific proteins}

The spliceosomal snRNPs were purified by the biochemical and immunological procedures with further identification of their protein composition, and structural and functional analysis (Kastner and Lührmann, 1999). It is known that, in addition to the common Sm core proteins, each U snRNP associates with a set of U snRNP-specific proteins (Table 1-1). The U1 and U2 snRNPs are the components of the early spliceosomal complexes (E and A complex) which are analyzed in this work. 
The human 12S U1 snRNP contains U1 snRNA, seven common Sm proteins and three specific proteins: U1-70K, U1-A and U1-C (Table 1-1). Biochemical studies, the high resolution structure of the U1-A protein bound to stem loop II of U1 snRNA and electron microscopy visualization of the intact U1 snRNP, as well as U1 snRNPs which lacked a specific protein, has led to the elucidation of the molecular architecture of U1 snRNP in some detail (Stark et al., 2001; Varani and Nagai, 1998). In the current model of U1 snRNP (Stark et al., 2001), the U1 snRNA adopts a four-way junction structure. The Sm core forms a central domain of the U1 snRNP, whereas U1-70K and U1-A form two protuberances. The U1-70K and U1-A proteins directly bind stem loops I and II of the U1 snRNA, respectively, via canonical RNA recognition motifs. In contrast, the U1-C protein binds to U1 snRNP only in the presence of both the Sm core and U1-70K, and probably contacts directly SmB and U1-70K proteins (Nelissen et al., 1994). The U1-C protein plays an important role in splicing, most likely contacting directly the pre-mRNA near its 5' splice site and stabilizing the U1 snRNA-pre-mRNA duplex (Heinrichs et al., 1990).

The human U2 snRNP, which consists of the U2 snRNA and several proteins, has a modular structure. The $12 \mathrm{~S}$ U2 snRNP particle consists of the seven common Sm proteins and two U2-specific proteins $\mathrm{A}^{\prime}$ and $\mathrm{B}^{\prime \prime}$. The mature 17S U2 snRNP contains the seven Sm proteins, as well as at least $12 \mathrm{U} 2$-specific proteins present in stoichiometric amounts. A further set of proteins, referred as U2-related proteins in Table 1-1, was found to be loosely associated with U2 snRNPs and, for the most part, to be present in substoichiometric amounts (Will et al., 2002).

The majority of $\mathrm{U} 2$-specific proteins form stable heteromeric complexes in the absence of the U2 snRNA, including U2-B"/U2-A', SF3a (SF3a120, SF3a66 and SF3a60 proteins) and SF3b (SF3b155, SF3b145, SF3b130, SF3b49, SF3b14a/p14, SF3b14b and SF3b10 proteins). Splicing active 17S U2 snRNP can be assembled in vitro in several distinct steps. First, the U2-B"/U2-A' heterodimer and common Sm proteins bind to the U2 snRNA, forming the 12S U2 snRNP (Ségault et al., 1995). SF3b binds to the 12S U2 particle to generate an intermediate $15 \mathrm{~S}$ U2 snRNP. This in turn can integrate SF3a to 
form the mature 17S U2 snRNP (Kramer et al., 1999). With the exception of SF3b130, SF3b14b and SF3b10 and SF3b14b, all SF3a and SF3b proteins can be crosslinked to a $\sim 20$ nucleotide region just upstream of the BPS which is called anchoring site (AS) (Gozani et al., 1996), while SF3b155 was shown to contact both sides of the branch site and SF3b14a/p14 to interact directly with the branch adenosine (Query et al., 1996; Gozani et al., 1998; Will et al., 2001). Several protein-protein interactions within the SF3a and SF3b complexes are well-documented, including highly stable interactions between SF3b155 and p14 (Will et al., 2001), SF3b145 and SF3b49 (Champion-Arnaud and Reed, 1994), SF3a120 and SF3a60 (Chiara et al., 1994), and SF3a120 and SF3a66 (Kramer et al., 1995). Electron microscopy studies suggest that the 17S U2 snRNP consists of two 10-12 nm globular domains, one of which contains SF3b and a 5' portion of U2 snRNA, whereas the other contains the Sm core, U2-B"/U2-A', SF3a and 3' part of the U2 snRNA (Behrens et al., 1993; Kramer et al., 1999). SF3b and SF3a not only recruit and stabilize the U2 snRNP on the pre-mRNA, contributing to branch site recognition, but also some of their subunits are likely positioned at or very near the catalytic core of the spliceosome (Will and Lührmann, 1997). The functional importance of SF3a and SF3b is supported by the high phylogenetic conservation of their component proteins; homologues carrying out nearly identical functions have been detected in organisms as distant as yeast. In addition, SF3b is shared by both the U2 and U11/U12 snRNP, suggesting it also plays a central role in branch site recognition in the U12dependent spliceosome (Will et al., 1999).

Recently the 3D structure of purified human SF3b, the largest U2 subunit, was obtained by single-particle electron microscopy (Golas et al., 2003). The relative orientation of several SF3b proteins and their domains could be determined. Thus, the C-terminal SF3b155 HEAT repeats are located on the outer shell of SF3b and curve around the entire complex, whereas the two RRMs of SF3b49 are found on the periphery and the SF3b14a/p14 RRM is localized in the central cavity. As the p14 protein was shown to directly interact with the branch site adenosine of pre-mRNA upon stable incorporation 


\begin{tabular}{|c|c|c|c|c|c|c|c|c|c|c|}
\hline \multicolumn{3}{|c|}{ U snRNP proteins } & $\begin{array}{c}\text { App.M } \\
\text { kDa }\end{array}$ & $\begin{array}{l}12 S \\
\text { U1 }\end{array}$ & $\begin{array}{c}17 \mathrm{~S} \\
\mathrm{U} 2\end{array}$ & $\begin{array}{c}20 \mathrm{~S} \\
\text { U5 }\end{array}$ & \begin{tabular}{|c|}
$13 S$ \\
U4/U6
\end{tabular} & \begin{tabular}{|c|}
$25 S$ \\
U4/U6.U5
\end{tabular} & $\begin{array}{c}\text { Sequence } \\
\text { motif }\end{array}$ & $\begin{array}{c}\text { Yeast } \\
\text { homologue }\end{array}$ \\
\hline \multicolumn{2}{|c|}{$\begin{array}{c}\text { Common } \\
\text { proteins }\end{array}$} & $\begin{array}{l}\mathrm{B} / \mathrm{B}^{\prime} \\
\mathrm{D} 3 \\
\mathrm{D} 2 \\
\mathrm{D} 1 \\
\mathrm{E} \\
\mathrm{F} \\
\mathrm{G}\end{array}$ & $\begin{array}{c}28 / 29 \\
18 \\
16.5 \\
16 \\
12 \\
11 \\
9\end{array}$ & $\begin{array}{l}0 \\
0 \\
0 \\
0 \\
0 \\
0 \\
0\end{array}$ & $\begin{array}{l}0 \\
0 \\
0 \\
0 \\
0 \\
0 \\
0\end{array}$ & $\begin{array}{l}0 \\
0 \\
0 \\
0 \\
0 \\
0 \\
0\end{array}$ & $\begin{array}{l}0 \\
0 \\
0 \\
0 \\
0 \\
0 \\
0\end{array}$ & $\begin{array}{l}0 \\
0 \\
0 \\
0 \\
0 \\
0 \\
0\end{array}$ & Sm-motif & $\begin{array}{l}\text { SMB1 } \\
\text { SMD3 } \\
\text { SMD2 } \\
\text { SMD1 } \\
\text { SME1 } \\
\text { SMX3 } \\
\text { SMX2 }\end{array}$ \\
\hline \multirow{6}{*}{ 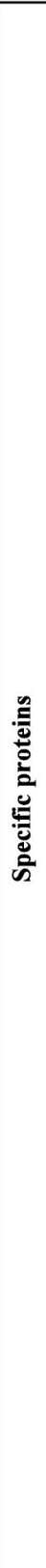 } & U1 snRNP & $\begin{array}{l}70 \mathrm{~K} \\
\mathrm{~A} \\
\mathrm{C}\end{array}$ & $\begin{array}{l}70 \\
34 \\
22\end{array}$ & • & & & & & $\begin{array}{l}\text { RRM, RS } \\
2 \text { RRMs } \\
\text { C2H2 ZnF }\end{array}$ & $\begin{array}{l}\text { SNP1 } \\
\text { MUD1 } \\
\text { YHC1 }\end{array}$ \\
\hline & U2 snRNP & \begin{tabular}{|l|} 
A' \\
B” \\
SF3a120 \\
SF3a66 \\
SF3a60 \\
SF3b155 \\
SF3b145 \\
SF3b130 \\
SF3b49 \\
SF3b14a/p14 \\
SF3b14b \\
SF3b10
\end{tabular} & $\begin{array}{c}31 \\
28.5 \\
110 \\
66 \\
60 \\
160 \\
150 \\
120 \\
53 \\
15 \\
15 \\
9\end{array}$ & & $\begin{array}{l} \\
\\
0 \\
0 \\
0 \\
0 \\
0 \\
0 \\
0 \\
0 \\
0 \\
0 \\
0\end{array}$ & & & & $\begin{array}{l}\text { Leu-rich } \\
2 \text { RRMs } \\
2 \text { SURP, UBQ } \\
\text { C2H2 ZnF } \\
\text { C2H2 ZnF } \\
\text { HEAT repeat } \\
\text { SAP,Pro-rich } \\
\text { CPSF A } \\
2 \text { RRMs } \\
\text { RRM } \\
\text { Cys-rich }\end{array}$ & $\begin{array}{l}\text { LEA1 } \\
\text { MSL1 } \\
\text { PRP21 } \\
\text { PRP11 } \\
\text { PRP9 } \\
\text { HSH155 } \\
\text { CUS1 } \\
\text { RSE1 } \\
\text { HSH49 } \\
\text { SNU17? } \\
\text { RDS3 } \\
\text { YSF3 }\end{array}$ \\
\hline & U2-related & $\begin{array}{l}\text { hPrp5 } \\
\text { SR140 } \\
\text { CHERP } \\
\text { hPrp43 } \\
\text { SPF45 } \\
\text { SPF31 } \\
\text { SPF30 }\end{array}$ & $\begin{array}{l}140 \\
140 \\
130 \\
90 \\
50 \\
33 \\
31\end{array}$ & & $\begin{array}{l}0 \\
0 \\
0 \\
0 \\
0 \\
0 \\
0\end{array}$ & & & & $\begin{array}{l}\text { DEAD } \\
\text { RRM, SWAP } \\
\text { SWAP, G-patch } \\
\text { DExH } \\
\text { G-patch, RRM } \\
\text { DnaJ domain } \\
\text { Tudor }\end{array}$ & $\begin{array}{l}\text { PRP5 } \\
\text { PRP43 } \\
\text { HLJ1? }\end{array}$ \\
\hline & \begin{tabular}{|l|} 
\\
U5 snRNP
\end{tabular} & $\begin{array}{l}\text { hPrp8 } \\
\text { U5-200K } \\
\text { hSnu114 } \\
\text { hPrp6 } \\
\text { hPrp28 } \\
\text { U5-52K } \\
\text { U5-40K } \\
\text { U5-15K }\end{array}$ & $\begin{array}{c}220 \\
200 \\
116 \\
102 \\
100 \\
52 \\
40 \\
15\end{array}$ & & & $\begin{array}{l} \\
0 \\
0 \\
0 \\
0 \\
0 \\
0 \\
0\end{array}$ & & $\begin{array}{l} \\
0 \\
0 \\
0 \\
0 \\
0 \\
0\end{array}$ & $\begin{array}{l}2 \text { DExH } \\
\text { G-domain } \\
\text { TPR repeat } \\
\text { DEAD, RS } \\
\text { GYF domain } \\
\text { WD40 } \\
\text { Thioredoxin fold }\end{array}$ & $\begin{array}{l}\text { PRP8 } \\
\text { BRR2 } \\
\text { SNU114 } \\
\text { PRP6 } \\
\text { PRP28 } \\
\text { LIN1 } \\
\text { DIB1 }\end{array}$ \\
\hline & $\begin{array}{l}\text { U4/U6 } \\
\text { snRNP }\end{array}$ & \begin{tabular}{|l|}
$\mathrm{U} 4 / \mathrm{U} 6-90 \mathrm{~K}$ \\
$\mathrm{U} 4 / \mathrm{U} 6-61 \mathrm{~K}$ \\
$\mathrm{U} 4 / \mathrm{U} 6-60 \mathrm{~K}$ \\
CypH \\
U4/U6-15.5K \\
LSm2 \\
LSm3 \\
LSm4 \\
LSm5 \\
LSm6 \\
LSm7 \\
LSm8
\end{tabular} & $\begin{array}{c}90 \\
61 \\
60 \\
20 \\
15.5 \\
10 \\
15 \\
15 \\
10 \\
8 \\
13 \\
13\end{array}$ & & & & $\begin{array}{l}0 \\
0 \\
0 \\
0 \\
0 \\
0 \\
0 \\
1 \\
0 \\
1 \\
1 \\
1 \\
1 \\
1\end{array}$ & $\begin{array}{l}0 \\
0 \\
0 \\
0 \\
0 \\
0 \\
0 \\
0 \\
0 \\
1 \\
0 \\
0 \\
0 \\
1\end{array}$ & $\begin{array}{l}\text { PWI, DSRM } \\
\text { Nop domain } \\
\text { WD40 } \\
\text { PPIase } \\
\text { RNA bdg domain } \\
7 \\
\text { Sm-motif }\end{array}$ & $\begin{array}{l}\text { PRP3 } \\
\text { PRP31 } \\
\text { PRP4 } \\
\text { SNU13 } \\
\text { LSM2 } \\
\text { LSm3 } \\
\text { LSm4 } \\
\text { LSm5 } \\
\text { LSm6 } \\
\text { LSm7 } \\
\text { LSm8 }\end{array}$ \\
\hline & $\begin{array}{l}\mathbf{U} 4 / \mathrm{U} 6.05 \\
\text { tri-snRNP }\end{array}$ & $\begin{array}{l}110 \mathrm{~K} \\
65 \mathrm{~K} \\
27 \mathrm{~K}\end{array}$ & $\begin{array}{l}110 \\
65 \\
27\end{array}$ & & & & & ? & $\begin{array}{l}\text { RS } \\
\text { RS } \\
\text { RS }\end{array}$ & $\begin{array}{l}\text { SNU66 } \\
\text { SAD1 }\end{array}$ \\
\hline
\end{tabular}

Table 1-1. Protein composition of the human spliceosomal snRNPs. The snRNPs consist of a set of common and specific proteins which contain various domains (see PROSITE SCAN and PFAM databank for details). Defined yeast homologues are displayed and "?" indicates those proteins for which the functional homology was not established yet (This table adapted from Kastner (1998) and Will and Lührmann (2006)). 
of U2 into spliceosome (Query et al., 1996; Will et al., 2001), SF3b likely undergoes a dramatic conformational change either upon integration into the U2 snRNP or during U2 association with the pre-mRNA. The former is supported by a recent electron cryomicroscopy study of the U11/U12 di-snRNP, a subunit of the minor, U12-dependent spliceosome. SF3b also associates with the U11/U12 di-snRNP, and it was found in a more open conformation in this particle compared to isolated SF3b (Golas et al., 2005).

Additionally, the U2-B"/U2-A' heterodimer was shown to directly bind the U2 snRNA, specifically recognizing stem-loop IV (Varani and Nagai, 1998). The atomic structure of the human U2-B"/U2-A' heterodimer complexed with an RNA hairpin comprising U2 stem-loop IV has been determined (Price et al., 1998).

As shown in the Table 1-1, the 13S U4/U6 snRNP contains 5 specific proteins $90 \mathrm{~K}, 61 \mathrm{~K}$, $60 \mathrm{~K}, 20 \mathrm{~K}$ (also known as $\mathrm{CypH}$ ) and $15.5 \mathrm{~K}$ in addition to the common LSm and $\mathrm{Sm}$ proteins. The core U5 snRNP (the U5 snRNA bound by the Sm protein heptamer) further associates with eight particle-specific proteins $(220 \mathrm{~K}, 200 \mathrm{~K}, 116 \mathrm{~K}, 102 \mathrm{~K}, 100 \mathrm{~K}, 52 \mathrm{~K}$, 40K and 15K) to generate the 20S U5 snRNP (Behrens and Lührmann, 1991; Black and Pinto, 1989). Under physiological conditions (i.e., salt concentrations less than $250 \mathrm{mM}$ ), the 13S U4/U6 and 20S U5 snRNPs associate with three additional proteins $(110 \mathrm{~K}, 65 \mathrm{~K}$ and 27K) to form the 25S U4/U6.U5 tri-snRNP (Behrens and Lührmann, 1991).

The protein composition of snRNPs forming the U12-dependent spliceosome was recently obtained (Will and Lührmann, 2005). Consistent with distinct cis-elements in U12-type introns, the U11/U12 di-snRNP (the functional analogue of U1 and U2, but existing as a di-snRNP) was found to contain in addition to seven Sm proteins a set of seven specific proteins, not found in U1 or U2 snRNPs. Furthermore, the SF3a complex, as well as all U1-specific proteins, are missing from the U11/U12 (Will et al., 2004). In contrast, all SF3b subunits are present in the U11/U12 di-snRNP (Will et al., 1999; Will et al., 2002). Thus, SF3b most likely helps to tether the U11/U12 di-snRNP to the BPS as it does with the U2 snRNP. Relative to U1 and U2, much less is known about the molecular architecture of the U11/U12 di-snRNP, aside from recent EM analyses and the 
establishment of an interaction between the $65 \mathrm{~K}$ protein and both the U12 snRNA and U11-59K protein (Benecke et al., 2005). The protein composition of the U4atac/U6atac.U5 tri-snRNP is strikingly similar to the major tri-snRNP (Nottrott et al., 1999; Schneider et al., 2002) and thus likely both tri-snRNPs share a similar higher order structure (Will and Lührmann, 2005).

\subsubsection{Non-snRNP splicing factors}

The proteomic analyses of various spliceosomal complexes carried out in several laboratories revealed an enormous complexity of the splicing machinery (Hartmuth et al., 2002; Jurica and Moore, 2002; Stevens et al., 2002; Zhou et al., 2002). More than one hundred non-snRNP proteins seem to participate in constitutive pre-mRNA splicing. A number of additional proteins contribute to alternative, temporary-, tissue- or pre-mRNAspecific splicing. Since only slightly more than 50 proteins associate tightly with the spliceosomal U snRNPs (listed in Table 1-1), it appears that the majority of splicing factors are recruited to the spliceosome independent of the snRNPs, and are therefore referred to as non-snRNP splicing factors.

The most crucial role in the recognition of the 3 ' boundaries of introns is played by the splicing factors SF1 (also known as branch point binding protein, BBP) and U2AF (Kramer, 1992; Ruskin et al., 1988; Zamore et al., 1992). U2AF is essential for splicing, while SF1 appears to be redundant in vivo (Tanackovic and Kramer, 2005). SF1 and $\mathrm{U} 2 \mathrm{AF}$ were shown to interact directly with the pre-mRNA, binding the BPS and polypyrimidine tract, respectively, and creating a platform for the further incorporation of the U2 snRNP (Berglund et al., 1998). The SF1 protein was shown to contain a maxi-KH domain responsible for the recognition of the BPS (Berglund et al., 1997; Peled-Zehavi et al., 2001). U2AF consists of two proteins (U2AF65 and U2AF35), which interact with each other via the atypical RRM of U2AF35 and proline-rich segment of U2AF65 (Kielkopf et al., 2001). Both of them possess a serine-arginine rich domain (see below). The U2AF65 contains additionally 3 RRMs, allowing a sequence-specific binding to the polypyrimidine tract, while its RS domain contacts the BPS (Kent et al., 2003; Valcarcel 
et al., 1996). It was also shown to recruit the U2 snRNP, apparently by direct binding to the SF3b155 protein (Gozani et al., 1998). U2AF35 recognizes the conserved AG dinucleotide at the 3' splice site (Wu et al., 1999). Additionally, U2AF65 was implicated in the recruitment of the U1 snRNP (Forch et al., 2003) and the DEAD-box helicase UAP56, suspected to facilitate displacement of SF1 from the pre-mRNA during the complex A formation and required for later steps of splicing and mRNA export (Fleckner et al., 1997). Thus, the SF1, U2AF65 and U2AF35 proteins interact with each other and simultaneously recognize the branch point sequence (BPS), polypyrimidine tract and the 3 ' splice site, respectively, at the 3 ' end of the intron.

SR proteins are essential metazoan splicing factors involved primarily in the early events of spliceosome assembly (Graveley, 2000; Hastings and Krainer, 2001). The major members of the SR protein family include the SRp75, SRp55, SRp40, SRp30c, SC35, $\mathrm{SF} 2 / \mathrm{ASF}, \mathrm{SRp} 20$ and 9G8 proteins. The characteristic feature of this protein family is a modular structure: all of them harbor one or two N-terminal RNA recognition motifs (RRMs) and a stretch of arginine-serine dipeptides at the C-terminus, which comprises a serine/arginine-rich domain (RS) (Birney et al., 1993) (Fig. 2-4). The former interacts in a sequence-dependent manner with specific exonic or intronic splicing enhancers (Schaal and Maniatis, 1999), whereas the latter usually acts as a protein-protein binding domain. This allows SR proteins to recruit other splicing factors to certain sites or stabilize their interactions with pre-mRNA during early events of spliceosome assembly. Since U2AF65, U2AF35, U1 70K, Srm 160, TRA, TRA2 possess RS and RRM domains, they are defined as SR-like proteins (Sanford et al., 2005). The SR proteins influence the interactions of U1 snRNP, U2 snRNP and U2AF with the 5' splice site, branchpoint sequence and the 3 ' splice site, respectively (Fig. 2-5). They were shown to modulate splice site choice (Guo and Kawamoto, 2000), bridge 5' and 3' splice sites (Wu and Maniatis, 1993), potentiate weak interactions of the U1 snRNP with the 5' splice site and U2AF with the 3 ' splice site, or even functionally substitute for them (Crispino et al., 1994; MacMillan et al., 1997). SR proteins also function at later events, such as trisnRNP incorporation into the spliceosome and after the first step of splicing (Chew et al., 1999). 


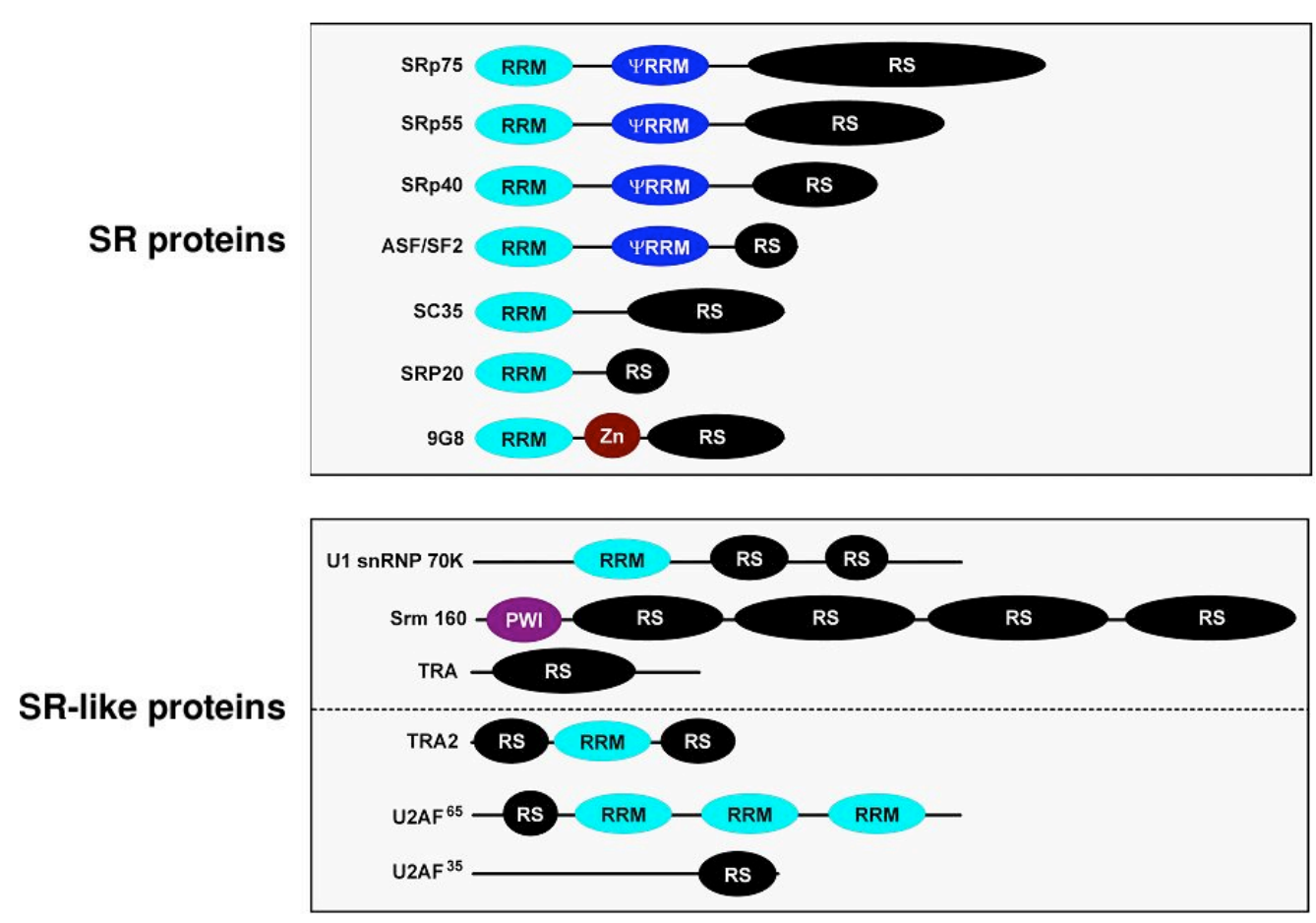

Figure 2-4. The domain structures of SR and SR-like proteins. RRM: RNA recognition motif; RS: Arginine/serine rich domain; $\Psi$ RRM: pseudo RRM domain. This figure is kindly provided by Berthold Kastner.

The crucial role of SR proteins as regulators in alternative splicing is also well established. SR proteins recognize pre-mRNA splicing enhancers, which contribute to the limited information provided by the degenerate $5^{\prime}$ and $3^{\prime}$ splice sites and the branchpoint sequence, facilitating not only precise identification of the exon-intron boundaries, but also splice site choice. This increases greatly the repertoire of mature pre-mRNAs. No SR proteins are found in $S$. cerevisiae, consistent with the absence of alternative splicing in this group of organisms and other lower eukaryotes. 


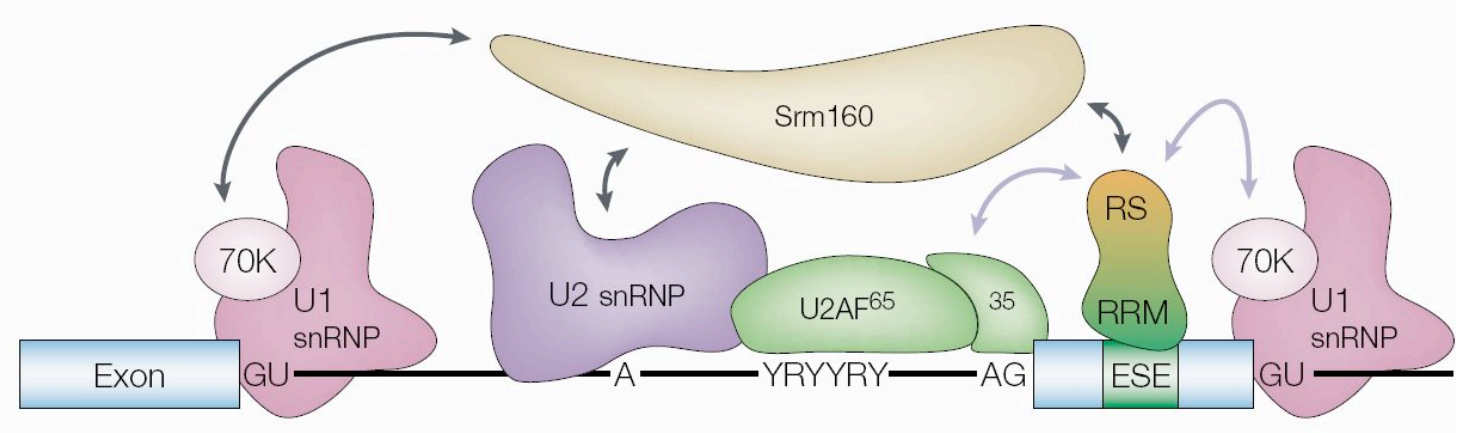

Figure 2-5. The SR protein-dependent recruitment model. An SR protein binds to an exonic splicing enhancer (ESE) through its RNA-recognition motifs (RRM) and may contact various proteins through its RS domain stabilizing them on the pre-mRNA. The splicing coactivator Srm160 bridges other splicing factors by protein-protein interactions (This figure is adapted from Cartegni et al., 2002).

A number of splicing factors (e.g., U5-200K/Brr2, hPrp2, hPrp5, hPrp16, hPrp22, U5100K/Prp28, hPrp43, UAP56) belong to the DExD/H-box protein family of ATPdependent RNA unwindases/RNPases (Rocak and Linder, 2004; Schwer, 2001) and facilitate RNP modelling and RNA-RNA rearrangements during splicing. The precise function of only a few of them has been elucidated. For example, U5-100K/Prp28 was suggested to act at the $5^{\prime}$ splice site and either unwind the U1/pre-mRNA duplex or promote U6/pre-mRNA annealing (Chen et al., 2001). hPrp5, which is found in purified 17S U2 snRNPs, seems to catalyze a conformational change in U2 snRNP facilitating its binding to pre-mRNA (Abu Dayyeh et al., 2002). UAP56 appears to help to exchange factors at the BPS, while hPrp16 was suggested to increase the fidelity of BPS selection. hPrp22 was found to promote the second transesterification reaction and subsequently catalyze the ATP-dependent release of mature mRNA from the spliceosome (Schwer and Meszaros, 2000). hPrp43 was implicated in the release of the intron from the postspliceosomal complex (Arenas and Abelson, 1997). Much remains to be learned about the function of the $\mathrm{DEaD} / \mathrm{H}$ box proteins and the exact mechanisms of their action despite 
the fact that their general role in facilitating the numerous RNP remodeling steps required for splicing has been revealed. Other well-characterized non-snRNP factors include hPrp17, hPrp8, hSlu7 and hPrp18, which are involved/required for the second step of splicing (Umen and Guthrie, 1995).

\subsubsection{The spliceosome assembly pathway}

\subsubsection{The spliceosomal cycle}

The highly regulated assembly of snRNP particles onto pre-mRNA results in a clear definition of the intronic sequences, despite the restricted sequence information on the pre-mRNA (Reed and Palandjan, 1997). During spliceosome assembly, numerous RNARNA base pair interactions required for splicing are formed (Nilsen, 1998). Formation of the RNA network is facilitated by RNA-protein and protein-protein interactions (Will and Lührmann, 1997). At first, U1 snRNP interacts with the 5' splice site in an ATPindependent manner via base pairing between the 5 ' end of U1 snRNA and the 5' splice site (Fig. 2-6) (Siliciano and Guthrie, 1988; Zhuang and Weiner, 1986). The interaction of U1 snRNP with the pre-mRNA is aided by proteins of the serine-arginine rich SR family, and also by the U1-specific proteins, 70K, A and C (Heinrichs et al., 1990; Kohtz et al., 1994). The E complex also contains the U2 snRNP (Das et al., 2000) and members of the SR protein family, as well as additional non-snRNP factors such as SF1/mBBP, U2AF65, U2AF35, which bind the BPS, the downstream polypyrimidine tract and the 3' splice site AG dinucleotide, respectively (Abovich and Rosbash, 1997; Staknis and Reed, 1994). Although U2 snRNP is loosely associated at this stage, E complex formation is dependent on its presence (Das et al., 2000).

After the E complex formation, the U2 snRNP interacts with the branch site in an ATPdependent manner forming the pre-spliceosome, which is called A complex (Fig. 2-6). During formation of the A complex, U2 snRNA basepairs with the branch-site region of pre-mRNA (Parker et al., 1987; Wu and Manley, 1989). It is also facilitated by several 
proteins such as $\mathrm{U} 2 \mathrm{AF}$ and the $\mathrm{U} 2$ snRNP specific protein complexes SF3a and SF3b (Will and Lührmann, 1997). The association of the pre-assembled tri-snRNP complex, which is comprised of a U4/U6 and a U5 snRNP particle, leads the pre-spliceosome to become a completely assembled spliceosome which is called B complex (Fig. 2-6). This complex remains inactive until a series of RNA-RNA rearrangements give rise to an active complex. These dynamic rearrangements take place in an ATP-dependent manner catalyzed by numerous spliceosomal proteins, including members of DEAD/H-box family of RNA unwindases (Staley and Guthrie, 1998; Will and Lührmann, 1997).

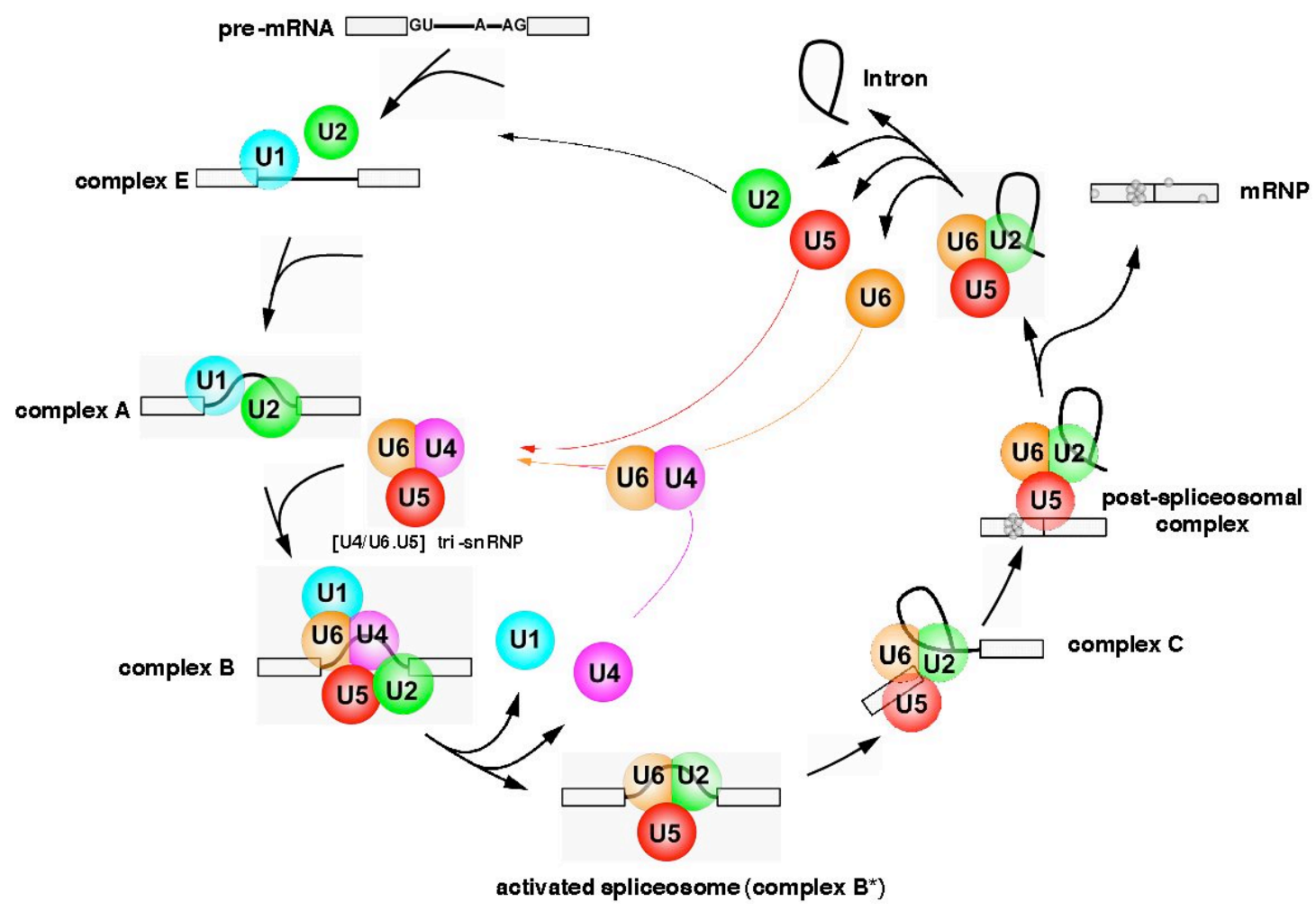

Figure 2-6. Stepwise assembly of the major (U2-type) spliceosome. Exon and intron sequences are shown by boxes and lines, respectively. The first two and the last two nucleotides of the intron, branch site adenosine are depicted. This figure is kindly provided by Berthold Kastner. 
After the U4/U6.U5 tri-snRNP integrates into the complex, the U1 snRNA-5' splice site interaction is destabilized, and the 5' splice site base pairs with the U6 snRNA (Sawa and Abelson, 1992; Wassarman and Steitz, 1992). The base pairing interactions between the U4 and U6 snRNAs within the U4/U6 particle are then destabilized, U4 snRNA is released and formation of base pairs between U6 snRNA and both the U2 snRNA and the 5' splice site occur (Madhani and Guthrie, 1992; Wolff et al., 1994). The resulting form of the spliceosome, which is called B* complex, is in a catalytically active state ready to carry out the two-step splicing reaction. Concomitant with the first step of splicing, the $\mathrm{C}$ complex is formed, which then catalyzes the second step of splicing. After completion of both transesterification steps, the spliceosome dissociates, releasing the mRNA and excised introns. The snRNPs are released and reform to take part in a new round of splicing.

A very similar assembly pathway has been demonstrated for the U12-dependent spliceosome, with the major difference that the U11/U12 di-snRNP binds as a preassembled particle, bridging the $5^{\prime}$ and $3^{\prime}$ splice sites in the minor A complex (Frilander and Meng, 2005; Frilander and Steitz, 1999).

\subsubsection{The RNA-RNA network in the spliceosome}

The RNA-RNA rearrangements which take place during the spliceosomal cycle contribute to splice site recognition, juxtaposing the reactive groups of the pre-mRNA and catalysis reaction (Madhani and Guthrie, 1994; Staley et al., 1998; Nilsen, 1998), (Brow, 2002). A series of highly dynamic snRNA-snRNA, as well as snRNA-pre-mRNA interactions, are required to form an active spliceosome and carry out the two catalytic steps of the splicing reaction. Selection of the 5' splice site and BPS is achieved in part by annealing of the $5^{\prime}$ end of $\mathrm{U} 1$ and the branch point recognition region of $\mathrm{U} 2$ snRNAs, respectively. The extensive base pairing between the U4 and U6 snRNAs (stem I and II) has to be unwound to facilitate the interaction of U6 with the pre-mRNA and U2 and the release of U4. At this stage, the U1 is displaced from the 5' splice site by U6. By this way 
the U1 snRNP is destabilized or even released from the spliceosome. In addition, a basepairing interaction between the first triplet of the absolutely conserved ACAGAGA box of the U6 snRNA and the +4 to +6 nucleotides of the intron is established. Additionally, the U6 snRNA anneals with the 5 ' end of U2 snRNA to form helix I (Sashital et al., 2004) and II (Hausner et al., 1990). For these interactions to occur, the internal stem I of the U2 snRNA should be at least partially denatured. In mammals, an additional helix III formed by the U2 and U6 snRNAs was described (Sun and Manley, 1995). The U5 snRNA interacts via uridines of its loop I with the 5' exon (Fig. 2-7).

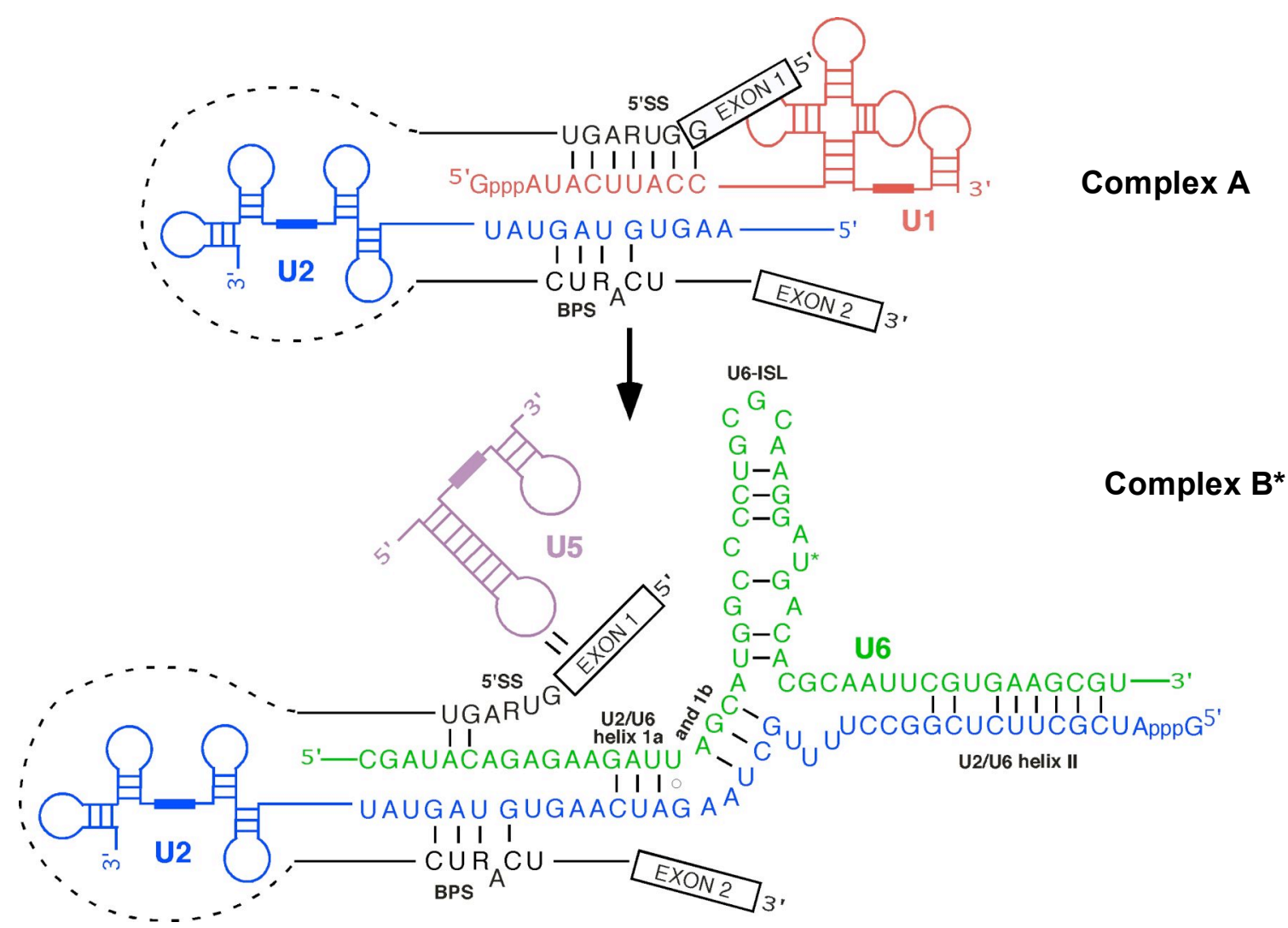

Figure 2-7. RNA-RNA rearragements accompanying the transition of the major spliceosomal A complex into the catalytically activated spliceosome (B*). Exons are depicted by open boxes. The conserved nucleotides of the $5^{\prime}$ splice site and branch point sequence (BPS) are according to metazoan consensus sequences and shown in black, the rest of the intron is represented by a black line. (adapted from Will and Lührmann, 2006) 
This complex RNA network, together with the help of proteins builds up the catalytic site of the spliceosome, assuring close proximity of the reactive moieties of the first catalytic step of splicing which are the nucleophilic 2'-oxygen of the branch point adenosine and the phosphodiester bond between the $5^{\prime}$ exon and the intron. After the first transesterification reaction, the catalytic site appears to be remodeled. The U5 snRNA binds now both the $3^{\prime}$ and 5 ' ends of the upstream and downstream exons, juxtaposing the exons to be ligated. The U2-U6 helix I is also thought to be reorganized (Madhani and Guthrie, 1992; Sashital et al., 2004). After catalysis, the U2, U6 and U5 snRNPs are released from the spliced out intron and their initial basepairing interactions (i.e. the U4/U6 duplex and intramolecular stem loop I of U2) are thought to reform in order to allow recycling of snRNPs. Analogous RNA-RNA interactions occur in the U12dependent spliceosome (Frilander et al., 2005)(Frilander and Steitz, 2001) and thus the catalytic core of both spliceosomes seems to be similar.

U2 was shown to be associated with ATP-independent E complex (Jamison and GarciaBlanco, 1992; Michaud and Reed, 1991; Wassarman and Steitz, 1992). Interestingly, a short while before this work began, purified $\mathrm{E}$ complexes were shown to contain both U1 and U2 snRNPs (Das et al., 2000) indicating that U2 may have an active role during early steps of intron recognition.

\subsubsection{The recognition and pairing of the splice sites}

To generate correct, mature mRNAs, the exons must be identified and joined together precisely and efficiently. The inaccurate recognition of exon-intron boundaries or the failure to remove an intron generates aberrant mRNAs that are either unstable or code for defective or deleterious protein isoforms. The correct determination of splice sites, which is a complex and formidable task, occurs either cross-intron or cross-exon (Fig. 2-8). Bridging interactions between the elements of the early complex (U1 snRNP, U2 snRNP, $\mathrm{U} 2 \mathrm{AF}, \mathrm{SR}$ proteins etc.) across the intron commit the pre-mRNA to the splicing pathway (cross-intron). Mutual stabilization of these factors binding to $5^{\prime}$ and 3 ' splice sites across internal exons also occurs (cross-exon), a process known as exon definition (Berget, 
1995; Black, 2003). Further modulation of intron and exon definition is mediated by exonic or intronic enhancer (stimulator) or silencer (repressor) sequences that are recognized by regulatory factors, often acting in a combinatorial fashion.
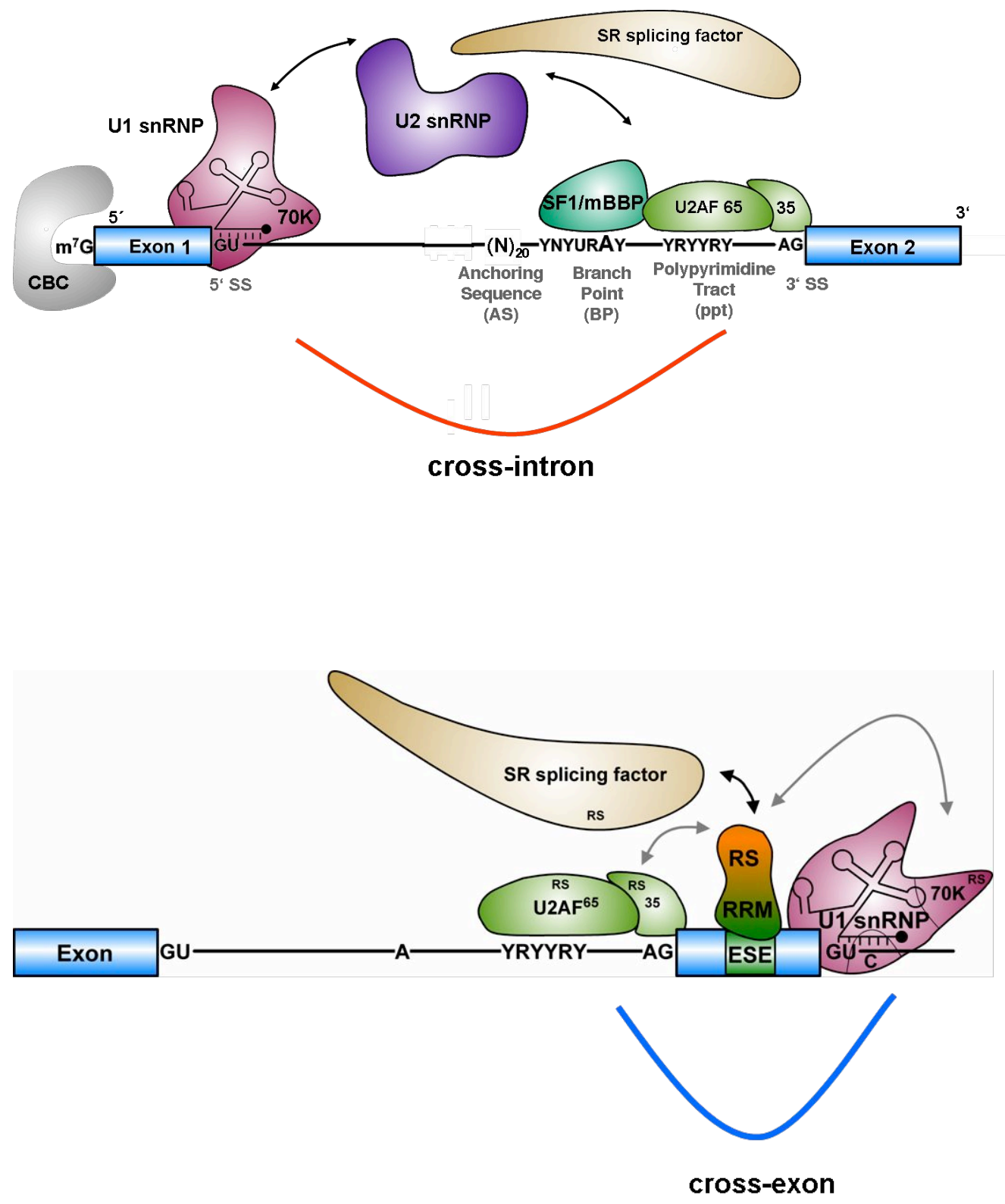

Figure 2-8. The cross-inron and cross-exon interactions to pair the splice sites in early complexes (adapted from Cartegni et al., 2002). 
As an example, Fas exon 6 can be included or skipped to generate mRNAs encoding a membrane bound form of the receptor that promotes apoptosis or a soluble isoform that prevents programmed cell death, respectively (Izquierdo and Valcarcel, 2006). It was reported that splicing factors TIA-1 and PTB regulate Fas splicing and possibly Fasmediated apoptosis by targeting molecular events that lead to exon definition. Stabilizing interactions across exon 6 are important for U2AF binding to the 3 ' splice site of intron 5, splicing of intron 5, exon 6 inclusion, and for the ability of PTB to mediate splicing repression.

For this work, we focused on the cross-intron interactions which facilitate the recognition of the splice sites and pairing of the intron ends in the very early spliceosomal complexes. U1 and U2 snRNPs are the major components of the early spliceosomal complexes and they interact with the ends of the intron. Therefore, the arrangement of U1 and U2 snRNPs is the major determinant of splice site pairing during cross-intron interactions. In order to learn more about the cross-intron communication, the components of the early spliceosomal complexes and the proximities among them should be analyzed. In the following section, the components of these early complexes will be summarized.

\subsubsection{Current knowledge on the interactions among the elements of early complexes}

\section{In E complex}

It was shown before that the juxtaposition of the splice sites and the functional pairing of the intron ends occur in E complex (Das et al., 2000; Kent and MacMillan, 2002; Michaud and Reed, 1993). The major components of the E complex are U1 snRNP base paired to the 5' splice site, U2AF65/35 heterodimer, SF1 (mBBP) and SR proteins (see Fig. 2-9). Bridging interactions between these factors across the intron commit the premRNA to the splicing pathway. Both U2AF35 and U1 70K have been reported to interact with SR protein SC35 (Wu and Maniatis, 1993) forming the first part of the bridge and SF1 was shown to interact with both U2AF65 and FBP11 forming the second part (Das et 
al., 2000). It was shown by site-directed hydroxyl radical footprinting method that the branch point and the 3 ' splice site are located within $20 \AA$ proximity to the 5 ' splice site in early complexes (Kent and MacMillan, 2002).

Recent evidence showed that $\mathrm{U} 2 \mathrm{snRNP}$ is loosely associated and required for E complex formation (Das et al., 2000). Purified functional E complexes were characterized and shown to contain U2 snRNP-specific components, SF3a and SF3b protein complexes (Das et al., 2000). U2 snRNP association with the E complex requires both the 5' and $3^{\prime}$ splice, but not the branch site (Das et al., 2000; Michaud and Reed, 1993). These findings raised the question of whether U2 snRNP plays a role in functional pairing of the intron ends during E complex formation. It was also reported that the U2 snRNP interacts with the U2AF65 via the SF3b155 protein of U2 snRNP (Gozani et al., 1998). As SF3b155 is a component of both U2 snRNP and E complex (Das et al., 2000), this protein may mediate the association of U2 snRNP within the E complex (Fig. 2-9). U1 snRNP may be involved in mediating the association of $\mathrm{U} 2 \mathrm{snRNP}$ with the $\mathrm{E}$ complex. The SR proteins which promote E complex assembly (Staknis and Reed, 1994) and interact with exon sequences in the E complex (Chiara et al., 1996) may stabilize the association of U2 snRNP within the E complex. These interactions indicate that U2 snRNP may be involved in bringing together the splice sites during E complex formation. However, the spatial organization of $\mathrm{U} 2$ with respect to other components of the E complex is not known.

\section{In A complex}

During the ATP-dependent transition from the E to A complex, U1 snRNP and U2AF become less tightly bound to the pre-mRNA (Figure 2-9) (Bennett et al., 1992; Michaud and Reed, 1993). SF1/mBBP is thought to dissociate from the branch point sequence to allow formation of the U2 snRNA-BPS duplex in the A complex (Abovich and Rosbash, 1997).

In the A complex U2 snRNP becomes very tightly bound to the pre-mRNA, and the SF3a and SF3b subunits interact directly with the pre-mRNA surrounding the BPS (Gozani et 
al., 1996; Gozani et al., 1998). In yeast, U2 snRNP undergoes an ATP-dependent conformational change that exposes the region of U2 snRNA which base pairs with the branch point sequence (O'Day et al., 1996). This change requires the DEAD box ATPase, Prp5 (O'Day et al., 1996). In metazoans, UAP56 was identified as a DEAD box protein that interacts directly with $\mathrm{U} 2 \mathrm{AF} 65$ and is required for A complex assembly (Fleckner $e t$ al., 1997). Thus, Prp5 and UAP56 are both candidates for factors that may mediate an ATP-dependent conformational change to allow tight binding of U2 snRNP to the branch point sequence (Das et al., 2000). The orientation of U2 snRNP in A complex with respect to the pre-mRNA and especially to U1 snRNP remains to be determined.
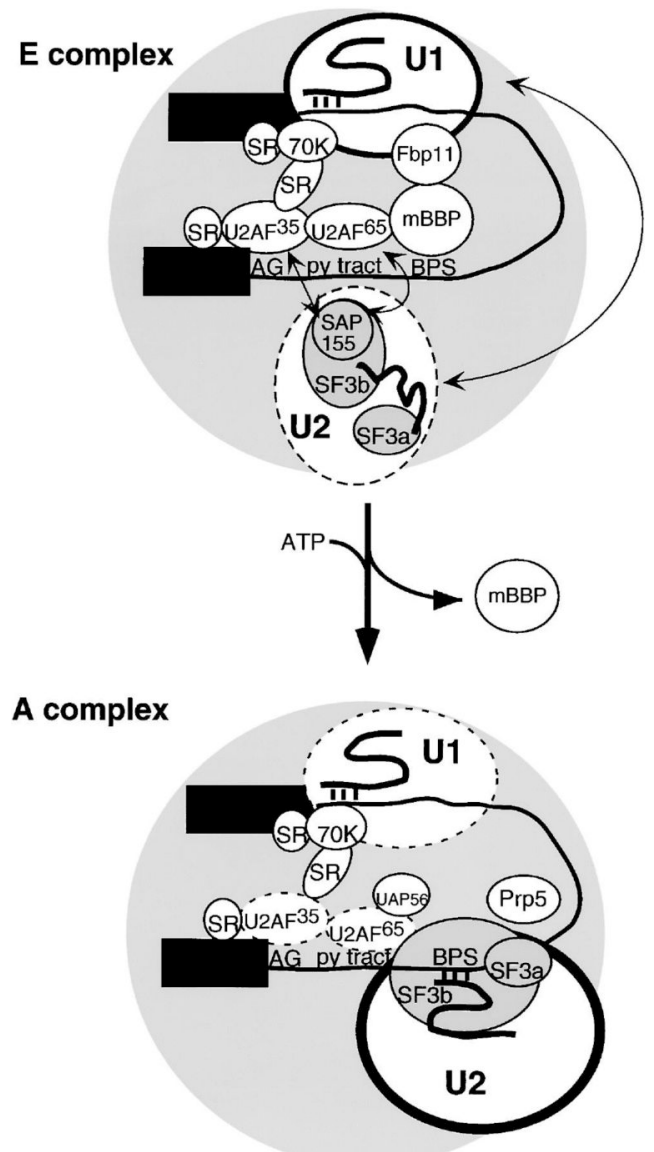

Figure 2-9. Model for interactions among the elements of $\mathrm{E}$ and $\mathrm{A}$ complexes. The tight binding of U1 and U2 snRNPs is indicated by thickly lined circles, and the loose binding of these snRNPs and U2AF is indicated by the dashed circles (adapted from Das et al., 2000). 
The proteomic analyses of spliceosomal complexes obtained via purification methods indicate presence of many proteins. However, there is a paucity of evidence for direct interactions among RNAs in early complexes. Is it the protein network which facilitates the cross-intron interactions in early complexes or is it the direct RNA-RNA interaction? The fact that U1 and U2 snRNPs interact with the intron ends in early spliceosomal complexes raises the probability that their close interaction has a role in pairing the intron ends during cross-intron communications. In minor spliceosomes, the U11 and U12 snRNPs form a stable di-snRNP in nuclear extracts (Kolossova and Padgett, 1997). They bind as a single entity to the 5 ' splice site and the branch point sequence, respectively, during assembly of the minor spliceosomal complex A (Frilander and Steitz, 1999). By this way, the intron ends are brought together by a preformed di-snRNP. Does U2 snRNP interact with $\mathrm{U} 1$ in a similar way in major spliceosomes in early complexes? The presence of a close interaction between $\mathrm{U} 1$ and $\mathrm{U} 2$ snRNPs as in the case of U11/U12 disnRNP in E complex might help to functionally pair the intron ends.

\subsubsection{The site-directed hydroxyl radical probing as a method to investigate the higher order RNA structure in early spliceosomal complexes}

A number of independent approaches were used in the literature to analyze interactions among the components of the early complexes (RNA-protein interactions). These include immunoblotting, radioimmunoprecipitations and site-specific UV-crosslinking. However, the direct measuring of the neighbourhoods of RNA and proteins (RNA-protein or protein-protein) within the complex has not been performed. For this purpose, sitedirected hydroxyl radical probing and FRET are the methods that can be applied. Sitedirected hydroxyl radical probing is a very important technique to gain insight into the three-dimensional arrangement of the RNA moieties in RNA-protein complexes and to investigate the RNA proximities. This method has the unique ability to provide experimental information on the solvent accessibility of each nucleotide in an RNA molecule and the 3D structures of large and complicated RNA-protein particles. FRET (Fluorescence Resonance Energy Transfer) is a powerful tool to measure the structural 
dynamics of biomolecules in real time. It can be used to study the conformational dynamics of RNA and proteins by imaging single molecules in real time.

Directed hydroxyl radical probing using tethered Fe(II)-EDTA is a powerful method for studying the tertiary structure of RNA at low resolution. In the presence of a reducing agent, Fe(II)-EDTA generates neutral and highly reactive species which are hydroxyl radicals. These attack riboses in the nucleic acid backbone, resulting in strand scission. As observed with RNA, it catalyzes nearly uniform strand breakage in single- and double-stranded regions of DNA. Tethering the Fe(II)-EDTA complex to a fixed position in the RNA causes cleavages to occur at regions of the RNA surrounding that positions (Joseph and Noller, 2000). Fe(II) can be tethered to RNA and proteins using the reagent 1-( $\rho$-bromoacetamido-benzyl)-EDTA (BABE) originally synthesized by Meares and co-workers (DeRiemer and Meares, 1981; Rana and Meares, 1991). This reagent can be attached covalently to nucleophilic positions of a macromolecule. These are cysteine sulfhydryls in proteins and phosphorothioates or other thio-substituted nucleotides in RNA. Fe(II) is bound firmly to the EDTA moiety of BABE (Kd $\sim 10^{-14}$ ) (see Fig. 2-10). Since hydroxyl radicals are small in size, highly reactive, and the reactivity is sequence and structure independent, they can be used to obtain a comprehensive picture of the nucleic acid elements surrounding the probe. The cleavage intensity depends on its distance from the tethered probe. The presence of a protein may also be a reason for the decreased intensity of the cleavages. The maximum target distance for strong cleavage is $\sim 18 \AA$, medium-strength cleavage is $\sim 26 \AA$, and weak cleavage is $\sim 42 \AA$ (Joseph and Noller, 2000). This method can be used to obtain information about the structure of the RNA in three dimensions at low resolution. There are various ways to detect the sites of strand scission. For short RNA and DNA chains (less than 200 nucleotides), the sites of cleavage can be best detected by using $5^{\prime}$ or $3^{\prime}{ }^{32} \mathrm{P}$-end-labelled target nucleic acid and separating the cleavage products on denaturing polyacrylamide gels. Alternatively, for longer chains, the sites of strand scission are detected by primer extension using reverse transcriptase (Joseph and Noller, 2000). 


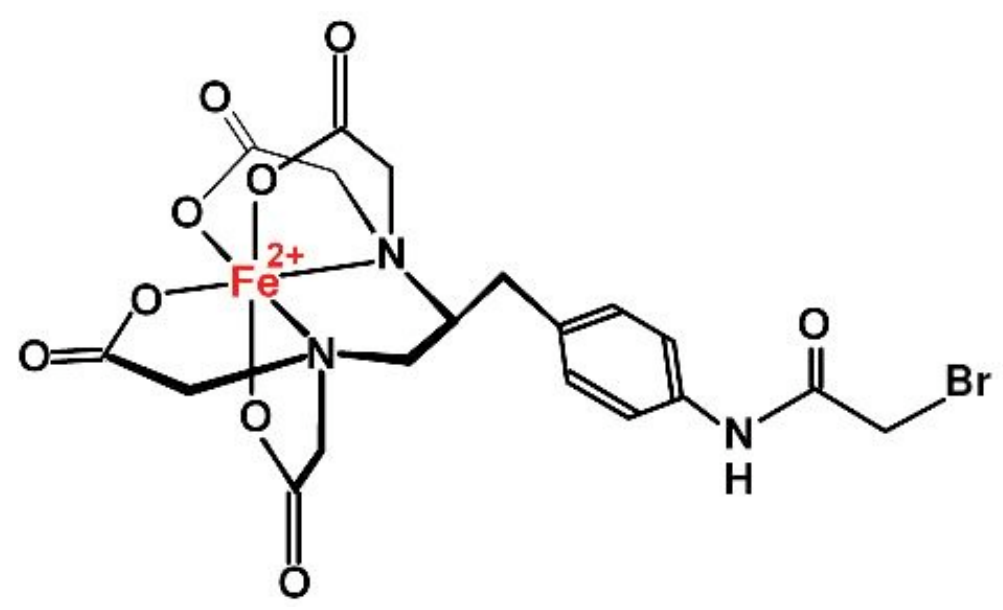

Figure 2-10. Structure of Fe-BABE. It is modified according to (Greiner et al., 1997). The EDTA subunit is shown here with the chelating Fe(II). The rest of the molecule is for binding to RNA or protein.

The reaction mechanism is a Fenton reaction in which ferrous iron reduces hydrogen peroxide to a reactive radical. The $\mathrm{HO}$ radical, a highly reactive oxidant, has been implicated in peroxide-mediated oxidation of a variety of substrates. The univalent reduction of $\mathrm{H}_{2} \mathrm{O}_{2}$ was postulated by Fenton (Fenton, 1894; Walling et al., 1975) and by Haber and Weiss (Haber, 1934) to explain the iron-dependent decomposition of $\mathrm{H}_{2} \mathrm{O}_{2}$ at acidic $\mathrm{pH}$. The metal acts as a redox catalyst of the catalase reaction. The reaction equation can be seen below.

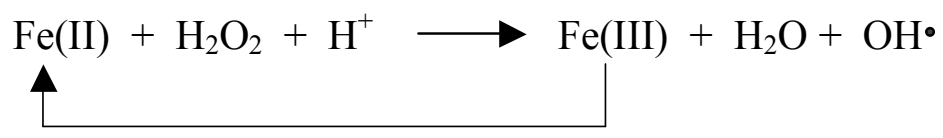

Ascorbic Acid

Hydroxyl radical footprinting can be conducted with picomole to nanomole concentrations of nucleic acid, and makes parsimonious use of biological materials.

This methodology has been used to investigate tertiary interactions in ribosomes, by tethering Fe-BABE to RNA or protein (Culver and Noller, 2000; Joseph and Noller, 2000). Similarly, attaching Fe-BABE to RNAs in the spliceosome would be very useful 
in order to study higher order RNA interactions or to investigate the RNA proximities in the spliceosome.

\subsection{Objectives}

The major goal of this work is to learn the molecular mechanisms of splice site pairing, the cross-intron communication of the intron ends and thereby to understand more about the architecture of early spliceosomal complexes. When this work began, not much was known about the communication of the splice sites during early spliceosome assembly. The U2 snRNP seemed to play a central role in splice site recognition/pairing during the early stages of the splicing process since it was functionally and loosely associated with the spliceosomal E complex (Das et al., 2000). However, the organization of U2 relative to the functional sites of the pre-mRNA and to the U1 snRNP is not known. We were interested to know the proximities among the components of the early spliceosomal complexes especially the U1 and U2 snRNPs. In order to investigate the RNA proximities of $\mathrm{U} 2$ relative to the functional sites of the pre-mRNA and to the U1 snRNP, we decided to use the site-directed hydroxyl radical probing method. Therefore, we have attached the hydroxyl radical probe Fe-BABE to the $5^{\prime}$ end of the U2 snRNA and analyzed the proximities to pre-mRNA and the U1 snRNA in E and A spliceosomal complexes.

For this purpose, the endogenous U2 were depleted from Hela nuclear extract and FeBABE-modified U2 snRNPs were provided to the sytem. Therefore, we used the twostep reconstitution/complementation system initially developed by Segault et al. (1995). The two steps of the system are as follows. First, core U2 snRNPs were reconstituted in vitro from anti- $\mathrm{m}_{3} \mathrm{G}$ purified native snRNP proteins (total proteins) and U2 snRNA. Second, the core U2 snRNP was added to HeLa cell nuclear extract depleted of U2 snRNP but still containing particle-specific proteins. These particle-specific proteins were allowed to assemble onto $12 \mathrm{~S}$ U2 snRNPs to form $17 \mathrm{~S}$ U2 snRNPs. By adding premRNA, the spliceosome assembly and the splicing reaction were analyzed. 
It was known that, in contrast to other snRNAs, in vitro transcribed U2 snRNA without any modifications did not support splicing (see 2.1.2.1.1). To generate Fe-BABE modified U2 snRNAs, we needed to identify which modified residues are required for U2 function in splicing so that the chimaeric U2 snRNA with the required modifications and the Fe-BABE could be prepared. Thus, the results of the first part of this work paved the way for the analysis of the question in the second part.

In the first part of this thesis, the role and the requirement of the individual modification of U2 snRNA within the first 24 nucleotides were studied. At the beginning of this work, it was known that the in vitro transcribed, unmodified U2 snRNA was not capable of complementing pre-mRNA splicing in HeLa cell nuclear extracts depleted of U2, while the native, HeLa U2 snRNA did so efficiently (Segault et al., 1995). This indicated for the first time that modified nucleotides of U2 snRNA are essential for its function. Then, in a study carried out in Xenopus oocytes, it was shown that the modifications within the first 27 nucleotides of U2 snRNA were required for splicing and spliceosome assembly in vivo ( $\mathrm{Yu}$ et al., 1998). However, the role that these modified nucleotides (13 pseudouridines and 10 2'-O-methyl groups) play for the structure and function of U2 snRNA remained to be investigated. In addition to this, according to Yu et al., 1998, the $\mathrm{m}_{3} \mathrm{G}$ cap of U2 snRNA was found to be essential for splicing within the context of the experimental system used. Therefore, we set out to investigate the requirement and the role of individual modifications within the first 24 nucleotides of the U2 snRNA by using the two-step reconstitution/complementation system. The native HeLa U2 snRNA, in vitro transcribed $\mathrm{U} 2$ snRNA and the chimaeric $\mathrm{U} 2$ snRNAs were used in this system. The chimaeric U2 snRNAs which contain different numbers and types of modifications within the first 24 nucleotides of U2 snRNA were generated via Moore and Sharp ligation (Moore and Sharp, 1992). After we have shown that the three pseudouridines and five 2'-O-methylations within the first 24 nucleotides of U2 snRNA are required for splicing, we analyzed the step of spliceosome assembly that they are essential for.

Importantly, it was also demonstrated in this study that the $5^{\prime}$ terminal $\mathrm{m}_{3} \mathrm{G}$ cap is not required for the function of $\mathrm{U} 2$ snRNA in splicing in vitro. These findings were of utmost 
practical importance, as this facilitates significantly the chemical synthesis of $5^{\prime}$ terminal U2 RNA oligonucleotide which is 24 nucleotide long and contain the required modifications and a $\mathrm{SH}$ group at its $5^{\prime}$ end. This $\mathrm{SH}$ groups is necessary to attach hydroxyl radical generator, Fe-BABE, at the 5 ' end of U2 snRNA to investigate which RNAs are in close proximity to this region of U2 snRNA in early spliceosomal complexes.

Distinct signals were observed on the pre-mRNA and U1 RNA in E complex indicating that these regions are located in close proximity to the 5 ' end of U2 RNA as investigated by primer extension analysis. Furthermore, the spatial proximities of the RNAs upon addition of ATP (the spliceosomal A complex) were investigated. In this way, the conformational changes of $\mathrm{U} 1$ and pre-mRNAs during spliceosomal $\mathrm{E}$ to A complex transition were monitored.

The cleavages observed on U1 snRNA provided constraints for modeling the orientation of $\mathrm{U} 1$ and $\mathrm{U} 2$ snRNPs in the E complex by using the protein-free 3D structure of $\mathrm{U} 1$ snRNA and the cryo-EM structure of U1 snRNP (Stark et al., 2001). Mapping of the cleavages observed on U1 RNA onto these structures revealed a distinct orientation of U2 relative to $\mathrm{U} 1$ in early spliceosomal complexes. The 5 ' end of $\mathrm{U} 2$ appears to be located on a specific "side" of the U1 snRNP, which for historical reasons designated as the "back" of the particle. By the help of the hydroxyl radical cleavage data on U1, the 5' end of U1 snRNA was placed on the U1 snRNP structure. 


\section{MATERIALS and METHODS}

\subsection{Materials}

\subsubsection{Chemicals}

\begin{tabular}{|c|c|}
\hline ABE (1-(4-Aminobenzyl)EDTA) & Dojindo, Japan \\
\hline acetone & Merck \\
\hline ammonium iron (II) sulphate $\left(\left(\mathrm{NH}_{4}\right)_{2} \mathrm{Fe}\left(\mathrm{SO}_{4}\right)_{2}\right)$ & Aldrich \\
\hline ammonium peroxodisulfate (APS) & Merck \\
\hline ascorbic acid & Sigma \\
\hline Bradford protein determination kit & Pierce \\
\hline bovine serum albumin (BSA) & Boehringer Mannheim \\
\hline bromoacetylbromide & Fluka \\
\hline bromophenol blue & Merck \\
\hline coomassie brillant blue G-250 & Serva \\
\hline cysteine & Sigma \\
\hline deoxynucleotide-5'-triphosphates (dNTPs) (0.1 M) & Pharmacia \\
\hline dideoxynucleotide-5'-triphosphates (ddNTPs) (0.1 M) & Amersham \\
\hline dimethylsulfoxide (DMSO) & Merck \\
\hline diethylaminoethyl cellulose 53 (DE53) & Whatman \\
\hline diguanosine triphosphate (GpppG) & Pharmacia \\
\hline 1,4-dithiothreitol (DTT) & Merck \\
\hline 1,4-dithioerythrol (DTE) & Merck \\
\hline EDTA (ethylene diamine-N,N,N',N'-tetraacetic acid) & Roth \\
\hline ethanol $(100 \%)$ & Merck \\
\hline ethidium bromide & Roche \\
\hline fluorescamine (FSC) & Sigma \\
\hline glycerol $(87 \%)$ & Merck \\
\hline
\end{tabular}


glycogen $(20 \mathrm{mg} / \mathrm{ml})$

heparin

HEPES (N-[2-hydroxyethylpiperazine-

N'-2-ethane sulfonic acid], free acid)

$\mathrm{m}^{7} \mathrm{GpppG}$

marker proteins for SDS gel electrophoresis

$\gamma($ p-Nitrobenzyl)pyridine (NBP)

Nonidet P-40 (NP-40)

nucleotide-5'-triphosphates (NTPs) (0.1 M each)

phenol/chloroform/isoamyl alcohol (PCI) (25:24:1) Roth

PMSF (phenylmethylsulphonylfluoride)

polyethylene glycol (PEG) 6000

Protein-A-Sepharose (PAS)

ribonucleotide-5'-triphosphates (rNTPs) (0.1 M each)

Rotiphorese Gel 30

(acrylamide : bisacrylamide 37:5:1)

Rotiphorese Gel 40

(acrylamide : bisacrylamide 19:1)

Rotiphorese Gel A

$$
\text { (30\% acrylamide) }
$$

sodium chloride

sodium dodecyl sulfate (SDS)

streptavidin agarose ( $1 \mathrm{ml}$ gel binds to $16 \mu \mathrm{g}$ biotin)

sucrose D ( +)

TCEP Bond-breaker solution (500 mM, neutral pH)

(tris (2-carboxyethyl) phosphine)

TEMED (N,N,N',N'-tetramethylethylene diamine)

Triton X-100

tRNA - Escherichia coli

Tween 20
Roche

Sigma

Roth

Edward Darzynkiewicz

Kedar sc., Warzaw, Poland

BioRad

Sigma

Fluka

Amersham

Roche

Merck

Pharmacia

Pharmacia

Roth

Roth

Roth

Merck

Merck

Sigma

Fluka

Pierce

Sigma

Sigma

Boehringer Mannheim

Calbiochem 
Urea

Merck

xylenecyanol FF (XC)

Fluka

All other chemicals not listed were purchased from Merck.

\subsubsection{Antibodies}

mAb Y12 (anti-Sm)

Ian Mattaj

mAb H4G3 (anti-U2B")

W. van Venrooij

anti-rabbit polyclonal

$\alpha-66.2$ (anti-SF3a66) and NIS-SF3a66

Cindy Will

anti-rabbit polyclonal

$\alpha-155.1$ (anti-SF3b155) and NIS-SF3b155

Cindy Will

\subsubsection{Plasmids}

pMRGU2-27

Marty Jacobson

(Jacobson et al., 1993)

pMINX (Zillmann et al., 1988)

Cindy Will

\subsubsection{Enzymes and enzyme inhibitors}

alkaline phosphatase

nuclease P1

proteinase $\mathrm{K}$

RQ1 DNAse

RNasin (RNAse inhibitor)

Restriction enzymes (Xho I, BamH1)

Reverse transcriptase (AMV)

T4 polynucleotide kinase
New England Biolabs

MP Biomedicals

Roche

Promega

Promega

New England Biolabs

Amersham

New England Biolabs 
T4 RNA ligase

T4 DNA ligase

T7 RNA polymerase
New England Biolabs

New England Biolabs

New England Biolabs, or a

gift from Heiko Maninga (prepared acc. to Davanloo et al., 1984)

Taq DNA polymerase

Promega

\subsubsection{Buffers}

Buffers and solutions were prepared by using autoclaved water and sterile-filtered with $0.22 \mu \mathrm{M}$ filter prior to use. Commonly used buffers are listed below. All other buffers and solutions are listed with the relevant protocols.

$\mathrm{NaOAc} \quad 3 \mathrm{M}, \mathrm{pH} 5.4$

CE buffer

$10 \mathrm{mM}$ cacodylic acid-KOH, pH 7.0

0.2 mM EDTA pH 8.0

TBE (10X)

$1 \mathrm{M}$ Tris

$1.06 \mathrm{M}$ Boric Acid

$20 \mathrm{mM}$ EDTA

Roeder D (10X)

200 mM HEPES-KOH, pH 7.9

$1 \mathrm{M} \mathrm{KCl}$

2 mM EDTA

$15 \mathrm{mM} \mathrm{MgCl}_{2}$

(kept at $4{ }^{\circ} \mathrm{C}, 0.5 \mathrm{mM}$ DTT and $0.5 \mathrm{mM}$ PMSF are added just before use.)

Proteinase K buffer (2X)

$0.2 \mathrm{M}$ Tris- $\mathrm{HCl}, \mathrm{pH} 7.5$

$25 \mathrm{mM}$ EDTA

$2 \% \operatorname{SDS}$ 
RNA Loading buffer

$$
\begin{aligned}
& 8.3 \mathrm{M} \text { urea } \\
& 0.5 \mathrm{X} \text { TBE } \\
& 0.05 \% \text { bromophenol blue } \\
& 0.05 \% \text { xylene cyanol }
\end{aligned}
$$

Native gel loading buffer

$$
\begin{aligned}
& 4.15 \mathrm{M} \text { urea } \\
& 0.5 \mathrm{X} \text { TBE } \\
& 0.05 \% \text { bromophenol blue } \\
& 0.05 \% \text { xylene cyanol } \\
& 50 \% \text { glycerol }
\end{aligned}
$$

Elution buffer

$20 \mathrm{mM}$ Tris-HCl, pH 7.5

0.2 M EDTA

$0.15 \mathrm{M} \mathrm{NaCl}$

$0.5 \% \mathrm{SDS}$

PBS (10X)

$200 \mathrm{mM} \mathrm{K}_{3} \mathrm{PO}_{4} \mathrm{pH} 8.0$

\section{$1.3 \mathrm{M} \mathrm{NaCl}$}

Transcription buffer (TRO) (10X) (according to Milligan and Uhlenbeck (1989))

$40 \mathrm{mM}$ Tris- $\mathrm{HCl}, \mathrm{pH} 8.1$ at $37^{\circ} \mathrm{C}$

$6 \mathrm{mM} \mathrm{MgCl}_{2}$

5 mM DTT

$1 \mathrm{mM}$ Spermidine

$0.01 \% \mathrm{w} / \mathrm{v}$ Triton X-100

Caco Buffer (10X)

1 M Cacodylic Acid pH: 7.0

$1 \mathrm{M} \mathrm{MgCl}_{2}$

$3 \mathrm{M} \mathrm{KCl}$ 


\subsubsection{Instruments}

automated DNA sequencer, ABI Prism 310

Biofuge fresco

Thermocycler (PCR)

centrifugation rotors HB6

developing machine X-Omat

gel drier model 583

gradient mixer

power supplies

PhosphorImager, Typhoon

revolving "head-over-tail" rotor 7637-01

sequencing gel apparatus

spectrophotometer Ultrospec 3000

speed-vac concentrator 5301

ultracentrifuge

UV lamps (254 or $312 \mathrm{~nm}$ )

pipettes $(1 \mathrm{ml}, 200 \mu \mathrm{l}, 20 \mu \mathrm{l}, 10 \mu \mathrm{l}, 2 \mu \mathrm{l})$

vortex

\subsubsection{Materials}

cellulose PEI plates

dialysis membrane

nucleotide removal and PCR purification kits

plasmid maxi- and mini-prep kits

polypropylene ultracentrifugation tubes

Slide-A-Lyzer dialysis products (3500 MWCO)

spacer $(0.5$ and $1 \mathrm{~mm})$

spacer, sharks comb $(0.3 \mathrm{~mm})$

Whatman 3MM paper

X-ray film Kodak BioMax
ABI, USA

Heraeus

Hybaid Omni Gene

Beckmann

Kodak

BioRad

Biocomp

Pharmacia

Molecular Dynamics

Cole-Palmer

BioRad

Pharmacia

Eppendorf

Sorvall

Bachhofer

Eppendorf

Vortex-Genie 2
Macherey-Nagel

Spectra Por

Qiagen

Qiagen

Beckmann

Pierce

Gibco

Gibco

Whatman Paper

Kodak 


\subsubsection{Radiochemicals}

Radiochemicals were obtained from Amersham Pharmacia.

$$
\begin{array}{ll}
{\left[\alpha-{ }^{32} \mathrm{P}\right] \text { UTP }} & 3000 \mathrm{Ci} / \mathrm{mmol}, 10 \mathrm{mCi} / \mathrm{ml} \\
{\left[\alpha-{ }^{32} \mathrm{P}\right] \text { GTP }} & 3000 \mathrm{Ci} / \mathrm{mmol}, 10 \mathrm{mCi} / \mathrm{ml} \\
{\left[\alpha-{ }^{32} \mathrm{P}\right] \text { ATP }} & 3000 \mathrm{Ci} / \mathrm{mmol}, 10 \mathrm{mCi} / \mathrm{ml} \\
\text { pCp }\left[5^{\prime}-{ }^{32} \mathrm{P}\right] 5^{\prime}, 3^{\prime}-\text { cytidine bisphosphate } & 3000 \mathrm{Ci} / \mathrm{mmol}, 10 \mathrm{mCi} / \mathrm{ml}
\end{array}
$$

\subsubsection{Oligonucleotides}

\subsubsection{DNA oligonucleotides}

DNA oligonucleotides were obtained from MWG Biotech AG.

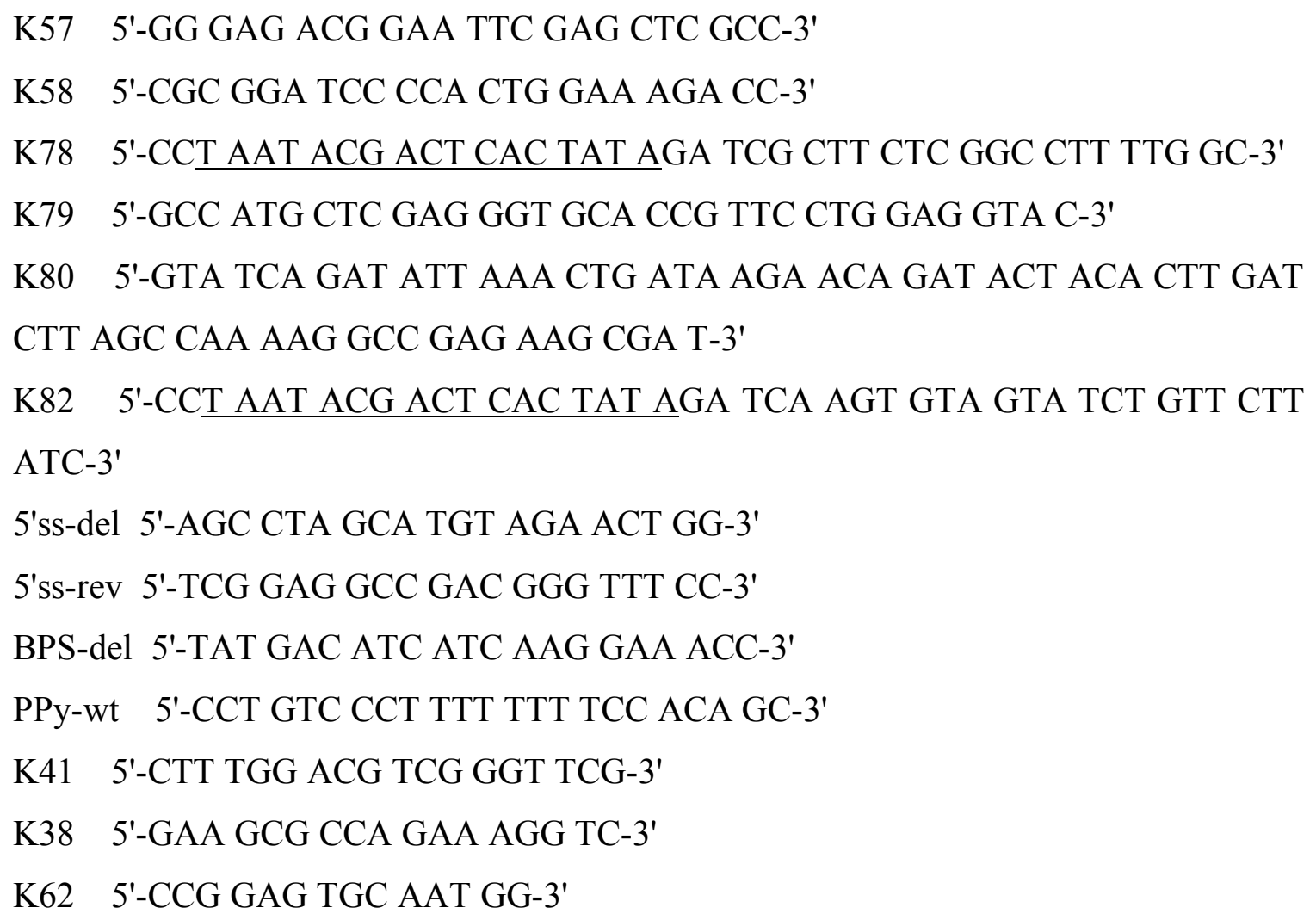




\section{K83 5'-GTC GAG TTT CCC ACA TTT G-3' \\ H6 5'-CGA ACG CAG TCC CCC ACT A-3'}

T7 RNA polymerase promoter sequences are underlined.

\subsubsection{RNA oligonucleotides}

bU2 RNA oligonucleotide was purchased from Xeragon AG or RNA-Tec. Its sequence is shown below.

5'-Cm Cm Am Am Am Am Gm Gm Cm Cm Gm Am Gm Am Am Gm Cm Gm Am Um bio-dT bio-dT bio-dT dT-3'

bio-dT shows biotinylated deoxynucleotide and " $\mathrm{m}$ " stands for 2'-O-methylated bases. bU2 RNA olgonucleotide is complementary to the first 20 nucleotides of U2 snRNA. It contains four biotinylated deoxythymine nucleotides at the $3^{\prime}$ end in order to bind to streptavidin.

U6e RNA oligonucleotide was purchased from RNA-TEC. Its sequence is shown below. It is complementary to the region between nucleotides 82 and 101 of U6 RNA.

5'-Am Um Gm Gm Am Am Cm Gm Cm Um Um Cm Am Cm Gm Am Am Um Um Um bio-dT bio-dT bio-dT dT-3'

U6_27/46 RNA oligonucleotide was purchased from Dharmacon. Its sequence is shown below. It is complementary to the region between nucleotides 27 and 46 of U6 RNA.

5'-Cm Um Cm Um Gm Um Am Um Cm Gm Um Um Cm Cm Am Am Um Um Um Um $-3^{\prime}$ 
The sequence of the 5' U2 RNA oligonucleotides corresponding to the 24 nucleotides of the $5^{\prime}$ end of U2 snRNA which were used in ligations to produce chimaeric U2 RNAs are shown below. $\Delta \psi \mathrm{m}, \psi \mathrm{m}, \Delta \psi$ and $\Delta \mathrm{m}$ were purchased from Brian Sproat. All the others were purchased from Dharmacon. $\psi$ stands for the pseudouridines and " $m$ " stands for the 2'-O-methylated nucleotides.

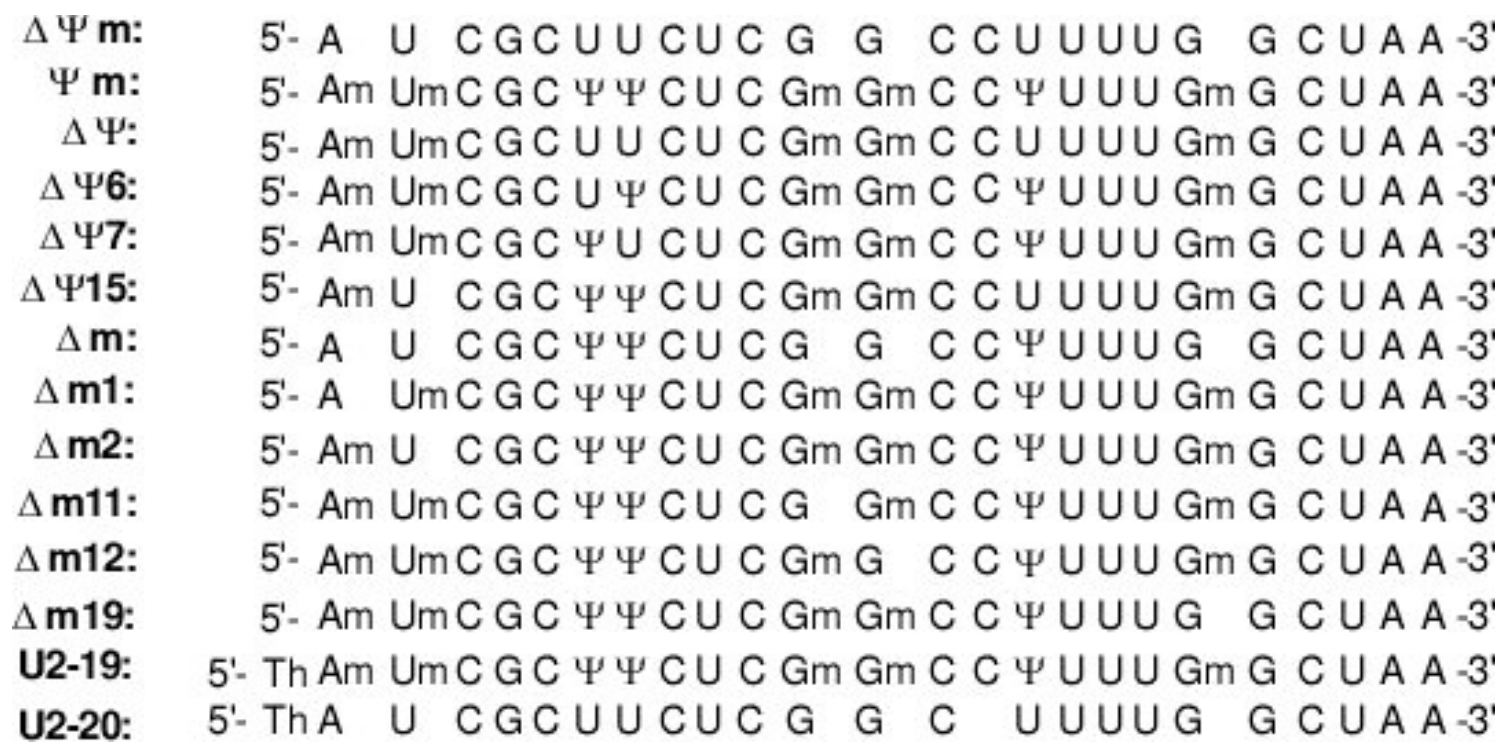

\subsection{Methods}

\subsubsection{General methods}

\subsubsection{Phenol/chloroform extraction}

The volume of the solution containing nucleic acids and proteins to be extracted was adjusted to a minimum of $100 \mu \mathrm{l}$ with water or CE buffer if necessary. An equal volume of phenol/chloroform/isoamylalcohol $(25: 24: 1)$ was then added to the mixture, vortexed, and centrifuged for $5 \mathrm{~min}$ at 13 000rpm. The nucleic acids in the aqueous phase are precipitated with ethanol. The proteins in the organic phase are precipitated by acetone. 


\subsubsection{Ethanol precipitation of nucleic acids}

To precipitate nucleic acids from an aqueous solution, 1/10 volume of $3 \mathrm{M} \mathrm{NaOAc}(\mathrm{pH}$ 5.2) and 3 volumes of ethanol were added. In order to recover as much as possible, the mixture has to be incubated for a minimum of 2 hours at $-20{ }^{\circ} \mathrm{C}$. Samples were then centrifuged at $13000 \mathrm{rpm}$ at $4{ }^{\circ} \mathrm{C}$ for $20 \mathrm{~min}$. The resulting pellets were washed with 150-300 $\mu 1$ 70\% ethanol and 50-100 $\mu 10.3 \mathrm{M} \mathrm{NaOAc}$ to remove salt and dried in a speed-vac for 5 to $15 \mathrm{~min}$. Pellets were resuspended in an appropriate volume of $\mathrm{CE}$ buffer or water. When precipitating low amounts of RNA or short oligonucleotides, $1 \mu 1$ glycogen $(10 \mathrm{mg} / \mathrm{ml})$ was added as a carrier.

\subsubsection{Concentration determination of DNA or RNA}

The concentration of DNA or RNA in aqueous solutions were measured in a spectrophotometer at $260 \mathrm{~nm}$ and $280 \mathrm{~nm}$. The nucleic acid concentration was determined from $260 \mathrm{~nm}$ absorption, $1 \mathrm{OD}_{260}$ corresponding to $50 \mu \mathrm{g} / \mathrm{ml}$ for doublestranded DNA, $40 \mu \mathrm{g} / \mathrm{ml}$ for single-stranded DNA or RNA and $20 \mu \mathrm{g} / \mathrm{ml}$ for oligonucleotides. Likely, $1 \mathrm{OD}_{260}$ corresponds to $0.15 \mathrm{mM}$ NTPs for double-stranded DNA and $0.11 \mathrm{mM}$ NTPs for single-stranded DNA or RNA. For example, in the case of singe-stranded RNA, the molar concentration of the RNA was determined by the following formula:

Concentration of RNA in $\mathrm{mM}=\#$ of units of $\mathrm{OD}_{260} \times 0.11 \div$ length of RNA in nts.

The ratio of $\mathrm{OD}_{260} / \mathrm{OD}_{280}$ is an indicator of the purity the of nucleic acid solution. The optimal ratio is 1.8 for DNA and 2.0 for RNA. Lower ratios show the presence of proteins in the solution which have to be removed by phenol/chloroform extraction and ethanol precipitation. 


\subsubsection{Concentration determination of proteins}

The concentration of the proteins were determined by the method of Bradford (Bradford, 1976) using the Bradford Protein Determination Kit.

\subsubsection{Proteinase K digestion}

For a $50 \mu \mathrm{l}$ volume of Proteinase K digestion, $25 \mu 12 \mathrm{X}$ PK buffer, $1 \mu 1$ glycogen (10 $\mathrm{mg} / \mathrm{ml}), 1 \mu \mathrm{l}$ RNA $(2.5 \mathrm{mg} / \mathrm{ml}), 2 \mu \mathrm{l}$ Proteinase K enzyme $(10 \mathrm{mg} / \mathrm{ml})$ and the sample to be Proteinase $\mathrm{K}$ digested were mixed. The volume was adjusted to $50 \mu 1$ with sterile $\mathrm{H}_{2} \mathrm{O}$. The reaction was incubated at $37{ }^{\circ} \mathrm{C}$ or $42{ }^{\circ} \mathrm{C}$ for $30 \mathrm{~min}$. If the Proteinase $\mathrm{K}$ digestion was needed to be carried out in a reaction volume of $100 \mu 1,4 \mu 1$ Proteinase $\mathrm{K}$ enzyme $(10 \mathrm{mg} / \mathrm{ml})$ was added and incubated at $37^{\circ} \mathrm{C}$ or $42{ }^{\circ} \mathrm{C}$ for 1 hour. Then the reaction was phenol/chloroform extracted, ethanol precipitated and resuspended in an appropriate volume of CE buffer or water.

\subsubsection{Radioactive labelling of nucleic acids}

\subsection{5'-End labeling with T4 Polynucleotide kinase and $\gamma-{ }^{32}$ P ATP}

RNA oligonucleotides were 5'-end labelled, using $\gamma-{ }^{32} \mathrm{P}$ ATP and T4 polynucleotide kinase, during $40 \mathrm{~min}$ incubation at $37^{\circ} \mathrm{C}$. Subsequent to the labelling reaction, the sample volume was completed to $50 \mu \mathrm{l}$ with CE buffer, purified with G25 spin column (used according to the manufacturer's instructions), phenol/chloroform extracted, ethanol precipitated, resuspended in $40 \mu \mathrm{CE}$ buffer and stored at $-20^{\circ} \mathrm{C}$. 


\section{$\underline{\text { Polynucleotide kinase (PNK) reaction }}$}

10 pmol RNA

$1 \mu \mathrm{1} \quad$ 10X PNK buffer (supplied by manufacturer)

$6 \mu \mathrm{l} \quad \gamma^{32} \mathrm{P}$ ATP $(5000 \mathrm{Ci} / \mathrm{mmol}, 10 \mu \mathrm{Ci} / \mu \mathrm{l})$

$1 \mu 1 \quad$ T4 polynucleotide kinase (20 units/ $\mu 1)$

volume adjusted to $10 \mu \mathrm{l}$ with sterile $\mathrm{H}_{2} \mathrm{O}$

\subsection{3'-End labelling with T4-RNA-Ligase (pCp labeling)}

RNAs were 3'-end labelled using pCp and T4 RNA ligase. The mixtures were incubated at $4{ }^{\circ} \mathrm{C}$ overnight. If the purpose of labelling was to monitor the RNA, $3.5 \mu 1$ of the reaction was analysed on $9.6 \%$ polyacrylamide- $8.3 \mathrm{M}$ urea gel. RNA from preparative labelling reactions was purified by G-50 micro columns, phenol/chloroform extracted, precipitated in ethanol, resuspended in an appropriate volume of CE buffer and stored in $50 \%$ ethanol at $-20{ }^{\circ} \mathrm{C}$.

$\underline{\text { T4 RNA ligase reaction }}$

10 pmol RNA

$0.7 \mu \mathrm{T} \quad$ T4 10X RNA ligase buffer (supplied by manufacturer)

$0.7 \mu 1 \quad 10 \%$ DMSO

$0.5 \mu \mathrm{R} \quad \mathrm{RNasin}(40 \mathrm{u} / \mu \mathrm{l})$

$2.2 \mu \mathrm{l} \quad{ }^{32} \mathrm{P}-\mathrm{pCp}(3000 \mathrm{Ci} / \mathrm{mmole}, 10 \mu \mathrm{Ci} / \mu \mathrm{l})$

$1 \mu \mathrm{l} \quad$ T4 RNA ligase $(20 \mathrm{u} / \mu \mathrm{l})$

volume adjusted to $10 \mu \mathrm{l}$ with sterile $\mathrm{H}_{2} \mathrm{O}$

\subsubsection{Gel electrophoresis}

\subsection{High-TEMED, SDS-polyacrylamide gel electrophoresis (PAGE)}

To separate total proteins from each other, $1 \mathrm{~mm}$ thick high-TEMED gels were prepared. Gels were run vertically in SDS-PAGE running buffer and protein samples were 
denaturated by adding SDS-PAGE loading buffer and heating at $90{ }^{\circ} \mathrm{C}$ for $2 \mathrm{~min}$ before loading. Electrophoresis was performed until the bromophenol blue dye reached the bottom of the gel.

Seperating gel $(13 \%)$

375 mM Tris-HCl, $\mathrm{pH} 8.8$

$0.1 \%$ SDS

$13 \%$ acrylamide:bisacrylamide diluted from Gel 30

$0.03 \%$ APS

$0.33 \%$ TEMED

Stacking gel $(5 \%)$

125 mM Tris-HCl, pH 6.8

$0.1 \%$ SDS

$5 \%$ acrylamide:bisacrylamide diluted from Gel 30

$0.05 \%$ APS

$0.25 \%$ TEMED

SDS-PAGE running buffer

25 mM Tris-HCl, $\mathrm{pH} 8.8$

$192 \mathrm{mM}$ glycine

$1 \%$ SDS

SDS-PAGE loading buffer

$50 \mathrm{mM}$ Tris-HCl, $\mathrm{pH} 6.8$

$2 \%$ SDS

$10 \%$ glycerol

$50 \mathrm{mM}$ DTE

$0.025 \%$ bromophenol blue

Protein bands were visualized by Coomasie staining for overnight on shaker. Gels were then incubated in the destaining solution until the background dye intensity was reduced to allow the visual detection of the protein bands. Gels were then transformed to Whatmann paper and dried at $80{ }^{\circ} \mathrm{C}$ for 1 hour. 
Coomassie solution

$0.25 \%$ Coomassie Brillant Blue R-250

$50 \% \mathrm{MeOH}$

$10 \%$ HOAc

Destaining solution

$40 \% \mathrm{MeOH}$

$10 \% \mathrm{HOAc}$

\subsection{Denaturing polyacrylamide gel electrophoresis of RNA}

RNA molecules were separated from each other on denaturing polyacrylamide-urea gels. Gels were $0.5 \mathrm{~mm}$ thick and run vertically in $1 \mathrm{X}$ TBE running buffer. Samples were dissolved in RNA loading buffer and boiled at $96{ }^{\circ} \mathrm{C}$ for 90 seconds before loading into pre-rinsed wells. Electrophoresis was performed until xylene cyanol dye migrated to the bottom of the gel. Splicing reaction was analysed on $15 \%$, U2 snRNAs were analysed on $9.6 \%$ and RNA oligonucleotides were analysed on $22 \%$ denaturing polyacrylamide urea gels.

Polyacrylamide-urea gel

$9.6 \%, 15 \%, 22 \%$ acrylamide:bisacrylamide diluted from Gel 40

$8.3 \mathrm{M}$ urea

$1 \mathrm{X}$ TBE

$0.0625 \%$ APS

$0.01 \%$ TEMED

Radioactive RNA was visualised by autoradiography. Nonradioactive RNA was visualized by UV light after ethidium bromide staining. 


\subsection{Agarose gel electrophoresis}

DNA molecules were separated from each other by electrophoresis on $1.5 \%$ agarose gel containing $1 \mu \mathrm{l}$ ethidium bromide/100 $\mathrm{ml}$ gel. It was performed horizontally in $1 \mathrm{X}$ TBE running buffer for $30 \mathrm{~min}$ to $1 \mathrm{hr}$ at $150 \mathrm{~V}$. Bands were visualized by UV irradiation at a wavelength of $256 \mathrm{~nm}$.

\subsection{Low-melting agarose gel electrophoresis for RNA complex gels}

Spliceosomal complexes were visualized by $1.5 \%$ low-melting agarose gel electrophoresis (Das and Reed, 1999). $2 \mu 120 \%$ sucrose and $1 \mu 1$ Heparin $(2 \mathrm{mg} / \mathrm{ml})$ were added to a $15 \mu \mathrm{l}$ splicing reaction and half of the mixture was loaded onto $1.5 \%$ low-melting agarose gel. Electrophoresis was run at RT at $8 \mathrm{~W}$ for 5 hours. The gel was then fixed in $10 \% \mathrm{MeOH} / 10 \% \mathrm{HOAc}$ for $30 \mathrm{~min}$ and dried at $60{ }^{\circ} \mathrm{C}$ for 4 hours. It was visualized by autoradiography. For E complex analysis, the nuclear extract was depleted from ATP by incubating at RT or $37^{\circ} \mathrm{C}$ for 1 hour and the heparin was excluded from the loading dye since E complex is not stable in the presence of heparin (Das and Reed, 1999).

\subsubsection{Gel purification of RNA}

The oligonucleotides used in ligation to produce chimaeric U2 RNA were purified from $22 \%$ denaturing polyacrylamide-8.3 M urea gel. Pre-mRNA and U2 snRNAs were purified from denaturing $9.6 \%$ polyacrylamide- $8.3 \mathrm{M}$ urea gel.

To recover nonradiolabelled RNA from denaturing polyacrylamide-urea gel, the gel was placed over a thin-layer chromatography plate containing a fluorescent indicator and wrapped in plastic wrap. Bands were visualized by irradiation at $302 \mathrm{~nm}$ by UV-lamp. RNA absorbs UV-light and can be seen as dark bands which are then excised with a razor blade. 
To recover radiolabelled RNA from polyacrylamide-urea gel, the gel was left on glass plate, covered with plastic wrap and exposed to an X-ray film for 2-5 min. The position of the glass plate on the film was marked with waterproof ink. After developing the film, the film was placed behind the glass plate, and the gel regions containing the RNA located by the help of bands visible on the film were excised with a razor blade.

To elute RNA, the gel pieces containing the RNA were cut into very small fragments and incubated with $600 \mu$ l elution buffer for $\mathrm{O} / \mathrm{N}$ at RT. The elution buffer was then recovered and the RNA was ethanol precipitated. The gel fragments were incubated once more with $600 \mu$ l elution buffer at $37^{\circ} \mathrm{C}$ for 2 hours and the eluate was used to resuspend the precipitate of the first elution. After that, the elution was phenol/chloroform extracted, ethanol precipitated and resuspended in $\mathrm{CE}$ buffer.

\subsubsection{Autoradiography and Phosphor Imager Analysis}

Native polyacrylamide gels and low melting agarose gels containing radioactive molecules were vacuum-dried in a gel drier prior to exposure to autoradiography. Native polyacrylamide gels were dried for $1 \mathrm{~h}$ at $80{ }^{\circ} \mathrm{C}$ and low melting agarose gels were dried for $4 \mathrm{~h}$ at $60^{\circ} \mathrm{C}$. Denaturating polyacrylamide gels were transferred to a used X-ray film, covered with plastic wrap, and exposed to Kodak BioMax X-ray film in a cassette at -80 ${ }^{\circ} \mathrm{C}$ with two intensifying screens for the appropriate time. Film was developed mechanically in a Kodak X-Omat developer. The radioactive gels are analyzed by Phosphor Imager in addition to autoradiography using the program Typhoon.

\subsubsection{Quantifications}

\subsection{Quantification of a single RNA band}

The quantification of a single RNA band, e.g. the analysis of modification efficiency or the splicing efficiency was performed with the Quantity One program. The small boxes with equal sizes were drawn around the bands to be quantified. The identical small box 
was also drawn for the background. The "intensity units" of these small boxes were calculated by Quantity One program and the results were transported into the Excel Table Calculation Program.

The following equation was used for the calculations in this program:

$$
\frac{m-b g}{m+u-2 \cdot b g}
$$

m: modified/spliced; bg: background; u: unmodified/not spliced

\subsubsection{Densitometric analysis of primer extension gels}

The autoradiographs of primer extension gels were analyzed by Quantity One program. A line was created over the entire lanes of $+\mathrm{BABE}+\mathrm{H}_{2} \mathrm{O}_{2}$ and $-\mathrm{BABE}-\mathrm{H}_{2} \mathrm{O}_{2}$ (background) which are to be compared. The graphs of the intensity units over these lanes were drawn and transported to Excel Table Calculation Program (e.g. 100 data points per centimer gel). The graphs of the "+BABE+ $\mathrm{H}_{2} \mathrm{O}_{2}$ ", the "-BABE- $\mathrm{H}_{2} \mathrm{O}_{2}$ " and the difference $\left["+\mathrm{BABE}+\mathrm{H}_{2} \mathrm{O}_{2} "\right.$ - "-BABE- $\mathrm{H}_{2} \mathrm{O}_{2}$ "] were drawn in Excel. In the graph of difference, nucleotides where the difference amounted to 50 or more arbitrary intensity units were considered to be cleaved. The cleavages were further classified as weak (50-99 units), medium (100-149 units) or strong (150 units and up) essentially according to Joseph et al. (2000).

\subsubsection{Preparation of competent $E$. coli bacteria and $E$. coli transformation}

E. coli $\mathrm{DH} 5 \alpha$ competent cells (Stratagene) were prepared and transformation was carried out according to the manufacturer protocol. 


\subsubsection{Preparative plasmid preparation}

Plasmids were isolated using Plasmid Maxi Kit (Qiagen) according to the manufacturer protocol.

\subsubsection{Standard polymerase chain reaction (PCR)}

$5 \mu 1$ DNA $(20 \mu \mathrm{g} / \mathrm{ml})$

$5 \mu \mathrm{l}$ oligo $1(20 \mu \mathrm{M})$ forward

$5 \mu$ l olgo $2(20 \mu \mathrm{M})$ reverse

$10 \mu 1$ 10X Taq buffer (Promega)

$1.6 \mu 1 \mathrm{dNTPs}(25 \mathrm{mM}$ each)

$1 \mu 1$ Taq DNA polymerase $(5 \mathrm{u} / \mu 1)$

The volume was adjusted to $100 \mu$ with sterile $\mathrm{H}_{2} \mathrm{O}$.

Cycle 1: $\quad 2 \min$ at $96^{\circ} \mathrm{C}$

Cycles 2-31: $1 \mathrm{~min}$ at $96^{\circ} \mathrm{C}$

$1 \mathrm{~min}$ at $50^{\circ} \mathrm{C}$

1 min at $72{ }^{\circ} \mathrm{C}$

Cycle 32 : $5 \min$ at $72{ }^{\circ} \mathrm{C}$

$5 \mu 1$ of a $100 \mu \mathrm{l}$ PCR reaction was checked on $1.5 \%$ agarose gel and visualized by ethidium bromide staining. The PCR reactions were phenol/chloroform extracted, ethanol precipitated, resuspended in $50 \mu \mathrm{CE}$ buffer and the concentration was determined by UV-spectrophotometry. 


\subsubsection{In vitro transcription}

a) Preparative transcription reaction

$19 \mu 1$ DNA

$5 \mu 1 \mathrm{BSA}(10 \mathrm{~g} / \mathrm{l})$

$150 \mu \mathrm{rNTPs}$ (25 mM each)

$15 \mu 1 \mathrm{MgCl}_{2}(1 \mathrm{M})$

$50 \mu 1$ 10X TRO buffer

$6 \mu 1$ T7 RNA polymerase

The volume was adjusted to $500 \mu \mathrm{l}$ with sterile $\mathrm{H}_{2} \mathrm{O}$ and the reaction was incubated at 37 ${ }^{\circ} \mathrm{C} \mathrm{O} / \mathrm{N} .20 \mu \mathrm{RQ} 1 \mathrm{DNase}(1 \mathrm{u} / \mu \mathrm{l})$ was added in order to remove the DNA template and incubated at $37^{\circ} \mathrm{C}$ for another $15 \mathrm{~min}$. The transcription reaction was then gel purified.

b) Transcription of radiolabelled RNA

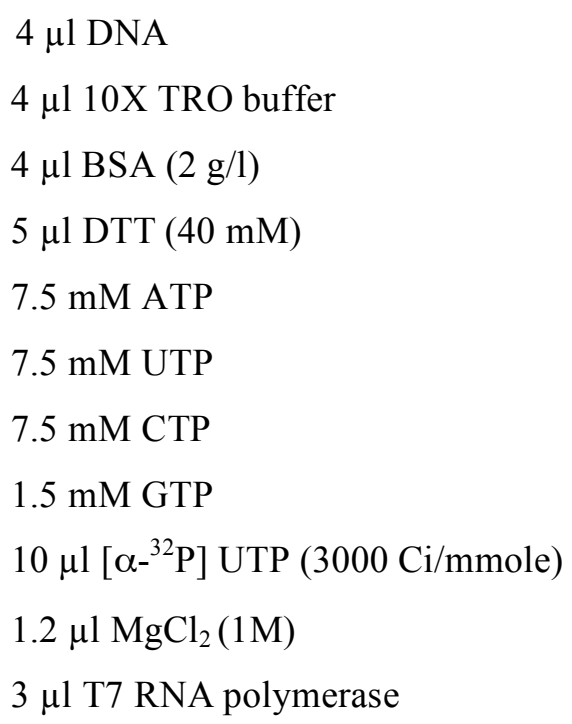

The volume of reaction was adjusted to $40 \mu \mathrm{l}$ with sterile $\mathrm{H}_{2} \mathrm{O}$ and incubated at $37{ }^{\circ} \mathrm{C}$ for 2.5 hours, $2 \mu \mathrm{l}$ RQ1 DNase $(1 \mathrm{u} / \mu \mathrm{l})$ was added to remove the DNA template and incubated for another $15 \mathrm{~min}$. The transcription reaction was then gel purified. $\mathrm{m}^{7} \mathrm{GpppG}$ 
capping of the transcript was achieved by adding $\mathrm{m}^{7} \mathrm{GpppG}$ to $3.125 \mathrm{mM}$ final concentration and lowering the GTP concentration to $0.1 \mathrm{mM}$ in the reaction.

\subsubsection{Preparation of the pre-mRNA}

DNA template for the pre-mRNA used in the experiments is the standard pMINX clone (Zillmann et al., 1988). 5 equivalent PCR reactions of $100 \mu 1$ each were set up to produce M7 DNA transcription template. The PCR reaction was carried out with K57 as a forward oligo to introduce T7 promoter and K58 as a reverse oligo to keep the BamH1 restriction site at $3^{\prime}$ end. The PCR reaction product was recovered and digested with BamH1 restriction enzyme $(20 \mathrm{u} / \mu 1)$, phenol/chloroform extracted, ethanol precipitated and resuspended in $150 \mu \mathrm{CE}$ buffer. $2 \mu \mathrm{l}$ of this template was radioactively transcribed in a $40 \mu \mathrm{l}$ transcription reaction under conditions of $\mathrm{m}^{7} \mathrm{GpppG}$ capping. The transcription reaction was gel purified.

\subsubsection{Generation of branchsite-deleted pre-mRNA}

The pre-mRNA without a branchsite was generated by using PCR primers to exclude the branchsite region ACUUAU which is between U150 and C157 and the MINX plasmid.

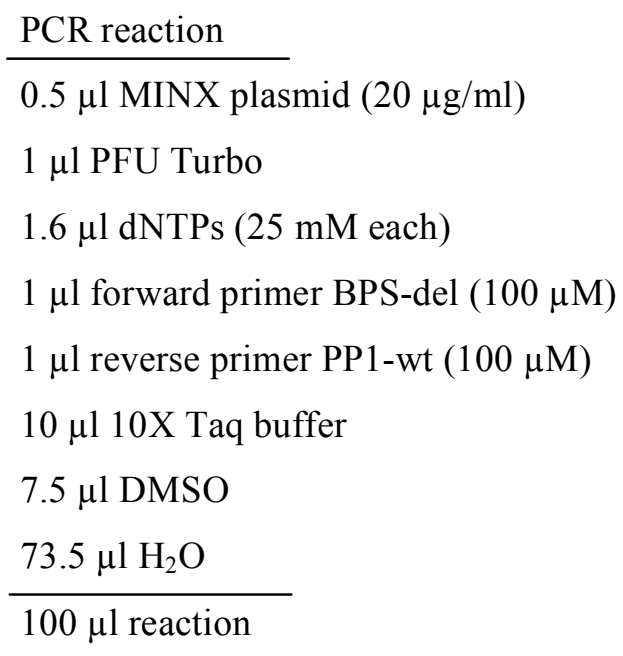




\begin{tabular}{lll|l} 
step 1 & 1 min 30 seconds & $95{ }^{\circ} \mathrm{C}$ \\
step 2 & 30 seconds & $95{ }^{\circ} \mathrm{C}$ & \\
& 45 seconds & $55^{\circ} \mathrm{C}$ & 32 cycles \\
& 7 min & $68^{\circ} \mathrm{C}$ &
\end{tabular}

step 3 hold $\quad 4{ }^{\circ} \mathrm{C}$

The PCR product which is a linearized plasmid was then purified by using Qiagen PCR purification kit. $30 \mu \mathrm{l}$ cleaned plasmid $(60 \mathrm{ng} / \mu \mathrm{l})$ was kinased with $3 \mu \mathrm{l}$ T4 polynucleotide kinase $(20 \mathrm{u} / \mu \mathrm{l}), 4 \mu \mathrm{l} 10 \mathrm{X}$ PNK buffer and $1 \mathrm{mM}$ ATP. $1 \mu 1 \gamma$-ATP ${ }^{32} \mathrm{P}$ was added to the kinase reaction in order to follow the clean-up afterwards. The reaction was incubated for $1 \mathrm{hr}$ at $37^{\circ} \mathrm{C}$ and purified with Qiagen nucleotide removal kit. It was then redissolved in the mixture of $16 \mu \mathrm{H} 2 \mathrm{O}$ and $2 \mu 1$ 10X T4 DNA ligase buffer, $2 \mu 1$ T4 DNA ligase $(400 \mathrm{u} / \mu \mathrm{l})$ was added, incubated first $37^{\circ} \mathrm{C}$ for $30 \mathrm{~min}$ and then at $16{ }^{\circ} \mathrm{C}$ $\mathrm{O} / \mathrm{N}$. To deactivate the kinase, it was incubated at $65^{\circ} \mathrm{C}$ for $10 \mathrm{~min} .20 \mu \mathrm{l}$ ligase reaction was ethanol precipitated, dissolved in $10 \mu \mathrm{l} \mathrm{H}_{2} \mathrm{O}$ and $3 \mu \mathrm{l}$ was used for transformation of dH5 $\alpha$ cells. Large-scale DNA isolation was performed with Qiagen Maxi prep kit and the cloned plasmids were sequenced by automated DNA sequencer (ABI Prism 310).

\subsubsection{Generation of 5' ss-deleted pre-mRNA}

The pre-mRNA without 5' ss was generated as explained in 3.2.2.1 but using the forward primer " 5 ' ss del" and the reverse primer " 5 ' ss rev" to exclude the region CGGUAAGA which is between A56 and G65.

\subsubsection{Preperation of U2 snRNAs}

\subsubsection{Preparation of U2 and U2G25 RNA transcripts}

The DNA template used for the U2 snRNA was the human U2 snRNA clone pMRG3U227 (Jacobson et al., 1993). 5 equivalent PCR reactions of $100 \mu 1$ each were set up to 
produce U2 DNA transcription template. The PCR reactions were carried out with $\mathrm{K} 78$ as a forward and K79 as a reverse oligo. They were then digested with Xho I restriction enzyme $(20 \mathrm{u} / \mu \mathrm{l})$ according to the manufacturer specification, phenol/chloroform extracted, ethanol precipitated and resuspended in $150 \mu \mathrm{l} \mathrm{CE}$ buffer. $4 \mu \mathrm{l}$ of this template was radioactively transcribed with T7 RNA polymerase and $19 \mu \mathrm{l}$ of the template was nonradioactively transcribed with the same enzyme. The transcription reactions were gel purified.

For U2G25 snRNA (U2 snRNA without the the first 24 nucleotides at the 5 ' end, from nucleotides 25 to 192), the DNA template was the same human U2 snRNA clone pMRG3U2-27. 5 equivalent PCR reactions of $100 \mu$ l each were set up to produce U2G25 DNA transcription template. The PCR reactions were carried out with K82 as a forward and K79 as a reverse oligo. They were then digested with Xho I restriction enzyme (20 $\mathrm{u} / \mu \mathrm{l})$, phenol/chloroform extracted, ethanol precipitated and resuspended in $150 \mu \mathrm{CE}$ buffer. $19 \mu \mathrm{l}$ of this template was transcribed nonradioactively, gel purified and used in ligations (see below in 3.2.3.3).

\subsubsection{Preparation of HeLa U2 snRNA}

$250 \mathrm{ml} \mathrm{HeLa} \mathrm{cell} \mathrm{nuclear} \mathrm{extracts} \mathrm{(Dignam} \mathrm{et} \mathrm{al.,} \mathrm{1983)} \mathrm{was} \mathrm{phenol} \mathrm{extracted,} \mathrm{RNA} \mathrm{was}$ resuspended in $1 \mathrm{ml} \mathrm{CE}$ buffer and treated with RQ1 DNase. For $500 \mu$ l aliquots, $50 \mu \mathrm{l}$ 10X RQ1 DNase buffer and $5 \mu \mathrm{l}$ RQ1 DNase was added, incubated at $37^{\circ} \mathrm{C}$ for $30 \mathrm{~min}$, phenol/chloroform extracted and ethanol precipitated. It was then run on 5-20\% sucrose gradient (w/v) prepared in $10 \mathrm{mM}$ Tris- $\mathrm{HCl} \mathrm{pH} 8.0$, and $50 \mathrm{mM} \mathrm{NaCl} .20 \mu 11 \mathrm{M}$ Tris$\mathrm{HCl} \mathrm{pH} 8.0$ and $20 \mu 15 \mathrm{M} \mathrm{NaCl}$ were added over to 2ml RNA (from 125 ml nuclear extract) and boiled at $96{ }^{\circ} \mathrm{C}$ for $3 \mathrm{~min}$. At this point the RNA became jelly at RT. $200 \mu 1$ gradient buffer and $\sim 100 \mu 150 \mathrm{mM} \mathrm{HCl}$ were added to $1 \mathrm{ml}$ RNA, the volume was completed to $1.5 \mathrm{ml}$ with $\mathrm{H}_{2} \mathrm{O}$ and $750 \mu \mathrm{l}$ was loaded onto each gradient. The gradient was run in $14 \mathrm{ml}$ tubes at $40000 \mathrm{rpm}$ for 6 hours in the TST 41.41 rotor at $16{ }^{\circ} \mathrm{C}$ in a Sorvall centrifuge. The 5S RNA fraction containing U snRNAs was pooled, further 
fractionated on a $10 \%$ polyacrylamide- $8.3 \mathrm{M}$ urea gel and the U2 snRNA was eluted from the gel.

\subsubsection{Preparation of chimaeric U2 snRNAs via ligations}

All ligation reactions were carried out according to Moore and Sharp (1992). The different 5' U2 RNA oligonucleotides (see Materials, 3.1.8.2, RNA oligonucleotides) were ligated to the G25U2 RNA (U2 snRNA transcript from nucleotides 25 to 192) with the T4 DNA Ligase in the presence of the splint oligo K80 (complementary to the first 67 nucleotides of U2 snRNA). 150 pmol each of 5' U2 oligo, 3' fragment G25U2 RNA and the splint oligo were used in each ligation reaction. Before ligation reaction, the $3^{\prime}$ fragment G25U2 RNA was dephosphorylated by alkaline phosphatase treatment. Then kinase reaction which includes low amount of radioactively labeled 3' fragment as a tracer was performed. Then the ligation was carried out and gel-purified.

Dephosphorylation of 3' fragment G25U2

$70 \mu 13^{\prime}$ fragment G25U2 ( 650 pmol)

$1.4 \mu 1 \mathrm{MgCl}_{2}(1 \mathrm{M})$

$14 \mu 1 \mathrm{DTT}(0.5 \mathrm{M})$

$7 \mu 1 \mathrm{RNasin}(40 \mathrm{u} / \mu \mathrm{l})$

$5.6 \mu 1$ Tris $(1 \mathrm{M}, \mathrm{pH} 7.5)$

$95 \mu 1 \mathrm{H}_{2} \mathrm{O}$

$7 \mu \mathrm{l}$ alkaline phosphatase (CIP, $20 \mathrm{u} / \mu \mathrm{l})$

$100 \mu \mathrm{l}$ reaction, $37^{\circ} \mathrm{C} 45 \mathrm{~min}$

$55^{\circ} \mathrm{C} 30 \mathrm{~min}$ (to inactivate the kinase)

The dephosphorylation reaction was PCI extracted, precipitated with EtOH and resuspended in $30 \mu \mathrm{H}_{2} \mathrm{O}$. This RNA $(20 \mathrm{pmol} / \mu \mathrm{l})$ was used in kinase reaction.1.2 $\mu \mathrm{l}$ of this RNA (24 pmol) was ${ }^{32} \mathrm{P}-\mathrm{pCp}$-labelled before kinase reaction. This trace amount of ${ }^{32} \mathrm{P}-\mathrm{pCp}$-labelled $3^{\prime}$ fragment G25U2 was added to the reaction in order to follow the ligation and to quantitate the yields. 
Kinase reaction of 3' fragment G25U2

$30 \mu 13^{\prime}$ fragment G25U2 (20 pmol/ $\mu 1$, total $\left.\sim 600 \mathrm{pmol}\right)$

$10 \mu 1^{32} \mathrm{P}$-pCp-labelled 3' fragment G25U2 (1.2 pmol/ $\mu 1$, total $\left.24 \mathrm{pmol}\right)$

$3 \mu 120 \mathrm{mM}$ ATP

$1 \mu \mathrm{l} \operatorname{RNasin}(40 \mathrm{u} / \mu \mathrm{l})$

$1 \mu 11 \mathrm{M} \mathrm{DTT}$

$4 \mu 1$ 10X PNK buffer (NEB)

$2 \mu \mathrm{l}$ PNK $(10 \mathrm{u} / \mu \mathrm{l})$

$40 \mu 1$ reaction, $37^{\circ} \mathrm{C} 30 \mathrm{~min}$

After the first incubation at $37^{\circ} \mathrm{C}$ for $30 \mathrm{~min}$, the kinase reaction was chased with $3 \mu 120$ $\mathrm{mM}$ ATP at $37^{\circ} \mathrm{C}$ for $30 \mathrm{~min}$ by adding $2 \mu \mathrm{PNK}(10 \mathrm{u} / \mu \mathrm{l})$ and incubated at $65^{\circ} \mathrm{C}$ for 20 min to inactivate the kinase enzyme. The kinase reaction was divided into four $(11 \mu 1$ each) meaning that four ligation reactions with four different $5^{\prime}$ oligonucleotides could be performed.

Ligation reaction

$4 \mu 15^{\prime}$ U2 oligonucleotides (150 pmol, the oligos e.g. $\Psi \mathrm{m}, \Delta \Psi \mathrm{m}, \Delta \Psi, \Delta \mathrm{m} \ldots$...tc.)

$11 \mu 1$ kinase reaction from above

$1.6 \mu 1$ splint oligo K80 (100 pmol/ $\mu \mathrm{l})$

$3.4 \mu \mathrm{l}$ glycogen $(10 \mathrm{mg} / \mathrm{ml})$

$14 \mu 18 \mathrm{M} \mathrm{NH}_{4} \mathrm{OAc}$

$35 \mu 1$ reaction

$35 \mu 1$ ligation reaction was precipitated with EtOH twice, resuspended in $12.6 \mu 1 \mathrm{H}_{2} \mathrm{O}$, incubated at $96{ }^{\circ} \mathrm{C}$ for $1 \mathrm{~min}$, at $37{ }^{\circ} \mathrm{C}$ for $5 \mathrm{~min}$ and at RT for $5 \mathrm{~min} .3 .4 \mu \mathrm{l}$ of ligation $\operatorname{mix}(0.7 \mu 12.5 \mathrm{mg} / \mathrm{ml} \mathrm{BSA}, 0.7 \mu \mathrm{l} 40 \mathrm{u} / \mu 1 \mathrm{RNasin}, 2 \mu 1$ 10X T4 DNA ligase buffer) was added to the ligation reaction together with $6 \mu 12000 \mathrm{u} / \mu 1 \mathrm{~T} 4$ DNA Ligase (NEB) and incubated $\mathrm{O} / \mathrm{N}$ at $16{ }^{\circ} \mathrm{C}$. Ligation reactions were purified from $9.6 \%$ polyacrylamide- 8.3 $\mathrm{M}$ urea preparative gel as explained before and resuspended in $15 \mu \mathrm{CE}$ buffer. The average ligation efficiency was $50.5 \% .3 .4 \mu \mathrm{l}$ of this ligated U2 snRNAs were used in a $12 \mu 1$ reconstitution reaction corresponding to $0.2 \mu \mathrm{M}$ final concentration. 


\subsubsection{Preparation of native HeLa total proteins (TPs)}

Native HeLa total proteins were prepared from native $U$ snRNPs, which are predominantly composed of U1 and U2 snRNPs and isolated according to Kastner et al. (1998). In order to obtain the total proteins from this mixture, the protein-RNA interactions within the snRNP particle are first weakened by chelation of divalent cations with EDTA. The proteins are subsequently separated from the RNA by ion-exchange chromatography over the polycationic resin DE53 (Sumpter et al., 1992) forming the total proteins.

A total of $8.4 \mathrm{mg} U$ snRNPs were contained in $6 \mathrm{ml}$. DEAE-cellulose (DE53, Whatman) was prepared by resuspending the resin in $\mathrm{H}_{2} \mathrm{O}$ (24 $\mathrm{ml}$ packed volume), subsequently washing three times with 3.5 volumes of $4 \mathrm{M} \mathrm{KOAc}$, five times with 3.5 volumes of $\mathrm{H}_{2} \mathrm{O}$ and two times 3.5 volumes of wash buffer (150 mM KOAc pH 5.5, $140 \mathrm{mM} \mathrm{NaCl}, 5 \mathrm{mM}$ EDTA, $0.5 \mathrm{mM}$ DTT, $0.5 \mathrm{mM}$ PMSF). The $6 \mathrm{ml}$ snRNPs were then added to $14 \mathrm{ml} \mathrm{RC}$ 420 buffer (25\% glycerol, $0.42 \mathrm{M} \mathrm{NaCl}, 1.5 \mathrm{mM} \mathrm{MgCl} 2,0.2 \mathrm{mM}$ EDTA, $20 \mathrm{mM}$ HEPES, 0.5 mM DTT, $0.5 \mathrm{mM}$ PMSF), divided into two and each was further diluted with $20 \mathrm{ml}$ DILUTE buffer (0.25 M KOAc pH 5.5, $7.5 \mathrm{mM}$ EDTA, $50 \mathrm{mM} \mathrm{MgCl} 2,0.5$ mM DTT, $0.5 \mathrm{mM}$ PMSF). The tubes were once more divided into two and the content of each was then added to $6 \mathrm{ml}$ packed volume of DEAE-cellulose and incubated $10 \mathrm{~min}$ on ice, followed by a $10 \mathrm{~min}$ incubation at $37^{\circ} \mathrm{C}$. The tubes were inverted every minute during the incubation. The DEAE-cellulose was pelleted by centrifugation for $2 \mathrm{~min}$ at 4 ${ }^{\circ} \mathrm{C}$ at $10000 \mathrm{rpm}$ in a Sorvall HB6 rotor, the supernatant carefully removed and placed on ice. The DEAE-cellulose was resuspended in $5 \mathrm{ml}$ of wash buffer, incubated for 10 min at $37{ }^{\circ} \mathrm{C}$, once again pelleted and the supernatant was saved. The DEAE-cellulose was pelleted once more by the same procedure, all the supernatants were combined and dialyzed against 21 reconstitution buffer (20 mM HEPES-KOH pH 7.9, $50 \mathrm{mM} \mathrm{NaCl}, 5$ $\mathrm{mM} \mathrm{MgCl} 2,0.5 \mathrm{mM}$ DTT, $0.5 \mathrm{mM}$ PMSF) at $4{ }^{\circ} \mathrm{C}$ for 2 hours by using dialysis tubes of $1 \mathrm{ml} / \mathrm{cm}$ (SpectraPor MWCO : 6-8 000). The protein solution was then concentrated by dialysis against 21 reconstitution buffer with $30 \%$ PEG-6000 (Merck) for 8 hours at 4 ${ }^{\circ} \mathrm{C}$. Every $30 \mathrm{~min}$, the tube was milked and shortened. A final $15 \mathrm{~min}$ dialysis against 21 
reconstitution buffer without PEG was performed before the protein solution was removed from the dialysis tube (final volume was $5.25 \mathrm{ml}$ ), aliquoted and stored at -80 ${ }^{\circ} \mathrm{C}$. The protein concentration was $0.48 \mu \mathrm{g} / \mu \mathrm{l}$. Total proteins were analysed on $13 \%$ SDS-polyacrylamide, high TEMED gel and stained with Coomassie. In order to show that the TP preparation was RNA-free, RNA was isolated from TPs and from the input snRNP preparation. For this purpose, TPs and snRNPs were Proteinase $\mathrm{K}$ digested, phenol/chloroform extracted, ethanol precipitated, $5 \mu \mathrm{g}$ equivalent of each were analysed on $9.6 \%$ polyacrylamide- $8.3 \mathrm{M}$ urea gel and stained with ethidium bromide.

\subsubsection{Preparation of U2 snRNP-depleted nuclear extract}

Nuclear extracts from HeLa cells were prepared according to Dignam et al.,1983.

Buffers used in depletion of nuclear extract:

$5 \mathrm{X}$ preblocking buffer

$20 \mathrm{mM}$ HEPES-KOH, pH 7.9

$0.3 \mathrm{M} \mathrm{KCl}$

$0.01 \% \mathrm{NP}-40$

Wash buffer

20 mM HEPES-KOH, pH 7.9

$50 \mathrm{mM} \mathrm{KCl}$

$0.1 \% \mathrm{NP}-40$

Roeder D buffer

20 mM HEPES, pH 7.9

$0.1 \mathrm{M} \mathrm{KCl}$

$0.2 \mathrm{mM}$ EDTA

$1.5 \mathrm{mM} \mathrm{MgCl}_{2}$

$0.5 \mathrm{mM}$ DTT

0.5 mM PMSF 
The following procedure is for the preparation of $1 \mathrm{ml} \mathrm{U} 2$-depleted nuclear extract. 0.6 $\mathrm{ml}$ packed volume of streptavidin agarose beads were blocked with a mixture of $1.2 \mathrm{ml}$ of preblocking buffer, $125 \mu \mathrm{l} \mathrm{BSA}(20 \mathrm{mg} / \mathrm{ml}), 12.5 \mu 1$ glycogen $(20 \mathrm{mg} / \mathrm{ml}), 5.72 \mu \mathrm{ltRNA}$ (44 mg/ml), $3.86 \mathrm{ml} \mathrm{H}_{2} \mathrm{O}$ and washed with $1 \mathrm{ml}$ wash buffer twice. Then $220 \mu 14 \mathrm{M} \mathrm{KCl}$ was added to $1 \mathrm{ml}$ of nuclear extract to raise the salt concentration to $0.8 \mathrm{M} .1 .5 \mathrm{mM}$ ATP, $5 \mathrm{mM}$ creatine phosphate and $8 \mu \mathrm{M}$ bU2 oligo were then added and the mixture was incubated first at $0{ }^{\circ} \mathrm{C}$ for $10 \mathrm{~min}$ and then at $30{ }^{\circ} \mathrm{C}$ for $30 \mathrm{~min}$. A mock depletion was carried out in parallel in which the oligo was omitted. After the incubations, nuclear extract was added to the beads $(0.15 \mathrm{ml}$ packed volume), incubated on rotating wheel at 4 ${ }^{\circ} \mathrm{C}$ for $55 \mathrm{~min}$, and then spun down at $5000 \mathrm{rpm}$ for one second. The supernatant was recovered, added to a fresh $0.15 \mathrm{ml}$ aliquot of streptavidin agarose beads and incubated on rotating wheel at $4{ }^{\circ} \mathrm{C}$ for $55 \mathrm{~min}$. The supernatant was then dialyzed against 1 liter Roeder D buffer for 5 hours using dialysis slides (Slide-A Lyzer) with the change of buffer after 2.5 hours. The depleted nuclear extract as flash frozen in $50 \mu 1$ aliquots in liquid nitrogen and kept at $-80{ }^{\circ} \mathrm{C}$. Depletion was checked by ${ }^{32} \mathrm{P}$-pCp labelling the RNA which was isolated from equivalent volumes $(50 \mu 1)$ of input (untreated), mock-depleted and U2-depleted nuclear extract. For this purpose, $50 \mu \mathrm{l}$ of these three different extracts were digested with Proteinase K, extracted with phenol/chloroform, precipitated with ethanol and resuspended in $6 \mu \mathrm{l} \mathrm{CE} .2 \mu \mathrm{l}$ of the resuspension was ${ }^{32} \mathrm{P}$-pCp-labelled and analysed on $9.6 \%$ polyacrylamide- $8.3 \mathrm{M}$ urea gel.

\subsubsection{In vitro splicing assay}

$15 \mu 1$ of splicing reactions, which were composed of $2.4 \mathrm{mM} \mathrm{MgCl}_{2}, 2 \mathrm{mM} \mathrm{ATP}, 20 \mathrm{mM}$ creatine phosphate, 50-100 fmol radiolabelled pre-mRNA and $40 \%$ nuclear extract (in $0.1 \mathrm{M} \mathrm{KCl}$ ) were incubated at $30{ }^{\circ} \mathrm{C}$ for $90 \mathrm{~min}$. The total $\mathrm{KCl}$ concentration in the splicing reaction was adjusted to $60 \mathrm{mM}$ with a solution of $0.1 \mathrm{M} \mathrm{KCl}$. When the splicing reaction contains U2-depleted nuclear extract and in vitro reconstituted U2 snRNPs, the incubation was performed for 3 hours at $30{ }^{\circ} \mathrm{C}$. Splicing reaction was digested with Proteinase K, phenol/chloroform extracted, ethanol precipitated, resuspended in $8 \mu 1$ 
RNA loading buffer, and $4 \mu 1$ of the resuspension was analyzed on $15 \%$ polyacrylamide8.3 M urea gel.

\subsubsection{In vitro reconstitution/complementation assay}

U2 snRNP reconstitution was carried out in two steps (Segault et al., 1995). In the first step, endogenous, in vitro transcribed or chimaeric U2 snRNA (final concentration 0.2 $\mu \mathrm{M}$ ) and purified native snRNP proteins (TPs) (final concentration $0.153 \mu \mathrm{g} / \mu \mathrm{l}$ ) were incubated with reconstitution buffer (20 mM HEPES-KOH pH 7.9, $50 \mathrm{mM} \mathrm{NaCl}, 5 \mathrm{mM}$ $\mathrm{MgCl}_{2}, 0.5 \mathrm{mM}$ DTT, $0.5 \mathrm{mM}$ PMSF), $0.66 \mathrm{mM}$ DTT, $0.1 \mu \mathrm{g} / \mu \mathrm{l}$ tRNA, $1.66 \mathrm{u} / \mu \mathrm{l}$ RNasin for $10 \mathrm{~min}$ at $4{ }^{\circ} \mathrm{C}$, then for $30 \mathrm{~min}$ at $30{ }^{\circ} \mathrm{C}$ and finally for $15 \mathrm{~min}$ at $37{ }^{\circ} \mathrm{C}$ in a total reaction volume of $12 \mu \mathrm{l}$. At this point, formation of the $12 \mathrm{~S}$ core U2 snRNP structure was monitored on native $6 \%$ polyacrylamide gel. In the second step, $1 \mu 1$ of this in vitro reconstitution reaction was added to a $13 \mu 1$ splicing reaction assembled with U2depleted nuclear extract without pre-mRNA and incubated at $0{ }^{\circ} \mathrm{C}$ for a further $30 \mathrm{~min}$. The pre-mRNA was then added and incubated at $30{ }^{\circ} \mathrm{C}$ for 3 hours for the splicing complementation reaction.

\subsubsection{Analysis of complex formation in nuclear extract}

The spliceosomal complexes were analyzed on $1.5 \%$ low melting agarose gels. After the desired time point $(5,10,15, \min .$.$) , the splicing reactions were processed as explained$ in 3.2.1.7.4.

\subsubsection{Radioimmunoprecipitation assays (RIPA)}

The Protein A-sepharose beads were washed with 6 volumes of PBS $\left(20 \mathrm{mM} \mathrm{K}_{3} \mathrm{PO}_{4} \mathrm{pH}\right.$ 8.0, $0.13 \mathrm{M} \mathrm{NaCl}$ ), with centrifuging for one second at $5000 \mathrm{rpm}$ at $4{ }^{\circ} \mathrm{C}$ between the washes to pellet the PAS. $15 \mu 1$ packed volume of PAS was used to couple $15 \mu 1$ anti- 
SF3a66 antibody, $15 \mu 1$ NIS (non-immunoserum) SF3a66, $15 \mu 1$ anti-SF3b155 antibody, $15 \mu 1$ NIS SF3b155, $40 \mu 1$ anti-Sm antibody (mAb Y12), $50 \mu 1$ anti-U2 B" antibody (mAb H4G3). Coupling was performed $\mathrm{O} / \mathrm{N}$ by head-over-tail rotation at $4{ }^{\circ} \mathrm{C}$. The antibody-bound PAS complexes were pelleted, the supernatant removed and washed four times with $700 \mu \mathrm{l}$ PBS. A $14 \mu \mathrm{l}$ splicing reaction, which contains $9 \mu 1$ U2-depleted nuclear extract (in $0.1 \mathrm{M} \mathrm{KCl}$ ), $1 \mu 12.4 \mathrm{mM} \mathrm{MgCl}_{2}, 1 \mu \mathrm{ATP} / \mathrm{CP}(2 \mathrm{mM}$ ATP, $20 \mathrm{mM}$ $\mathrm{CP}$ ), $1 \mu \mathrm{l}$ in vitro reconstituted U2 snRNP (reconstituted either from ${ }^{32} \mathrm{P}-\mathrm{pCp}$ labelled native or in vitro transcribed U2 snRNA), $2 \mu \mathrm{l} \mathrm{CE}$ buffer, was added to antibody-bound PAS complexes and incubated for 1 hour at $4{ }^{\circ} \mathrm{C}$ by head-over-tail rotating. The beads were washed five times with IPP250 (10 mM Tris- $\mathrm{HCl} \mathrm{pH} 8.0,250 \mathrm{mM} \mathrm{NaCl}, 0.1 \% \mathrm{NP}-$ 40), with brief centrifugation steps to pellet the beads between each washing step. Since free Sm proteins are known to bind to the walls of the tube, the slurry was transferred to new tubes after the fourth wash with IPP250. After the last wash, the wet pellets were digested with Proteinase K, phenol/chloroform extracted, ethanol precipitated, washed with $100 \mu 10.3 \mathrm{M} \mathrm{NaOAc}$ and $250 \mu 1$ ethanol, vacuum dried and resuspended in $6 \mu \mathrm{CE}$. Samples were analyzed on $9.6 \%$ polyacrylamide- $8.3 \mathrm{M}$ urea gel via autoradiography.

\subsubsection{Glycerol gradient centrifugation}

$140 \mu 1$ in vitro reconstituted U2 snRNP (see 3.2.7) with 3' end-labelled HeLa U2 snRNA, $\mathrm{U} 2$ transcript or BABE-modified chimaeric U2 snRNA were prepared, incubated at $0{ }^{\circ} \mathrm{C}$ for $30 \mathrm{~min}$ (assumed to be 17S U2) and loaded onto $10 \%$-30 \% glycerol gradient. The gradient buffer was composed of $150 \mathrm{mM} \mathrm{KCl,} 20 \mathrm{mM}$ Hepes $\mathrm{pH} 7.9$ and $1.5 \mathrm{mM}$ $\mathrm{MgCl}_{2}$. The gradient was run in thick-walled $4 \mathrm{ml}$ polypropylene tubes at $4{ }^{\circ} \mathrm{C}$ for 17 hours in a TH660 rotor. 24 fractions were collected of $175 \mu$ l each. Odd fractions were digested with Proteinase $\mathrm{K}$, phenol/chloroform extracted, ethanol precipitated and analyzed on $9.6 \%$ polyacrylamide- $8.3 \mathrm{M}$ urea gel via autoradiography. 


\subsubsection{Pseudouridine modification assay}

Chimaeric $\Psi \mathrm{m}$ and $\Delta \Psi \mathrm{m}-\mathrm{U} 2$ RNAs were prepared as described above, except that a $\left[{ }^{32} \mathrm{P}\right]$ UTP-labelled G25-U2 snRNA transcript was used and 3' end labelling was omitted. After U2 snRNP reconstitution, reaction mixtures were incubated for $3 \mathrm{~h}$ at $30{ }^{\circ} \mathrm{C}$ under splicing conditions. The RNA was purified and then resuspended in $5 \mu 1$ of $20 \mathrm{mM}$ sodium acetate ( $\mathrm{pH}$ 5.2) containing nuclease $\mathrm{P} 1$ of $200 \mu \mathrm{g} / \mathrm{ml}$, and then incubated at 37 ${ }^{\circ} \mathrm{C}$ for 90 min. Samples were chromatographed on cellulose PEI plates as described (Segault et al., 1995) with isopropanol/concentrated $\mathrm{HCl} / \mathrm{H}_{2} \mathrm{O}$ 70:15:15 (v/v/v) as solvent for $6 \mathrm{~h}$ and $15 \mathrm{~min}$. The plate was air-dried $\mathrm{O} / \mathrm{N}$ and exposed to PhosphorImager.

\subsubsection{Site-directed hydroxyl radical probing}

\subsubsection{Synthesis of bromoacetamidobenzyl-EDTA (BABE)}

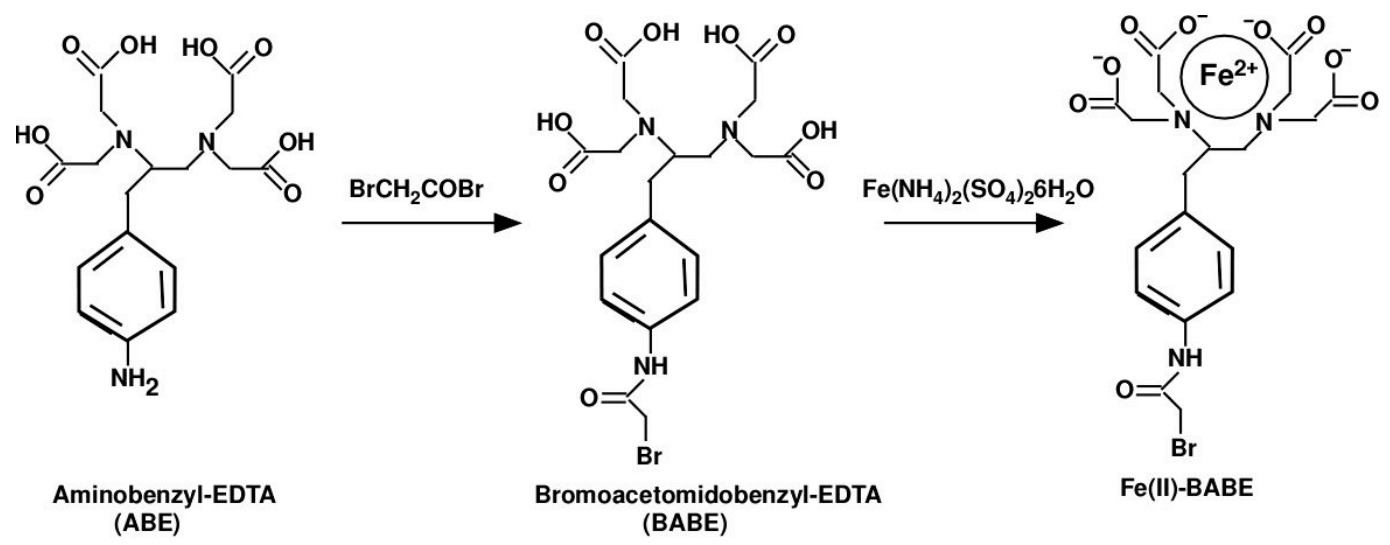

Figure 3-1. Fe (II)-BABE synthesis. The synthesis of Fe(II)-BABE from $\mathrm{ABE}$ and bromoacetylbromid-EDTA is displayed (modified from Greiner et al., 1997).

$25 \mathrm{mg}(62.8 \mu \mathrm{mol})$ 1-(4-Aminobenzyl)EDTA (ABE, $\mathrm{Mr}=397.38 \mathrm{~g} / \mathrm{mol})$ was dissolved in $125 \mu \mathrm{H}_{2} \mathrm{O}$ and the $\mathrm{pH}$ was adjusted to 7 with $\mathrm{NaOH}(\mathrm{pH} 10) .5$ times $5 \mu \mathrm{l}$ 
bromoacetylbromide ( $25 \mu \mathrm{l}$ corresponds to $0.288 \mathrm{mmol}$ since the molecular weight is $201.84 \mathrm{~g} / \mathrm{mol}$ ) was added to the reaction. The full derivatization was checked with flurescamine (FSC) test, (Udenfriend et al., 1972). It reacts with free $\mathrm{NH}_{2}$ groups and lack of fluorescence indicates a complete conversion of ABE. $1 \mu \mathrm{l}$ sample was added to $50 \mu 1 \mathrm{H}_{2} \mathrm{O}$ and $25 \mu \mathrm{FSC}$ ( $1 \%$ in Aceton) and vortexed. If the colour is clear, this indicates that the derivatization is complete where the yellow colour shows an incomplete derivatization. When the colour is yellow, another aliquot of bromoacetylbromide should be added. Unreacted bromoacetylbromide was extracted with 2 volumes of Diethylether $(\sim 250 \mu 1)$. A total of 7 extractions were needed. The mixture was vortexed, the upper phase (ether phase) was discarded. The extractions were checked with NBP $(\gamma(\mathrm{p}-$ Nitrobenzyl)pyridine test (Friedmann, 1961). The acetyl group of bromoacetylbromide reacts with the pyridine group of NBP. Blue/green colour shows that the extraction is not complete whereas the yellow colour indicates the complete extraction.

NBP test

$100 \mu \mathrm{l} \mathrm{NaOAc}(25 \mathrm{mM}, \mathrm{pH} 5.3)$

$25 \mu \mathrm{NBP}(0.5 \%$ in Aceton $(5.3 \mathrm{mg}$ in $1060 \mu \mathrm{l}$ Aceton $)$

$30 \mu 1 \mathrm{NaOH}(1 \mathrm{~N})$

$30 \mu 1$ of ether phase OR $1 \mu$ l of solution

wait 1 min at RT

After the last extraction, the remaining ether was evaporated in a hood. At this point the $\mathrm{pH}$ was checked which should be around zero. Everything was transferred into new Eppendorf tube (the empty tube was weighed here), $\mathrm{NaOH}(10 \mathrm{~N})$ was added in $1.5 \mu \mathrm{l}$ aliquots until BABE precipitates. Precipitation occurred with 12th aliquot, and one more aliquot was added and the suspension was carefully vortexed. At this point the $\mathrm{pH}$ was checked which should be around 2 . If it is less than 2 , a few more $\mu 1 \mathrm{NaOH}$ should be added. It was centrifuged for $10 \mathrm{~min}$ at $13000 \mathrm{rpm}$ at $4{ }^{\circ} \mathrm{C}$, the supernatant was removed and the pellet was washed with $200 \mu \mathrm{l} 0.01 \mathrm{M} \mathrm{HCl}$ without vortexing and centrifuged again for $10 \mathrm{~min}$ at $13000 \mathrm{rpm}$ at $4{ }^{\circ} \mathrm{C}$. The supernatant was removed and the pellet was dried under vacuum for approximately $40 \mathrm{~min}$. The tube was weighed and the weight of the empty tube was subtracted. The yield was $31.77 \mathrm{mg}$ corresponding to $63 \mu \mathrm{mol} \mathrm{BABE}$ 
(the molecular weight of BABE is $504 \mathrm{~g} / \mathrm{mol}$ ). It was dissolved in a mixture of $205 \mu 1$ $\mathrm{H}_{2} \mathrm{O}$ and $12 \mu \mathrm{l} \mathrm{NaOH}(10 \mathrm{~N})$ by pipetting up and down. The $\mathrm{pH}$ was checked and it should be around 6-7. Four aliquots of $50 \mu$ each were prepared and lyophilized until the pellets became yellowish. One aliquot was resuspended in $40 \mu \mathrm{H}_{2} \mathrm{O}$ which has a concentration of around 0.25-0.3 M. The others were flushed with Argon, tightly capped and kept at $-20^{\circ} \mathrm{C}$.

\subsubsection{Cysteine-test to control the reactivity of $\mathrm{BABE}$}

The functionality of BABE was tested by reaction with the sulfhydryl group of cysteine. The reaction between BABE and sulfhydryl groups was tested by using cysteine. $1 \mu \mathrm{l}$ $\operatorname{BABE}(0.3 \mathrm{M}), 2 \mu \mathrm{l}$ cysteine $(0.5 \mathrm{M}), 7 \mu \mathrm{NH}_{4}{ }^{+}$-Hepes, $\mathrm{pH}$ : 8.5 are mixed, incubated for $30 \mathrm{~min}$ at $37{ }^{\circ} \mathrm{C}$. Another reaction was prepared for control where $2 \mu \mathrm{H}_{2} \mathrm{O}$ was added instead of cysteine. $1 \mu \mathrm{l}$ from each incubated mix was spotted on Kieselgel $60 \mathrm{~F}_{254}$ Thin Layer Chromatography plate which was developed in 5\% $\mathrm{NH}_{4} \mathrm{OAc} / 50 \% \mathrm{MeOH}$ buffer for $1 \mathrm{~h}$. It was then visualized with UV light $(254 \mathrm{~nm})$ and photographed. BABE migrates at the bufferfront whereas with the cysteine, derivative of BABE is retarded showing that BABE is able to react with sulfhydryl group and to be modified.

\subsubsection{Modification of the 5' U2 RNA oligo with Fe(II)-BABE}

In a pilot experiment, the efficiency of Fe-BABE modification was determined by using ${ }^{32} \mathrm{P}-\mathrm{pCp}$ labelled 5' U2 oligonucleotides. The $\psi \mathrm{m}, \Delta \psi \mathrm{m}, \mathrm{U} 2-19$ and U2-20 (see 3.1.9) were ${ }^{32} \mathrm{P}-\mathrm{pCp}$ labelled and subjected to Fe-BABE modification reaction. Both the U2-19 and U2-20 were modified with Fe-BABE. The $\psi \mathrm{m}$ and $\Delta \psi \mathrm{m}$ were selected as respective controls to U2-19 and U2-20 for the Fe-BABE modification, since they were of identical except for the lack of the SH group at their 5' end. First, all possible disulfides in the oligo preparation were destroyed by reduction with TCEP. 
TCEP reaction

$1 \mu 1 \quad$ pCp ${ }^{32}$ P-labelled 5' U2 RNA oligo ( $\psi$ m, $\Delta \psi$ m, U2-19 or U2-20; 2 pmol)

$1.25 \mu 1$ Hepes- $\mathrm{NH}_{4}{ }^{+}, \mathrm{pH} 7.0(1 \mathrm{M})$

$1 \mu \mathrm{l} \quad$ TCEP solution at neutral $\mathrm{pH}(500 \mathrm{mM})$

$46.75 \mu \mathrm{l} \quad \mathrm{H}_{2} \mathrm{O}$

$50 \mu 1,55^{\circ} \mathrm{C}, 1 \mathrm{hr}$

After the incubation, the reaction was ethanol precipitated, and resuspended in $6.25 \mu \mathrm{l}$ $\mathrm{H}_{2} \mathrm{O}$. This 5' U2 RNA of which disulfides were reduced was then ready for the Fe-BABE modification. Meanwhile, Fe-BABE was prepared as described (Newcomb and Noller, 1999). The incubation reaction below was for 4 reactions.

Fe-BABE reaction

$2.8 \mu \mathrm{l} \quad \operatorname{BABE}(0.3 \mathrm{M})$

$8.14 \mu \mathrm{l} \quad\left(\mathrm{NH}_{4}\right)_{2} \mathrm{Fe}\left(\mathrm{SO}_{4}\right)_{2}(40 \mathrm{mM})$

$14.06 \mu 1 \mathrm{H}_{2} \mathrm{O}$

$25 \mu \mathrm{l}$, at $\mathrm{RT}, 15 \mathrm{~min}$

After the incubation, $1.2 \mu 1$ EDTA $(80 \mathrm{mM})$ was added to the reaction in order to chelate the free $\mathrm{Fe}(\mathrm{II})$ not reacted with Fe-BABE. This reaction mixture $(26.2 \mu \mathrm{l}$ in total) was divided into four. $6.1 \mu 1$ of this mixture $\left(1 / 4^{\text {th }}\right)$ was added to $6.25 \mu 15^{\prime}$ U2 oligos (see above) together with $1 \mu \mathrm{l}$ tRNA $(2.5 \mathrm{~g} / \mathrm{l})$ and $3.34 \mu 1$ Hepes- $\mathrm{NH}_{4}{ }^{+} \mathrm{pH} 8.5$ (100 mM) and incubated at $37^{\circ} \mathrm{C}$ for $1 \mathrm{~h}$. $6.1 \mu 1 \mathrm{H}_{2} \mathrm{O}$ was added to the reaction in the case of $-\mathrm{BABE}$ control reactions. After that, $35 \mu 1 \mathrm{H}_{2} \mathrm{O}$ was added over to the reaction, purified with $\mathrm{G} 25$ spin column, ethanol precipitated and resuspended in $10 \mu \mathrm{l}$ RA load and checked on 22 $\%$ polyacrylamide- $8.3 \mathrm{M}$ urea gel. Long glass plates $(1=34 \mathrm{~cm}, \mathrm{w}=20 \mathrm{~cm})$ were used and the gel was run for $16 \mathrm{~h}$ at $2 \mathrm{~W}$ and $4 \mathrm{~h}$ at $18 \mathrm{~W}$. It was visualized by autoradiography. The modification efficiency of oligonucleotides was around 35-40\%. Therefore, the modified band was needed to be purified.

The modification of the U2-19 and U2-20 oligos were carried out as explained above in this section in large scale. 


\begin{tabular}{|c|c|}
\hline & $\mathrm{X} 10$ \\
\hline $6.25 \mu 15^{\prime}$ U2 RNA oligo (2 pmol) & $62.5 \mu 1$ 5'U2 RNA oligo (20 pmol) \\
\hline $1 \mu \mathrm{l}$ tRNA $(2.5 \mathrm{~g} / \mathrm{l})$ & $10 \mu 1$ tRNA $(2.5 \mathrm{~g} / 1)$ \\
\hline $3.34 \mu 1$ Hepes- $\mathrm{NH}_{4}{ }^{+} \mathrm{pH} 8.5(100 \mathrm{mM})$ & $33.4 \mu \mathrm{l}$ Hepes- $\mathrm{NH}_{4}{ }^{+} \mathrm{pH} 8.5(100 \mathrm{mM})$ \\
\hline $6.1 \mu 1 \mathrm{Fe}-\mathrm{BABE}$ reaction & $61 \mu 1 \mathrm{Fe}-\mathrm{BABE}$ reaction \\
\hline $17 \mu 1,37^{\circ} \mathrm{C}, 1 \mathrm{hr}$ incubation & $170 \mu 1,37^{\circ} \mathrm{C}, 1 \mathrm{hr}$ incubation \\
\hline
\end{tabular}

This large scale incubation was gel purified from $22 \%$ polyacrylamide- $8.3 \mathrm{M}$ urea gel. It was visualized by UV shadowing and the upper band which corresponded to the BABEmodified chimaeric U2 RNA was cut out. The gel was run for $16 \mathrm{~h}$ at $2 \mathrm{~W}$ and $4 \mathrm{~h}$ at 18 W.

\subsubsection{Generation of functional Fe(II)-BABE modified U2 snRNPs}

Firstly, Fe(II)BABE modified 5' U2 RNA oligos U2-19 and U2-20 (gel-purified, see 3.2.12.3) were ligated to the G25U2 RNA transcript (starting at nucleotide 25 of U2 RNA) in order to generate chimaeric Fe-BABE modified U2 RNAs as explained in 3.2.3.3. $12 \mathrm{~S}$ core $\mathrm{U} 2$ snRNPs were reconstituted with the Fe-BABE modified chimaeric U2 snRNAs. Afterwards, the 17S U2 snRNP formation was performed with these FeBABE modified $12 \mathrm{~S}$ core U2 snRNPs. Then, spliceosomal complex formation and the splicing were assayed.

Fe-BABE modified $12 \mathrm{~S}$ core U2 snRNP reconstitution

$6 \mu 1$ BABE modified chimaeric U2 RNA (2.4 pmol)

$1 \mu \mathrm{l}$ DTT/10X Rec buffer ( $2 \mu 140 \mathrm{mM}$ DTT and $8 \mu$ 10X reconstitituon buffer)

$1 \mu \mathrm{ltRNA} /$ Rnasin $(5 \mu 12.5 \mathrm{~g} / 1 \mathrm{tRNA}$ and $5 \mu \mathrm{l}$ RNasin $(40 \mathrm{u} / \mu \mathrm{l})$

$4 \mu 1 \mathrm{TPs}(0.48 \mathrm{~g} / 1)$

$\begin{array}{rl}12 \mu \mathrm{l} & 4{ }^{\circ} \mathrm{C} \quad 10 \mathrm{~min} \\ & 30^{\circ} \mathrm{C} \quad 30 \mathrm{~min} \\ 37{ }^{\circ} \mathrm{C} & 15 \mathrm{~min}\end{array}$

10X reconstitution buffer used here was composed of $200 \mathrm{mM}$ HEPES-KOH pH 7.9, 500 $\mathrm{mM} \mathrm{NaCl}$ and $50 \mathrm{mM} \mathrm{MgCl}$. Afterwards $17 \mathrm{~S}$ U2 snRNP formation was performed by 
incubating the Fe-BABE modified 12S core U2 snRNP particles with the U2-depleted nuclear extract. Glycerol gradient centrifugation was performed as explained in 3.2.10 in order to test whether the Fe(II)BABE modified chimaeric U2 RNA is able form 17S U2 SnRNP.

Fe-BABE modified 17S U2 snRNP reconstitution

$4.5 \mu 1 \mathrm{KCl}(0.1 \mathrm{M})$

$6.0 \mu 1 \mathrm{U} 2$-depleted nuclear extract

$1 \mu \mathrm{ATP} / \mathrm{CP} / \mathrm{MgCl}_{2}$ (final conc. $2 \mathrm{mM}, 20 \mathrm{mM}, 2.4 \mathrm{~mm}$, respectively)

$12 \mu 112 \mathrm{~S}$ reconstitution reaction (from above)

$22 \mu 1,0{ }^{\circ} \mathrm{C}$ for $30 \mathrm{~min}$

$+$

$1 \mu \mathrm{l}$ premRNA (100 fmol/ $\mu \mathrm{l})$ [for spliceosomal complex formation and splicing]

$23 \mu 1,30{ }^{\circ} \mathrm{C}$

At this point the splicing and complex formation was analyzed. Splicing reaction was carried out for $3 \mathrm{~h}$ as explained in 3.2.6 and the complex formation was performed for 2, $5,10,20,30 \mathrm{~min}$, analyzed on $1.5 \%$ low melting agarose gel as explained in 3.2.8.

\subsubsection{Fe(II)-BABE induced hydroxyl radical formation}

In order to induce site-directed hydroxyl radical production from $\mathrm{Fe}-\mathrm{BABE}$ tethered to the 5' end of chimaeric U2 snRNA, $\mathrm{H}_{2} \mathrm{O}_{2}$ was added to the reaction mixture from 3.2.11.4 as follows.

$22 \mu 1$ reaction (from 3.2.11.4)

$20 \mu 1$ 10X Caco buffer ( $\mathrm{pH} 7.0)$

$0.8 \mu \mathrm{l}$ ascorbic acid $(0.5 \mathrm{M})$

$1 \mu 1 \mathrm{tRNA}(2.5 \mathrm{~g} / \mathrm{l})$

$2 \mu \mathrm{H}_{2} \mathrm{O}_{2}(0.4 \%)$

$154.20 \mu 1 \mathrm{H}_{2} \mathrm{O}$

$$
\begin{aligned}
& \frac{-\mathrm{H}_{2} \mathrm{O}_{2} \text { control }}{22 \mu 1 \text { reaction }} \\
& 20 \mu 110 \mathrm{X} \text { Caco buffer } \\
& \frac{158 \mu 1 \mathrm{H}_{2} \mathrm{O}}{4^{\circ} \mathrm{C}, 10 \mathrm{~min}}
\end{aligned}
$$

$4^{\circ} \mathrm{C}, 10 \mathrm{~min}$ 
After the incubation of $10 \mathrm{~min}$ at $4{ }^{\circ} \mathrm{C}$, the reaction was quenched by addition of $2.5 \mu \mathrm{l}$ $50 \%$ glycerol and subsequently digested with Proteinase K. Glycerol acts as a quencher for hydroxyl radicals. Then, $14 \mu 11 \mathrm{M}$ Thiourea (also a quencher for hydroxyl radicals) was added to the reaction which was then phenol/chloroform extracted. The RNA was ethanol precipitated, dried and finally resuspended in $10 \mu \mathrm{H}_{2} \mathrm{O}$. The radioactivity contained in U2 snRNA (see above) was determined by scintillation counting and served as quantification calibration. At most, $1 \mu \mathrm{l}$ of this was used for primer extension. For one particular assay, corresponding to $+\mathrm{BABE}+\mathrm{H}_{2} \mathrm{O}_{2}$, three control reactions were performed: i) $-\mathrm{BABE}-\mathrm{H}_{2} \mathrm{O}_{2}$, ii) $-\mathrm{BABE}+\mathrm{H}_{2} \mathrm{O}_{2}$ and iii) $+\mathrm{BABE}-\mathrm{H}_{2} \mathrm{O}_{2}$. For the experiment in Fig. 421E, $4.5 \mu 1$ nuclear extract which contains 1 pmol of U1 RNA was used. The reaction volume was completed to $22 \mu \mathrm{l}$ as above by adding $\mathrm{H}_{2} \mathrm{O}$. The HeLa U1 snRNP was purified according to (Bach et al., 1990) by using ion-exchange chromatography and kindly provided by Simon Trowitzsch and Gert Weber.

\subsubsection{Primer extension analysis}

The primer extension basically followed the protocol as described (Hartmuth et al., 1999) with some modifications. The RNAs were pipetted into Eppendorf tubes and then dried. For sequencing lanes which are $0, \mathrm{~A}, \mathrm{C}, \mathrm{G}, \mathrm{T}$, five tubes were used that contain $1 \mu 1100$ fmol of the RNA to be sequenced (U1 or pre-mRNA). $1 \mu 1$ hybridization mix (HY-mix) was added to the dried samples and resuspended by shaking at RT for $10 \mathrm{~min}$.

HY-mix

\begin{tabular}{ll|l} 
10X Hybridization buffer & $0.25 \mu \mathrm{l}$ & \\
oligo & $0.5 \mu \mathrm{l}$ & $1 \mu \mathrm{l}$ Hybridization mix for one reaction \\
$\mathrm{H}_{2} \mathrm{O}$ & $0.25 \mu \mathrm{l}$ &
\end{tabular}

Then, the resuspended RNA was heated at $96^{\circ} \mathrm{C}$ for 1 min and $1 \mu 10.1 \mathrm{mM}$ ddNTPs were added to the sequencing reactions. Afterwards, $2 \mu 1$ reverse transcription mix (RTmix) was added to all samples and incubated at $42{ }^{\circ} \mathrm{C}$ for $1 \mathrm{~h}$. 
RT-mix

\begin{tabular}{ll|l}
$\mathrm{H}_{2} \mathrm{O}$ & $1.477 \mu \mathrm{l}$ & \\
10X Reverse Transcription buffer & $0.25 \mu \mathrm{l}$ & $2 \mu \mathrm{l}$ reverse transcription mix for one reaction \\
$5 \mathrm{mM}$ dNTPs & $0.1 \mu \mathrm{l}$ & \\
Reverse transcriptase enzyme & $0.173 \mu \mathrm{l}$ &
\end{tabular}

After incubation at $42{ }^{\circ} \mathrm{C}, 12.5 \mu 1100 \mathrm{mM} \mathrm{NaOH}$ was added to the reactions and further incubated at $60{ }^{\circ} \mathrm{C}$ for $1 \mathrm{~h}$. Reactions were then ethanol precipitated, dried, resuspended in $4 \mu \mathrm{l}$ RNA loading dye, heated for $1 \mathrm{~min}$ at $96{ }^{\circ} \mathrm{C}$ and analyzed on a sequencing gel. Glass plates were $34 \mathrm{~cm} \mathrm{X} 42 \mathrm{~cm} .0 .3 \mathrm{~mm}$ spacer and shark combs were used. Electrophoresis was at $65 \mathrm{~W}$ for approximate 3 hours. Gels were visualized by autoradiography. 


\section{RESULTS}

\subsection{Modifications of $\mathrm{U} 2$ at the 5 ' end are required for splicing}

In order to explore the roles of modifications at the $5^{\prime}$ end of U2 snRNA, the following strategy was carried out. Firstly, the chimaeric U2 snRNAs containing different number and type of modifications at the 5' end of U2 snRNA were generated. Secondly, these chimaeric U2 snRNAs were used in the two-step reconstitution/complementation system to assay the spliceosomal complex formation and splicing reaction. By this way, the roles of individual modifications at the 5' end of U2 snRNA in spliceosomal complex formation and splicing were studied. It was shown before in Xenopus oocytes that, the modifications within the first 27 nucleotides of U2 snRNA were required for splicing (Yu et al., 1998). The modifications in the same region of human U2 snRNA were investigated in this study. The oligos which correspond to the first 24 nucleotides in the 5' end of U2 snRNA were chosen to be chemically synthesized since the nucleotide G25 was an efficient position to start the in vitro transcription.

\subsubsection{Generation of chimaeric U2 snRNAs}

To generate chimaric U2 snRNAs, the RNA oligonucleotides corresponding to the 5'terminal 24 nucleotides of U2 snRNA and containing different number and type of modifications were chemically synthesized (Fig. 4-1A). These were ligated to an in vitro transcript encompassing the remaining nucleotides of U2 snRNA (G25U2 RNA; from 25 to 192) via Moore and Sharp ligation (Moore and Sharp, 1992), resulting in "chimaeric" U2 snRNA molecules (Fig. 4-1B). It is a simple and efficient method for synthesizing long, site-specifically modified RNA molecules whereby segments of RNA are joined with the use of bacteriophage T4 DNA ligase and bridging deoxyoligonucleotide template (cDNA). 


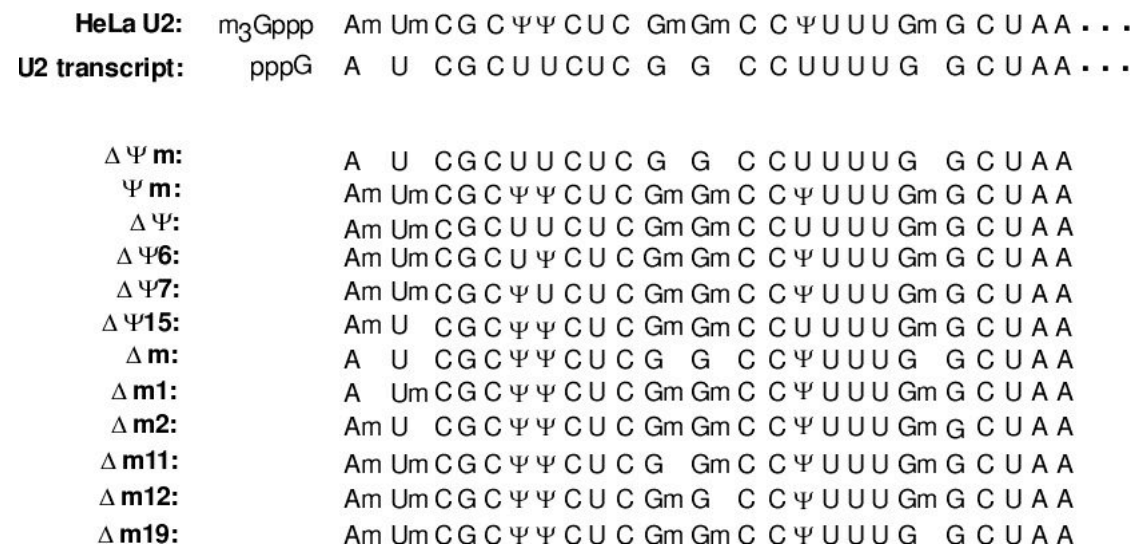

Figure 4-1A. The sequence composition of the chemically synthesized oligonucleotides corresponding to the first 24 nucleotides of U2 snRNA. The following notation is used: $\Delta \Psi \mathrm{m}$, replacement of all pseudouridines $(\Psi)$ by uridines (U) and deletion of all 2'-O-methylations (2'-O-Me); $\Psi \mathrm{m}$, retention of all $\Psi$ and 2'O-Me; $\Delta \Psi$, replacement of all $\Psi_{\mathrm{s}}$ by $\mathrm{U} ; \Delta \Psi n$, replacement of $\Psi$ at position $n$ with $\mathrm{U} ; \Delta \mathrm{m}$, deletion of all 2'-O-Me; $\Delta \mathrm{m} n$, deletion of 2'-O-Me at position $n$. The oligonucleotides were ligated to in vitro transcribed U2 snRNA starting at G25. For comparison, sequences of the first 24 nucleotides of purified HeLa U2 snRNA and U2 transcript are shown above. This figure is published in Dönmez et al., 2004.

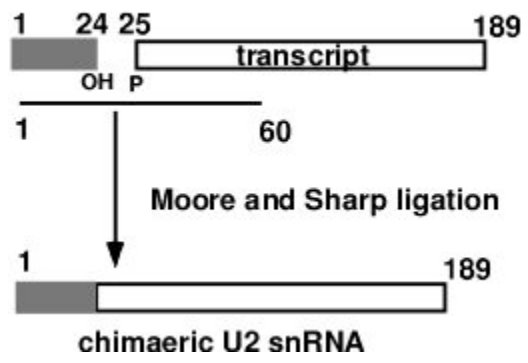

Figure 4-1B. The Moore and Sharp ligation (Moore and Sharp, 1992). The chemically synthesized oligonucleotides corresponding to the first 24 nucleotides of U2 snRNA containing different number and type of modifications (denoted with gray) are ligated to a transcript comprising the remaining portion of U2 snRNA with a bridging oligo (cDNA) complementary to the first 60 nucleotides of U2 snRNA.

In Fig. 4-2, typical ligations resulting in $\psi \mathrm{m}, \Delta \psi \mathrm{m}, \Delta \psi$ and $\Delta \mathrm{m}$ chimaeric U2 RNAs are shown. The 5' oligonucleotides and the 3' U2 fragment (G25U2) which is a transcript encompassing the nucleotides 25 to 192 of U2 snRNA were ligated successfully with an average efficiency of $50 \%$. Trace amounts of ${ }^{32} \mathrm{P}$-pCp-labelled $3^{\prime}$ fragment G25U2 were 
included in order to monitor the reaction and to recover the ligation products. The other $5^{\prime}$ oligonucleotides were ligated almost with the same efficiency as well. When the name given to the oligonucleotide is followed by "U2 RNA", this then denotes the ligated (chimaeric) U2 RNA.

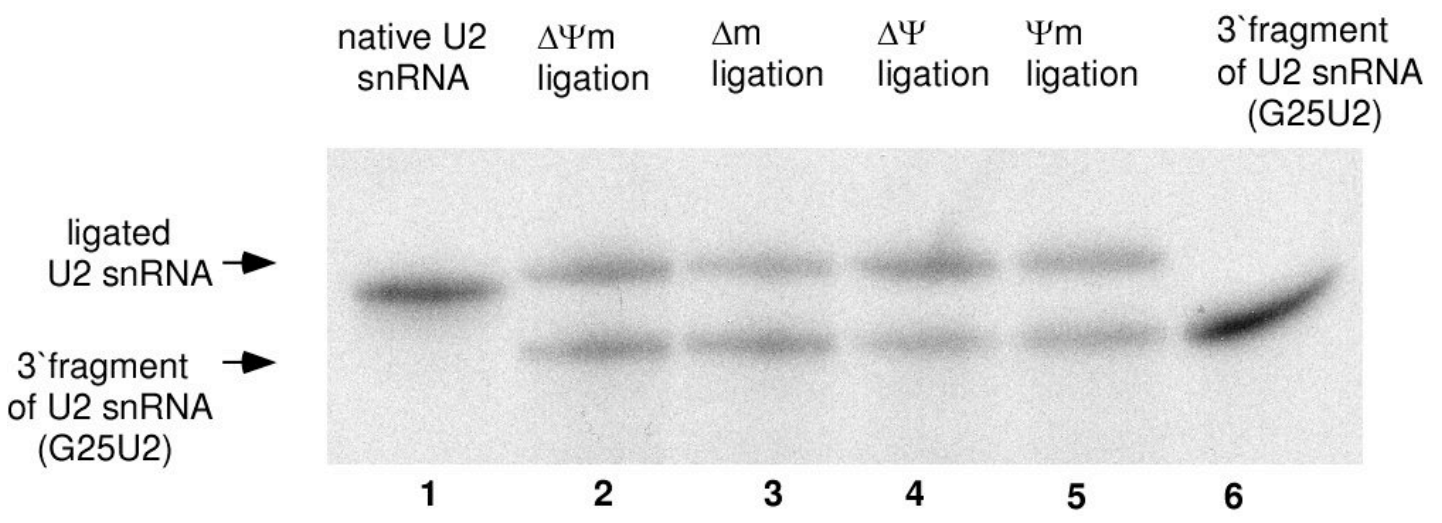

Figure 4-2 . Ligations performed according to Moore and Sharp ligation procedure. 3 ' fragment of U2 snRNA (a U2 transcript from nucleotides 25 to 192) was ligated with a series of U2 $5^{\prime}$ oligos which are shown in lanes 2-5. Lane 2: Ligation with $\Delta \Psi \mathrm{m}$ oligo containing no modifications; lane 3: ligation with $\Delta \mathrm{m}$ oligo containing only pseudouridines; lane 4: ligation with $\Delta \Psi$ oligo containing only 2'-O-methyl groups; lane 5: ligation with $\Psi \mathrm{m}$ oligo containing both of the modifications (see Fig. 4-1A). Lane 6 shows the input 3 ' fragment for the ligation reaction. Lane 1 shows the ${ }^{32} \mathrm{P}$-pCp-labelled native U2 snRNA. The difference between native U2 snRNA (189 nts) and ligated ones comes from the extra three G nts after 189th in ligated U2 snRNAs. The ligation mixtures were loaded directly onto $9.6 \%$ polyacrylamide-8.3 $\mathrm{M}$ urea gel and gel-purified.

The successful synthesis of these chimeric U2 snRNA molecules allowed their investigation in the two-step U2 snRNP reconstitution/complementation assay.

\subsubsection{Native snRNP protein (total protein) preparations and in vitro reconstitution of core $U 2$ snRNPs}

Reconstitution of U2 snRNP is achieved by a two-step procedure (Fig. 4-3). In the first step, U2 snRNA is incubated with native, RNA-free snRNP proteins (denoted total proteins or TPs) to form $12 \mathrm{~S}$ core U2 snRNPs. Since TPs lack the $17 \mathrm{~S}$ U2 snRNP- 
specific proteins, the reconstitution of splicing active forms of $\mathrm{U} 2$ snRNP requires an additional incubation step (the second step in the two step reconstitution/ complementation system) with nuclear extract. Therefore, in the second step, these $12 \mathrm{~S}$ U2 snRNPs were incubated with U2-depleted nuclear extract to produce fully active $17 \mathrm{~S}$ U2 snRNPs. By adding radiolabelled pre-mRNA, the spliceosomal complex formation and splicing were analyzed. In order to reconstitute core U2 snRNPs, it was thus necessary first to prepare the total proteins.

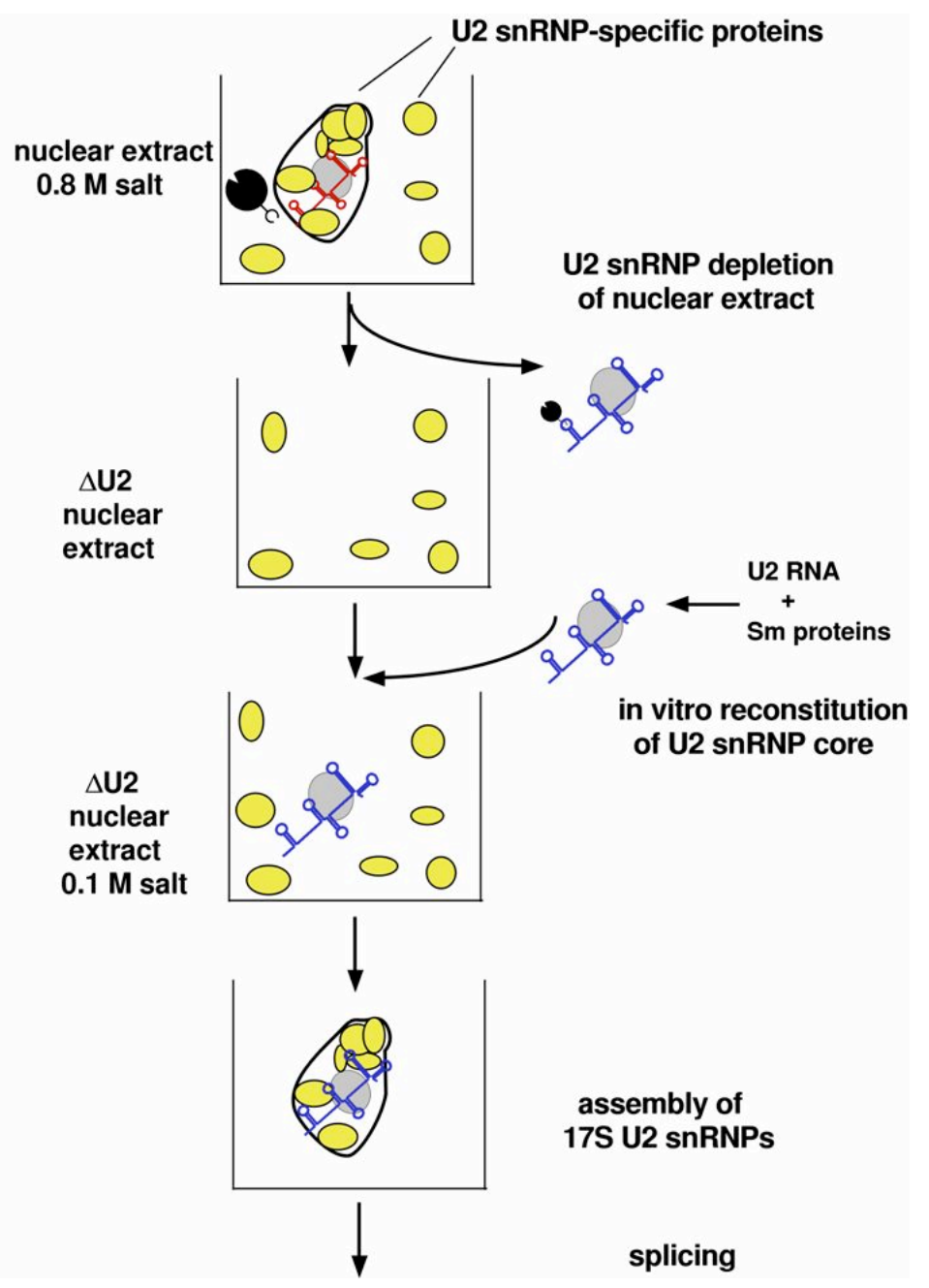

Figure 4-3 . The two-step reconstitution/complementation system. In the first step, the U2 snRNPs are depleted from the nuclear extract at high salt concentration $(0.8 \mathrm{M})$. The U2-specific proteins (SF3a and SF3b protein complexes) are retained in the nuclear extract due to high salt. In the second step, the core U2 snRNPs were reconstituted in vitro and incubated with the U2-depleted nuclear extract which contains the U2-specific proteins at low salt concentration $(0.1 \mathrm{M})$. Finally, mature $17 \mathrm{~S} \mathrm{U} 2$ snRNPs are formed and used in splicing assays (see Materials and Methods). 


\subsubsection{Native snRNP protein (total protein) preparations}

Total proteins were prepared from a mixture of U1, U2, U5 and U4/U6 snRNPs which had been isolated according to Kastner et al. (1998). This mixture contained predominantly U1 snRNP and traces of U2, U4/U5.U6 snRNP (see lane 3, in Fig. 4-4 for the RNA composition). In contrast to most of the specific proteins, the core proteins are stably associated with the snRNAs. Thus, dissociation of the snRNP core particle without denaturation of the core proteins requires particular conditions. The protein-RNA interactions within the snRNP particle are first weakened by chelation of divalent cations with EDTA. The proteins are subsequently separated from the RNA by ion-exchange chromatography over the polycationic resin DE53 (Sumpter et al., 1992) forming the total proteins. The U snRNAs were quantitatively removed during the TP preparation as shown in lane 2 in Fig. 4-4. The native snRNP protein preparation used for U2 snRNP reconstitution is thus essentially RNA-free.

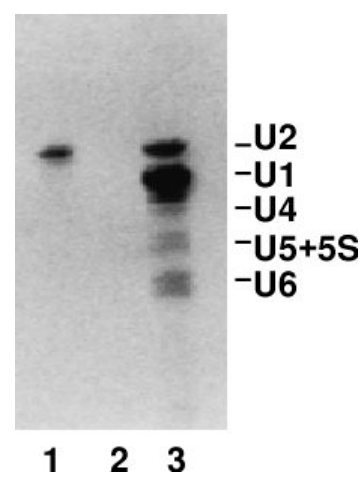

Figure 4-4. Analysis of the RNA content of native snRNP protein (TP) preparation. RNA was isolated by Proteinase $\mathrm{K}$ digestion and phenol/chloroform extraction of $5 \mu \mathrm{g}$ TPs (lane 2) and $5 \mu \mathrm{g}$ U1-U6 snRNPs (lane 3). Lane 1 shows $0.2 \mu \mathrm{g}$ native U2 snRNA for control. snRNAs were fractionated on a $9.6 \%$ polyacrylamide- $8.3 \mathrm{M}$ urea gel and visualized by staining with ethidium bromide.

The composition of these native snRNP preparations is shown in Fig. 4-5. They contain predominantly the snRNP core proteins (Sm proteins), B, B', D1, D2, D3, E, F and G. 
Compared to the Sm proteins, the particle specific proteins, in particular, U2 A' and U2 B" proteins, are underrepresented. As observed by others (Raker, 2000), the U1 70K protein was lost during the TP preparations.

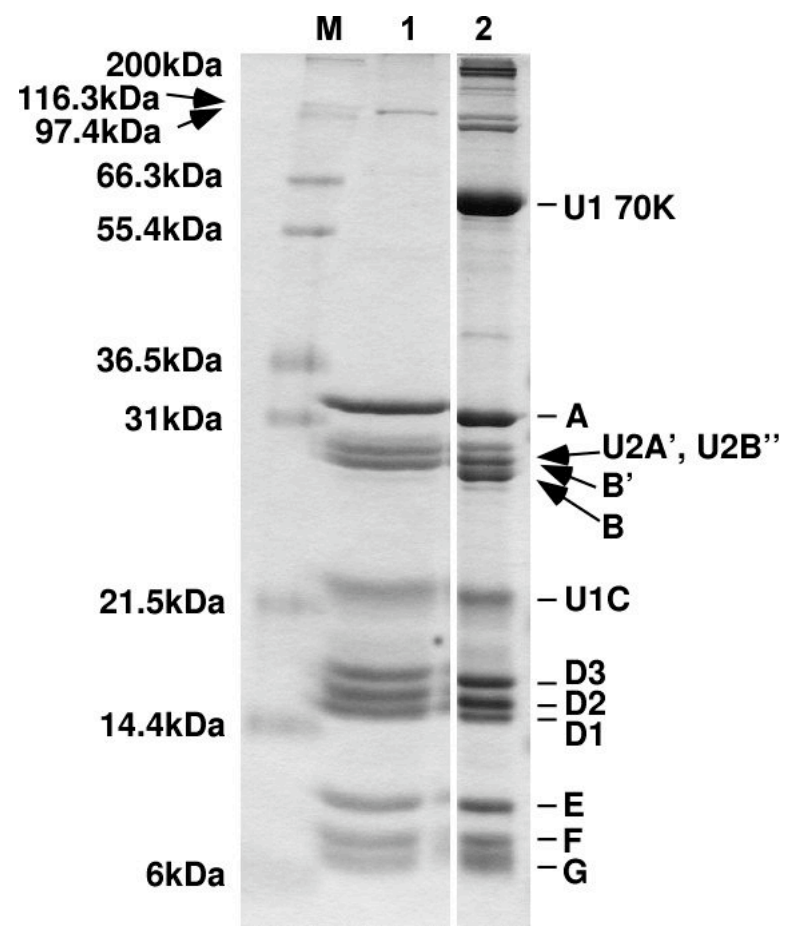

Figure 4-5. Protein composition of native snRNP protein (TP) preparations. TPs used for U2 snRNP reconstitution were prepared as described in Materials and Methods, were fractionated on a $13 \%$ SDS-polyacrylamide - high TEMED gel and stained with Coomassie. $23 \mu \mathrm{g}$ of the TP preparation used in in vitro reconstitutions in these experiments is shown in lane $1.32 \mu \mathrm{g} \mathrm{U}$ snRNPs are shown in lane 6 and $\mathrm{M}$ shows marker (NOVEX). 


\subsubsection{In vitro reconstitution of core $\mathrm{U} 2 \mathrm{snRNP}$}

After the preparation of total proteins, the first step of the two-step reconstitution/ complementation system was carried out by incubating the HeLa, in vitro transcribed or chimaeric U2 snRNAs with TPs to form core 12S U2 snRNPs. The formation of in vitro reconstituted core U2 snRNP particles includes binding of Sm proteins to Sm binding site. As shown in Fig. 4-6, native and in vitro transcribed U2 snRNA can form core U2 snRNPs successfully.

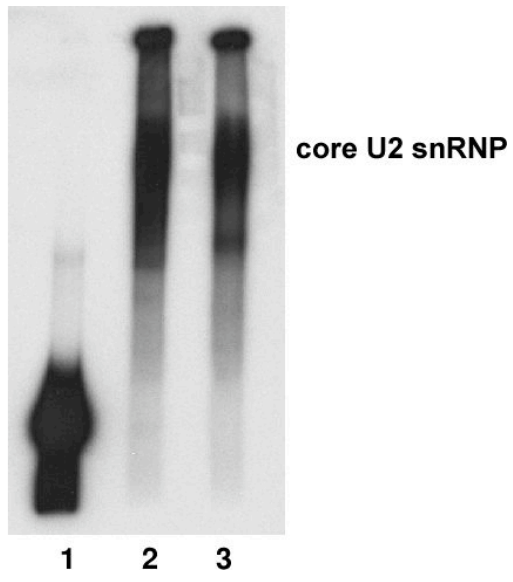

Figure 4-6. Native gel analysis of core U2 snRNP formation. Core U2 snRNPs were reconstituted with the ${ }^{32} \mathrm{P}-\mathrm{pCp}$ labelled HeLa U2 snRNA or in vitro transcribed U2 snRNA. Reconstitutions were analyzed on $6 \%$ polyacrylamide non-denaturing gel and visualized by autoradiography. Lane 2 and 3 show core U2 snRNP reconstituted with the HeLa U2 snRNA and in vitro transcribed U2 snRNA, respectively. HeLa U2 snRNA is shown in lane 1 for control.

Previous studies (Raker et al., 1999) showed that the minimal requirement for the Sm core RNP was a nonameric Sm site RNA oligonucleotide. This shows that core U2 snRNPs will form on the Sm binding site of U2 snRNAs irrespective of the presence or absence of modifications within the first 24 nucleotides since the chimaeric U2 snRNAs have their Sm binding site. 
The $12 \mathrm{~S}$ core U2 snRNPs were needed to be incubated with the U2-depleted nuclear extract to form fully active $17 \mathrm{~S}$ U2 snRNP.

\subsubsection{Depletion of U2 snRNP from HeLa nuclear extracts}

The U2-depleted nuclear extract required for the second step of two-step reconstitution/complementation system was prepared by using a biotinylated 2'-Omethylated oligonucleotide, complementary to nucleotides 1-20 of U2 snRNA. Mockdepleted extract was prepared in an identical manner, except that the oligonucleotide was omitted. The efficiency of depletion was verified by analysis of the RNA composition. No U2 snRNA could be detected by ${ }^{32} \mathrm{P}-\mathrm{pCp}$-labelling of RNA isolated from the U2depleted nuclear extract (Fig. 4-7A, lane 4). In addition, the function of U2-depleted nuclear extract was assayed by performing a splicing reaction (Fig. 4-7B). Untreated nuclear extract (lanes 7 to 12) and mock-depleted nuclear extract (lanes 13 to 18) showed efficient splicing whereas splicing activity was almost completely blocked in U2-depleted nuclear extracts (lanes 19 to 24) even at increased concentrations of nuclear extract.

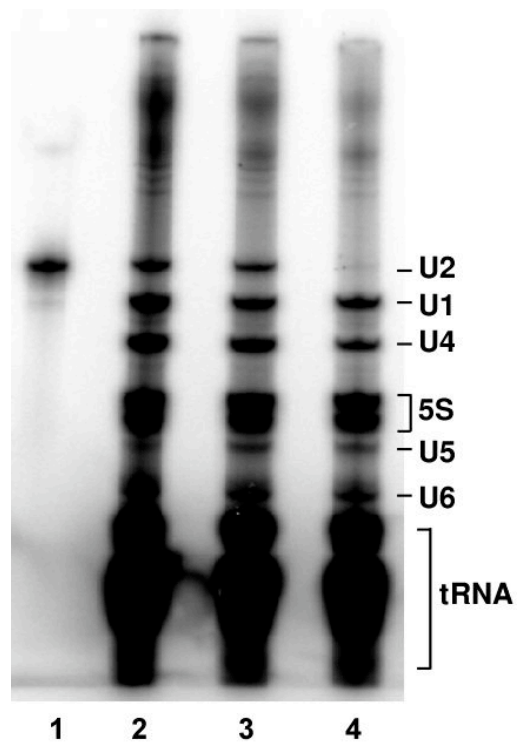

Figure 4-7A. RNA composition of input, mockdepleted and U2-depleted nuclear extract. Total RNA was isolated by Proteinase $\mathrm{K}$ digestion and phenol/chloroform extraction from the $50 \mu 1$ equivalents of input (lane 2), mock-depleted (lane 3 ) and U2-depleted (lane 4) nuclear extracts. The RNA was ${ }^{32} \mathrm{P}-\mathrm{pCp}$-labeled, fractionated on a $9.6 \%$ polyacrylamide- $8.3 \mathrm{M}$ urea gel and visualized by autoradiography. The ${ }^{32} \mathrm{P}$-pCp-labelled native U2 snRNA (lane 1) served as a marker. 


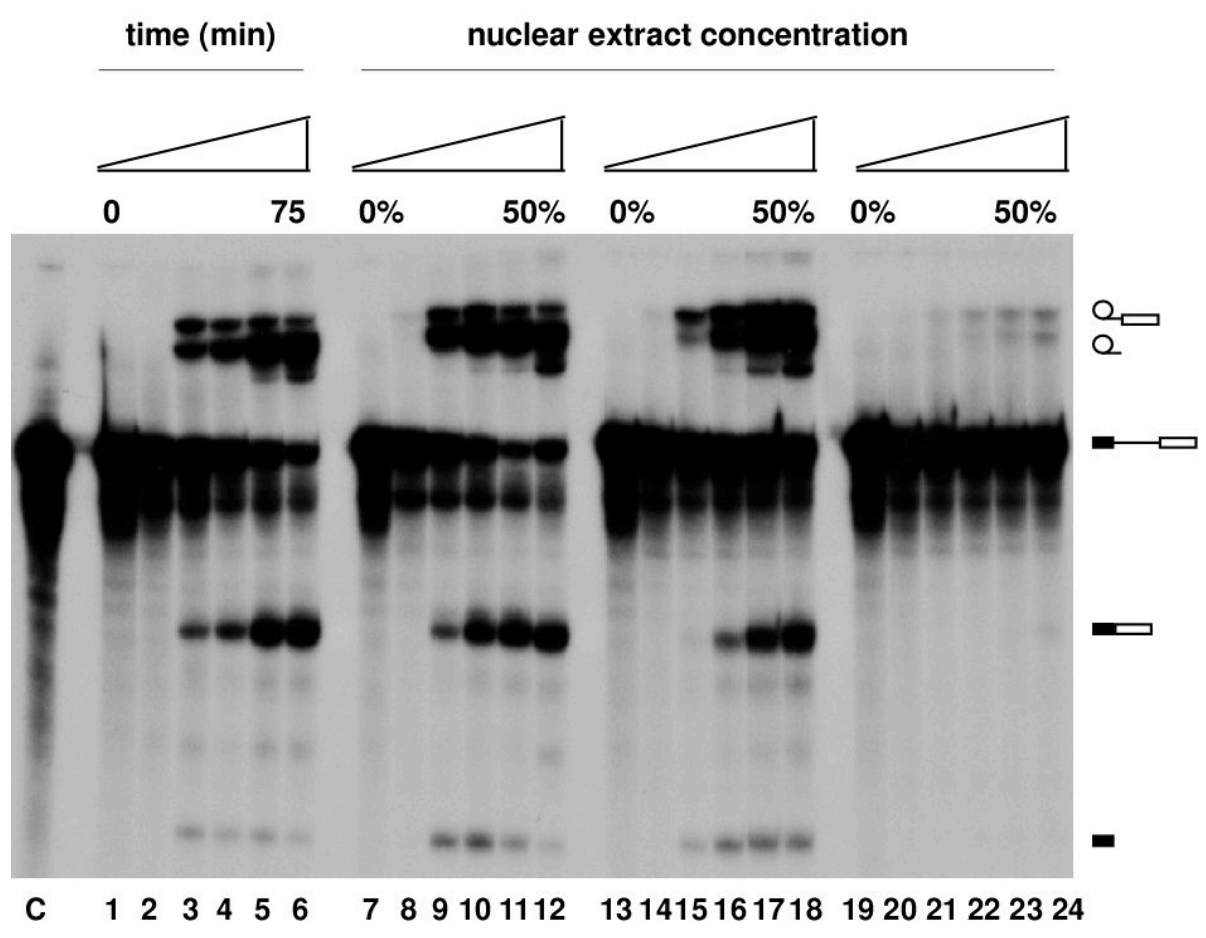

Figure 4-7B. Splicing assay of the untreated, mock-depleted and U2-depleted nuclear extract. Lanes 1-6 show kinetics of the splicing reaction of $35 \%$ input nuclear extract from 0 to 75 minutes with 15 min steps. Lanes 7-24 show the splicing reaction as a function of extract concentration in steps of $10 \%$. Lanes 7-12, 13-18, 19-24 show the untreated, mock-depleted and U2-depleted nuclear extract, respectively. The lane C shows the pre-mRNA. In all cases, the total $\mathrm{KCl}$ concentration in the splicing reaction was adjusted to $60 \mathrm{mM}$. The splicing reaction was analyzed on a $15 \%$ polyacrylamide$8.3 \mathrm{M}$ urea gel.

\subsubsection{Splicing assay of the in vitro reconstituted chimaeric U2 snRNPs}

The mature 17S U2 snRNPs were finally reconstituted by adding core U2 snRNPs to nuclear extract depleted specifically of core U2 snRNP and incubating first at $30{ }^{\circ} \mathrm{C}$ for $30 \mathrm{~min}$ and then at $4{ }^{\circ} \mathrm{C}$ for $10 \mathrm{~min}$. Splicing activity of the reconstituted U2 snRNPs was then assayed by the addition of ${ }^{32} \mathrm{P}$-labelled pre-mRNA and incubation for $3 \mathrm{~h}$ at $30{ }^{\circ} \mathrm{C}$ (Fig. 4-8). The splicing activity of the mock-depleted nuclear extract (Fig. 4-8, lane 3) was comparable to the untreated nuclear extract (lane 2). In contrast, U2-depleted nuclear extract was no longer active in splicing (lane 4). Reconstituted U2 snRNPs containing U2 snRNA purified from HeLa U2 snRNPs (lane 5) restored splicing to the level of mock- 
depleted nuclear extract. Consistent with earlier results (Segault et al., 1995), reconstituted U2 snRNPs containing in vitro transcribed U2 failed to complement splicing (lane 6). In the absence of functionally-active U2 snRNPs, the pre-mRNA was apparently more readily degraded in nuclear extract under splicing conditions (compare, for example, lanes 4 and 6 with 3 and 5).

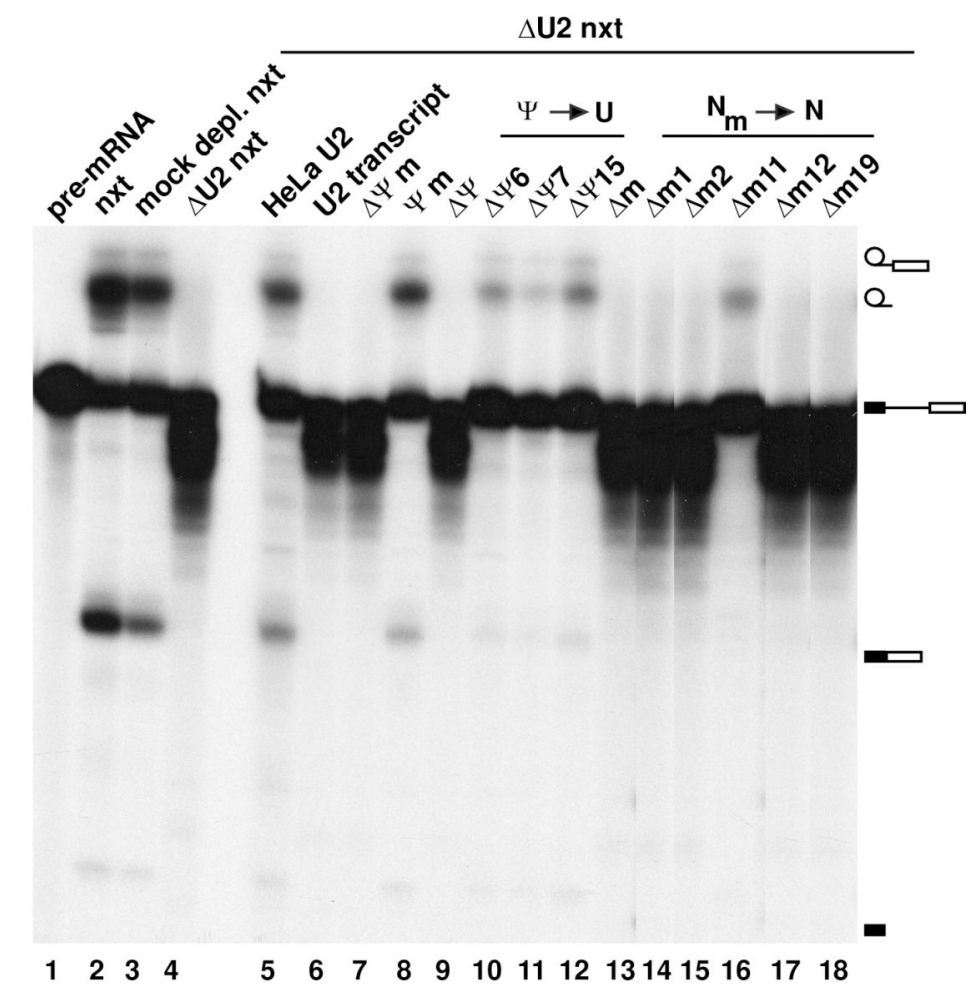

Figure 4-8. Internal modifications within the first 24 nucleotides of U2 snRNA are required for efficient complementation of splicing. Splicing complementation of U2 snRNAs differing in the number and type of internal modifications was assayed in the two-step reconstitution system by monitoring splicing of ${ }^{32} \mathrm{P}$-labeled pre-mRNA (lane 1). Untreated (lane 2), mock-depleted (lane 3) and U2-depleted (lane 4) nuclear extract are shown as controls. Lanes 5 to 18 show complementation of U2-depleted nuclear extract with U2 snRNPs reconstituted with the U2 snRNA indicated above each lane. RNA was analysed by denaturing-PAGE and visualized by autoradiography. This figure is published in Dönmez et al., 2004. 


\subsubsection{Internal modifications at the $5^{\prime}$ end of $U 2$ snRNA, but not the $m_{3} G$ cap structure, are required for splicing in vitro}

We next tested whether modifications at the $5^{\prime}$ end of $\mathrm{U} 2$ are generally required for splicing. As observed with U2 transcript (Fig. 4-8, lane 6), a chimaeric U2 snRNA lacking any modification ( $\triangle \Psi$ m $-\mathrm{U} 2$ snRNA) was found to be inactive in splicing (lane 8). In contrast, the $\Psi \mathrm{m}-\mathrm{U} 2$ snRNA, which contains all 2'-O-methylated and pseudouridine residues within the first 24 nucleotides, but lacks an $\mathrm{m}_{3} \mathrm{G}$ cap, complemented splicing almost as efficiently as HeLa U2 snRNA (c.f. lanes 5 and 8). Importantly, HeLa nuclear extract on its own does not support pseudouridylation of chimaeric RNAs $\Psi \mathrm{m}$ and $\Delta \Psi \mathrm{m}$ under a variety of conditions assayed (Fig. 4-9A). This is consistent with the previous results where pseudouridine was not detected in in vitro transcribed U2 snRNA after in vitro reconstitution and splicing (Segault et al., 1995). Furthermore, during reconstitution and splicing, no selective degradation of $\Delta \Psi \mathrm{m}, \Delta \mathrm{m}, \Delta \Psi$ and $\Psi \mathrm{m}$ chimaeric U2 snRNAs was observed (Fig. 4-9B, lanes 1-4). Thus, internal modifications have no significant effect on the stability of U2 snRNA in nuclear extract. Taken together, it is concluded that only the internal modifications present in $\Psi \mathrm{m}-\mathrm{U} 2$ snRNA, namely those within the first 24 nucleotides, functionally contribute to splicing complementation in the in vitro system, while the $\mathrm{m}_{3} \mathrm{G}$ cap is dispensable. 


\section{A}

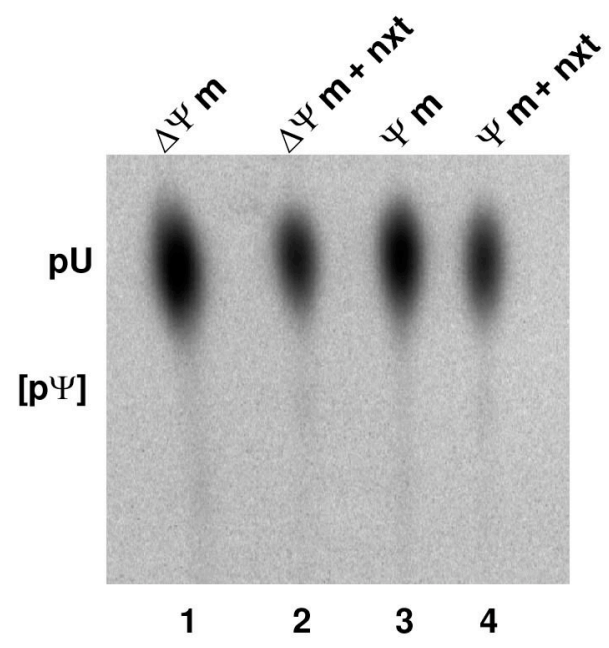

B

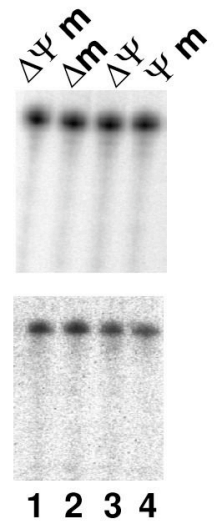

Figure 4-9: Chimaeric U2 snRNAs are not pseudouridylated and remain stable during reconstitution and splicing in the HeLa cell nuclear extract. (A) Chimaeric U2 RNAs $\Delta \Psi_{\mathrm{m}}$ (lanes 1 and 2 ) and $\Psi \mathrm{m}$ (lanes 3 and 4 ) bearing internal $5^{\prime}\left[{ }^{32} \mathrm{P}\right] \mathrm{U}$ labels downstream of G25 were treated with nuclease P1 before (lanes 1 and 3) or after reconstitution and splicing (lanes 2 and 4) and analysed by TLC on PEI plates. The position of uridine 5'-monophosphate $(\mathrm{pU})$ is indicated. Pseudouridine 5'monophosphate $(\mathrm{p} \Psi)$ would be expected at the position indicated by square brackets. (B) Internal RNA modifications do not differentially affect the stability of U2 snRNP in nuclear extract. Equivalent amounts of 4 different 3 '-end labelled chimaeric U2 snRNAs (indicated above the panels) were analysed before (top panel) and after (bottom panel) an in vitro splicing complementation reaction, using unlabelled pre-mRNA. This figure is published in Dönmez et al., 2004.

\subsubsection{The three pseudouridines within the first 24 nucleotides contribute to $\mathrm{U} 2$ snRNA function in pre-mRNA splicing}

The contribution of individual pseudouridines to splicing complementation was next investigated (Fig. 4-8). A U2 snRNA in which all pseudouridines within the first 24 nucleotides are replaced by uridines, but the 2'-O-methyl groups are retained $(\Delta \Psi-\mathrm{U} 2)$ did not support splicing (lane 9), demonstrating that one or more of these pseudouridines 
is required for splicing. However, when individual pseudouridines at positions 6, 7, or 15 were replaced by uridines, generating the $\Delta \Psi 6-, \Delta \Psi 7-$, and $\Delta \Psi 15-\mathrm{U} 2$ snRNAs, splicing activity was significantly reduced, as compared to HeLa U2 or $\Psi \mathrm{m}-\mathrm{U} 2$, but not abolished completely (lanes 10-12). Thus individual pseudouridines are not absolutely required for splicing complementation, but contribute to U2 function. The inactivity of the $\Delta \Psi-\mathrm{U} 2$ snRNA thus arises from the cumulative effect of the loss of individual pseudouridines at positions 6,7 or 15 of U2 snRNA.

\subsubsection{Four 5'-terminal 2'-O-methylations are essential for the function of U2 snRNA in pre-mRNA splicing}

To investigate the role of 2'-O-methylations, we performed reconstitution/ complementation studies with chimaeric U2 snRNAs lacking one or more 2'-O-methyl groups. A U2 snRNA lacking all five 2'-O-methyl groups, but containing pseudouridines ( $\Delta \mathrm{m}-\mathrm{U} 2)$, was inactive in splicing (Fig. 4-8, lane 13). Chimaeric U2 snRNAs lacking individual 2'-O-methyl groups at positions 1, 2, 12 or 19 (i.e., $\Delta \mathrm{m} 1-, \Delta \mathrm{m} 2-, \Delta \mathrm{m} 12-$, and $\Delta \mathrm{m} 19-\mathrm{U} 2)$ also failed to complement splicing activity (lanes 14, 15, 17 and 18, respectively). In contrast, deletion of the 2'-O-methyl of nucleotide G11 reduced, but did not abolish, splicing (lane 16). Thus, 2'-O-methyl groups at positions 1, 2, 12, and 19, but not at position 11, are individually required for the function of U2 snRNA in pre-mRNA splicing.

\subsubsection{Complex formation analysis of HeLa, in vitro transcribed and chimaeric U2 RNAs by using reconstitution/complementation system}

To determine whether modified U2 nucleotides act prior to the catalytic steps of splicing, we next investigated whether they affect spliceosome assembly. For this purpose, we performed splicing in the presence of ATP and analysed A complex formation by native gel electrophoresis with low-melting agarose gels (Das and Reed, 1999). HeLa and $\Psi$ m- 
U2 snRNA supported A complex formation as efficiently as untreated and mock-depleted nuclear extract (Fig. 4-10A, c.f. lanes 4 and 7 with lanes 1 and 2). In contrast, no A complex could be detected with U2-depleted extract or upon complementation with any of the other chimaeric U2 snRNAs assayed for splicing in Fig. 4-10A (lanes 3, 8-17). The apparent lack of detectable A complex with the $\Delta \Psi 6-, \Delta \Psi 7-, \Delta \Psi 15-$, and $\Delta \mathrm{m} 11-\mathrm{U} 2$ snRNAs was unexpected, as low levels of splicing activity had been observed with these snRNAs (Fig. 4-8). However, A complexes formed with these U2 chimera could have escaped detection either due to their inherent instability during gel electrophoresis or due to fast turnover of the low amounts formed. These data indicate that individual 2'-Omethyl groups at positions 1,2,12 and 19, and collectively pseudouridines at positions 6 , 7 and 15, are required either prior to or at the time of A complex formation.

To find out whether internal modifications are required at an earlier step, we next performed splicing in the absence of ATP and assayed E complex formation (Fig. 410B). In contrast to mock-depleted extract, U2-depleted nuclear extract on its own did not support E complex assembly (lane 3), corroborating the requirement for U2 snRNP during this process (Das et al., 2000). HeLa and $\Psi \mathrm{m}-\mathrm{U} 2$ snRNA supported E complex assembly as efficiently as untreated or mock-depleted nuclear extract (c.f. lanes 4 and 7 with lanes 1 and 2). U2 transcript or $\Delta \Psi \mathrm{m}-\mathrm{U} 2$ snRNA (lanes 5 and 6) on the other hand, did not support E complex assembly suggesting that at least some of the modifications are required for U2 function at this assembly stage. U2 snRNPs reconstituted from the $\Delta \Psi 6-, \Delta \Psi 7-, \Delta \Psi 15-$ and $\Delta \mathrm{m} 11-\mathrm{U} 2$ snRNAs formed $\mathrm{E}$ complex, albeit less efficiently than HeLa or $\Psi \mathrm{m}-\mathrm{U} 2$ (lanes 9-11 and 15), consistent with their reduced splicing activity observed before (Fig. 4-8). All other 2'-O-methyl deletions (lanes 13, 14, 16, and 17) were inactive in E complex formation, demonstrating that these modifications are individually required for E complex formation. 

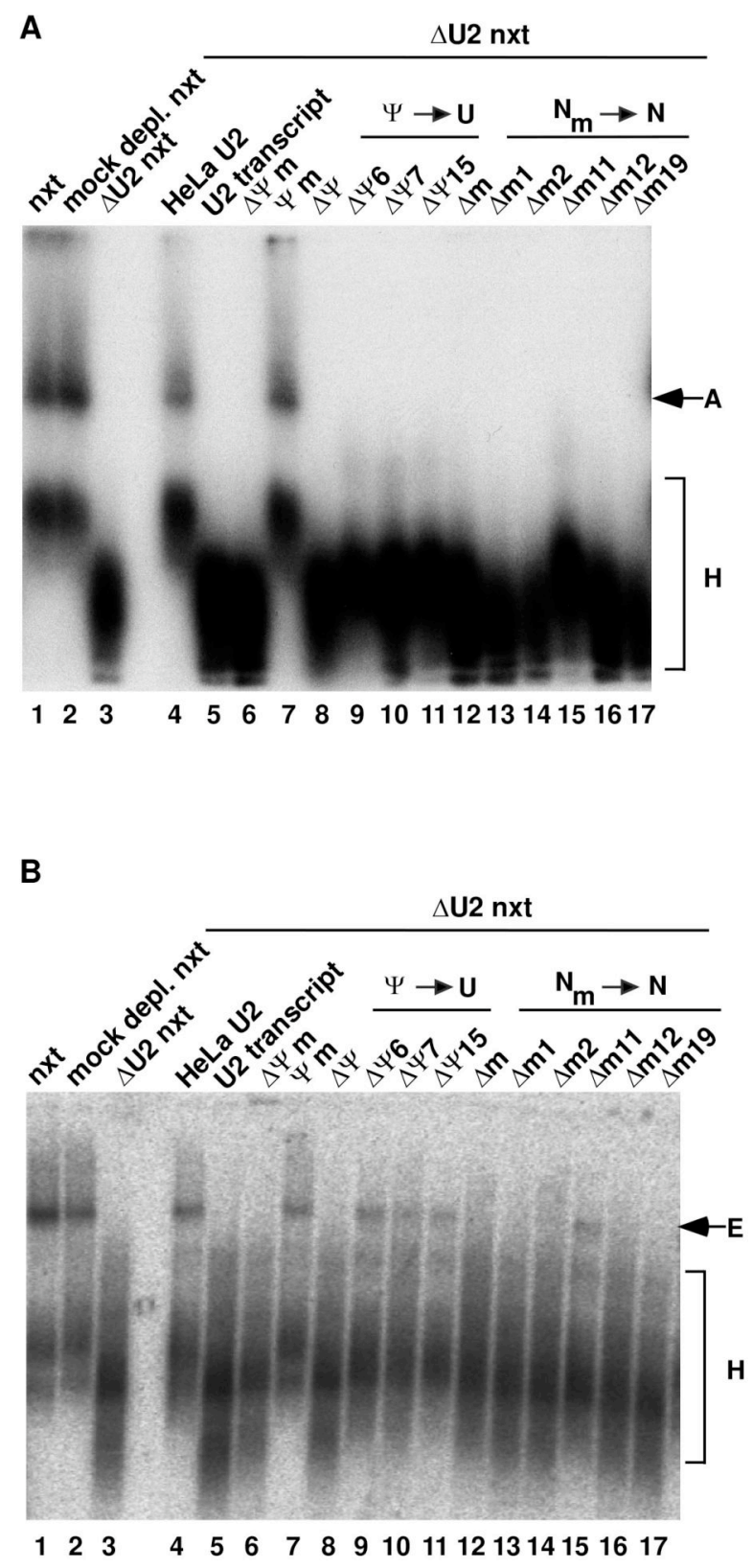

Figure 4-10: Internal modifications within the first 24 nucleotides of U2 snRNA are required for efficient spliceosome assembly. Analysis of A complex (panel A) and E complex (panel B) formation with chimaeric U2 snRNAs. Untreated (lane 1), mockdepleted (lane 2) and U2-depleted (lane 3) nuclear extract are shown as controls. Lanes 4 to 17 in each panel show complementation of the U2-depleted nuclear extract with U2 snRNPs reconstituted with the U2 snRNA indicated above each lane. Positions of the H, $\mathrm{A}$, and E complexes are indicated. The ATP depletion of nuclear extract for the E complex assay (panel B) was complete, as no A complex could be detected when control samples were analysed in the presence of heparin (data not shown). Complexes were analysed on native agarose gels and visualized by autoradiography. This figure is published in Dönmez et al., 2004. 


\subsubsection{Modifications are not required for 17S U2 snRNP assembly}

The inability of certain U2 snRNA chimaera lacking modified nucleotides to support E complex formation could be due to inhibition of U2 snRNP assembly. It was therefore investigated whether $17 \mathrm{~S} \mathrm{U} 2 \mathrm{snRNP}$ formation is compromised in the absence of modifications. U2 snRNPs were thus reconstituted with ${ }^{32} \mathrm{P}$-labelled HeLa snRNA or U2 transcript and analyzed by glycerol gradient centrifugation. U2 snRNPs assembled with either RNA peaked in the 17S region of the gradient (fractions 13-17; Fig. 4-11A) and no apparent difference in their distribution across the gradient could be detected. These results provided a first indication that neither internal modifications nor the $m_{3} G$ cap are required for $17 \mathrm{~S} \mathrm{U} 2 \mathrm{snRNP}$ assembly.

\subsubsection{Modifications are not required for the association of $17 \mathrm{~S}$ U2-specific proteins}

The reconstituted 17S U2 snRNPs could potentially lack one or (Behrens et al., 1993; Will et al., 2002) more U2-specific protein, which would not necessarily be detectable by sedimentation analysis (c.f. Will et al., 2002). Thus, U2 snRNP formation was additionally assayed by immunoprecipitation with antibodies against a subset of U2 snRNP-specific proteins. As expected, both fully modified and unmodified U2 snRNAs were precipitated with anti-Sm (Fig. 4-11B, lanes 6, 12) and anti-U2 B" (data not shown) antibodies, indicating that $12 \mathrm{~S} \mathrm{U} 2 \mathrm{snRNP}$ formation is not dependent on modifications. In addition, both RNAs were precipitated by SF3a66 (lanes 2, 8) and SF3b155 (lanes 4, 10) antibodies. As SF3a66 and SF3b155 are components of the highly stable heteromeric SF3a and SF3b protein complexes respectively, it is highly likely that all subunits of SF3a and SF3b are present. Thus, consistent with the observed sedimentation behaviour of reconstituted U2 snRNPs, association of these complexes with U2 snRNA does not require modifications. Further, when immunoprecipitations were performed with antibodies against SPF30/SMNrp, SPF31, and hPrp5, which are substoichiometrically present in 17S U2 snRNPs (Fig. 4-11C), no significant difference in precipitation 
efficiency was observed between HeLa U2 snRNA and U2 transcript. Taken together, we conclude that U2 snRNA modifications are not required for the formation of intact $17 \mathrm{~S}$ U2 snRNPs.

A

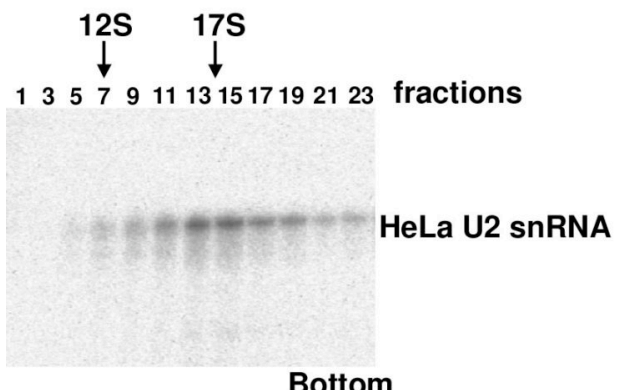

13557911131517192123 fractions

U2 transcript
B

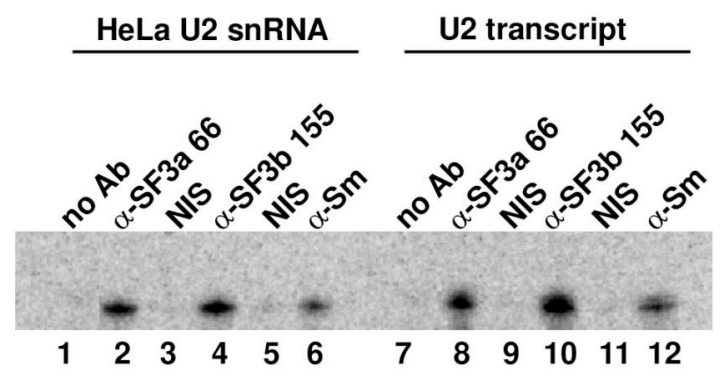

C

HeLa U2 snRNA U2 transcript

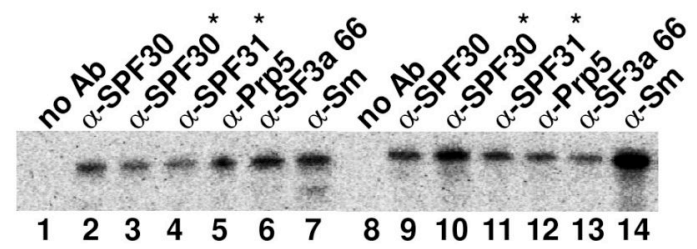

Figure 4-11: 17S U2 snRNP assembly is not dependent on the presence of modifications in U2 snRNA. (A) Both HeLa U2 snRNA (top panel) and U2 transcript (bottom panel) assemble into a 17S U2 snRNP in vitro. 3'-end labelled RNAs were used for two-step reconstitution and RNPs were analysed on a $10-30 \%$ glycerol gradient. The RNA content of the odd fractions was analysed by denaturing PAGE and visualized by autoradiography. Native $17 \mathrm{~S}$ U2 snRNP, isolated according to Will et al. (2002), exhibited an identical sedimentation behaviour (not shown). (B) and (C) Immunoprecipitation assays of U2 snRNPs reconstituted with 3'-end labelled HeLa U2 snRNA (lanes 1-6 in panel B and 1-7 in panel C) or U2 transcript (lanes 7-12 in panel B and 8-14 in panel C). The antibody used is indicated above each lane. NIS: non-immune serum of the antibody in the preceeding lane. Antibodies denoted with * were affinity purified. Major (panel B) and substoichiometric (panel C) components of U2 snRNP were analyzed. This figure is published in Dönmez et al., 2004. 


\subsection{Site-directed hydroxyl radical probing in early complexes}

The demonstration in the first part of this work that the functionally active U2 snRNPs can be reconstituted in vitro from chimaeric U2 snRNAs facilitated the use of sitedirected hydroxyl radical probing method in early complexes in the second part. To investigate the 3D architecture and dynamic organization of early spliceosomal complexes, we probed RNA proximities by site-directed generation of hydroxyl radicals from Fe-BABE covalently attached to the U2 snRNA. As the $m_{3} G$ cap of U2 snRNA was found to be dispensable for splicing in the first part of this work, we targeted Fe-BABE to the 5 ' terminal nucleotide. To this end, a 6-carbon spacer containing a sulfhydryl group was inserted during the chemical synthesis of an oligomer that comprises the 5 ' end of U2 snRNA (i.e. nts 1-24) and contains all natural modifications required for U2 function (Fig. 4-12). The oligomer was first derivatized with Fe-BABE. The reaction product was then purified and ligated to in vitro transcribed RNA comprising the remaining portion of U2 via Moore and Sharp ligation (Fig. 4-12). U2 snRNPs were then reconstituted in vitro first by incubating with total snRNP proteins (to form $12 \mathrm{~S}$ particles) and then in nuclear extract specifically depleted of $12 \mathrm{~S}$ U2 snRNPs to form the functional $17 \mathrm{~S}$ form as before. Then, this functional Fe-BABE modified chimaeric U2 snRNPs were used in spliceosomal complex formation and splicing assays.

As a first step, BABE was synthesized in order to derivatize the oligomer comprising the 5 ' end of U2 snRNA with Fe-BABE. 


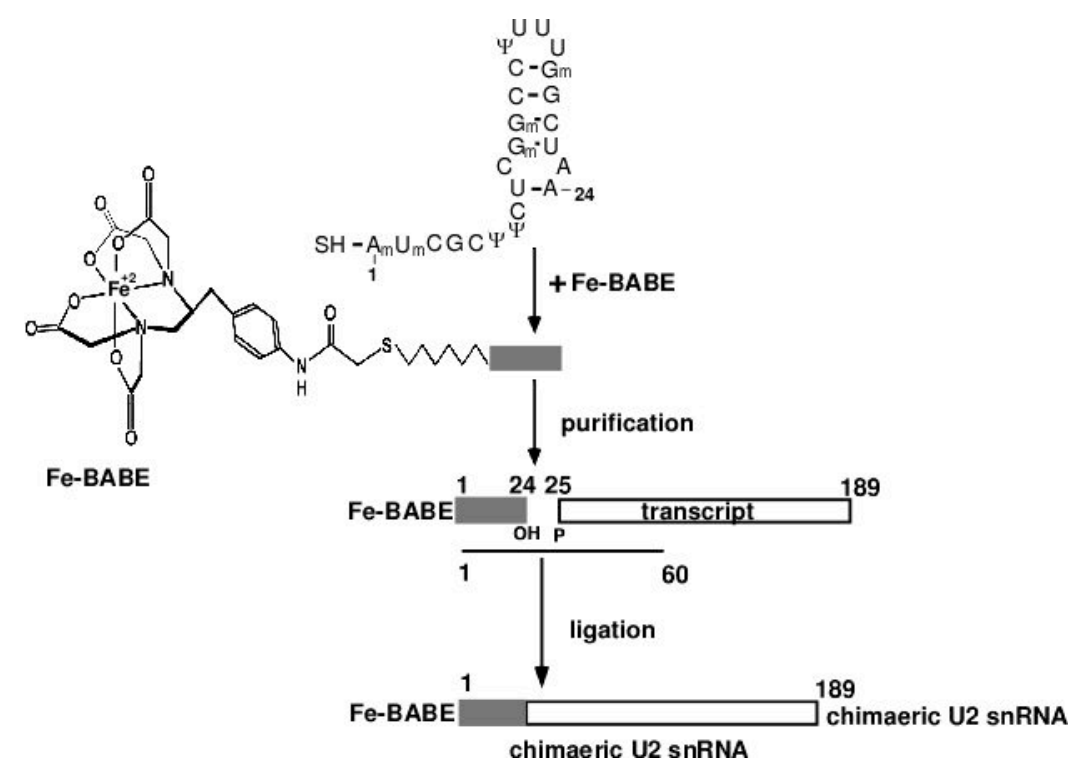

Figure 4-12: Synthesis of Fe-BABE modified human U2 snRNA. An oligomer which corresponds to the first 24 nucleotides of U2 snRNA containing all the natural modifications within and a SH group at its 5' end was chemically synthesized and modified with Fe-BABE. This modified oligomer was ligated to a transcript comprising the remaining part of U2 snRNA (between nucleotides 25-189). This Fe-BABE modified chimaeric U2 snRNA was used in in vitro reconstitution/complementation assays.

\subsubsection{BABE synthesis and reactivity test}

As explained in Materials and Methods 3.2.12.1, BABE was synthesized from ABE and bromoacetylbromide. In order to test the reactivity of BABE, the cysteine-test was carried out. In this test, the bromo-group of BABE reacts with the sulfhydryl $(\mathrm{SH})$ group of cysteine by forming a covalent bond when BABE has reactivity. The efficiency can be analysed by thin layer chromatography (TLC). The reaction between BABE and cysteine causes the retardation of BABE on TLC assay (Fig. 4-13, lane 2) whereas BABE alone migrates at the same level with the bufferfront (Fig. 4-13, lane 1). This shows that BABE is active and can be used for the further modification experiment of the 5' U2 RNA oligo. 


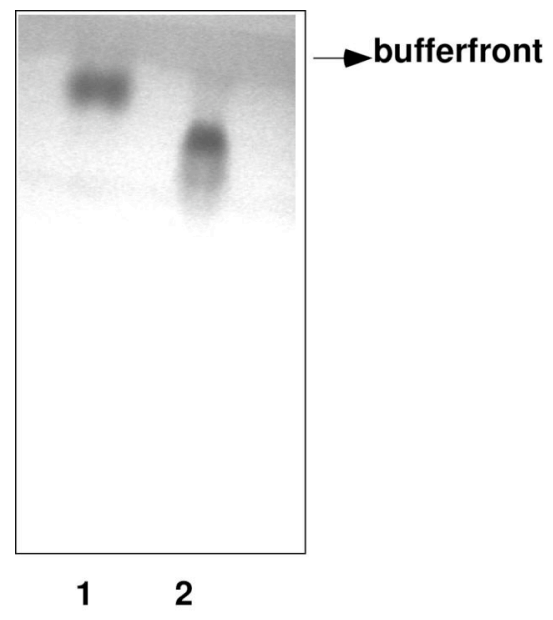

Figure 4-13: $B A B E$ and cysteine were incubated as explained in 3.2.12.2 and $1 \mu \mathrm{l}$ from this reaction was loaded on TLC plate (lane 2). BABE alone migrates together with the bufferfront (lane 1). It was visualized with UV shadowing $(254 \mathrm{~nm})$ and photographed.

\subsubsection{Modification of 5' U2 RNA oligo with Fe(II)-BABE}

$\psi \mathrm{m}, \Delta \psi \mathrm{m}, \mathrm{U} 2-19$ and $\mathrm{U} 2-20$ oligonucleotides (see 3.1.9) were first pCp-labeled and then modified with $\mathrm{Fe}(\mathrm{II})-\mathrm{BABE}$ as explained in 3.2.12.3. U2-19 is the $\psi \mathrm{m}$ oligo with the SH group at the 5' end and U2-20 is the $\Delta \psi \mathrm{m}$ oligo with the SH group at the 5 ' end. $\psi \mathrm{m}$ and $\Delta \psi \mathrm{m}$ were chosen as control oligos since they lack a SH-group at their $5{ }^{\prime}$ end (Fig. 4-14, lanes 1-4). For further controls, the reactions without the addition of Fe(II)BABE were carried out (Fig. 4-14, lanes 1, 3, 5, 7). The reactions were analysed on $22 \%$ polyacrylamide-8.3 M urea gel. As shown in Fig. 4-14, the oligonucleotides $\Delta \psi \mathrm{m}$ (lane 1) and $\psi \mathrm{m}$ (lane 3 ) showed no shift on the gel when they were incubated with Fe(II)BABE (lanes 2 and 4, respectively). Since these oligonucleotides do not have the SHgroup at their 5' end, they can not be modified with Fe(II)-BABE. U2-19 and U2-20 oligonucleotides carrying SH-group at their 5 ' ends did not show any shift in the absence of $\mathrm{Fe}$ (II)-BABE (lanes 7 and 5, respectively) whereas they showed a shift when they were incubated with Fe(II)-BABE (lanes 8 and 6 , respectively). This indicates that the modification of an oligonucleotide with Fe(II)-BABE is specific for the presence of a thiol group. 
Since the modification efficiency was at most $50 \%$ (lane 8), the Fe(II)-BABE modified oligo had to be purified. It was purified from $22 \%$ polyacrylamide- $8.3 \mathrm{M}$ urea gel via visualizing with UV-shadowing. This material was then used in the ligation procedure where it was ligated to a transcript corresponding to the U2 RNA starting from nucleotide 25.

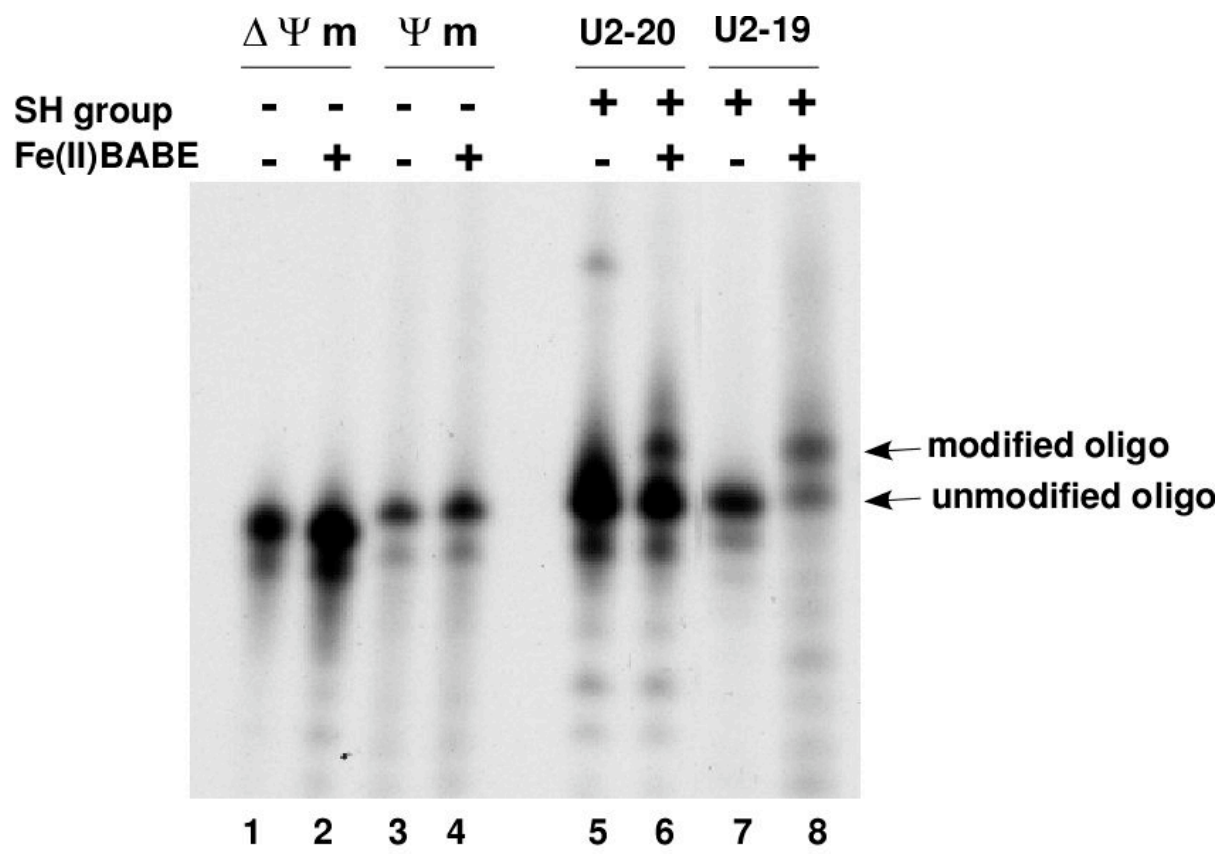

Figure 4-14: pCp-labelled oligonucleotides were modified with $\mathrm{Fe}(\mathrm{II}) \mathrm{BABE}$ and analyzed on $22 \%$ polyacrylamide- $8.3 \mathrm{M}$ urea gel. $\psi \mathrm{m}$ and $\Delta \psi \mathrm{m}$ oligonucleotides did not show any shift due to modification since they lack an SH-group at their 5' end (lanes 2 and 4). U2-19 and U220 oligos showed a shift which indicates the attachment of Fe(II)-BABE to the SH-group (compare 5 and 7 with 6 and 8, respectively).

\subsubsection{Formation of chimaeric Fe-BABE modified U2 snRNAs via ligation}

Fe(II)-BABE modified 5' U2 RNA oligos (U2-19 and U2-20) were ligated with the U2 RNA transcript starting from the 25th nucleotide (U2G25 RNA) in order to generate chimaeric Fe(II)BABE modified U2 RNAs via Moore and Sharp ligation. The Fe(II)- 
BABE modified U2-19 and U2-20 oligos were ligated with the U2G25 RNA with almost $50 \%$ efficiency (Fig. 4-15, lanes 1 and 2, respectively). The Fe-BABE modified chimaeric U2 RNA was gel purified from $9.6 \%$ polyacrylamide-8.3 M urea gel and used for further reconstitutions.

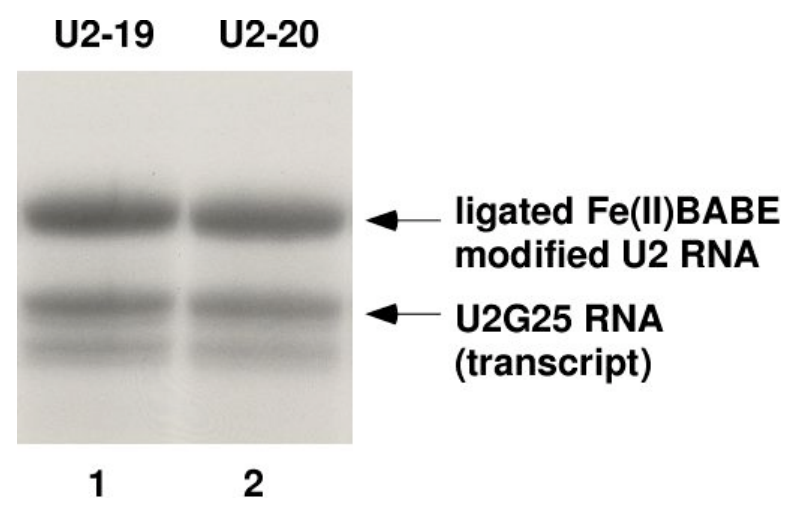

Figure 4-15: $\mathrm{Fe}(\mathrm{II})-\mathrm{BABE}$ modified U2-19 and U2-20 were ligated with the U2G25 RNA as explained in 3.2.3.3 (lanes 1 and 2 respectively). The upper band which corresponds to the chimaeric Fe(II)-BABE modified U2 RNA was gel purified from $9.6 \%$ polyacrylamide- $8.3 \mathrm{M}$ urea gel.

\subsubsection{S U2 snRNP assembly with Fe-BABE modified chimaeric U2 snRNAs}

In order to form mature 17S Fe-BABE modified U2 snRNPs, the two-step reconstitution/ complementation system was applied. The Fe-BABE modified chimaeric U2 snRNAs (see 4.2.3) were incubated with total proteins to form $12 \mathrm{~S}$ core U2 snRNPs and then with the U2-depleted nuclear extract to produce fully active 17S U2 snRNPs. The reaction was then loaded onto 10-30\% glycerol gradient in order to analyze whether the presence of $\mathrm{Fe}(\mathrm{II})-\mathrm{BABE}$ at the $5^{\prime}$ end of the chimaeric U2 RNA affects the sedimentation pattern on 10-30 \% glycerol gradient. The experiment was performed as explained in 3.2.10. Instead 
of HeLa U2 RNA or the U2 transcript, the same amount of Fe(II)-BABE modified chimaeric U2 RNA was used.

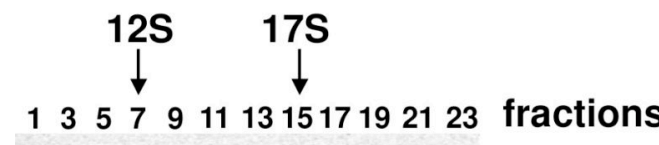

\section{HeLa U2 snRNA}

\section{Bottom}

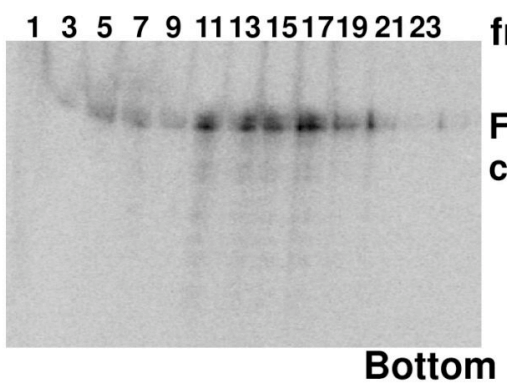

fractions

Fe(II)BABE modified chimaeric U2 RNA (U2-19)

Figure 4-16: The 17S U2 snRNP particles reconstituted with pCp-labelled, Fe(II)-BABE modified chimaeric U2 RNA or HeLa U2 RNA were analyzed on 10-30 \% glycerol gradient. Fe(II)-BABE modified chimaeric U2 RNA and HeLa U2 RNA demonstrate the identical sedimentation peaks and patterns indicating that $\mathrm{Fe}(\mathrm{II})-\mathrm{BABE}$ modified U2 RNA assembles into 17S U2 snRNP particle. The odd fractions of the gradient were Proteinase K digested and ethanol precipitated. The RNA was analyzed on $9.6 \%$ polyacrylamide- $8.3 \mathrm{M}$ urea gel which was visualised by autoradiography.

As it is seen in Fig. 4-16, 12S and 17S peaks of the U2 snRNP particle reconstituted with the Fe(II)-BABE modified chimaeric U2 RNA were observed in the same fractions as in the case of the U2 snRNP particle reconstituted with the HeLa U2 RNA (compare the lower panel with the upper one). They thus display identical sedimentation behaviour. 
This indicates that Fe(II)-BABE modified chimaeric U2 RNA assembled into 17S U2 snRNP. The presence of Fe(II)-BABE at the 5' end of U2 RNA therefore does not affect this assembly. The Fe-BABE modified chiameric 17S U2 snRNPs were subsequently used in the analysis of spliceosomal complex formation and splicing.

\subsubsection{Analyzing the functionality of Fe-BABE modified chimaeric U2 snRNAs in complex formation and splicing}

The Fe-BABE modified chimaeric 17S U2 snRNPs were analyzed for spliceosomal complex formation and splicing by adding a radiolabeled pre-mRNA. E complexes did not form on MINX pre-mRNA in U2-depleted ( $\Delta U 2)$ extract (Fig. 4-17A, lane 1). However, when $12 \mathrm{~S}$ U2 snRNPs containing Fe-BABE were added to the $\Delta \mathrm{U} 2$ extract (and 17S U2 snRNPs were allowed to form), E complex formation was observed with an efficiency comparable to that of native nuclear extract (Fig. 4-17A, lanes 3 and 4) after incubating for 10 min under splicing conditions (but in the absence of ATP). Fe-BABEU2 snRNPs also supported A and B complex formation in the presence of ATP as efficiently as in vitro reconstituted U2 snRNPs lacking BABE (Fig. 4-17B, cf lanes 6-10 and 11-15); the efficiency and kinetics of complex formation in both cases were comparable to that observed with native nuclear extract (Fig. 4-17B, lanes 1-5). Finally, whereas no splicing was observed with $\Delta \mathrm{U} 2$ extract extract alone or when complemented with U2 snRNPs reconstituted from U2 snRNA lacking natural modifications (Fig. 4-18, lanes 2 and 4), MINX pre-mRNA was spliced at wildtype levels (lane 1) upon addition of U2 snRNPs reconstituted from either purified HeLa U2 snRNA (containing all modifications) or chimeric U2 snRNA with natural modifications within nts 1-24 (lanes 3 and 5). 5' Fe-BABE-U2 snRNPs also complemented splicing (lane 7), albeit at a reduced efficiency ( $45 \%$ when compared to reconstituted U2 snRNPs lacking BABE, lane 5). This reduction is probably due to the bulky Fe-BABE group, as the 6-carbon spacer with the sulfhydryl group alone did not inhibit splicing (cf lanes 5 and 6). In subsequent experiments the latter RNA was used as a "minus BABE" control. 
A
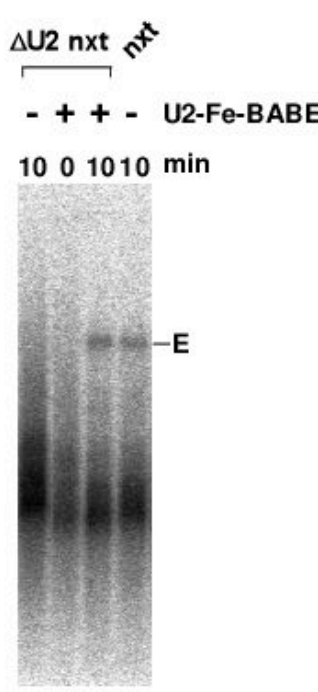

$\begin{array}{llll}1 & 2 & 3 & 4\end{array}$
B

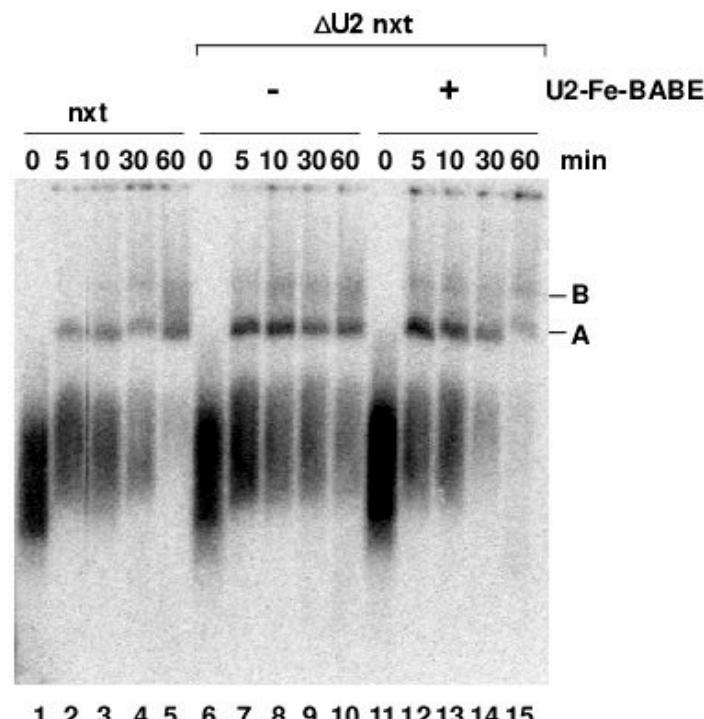

Figure 4-17: Spliceosomal complex formation with Fe-BABE modified chimaeric U2 snRNPs. (A) E complex formation in untreated HeLa nuclear extract (lane 4$)$ and U2-depleted extract $(\Delta U 2)$ either alone (lane 1) or complemented with in vitro reconstituted U2 snRNPs containing FeBABE modified U2 snRNA (lanes 2-3) after incubating in the absence of ATP for the indicated times. Complexes were analysed on a $1.5 \%$ lowmelting agarose gel. (B) Time course of splicing complex formation in untreated extract (lanes 1-5) and $\Delta \mathrm{U} 2$ extract complemented with $\mathrm{U} 2$ snRNPs containing either non-BABE modified (lanes 6-10) or BABEmodified, chimeric U2 snRNA (lanes 11-15) Complex formation was analysed as above and the positions of the $\mathrm{A}$ and $\mathrm{B}$ complexes are indicated on the right.

This result indicates that the presence of an SH-group at the $5^{\prime}$ end or the modification of the chimaeric U2 RNA with the Fe-BABE do not affect the spliceosomal complex formation and the splicing reaction. Fe-BABE modified chimaeric U2 snRNPs support spliceosomal A and B complex formation and splicing reaction. 


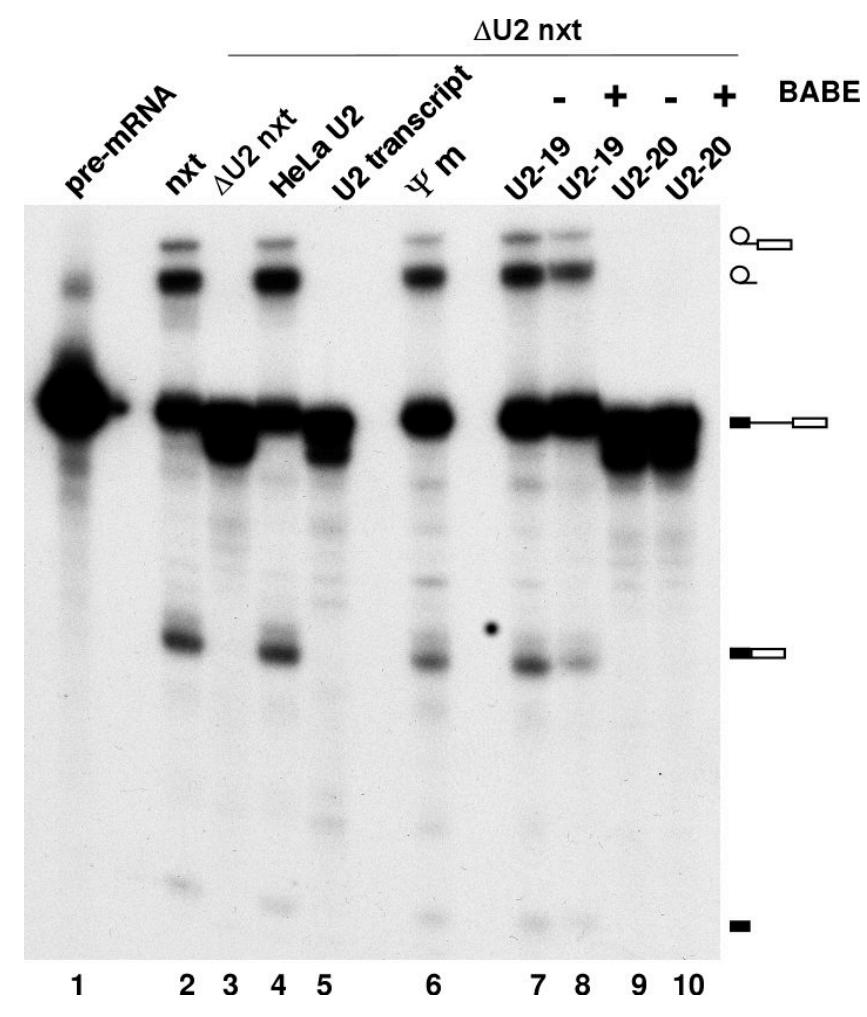

Figure 4-18: Analysis of splicing reaction with Fe-BABE modified chimaeric U2 snRNPs. In vitro splicing with untreated extract (lane 1) and $\Delta \mathrm{U} 2$ extract alone (lane 2) or complemented with U2 snRNPs containing endogeneous HeLa or in vitro transcribed U2 snRNA (lanes 3-4), or either unmodified (lanes 5 and 6) or Fe-BABE-modified (lane 7) chimaeric U2 snRNA are shown. Splicing intermediates/products (shown schematically on the right) were analyzed on $15 \%$ denaturing PAGE and visualized by autoradiography.

\subsubsection{Site-directed hydroxyl radical probing of pre-mRNA in E complexes}

We next investigated proximities of the $5^{\prime}$ end of $U 2$ snRNA relative to the pre-mRNA in the E complex by site-directed hydroxyl radical probing. E complex assembly was performed with U2 snRNA lacking or bearing Fe-BABE at its 5' end and hydroxyl radical production was subsequently initiated by addition of $\mathrm{H}_{2} \mathrm{O}_{2}$. Subsequently, the RNA was recovered. Primer extension was then carried out with primers complementary 
to the intron (nts 83-100, Fig. 4-19B) or exon 2 (nts 199-215, Fig. 4-19A) of the premRNA (see also Fig. 4-19D for summary of cleavages). Bands observed in lane 4 $\left("+\mathrm{BABE}+\mathrm{H}_{2} \mathrm{O}_{2} "\right)$ that are missing or less intense in the control lanes 1 to 3 , arise from cleavage of the pre-mRNA by hydroxyl radicals generated by Fe-BABE and indicate that the cleaved nucleotide is in proximity to the $5^{\prime}$ end of $U 2$.

Cleavage intensities were quantified in this and all subsequent experiments as explained here for a portion of the gel shown in Fig. 4-18B (i.e., nts 40-61). The intensity of the bands in the "+BABE $+\mathrm{H}_{2} \mathrm{O}_{2}$ " and "-BABE $-\mathrm{H}_{2} \mathrm{O}_{2}$ " lanes was determined by densitometric scanning (Fig. 4-19C, blue and green lines) and the difference in intensity of each band was subsequently calculated (Fig. 4-19C, red line). Nucleotides where this difference amounted to 50 or more arbitrary intensity units were considered to be cleaved and further classified, essentially according to Joseph et al. (2000), as weak (50-99 units; e.g. C42, C43 in Fig. 4-19B), medium (100-149 units; e.g., C57) or strong (150 units and up; e.g., C50, C52, C53) cleavages.

As a control, we also performed hydroxyl radical probing with 5' Fe-BABE U2 snRNA lacking internal modifications, which therefore cannot be incorporated into the $\mathrm{E}$ complex as analyzed in the first part of this work. Only three $\mathrm{H}_{2} \mathrm{O}_{2}$-induced cleavages above background (as determined by densitometric scanning) were observed (Fig. 4-19B, cf lanes 5 and 6; data not shown), demonstrating that nearly all of the cleavages observed in lane 4 are not due to "free" Fe-BABE U2 snRNPs in the reaction mixture. In addition, we performed hydroxyl radical probing with MINX pre-mRNA lacking the BPS ( $\triangle U 150$ C157), which can undergo $\mathrm{E}$, but not A complex formation (Das et al., 2000). Significantly, a nearly identical cleavage pattern was observed with this mutant (data not shown), confirming that the cleavages detected in lane 4 solely arise from pre-mRNA present in E complexes.

Strong cleavages were observed in four main regions of the pre-mRNA (Fig. 4-19D, R1R4), including a portion of the polypyrimidine tract (R4) and the so-called anchoring site 
(AS) located upstream of the BPS (R3). In addition, weak cleavages were detected at the 3' end of the polypyrimidine tract and in exon 2 (Fig. 4-19A). Strong cleavages were also

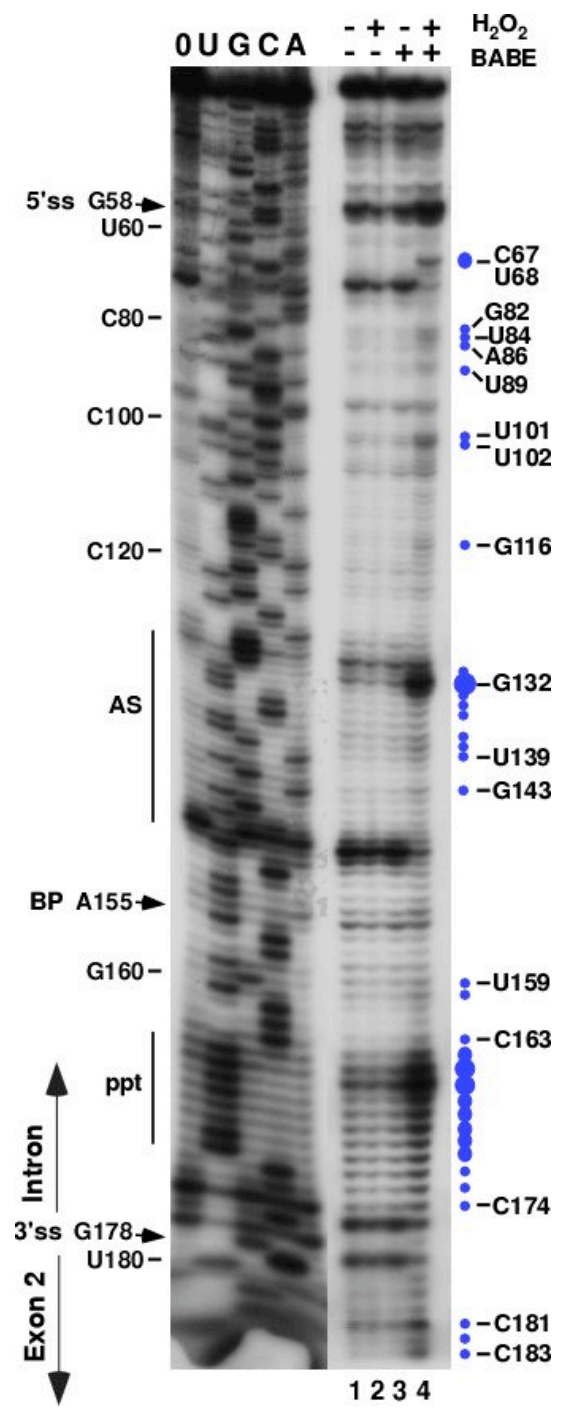

Figure 4-19A: Site directed hydroxyl radical probing of pre-mRNA in E complexes. Cleavage sites on the 3' half of the pre-mRNA were determined by primer extension with a primer complementary to nts 199-215 of exon 2. Hydroxl radical cleaved nucleotides are indicated by blue dots on the right. The size of the dots reflects the intensity of the cleavages which is classified as strong, medium or weak. 0: input RNA. U, $\mathrm{G}, \mathrm{C}, \mathrm{A}$ : dideoxy sequencing reactions of input RNA. Spontaneous reverse transcriptase stops or cleavages due to nuclease activity other than Fe-BABE in the absence (lane 1) or presence of Fe-BABE (lane 3). Lane 2: background cleavage of pre-mRNA in the absence of Fe-BABE-U2 after addition of $\mathrm{H}_{2} \mathrm{O}_{2}$. Lane 4: Hydroxl radical cleavages in the presence of $\mathrm{Fe}-$ BABE-U2 after addition of $\mathrm{H}_{2} \mathrm{O}_{2}$. ss: splice site, BP: branchpoint, AS: anchoring site, ppt: polypyrimidine tract. For detailed densitometric analysis, see 4.2.9.

found close to the 5' ss (C50, C52, C53) near the 3' end of exon 1 (R2) and less intense cleavages both 5' and 3' of R2 (Fig. 4-19B). An additional strong cleavage (R1) was observed in exon 1 (C22) (Fig. 4-19B). Scattered weak cleavages were also detected in the central part of the intron (Fig. 4-19A and D). Taken together the data demonstrate that regions bordering both the $5^{\prime}$ and $3^{\prime}$ ss, as well as the polypyrimidine tract and anchoring site of the pre-mRNA are proximal to the 5' end of U2 snRNA already in the E complex. 
To determine whether the observed proximities are dependent on the U1 snRNP, we prevented U1 binding by deleting the 5'ss (i.e., $\Delta$ A56-G65) of the pre-mRNA. This $\Delta 5$ 'ss pre-mRNA was completely inactive in E complex formation and no pre-mRNA cleavages were detected when site-directed hydroxyl radical probing was performed (not shown). Thus, U1 snRNP bound to the $5^{\prime}$ ss is essential for the functional interaction of U2 snRNP with the pre-mRNA during E complex formation.
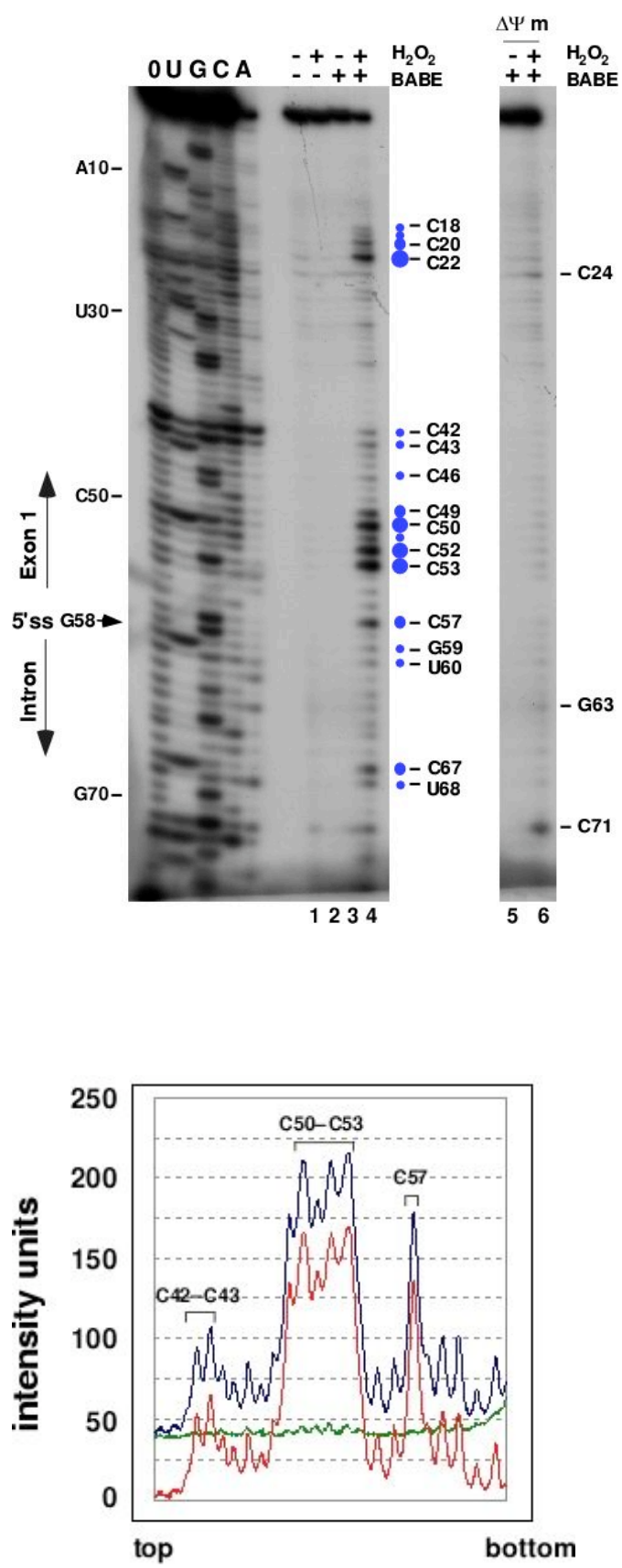

Figure 4-19B: Site directed hydroxyl radical probing of pre-mRNA in E complexes. The hydroxyl radical cleavages in the $5^{\prime}$ half of the pre-mRNA were analyzed with a primer complementary to nts $83-100$ of the intron. Lane designations are as in 4-19A. Lane 6: hydroxyl radical cleavage of pre-mRNA in the presence of "free" Fe-BABE U2 snRNPs not incorporated into the $\mathrm{E}$ complex due to the lack of natural modifications in $\mathrm{U} 2$ nts $1-24(\Delta \Psi \mathrm{m})$ and corresponding background cleavage control (lane 5). For detailed densitometric analysis, see 4.2.9.

Figure 4-19C: Quantification of cleavage intensities in a portion of the gel from 4$19 \mathrm{~B}$ by densitometric scanning (see text for detailed description). The band intensities of the "+BABE $+\mathrm{H}_{2} \mathrm{O}_{2}$ " lane (blue line), "$\mathrm{BABE}-\mathrm{H}_{2} \mathrm{O}_{2}$ " lane (green line) and the difference in their intensities (red line) are shown. 


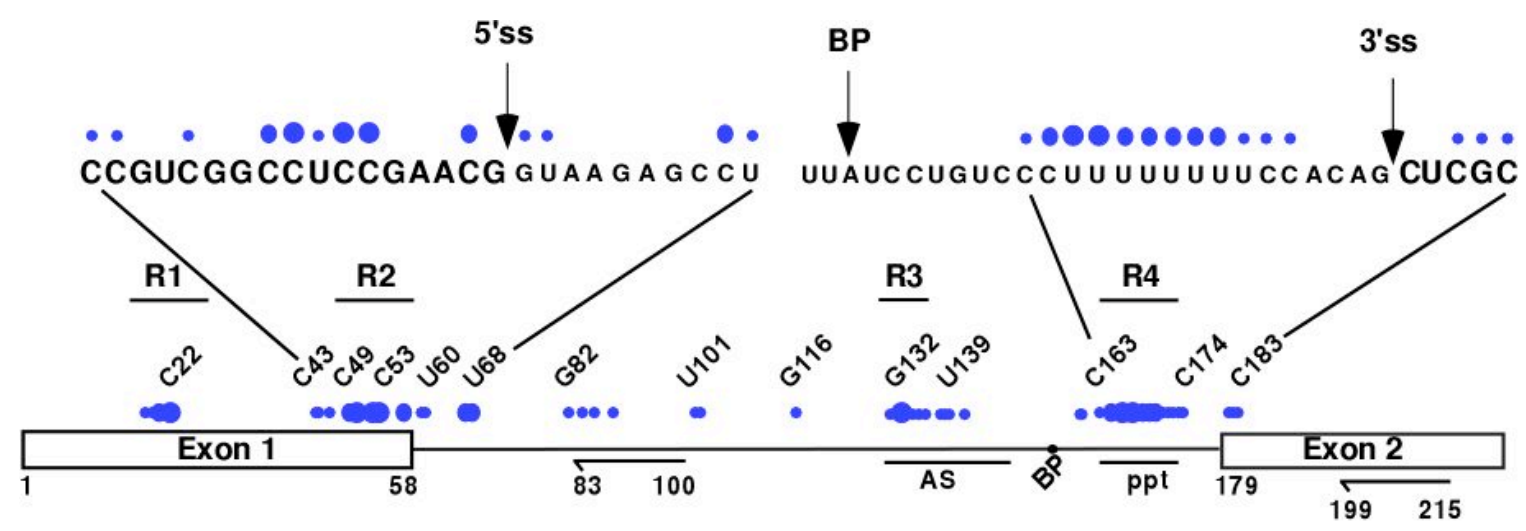

E complex

Figure 4-19D: Summary of the cleaved nucleotides on the pre-mRNA in E complex. R1, R2, R3 and R4 indicate regions where strong cleavages are observed. Note that due to the major cleavage at position 132 (which leads to a lower amount of cDNA that encompasses the 5 ' end of the pre-mRNA) cleavages at nts 60-67 are much less prominent in 4-19A than in panel 4-19B.

\subsubsection{Site-directed hydroxyl radical probing of pre-mRNA in the A complex}

To determine whether the spatial organization of U2 relative to the pre-mRNA changes during the $\mathrm{E}$ to $\mathrm{A}$ transition, we performed hydroxyl radical probing in A complexes containing 5' Fe-BABE U2 snRNA. To this end, splicing was performed in the presence of ATP and a 2'-O-Me oligonucleotide complementary to the ACAGAG box of U6 snRNA (i.e., nts 27-46). The latter blocks tri-snRNP integration, thereby inhibiting B complex formation and enhancing the accumulation of A complexes (Frilander and Steitz, 1999). Primer extension analyses (Fig. 4-20) revealed cleavages in the premRNA's polypyrimidine tract, regions surrounding the $5^{\prime}$ and 3 ' splice sites, and in the anchoring site. Thus, the global distribution of cleavages was similar to that observed in the E complex (see Fig. 4-20C for comparison). However, several notable differences can be discerned. For example, cleavages in the polypyrimidine tract appeared shifted upstream, and novel cleavages were detected in the branch point sequence (BPS), including the branchpoint adenosine at position 155 (Fig. 4-20A). Furthermore, cleavages 
around the 3 ' splice site (A177 to C183) were enhanced. Most strikingly, cleavages near the middle of exon 1 (region R1, C18-C22) were completely lost, whereas those at the 3' end of exon 1 were significantly reduced (Fig. 4-20B). Conversely, cleavages at the $5^{\prime}$ end of the intron were enhanced in the A complex (e.g., A64 and C67). The loss of cleavages in the R1 region indicates that they are E complex specific, and further demonstrates that the splicing conditions used here have led to the formation of A complexes that are devoid of $\mathrm{E}$ complexes. In contrast to the aforementioned differences, cleavages in the anchoring sequence did not change significantly.

Taken together, these data reveal that the global organization of functionally important RNA elements is similar in the $\mathrm{E}$ and A complex: regions bordering both splice sites, the polypyrimidine tract, and the anchoring site are close to the 5' end of the U2 snRNA. On the other hand, they suggest that during A complex formation either (i) the $5^{\prime}$ end of the U2 has moved relative to the pre-mRNA's BPS and 5' exon or that (ii) a rearrangement and/or the addition of other spliceosomal factors has lead to a differential accessibility of these regions to hydroxyl radicals. 


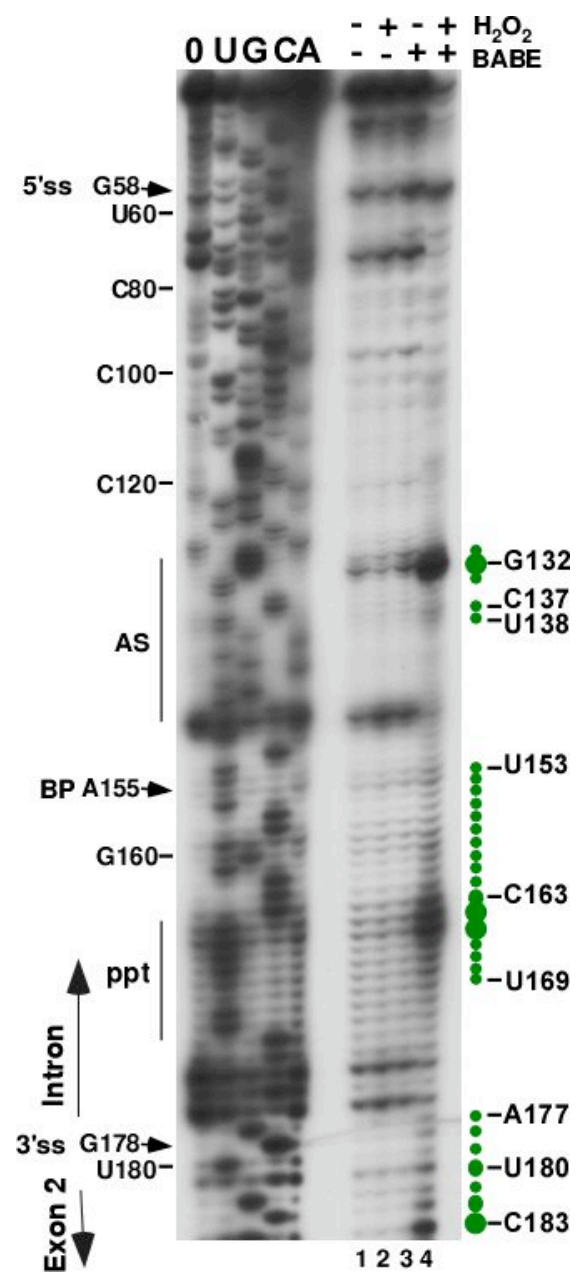

Figure 4-20A: Site-directed hydroxyl radical probing of pre-mRNA in A complexes. The hydroxyl radical cleavages on the $3^{\prime}$ half (primer complementary to nts 199-215) of the pre-mRNA is shown. Lane designations are as in Fig. 4-19A. Cleaved nucleotides are indicated by green dots. For detailed densitometric analysis, see 4.2.9. 


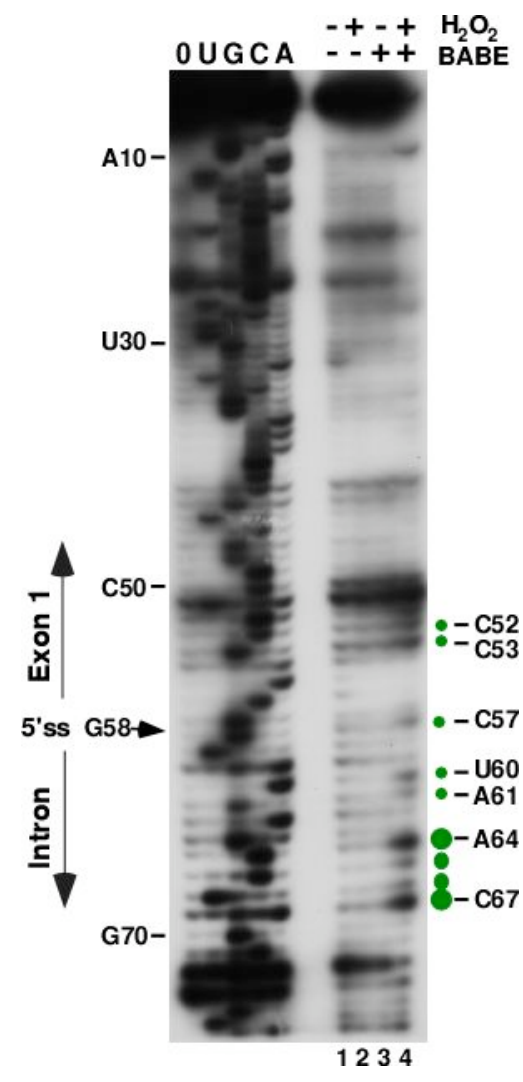

Figure 4-20B: Site-directed hydroxyl radical probing of pre-mRNA in A complexes. The hydroxyl radical cleavages on the $5^{\prime}$ half (primer complementary to nts 83100) of the pre-mRNA is shown. Lane designations are as in Fig. 4-19A. Cleaved nucleotides are indicated by green dots. For detailed densitometric analysis, see 4.2.9.

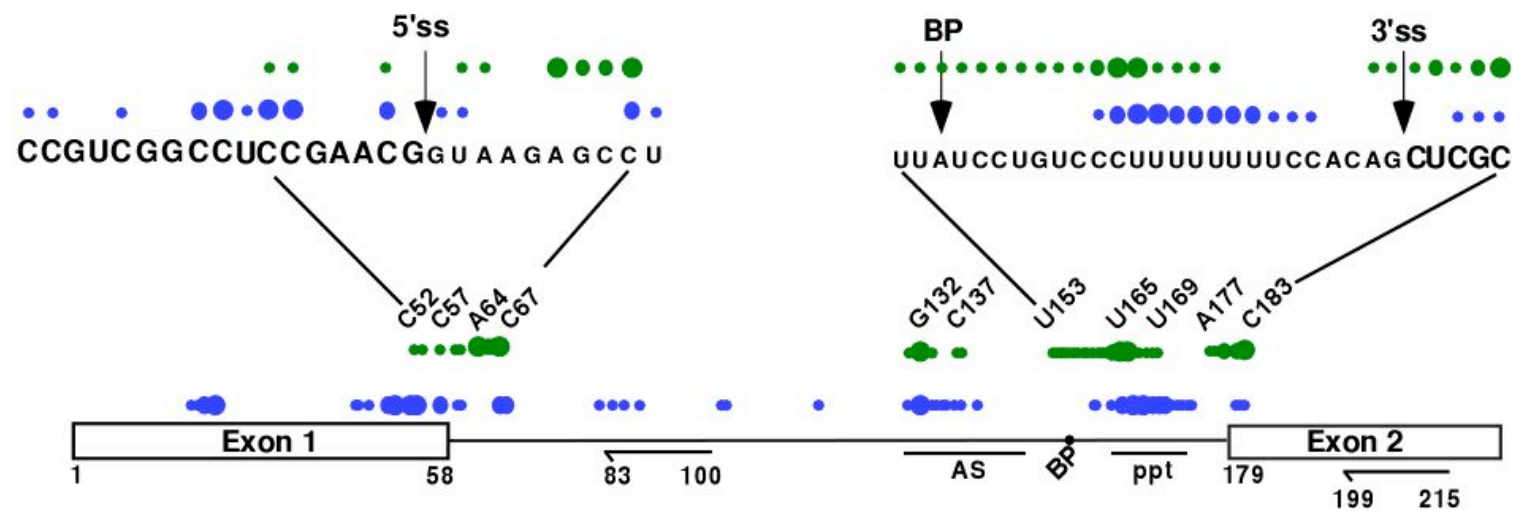

- E complex

- A complex

Figure 4-20C: Summary of cleaved nucleotides on the pre-mRNA in the E and A complexes. 


\subsubsection{Proximity of the $5^{\prime}$ end of U2 snRNA to U1 snRNA in early spliceosomal complexes}

U1 snRNA is a central component of both the E and A complexes. In both, it is held in position by base pairing to the 5 ' splice site. The observed cleavages in the vicinity of the $5^{\prime}$ splice site prompted us to examine whether the 5' end of the U2 snRNA is also in close proximity to the U1 snRNP. We thus performed hydroxyl radical footprinting with $\mathrm{E}$ and A complexes containing 5' Fe-BABE U2 snRNA, as described above (see 4.2.6 and 4.2.7) and analysed the U1 snRNA for hydroxyl radical induced cleavages via primer extension (Fig. 4-21A-C; see also Fig. 4-22A for summary). Strong cleavages were observed in stem I (nts 39, 41-42) and stem-loop III (nts 100, 101 and 110). Moderate cleavages were found in the upper part of stem II (nts 73-77) and the internal loop of stem II (nts 52-56) whereas weak cleavages were detected at the 5' end of U1, which base pairs with the $5^{\prime}$ splice site, and also at a limited number of nucleotides in stem I, stemloop II, and stem-loop III. Significantly, no U1 cleavages above background were detected when the pre-mRNA was omitted (Fig. 4-21D) or if MINX pre-mRNA lacking the $5^{\prime}$ splice site was used (data not shown), confirming that the observed cleavages are dependent on splicing complex formation. These data indicate that the 5 ' end of the U2 snRNA is indeed in close proximity to the U1 snRNP, already at the time of E complex formation. Interestingly, the cleavage pattern did not differ dramatically between the $\mathrm{E}$ and A complex (Fig. 4-21A-D), indicating that the close spatial relationship between the U1 snRNP and the $5^{\prime}$ end of the U2 snRNA does not change significantly during the E to A complex transition. Most of the limited number of changes in the U1 cleavage pattern were concentrated in the 4-way junction and stem/loop III, as well as helix H, to which the $5^{\prime}$ splice site interacting sequence is directly connected.

The U1 cleavage pattern is not random, but rather cleavages are limited to selected regions of the molecule, suggesting that $\mathrm{U} 1$ and $\mathrm{U} 2$ are oriented in a specific manner. To rule out that solely those U1 regions that are acessible to hydroxyl radicals were cleaved in $\mathrm{E}$ and A complexes, we subjected purified U1 snRNPs (either in nuclear extract or in buffer) to hydroxyl radicals and analysed the cleavage pattern as described above. 
Significantly, many additional U1 nucleotides were cleaved and the relative cleavage intensities in several regions differed from those observed in the E and A complex (Fig. 4-21E).
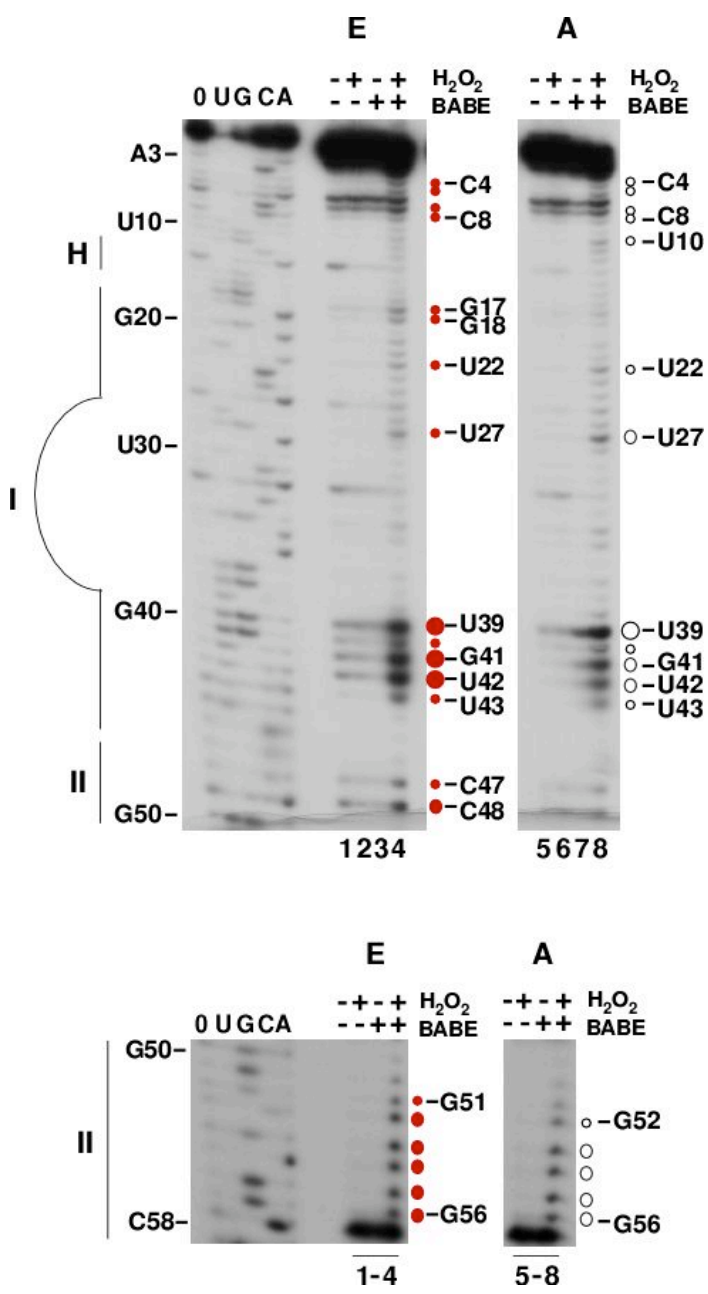

Figure 4-21A: Site-directed hydroxyl radical probing of U1 snRNA in E and A complexes. Fe-BABE-U2 induced cleavages within the first 58 nts of U1 including stem $\mathrm{H}$, I and the lower part of stem II were analyzed by primer extension (primer complementary to nts 63-76) in E (lanes 1-4) and A (lanes 5-8) complexes. U1 cleavages above background in E and A complexes are indicated by red and white dots, respectively. Lane designations are as in Fig. 4-19A. For detailed densitometric analysis, see 4.2.9. 


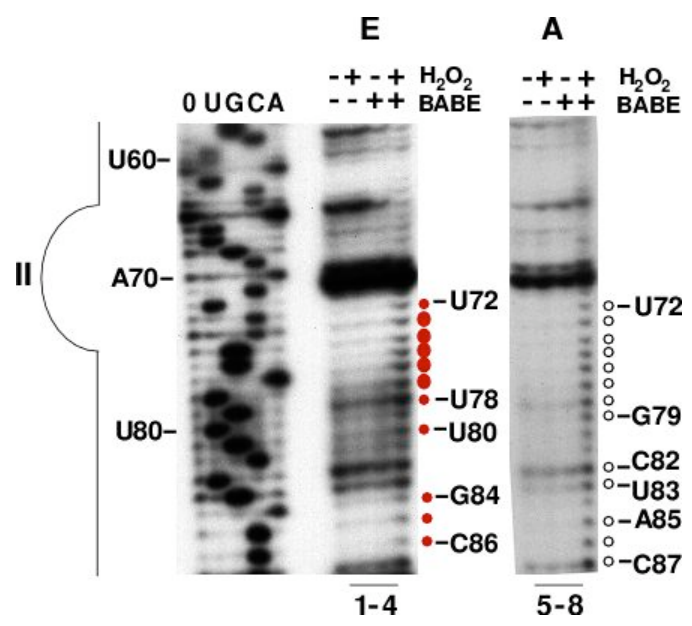

Figure 4-21B: Site-directed hydroxyl radical probing of U1 snRNA in E and A complexes. Fe-BABE-U2 induced cleavages in nucleotides 58-87 (stem II) were analyzed with a primer complementary to nucleotides 101-119 in E (lanes 1-4) and A (lanes 5-8) complexes. U1 cleavages above background in E and A complexes are indicated by red and white dots, respectively. Lane designations are as in Fig. 4-19A. For detailed densitometric analysis, see 4.2.9.

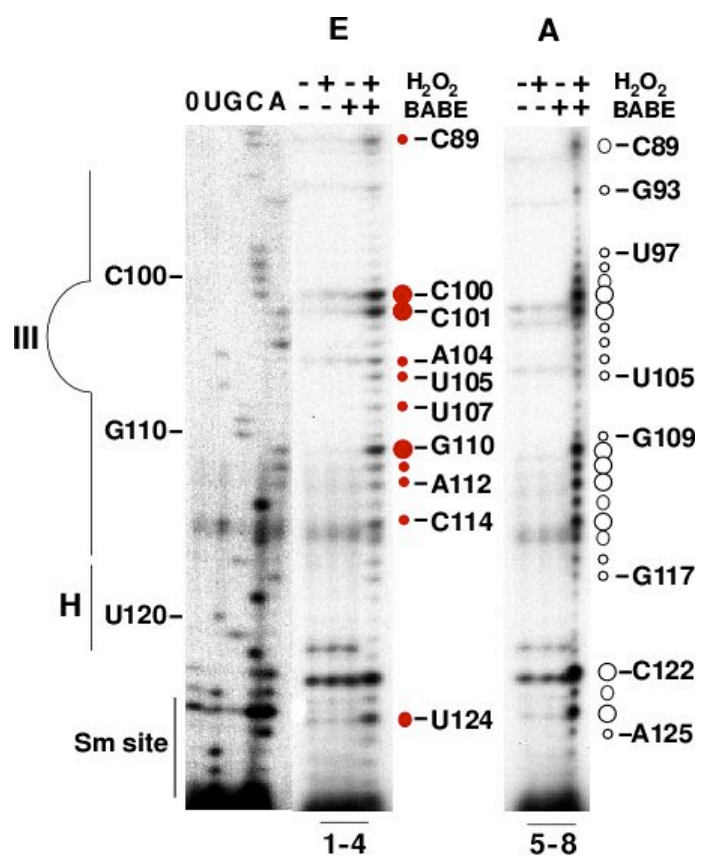

Figure 4-21C: Site-directed hydroxyl radical probing of U1 snRNA in E and A complexes. Fe-BABE-U2 induced cleavages in nucleotides 88-126 (stem III and $\mathrm{H})$ with a primer complementary to nucleotides $134-152$ in $\mathrm{E}$ (lanes 1-4) and A (lanes 5-8) complexes. U1 cleavages above background in E and A complexes are indicated by red and white dots, respectively. Lane designations are as in Fig. 419A For detailed densitometric analysis, see 4.2.9. 

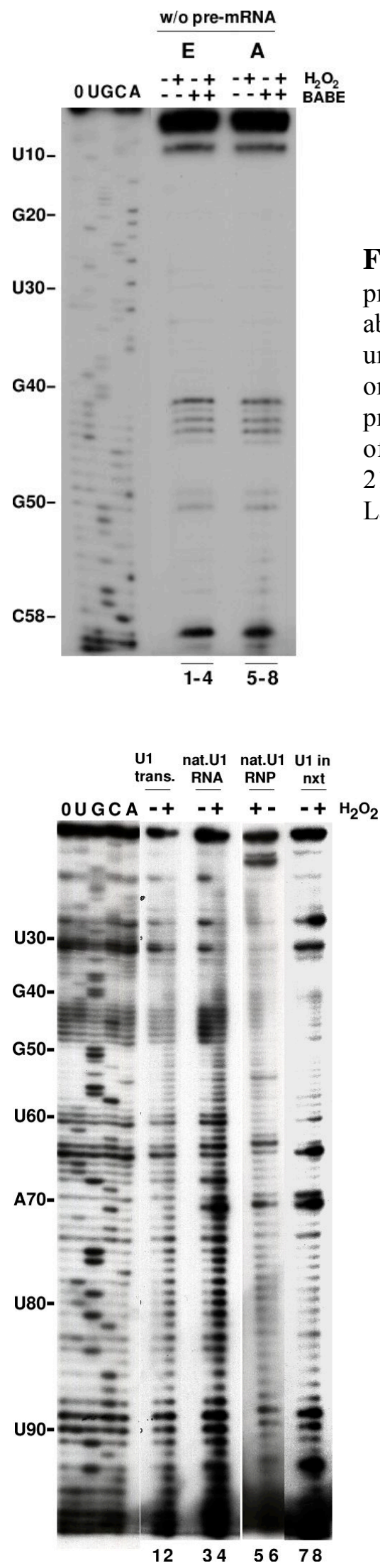

Figure 4-21D: Site-directed hydroxyl radical probing of U1 snRNA in E and A complexes in the absence of pre-mRNA. Splicing was performed under conditions normally generating E (lanes 1-4) or A complexes (lanes 5-8), but in the absence of pre-mRNA. Cleavages within the first 58 nucleotides of U1 were analyzed with the primer used in panel 4$21 \mathrm{~A}$. No cleavages above background were detected. Lane designations are as in Fig. 4-19A.
Figure 4-21E: Hydroxyl radical probing of the purified U1 snRNP in nuclear extract or buffer. Equivalents of in vitro transcribed U1 RNA (lanes 1, 2), Hela (native) U1 RNA (lanes 3, 4), purified (native) U1 snRNP (lanes 5, 6) and U1 in nuclear extract (lanes 7,8 ) were subjected to hydroxyl radical probing as in the same way in Fig. 4-21A-C. The Fe-BABE induced cleavages were analyzed by a primer complementary to nucleotides 101-119. All the lanes belong to the same set of experiments. 


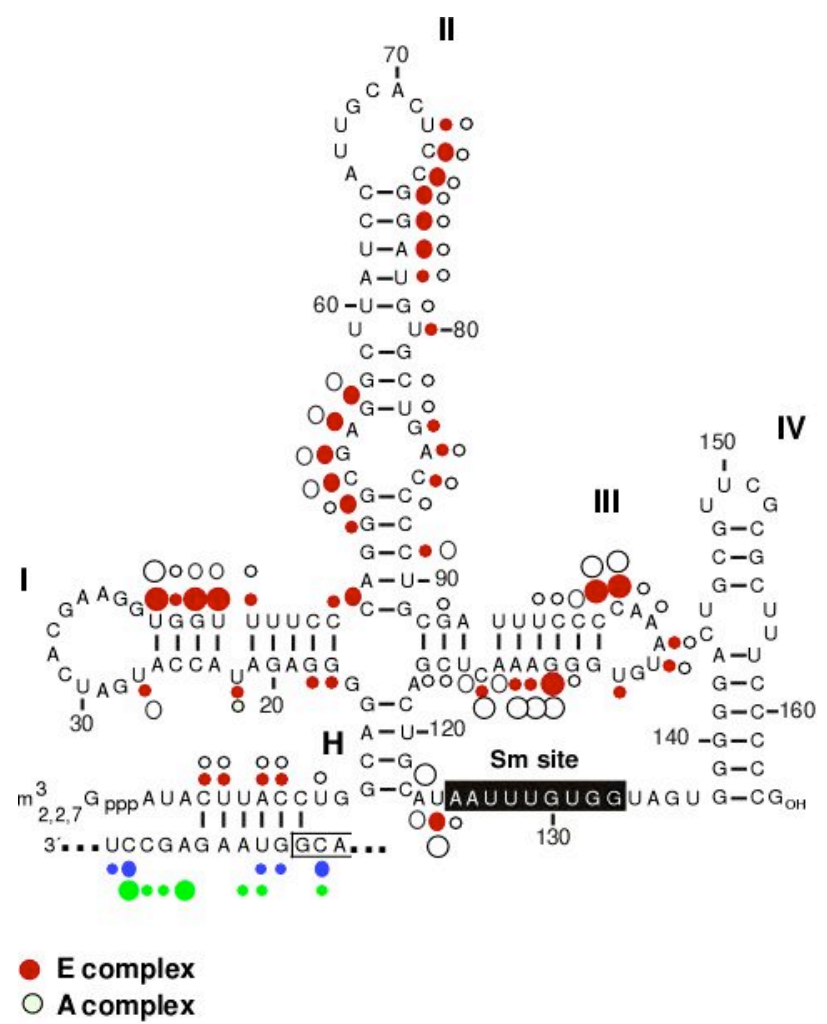

Figure 4-22A: Secondary structure of the human U1 snRNA with summary of Fe-BABE-U2 induced cleavages in the $\mathrm{E}$ and A complex (red and white dots, respectively). The 5' end of U1 is shown base paired with the 5'ss of the MINX pre-mRNA, where cleaved pre-mRNA nucleotides in the E and A complex are indicated by blue and green dots, respectively.

To learn more about the spatial relationship of the U1 and U2 snRNAs, we first mapped those cleavages observed in the E complex onto the protein-free, $3 \mathrm{D}$ model proposed for the human U1 snRNA (Krol et al., 1990) which was later supported experimentally (Duckett et al., 1995) (Fig. 4-22B). This model posits a four-way junction with coaxial stacking of helices I and II, and helices H and III. Significantly, nearly all cleavages are located on one side of each of the coaxial helices and these sides face in the same direction. Thus, the cleaved nucleotides are oriented such that they could face a single point source of hydroxyl radicals, consistent with the idea that the 5 ' end of U2 is located on one side of the U1 snRNA. 


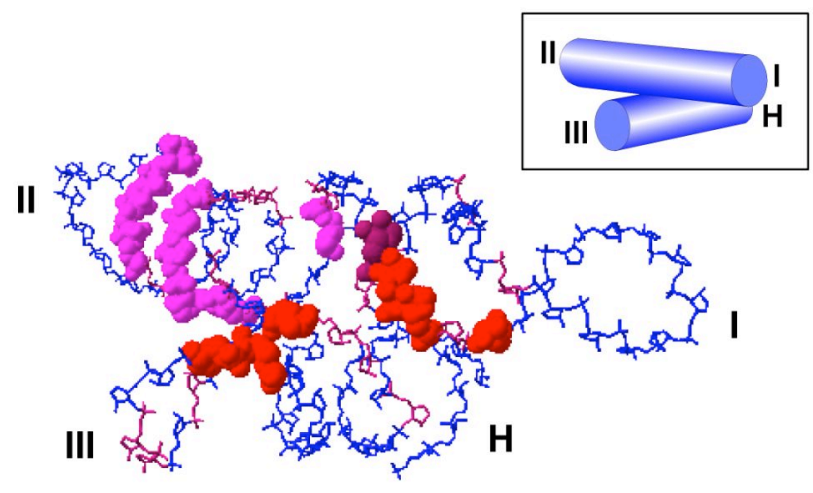

Figure 4-22B: 3D structure model of the human U1 snRNA (Krol et al., 1990), where uncleaved (blue) and weakly cleaved (red) nucleotides are modeled as sticks, and strongly and moderately cleaved nucleotides detected in the E complex, as space filling entities. Strongly and moderately cleaved nucleotides are highlighted red and pink, respectively. Inset, the stacking scheme of RNA double helices in the four-way junction, with stems I, II, III, and the 5'-3' connecting helix H.

We next extended our analysis to the proposed 3D structure of the human U1 snRNP (Stark et al., 2001) (Fig. 4-23), which is based not only on the single particle cryo-EM 3D reconstruction of the native U1 snRNP, but also incorporates all biochemical and additional structural information that was available at that time including the U1 snRNA helical stacking model. The classical "frontal" view of the U1 model is shown at the left of Fig. 4-23A, where the position of the Sm protein ring (highlighted green) and other U1 snRNP proteins (e.g., U1-70K and U1-A) are indicated, together with the U1 snRNA (dark blue). To accommodate the U1 snRNA model into the 3D density map of the U1 snRNP obtained by cryo-EM, the stem I/II coaxial stacking helix was bent upward into a crescent and stem III was tilted toward stem II (Stark et al., 2001). A "back-top" view of the U1 snRNP, looking at stem-loops I, II and III, is shown on the right; due to the inability to precisely locate the $5^{\prime}$ end of U1, note that this part of the snRNA was not included in the model. 
When we map our cleavage data onto the slightly modified RNA structure in the U1 snRNP model, cleaved nucleotides are still found on one side of the RNA at the "back" of the U1 snRNP and, moreover, the cleaved regions are brought even closer together (Fig. 4-23B, red and pink patches). Uncleaved nucleotides are mostly on the opposite side of the U1 snRNP. These data indicate that the U2 snRNP interaction domain is located predominantly at the "back" of the U1 snRNP and, furthermore, support the apparent structure/position of the U1 snRNA in the U1 snRNP 3D model. The largest distance between strong and medium cleavages, those on the coaxial stems I/II, still spans some $50 \AA$. Thus, the $5^{\prime}$ end of the U2 snRNA must indeed be very close to the U1 snRNP (presumably at an approximately equal distance from the most strongly cleaved nucleotides), considering a migration distance of hydroxyl radicals $(\sim 20 \AA)$ and the length of the spacer arm $(\sim 10 \AA)$.

Electron microscopy immuno-localization studies previously indicated that the $\mathrm{m}_{3} \mathrm{G}$ cap of U1 (and thus its $5^{\prime}$ end) are positioned somewhere in the lower right hand region of the particle as depicted in Fig 4-23B (Kastner et al., 1992). However, as there was not enough biochemical and stuctural information to place it on a particular "side" of the U1 particle, this portion of the U1 snRNA was not included in the original U1 snRNP 3D model (Stark et al., 2001). The detection of hydroxyl radical cleavages at the 5 ' end of the U1 snRNA suggests that this functionally important region is also positioned on the same side of the U1 snRNP as the other cleaved nucleotides. Furthermore, our data also are consistent with the formation of a based paired U1/5'ss helix. That is, when cleaved nucleotides at the pre-mRNA's 5' splice site and those in the 5' splice site interacting region of $\mathrm{U} 1$ are mapped onto a double-stranded RNA helix, cleaved nucleotides of both RNA species could potentially be hit by a single point source of hydroxyl radicals. In summary, our data show for the first time that as early as in the E complex, the U2 and U1 snRNPs are in close proximity and in a defined orientation relative to one another. 
A

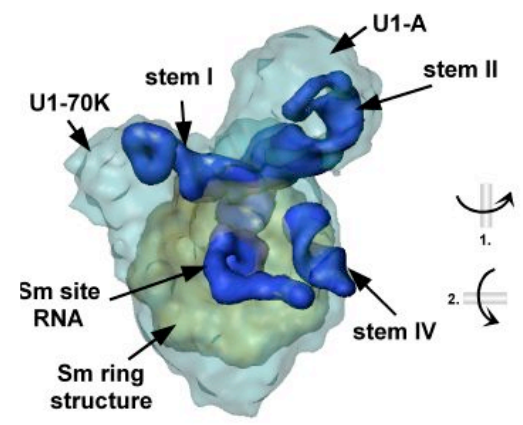

front view

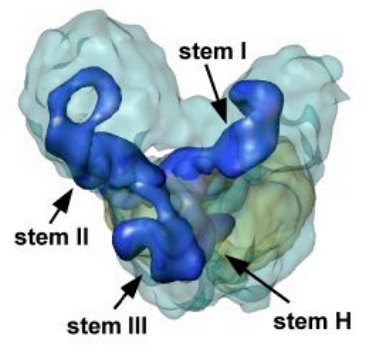

back-top view

B

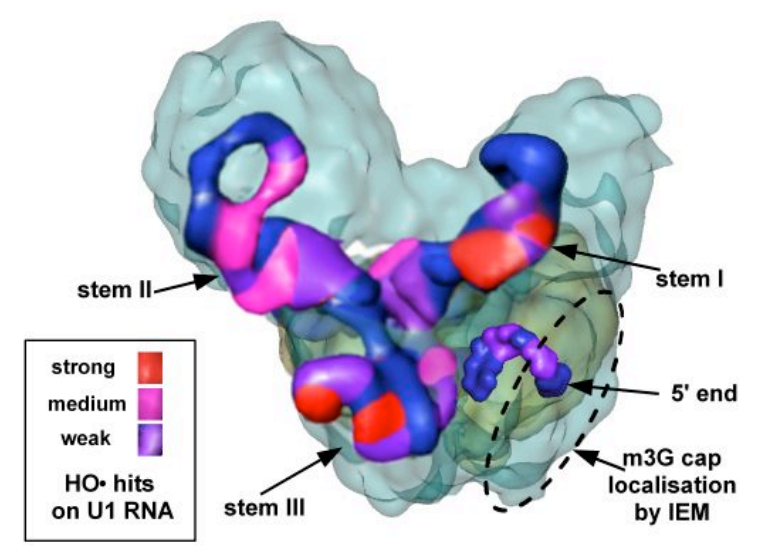

Figure 4-23: Mapping of the U1 hydroxyl radical cleavages observed in the E complex, onto the U1 snRNA in the U1 snRNP 3D model. A. 3D model of the U1 snRNP (Stark et al., 2001) is shown. The classical "frontal" view is shown on the left and a "back-top" view is shown on the right. B. The U1 hydroxyl radical cleavages observed in the E complex are mapped onto the U1 snRNA in the U1 snRNP 3D model. The dashed line indicates the region where the $5^{\prime}$ end of U1 should be located based on immuno-EM studies with anti- $\mathrm{m}_{3} \mathrm{G}$ antibodies. The $5^{\prime}$ end of $\mathrm{U} 1$ is placed arbitrarily in this region. 


\subsubsection{Densitometric analysis of the hydroxyl radical probing experiments}

The quantifications were performed with the Quantity One program (see 3.2.1.10.2). In all of the quantification graphs below, $+\mathrm{BABE}+\mathrm{H}_{2} \mathrm{O}_{2},-\mathrm{BABE}-\mathrm{H}_{2} \mathrm{O}_{2}$, and the difference between $+\mathrm{BABE}+\mathrm{H}_{2} \mathrm{O}_{2}$ and $-\mathrm{BABE}-\mathrm{H}_{2} \mathrm{O}_{2}$ are shown with blue, green and red, respectively.

\section{Quantification for Fig. 4-19A (the $3^{\prime}$ half of the pre-mRNA)}

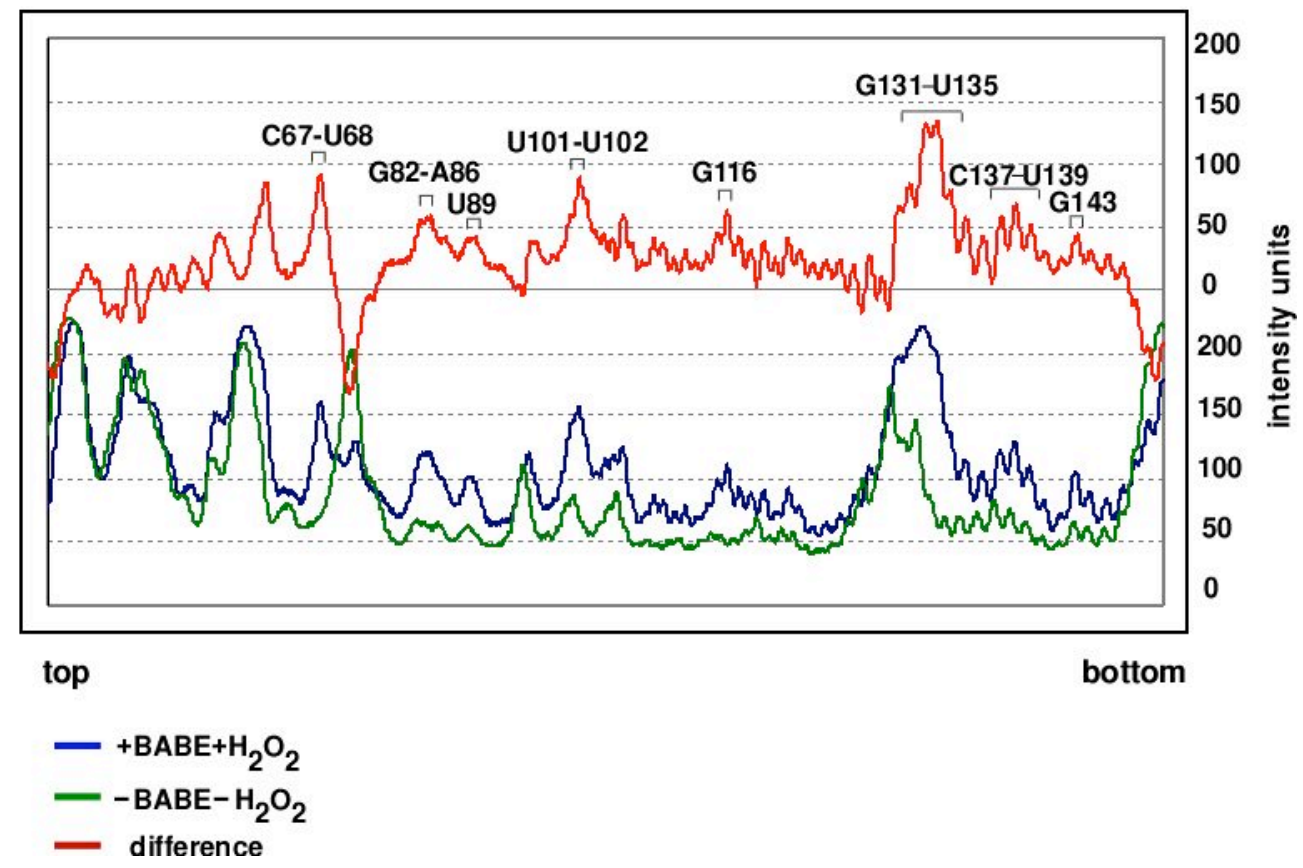


Quantification for Fig. 4-19A (the polypyrimidine tract of pre-mRNA, nts 159-183)

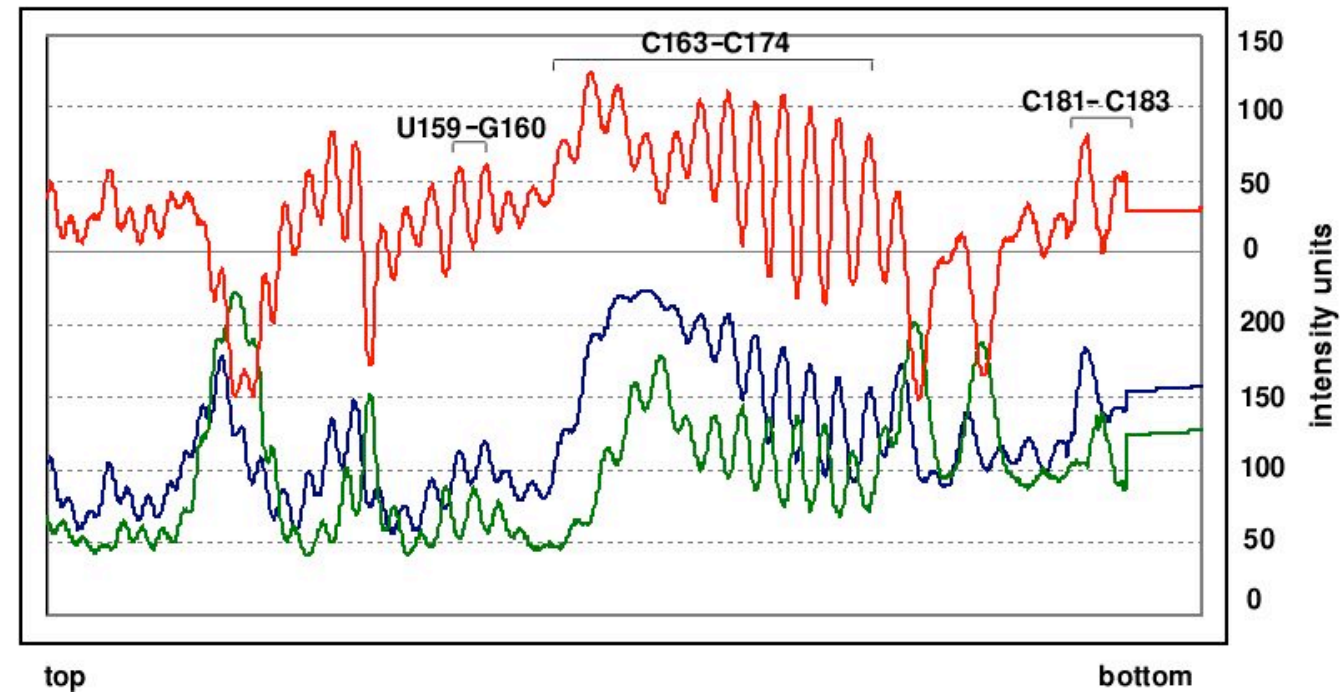

Quantification for Fig. 4-19B (the $5^{\prime}$ half of the pre-mRNA)

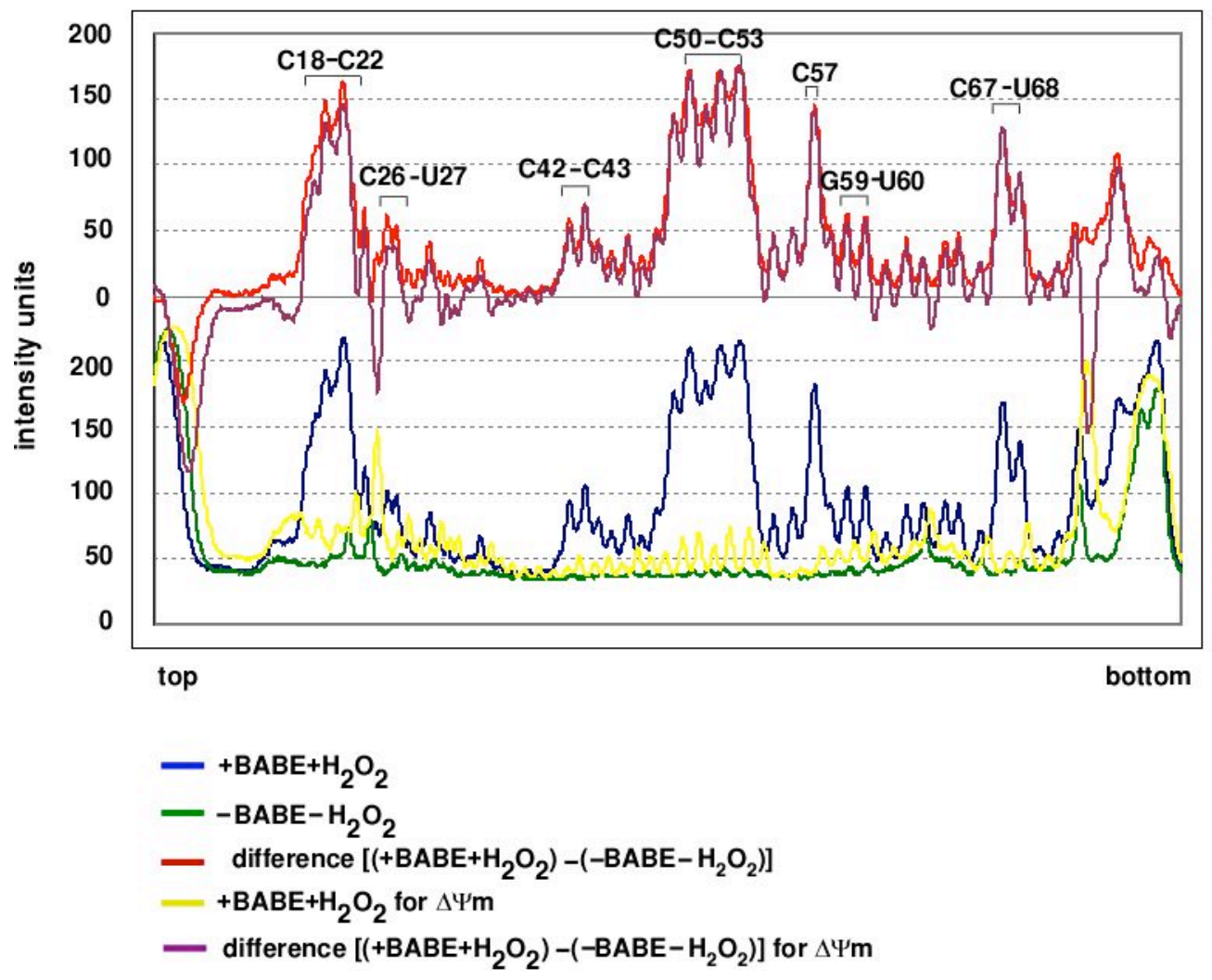


Quantification for Fig. 4-20A (the $3^{\prime}$ half of the pre-mRNA)

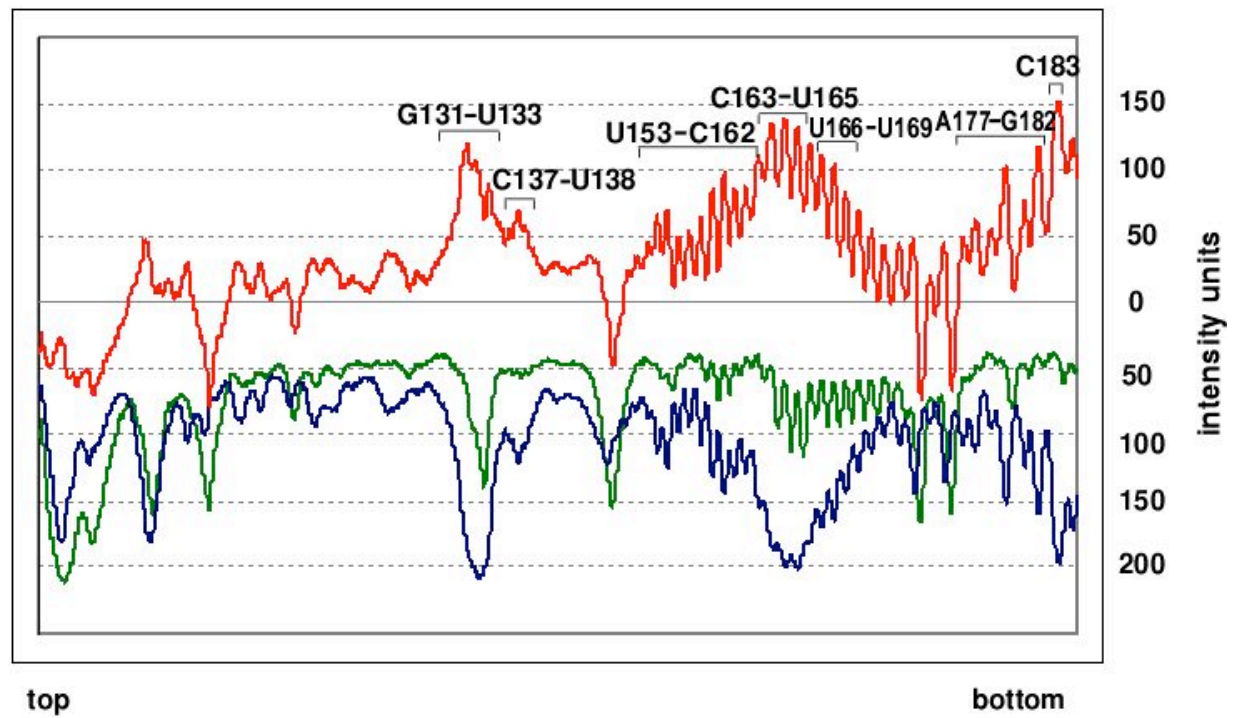

Quantification for Fig. 4-20B (the 5' half of the pre-mRNA)

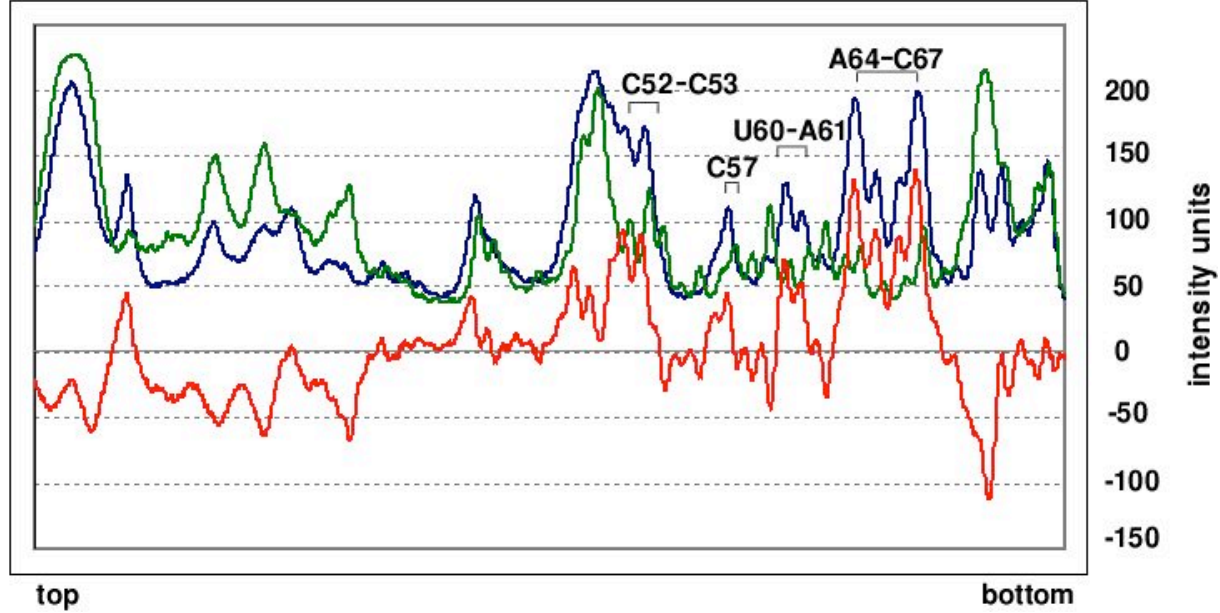


Quantification for Fig. 4-21A, left panel, lanes 1-4 (the first 50 nucleotides of U1 SnRNA)

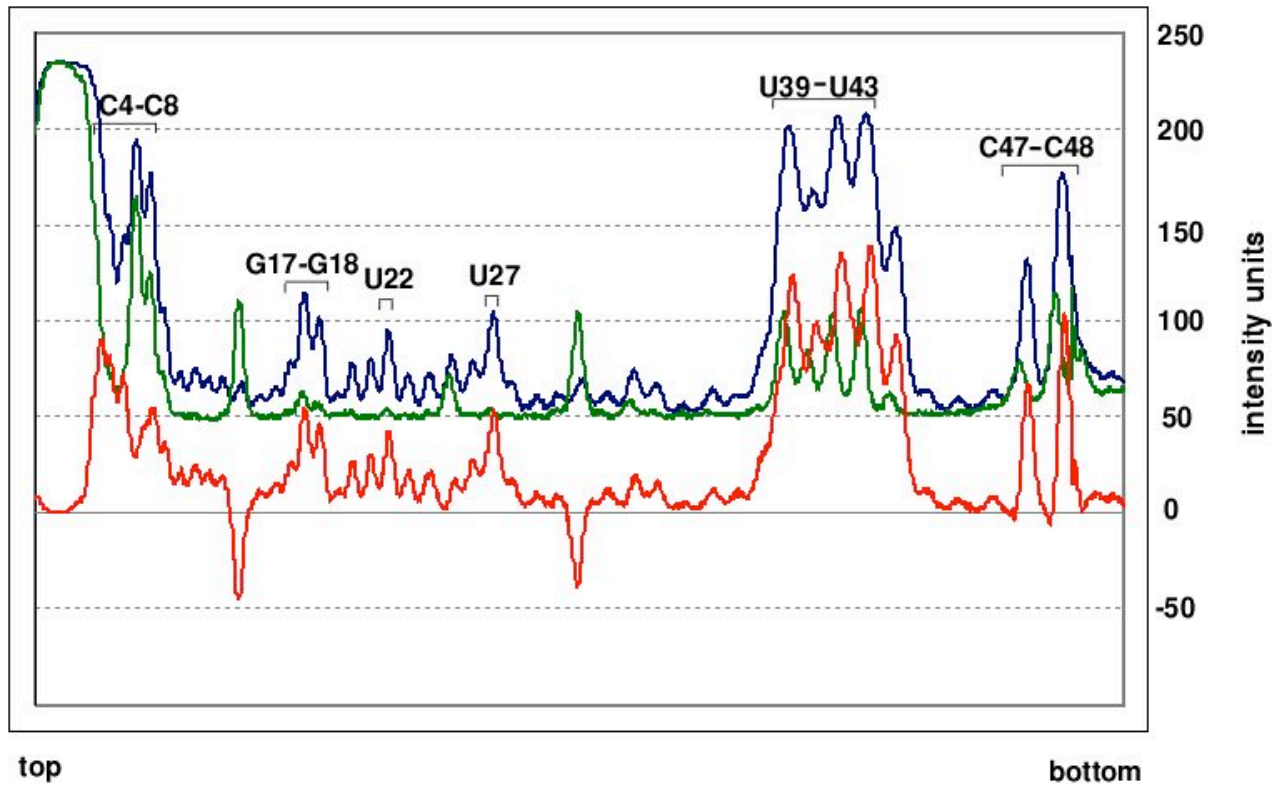

Quantification for Fig. 4-21A, right panel, lanes 5-8 (the first 50 nucleotides of U1 SnRNA)

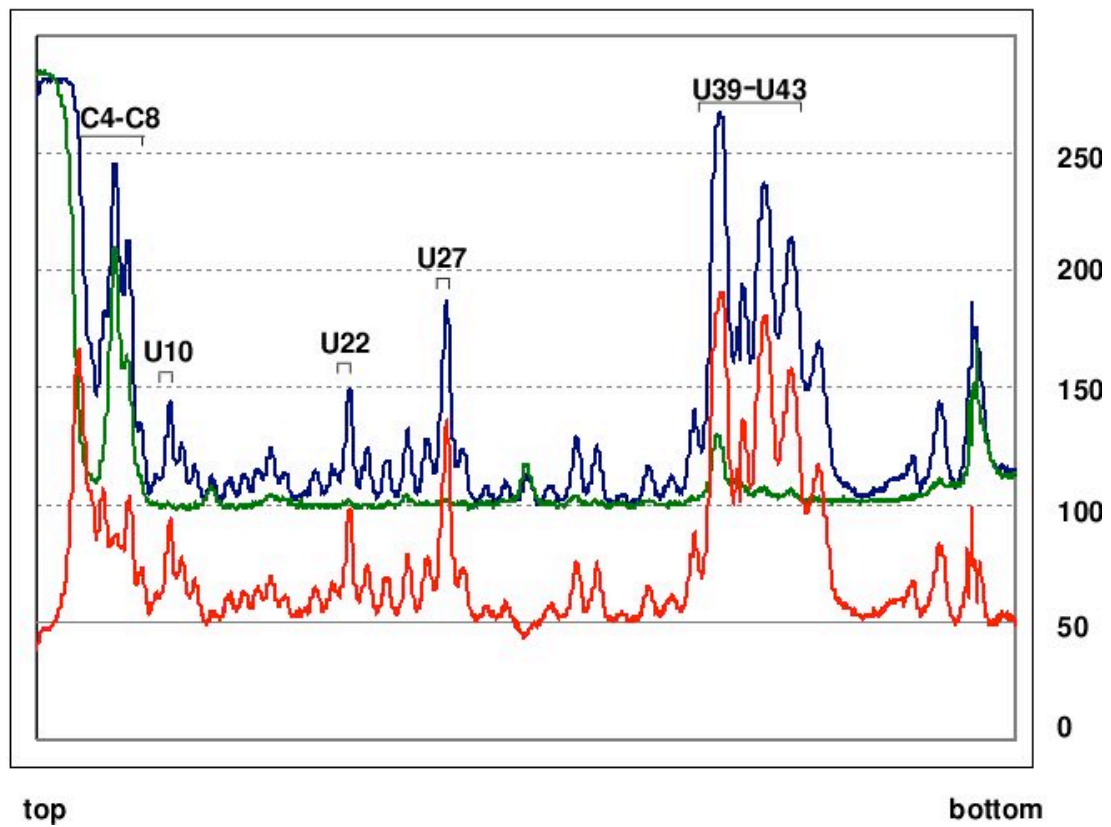


Quantification for Fig. 4-21A, left panel, lanes 1-4 (between nucleotides 50-58 of U1 SnRNA)

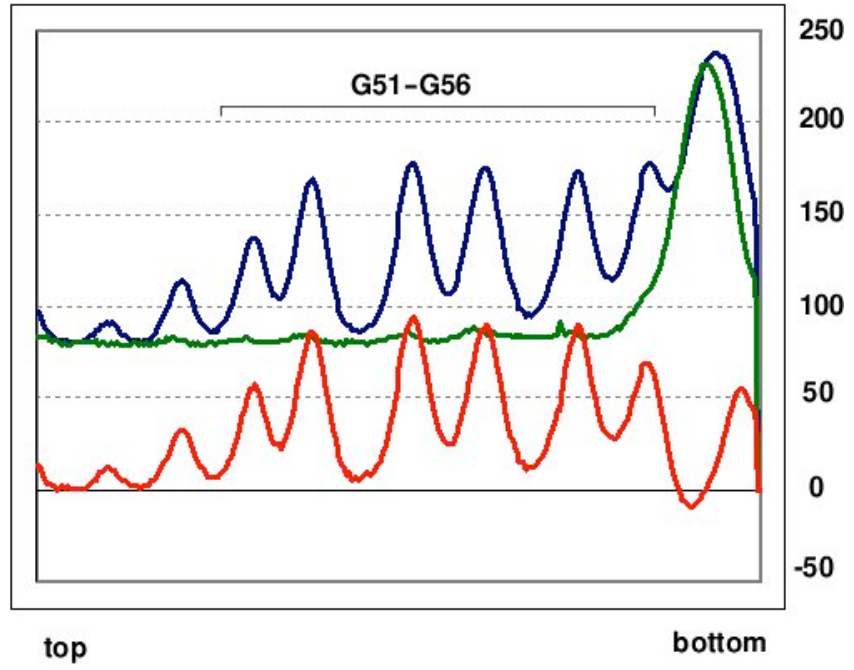

Quantification for Fig. 4-21A, right panel, lanes 5-8 (between nucleotides 50-58 of U1 snRNA)

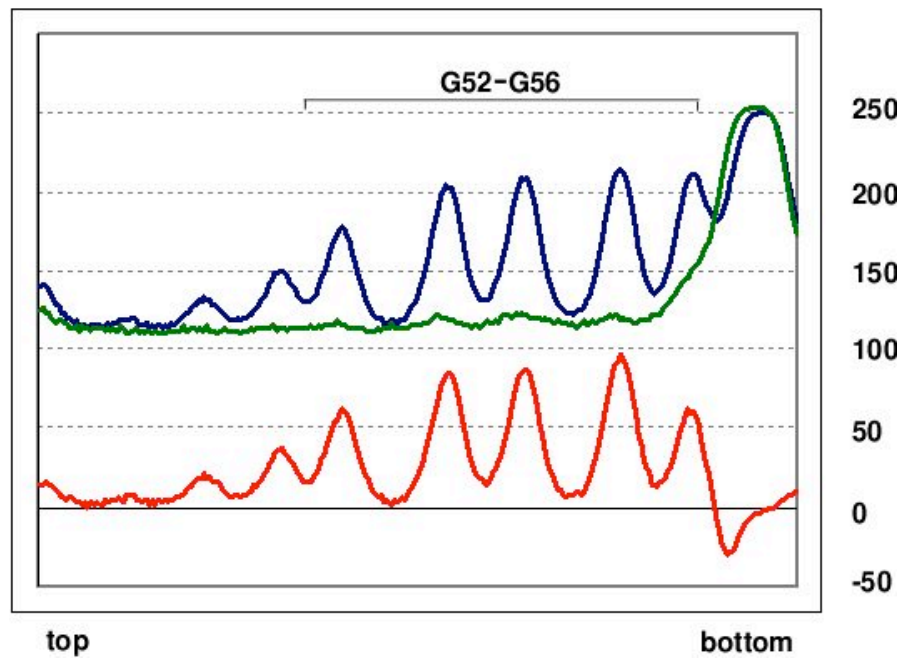


Quantification for Fig. 4-21B, left panel, lanes 1-4 (between nucleotides 58-87 of U1 SnRNA)

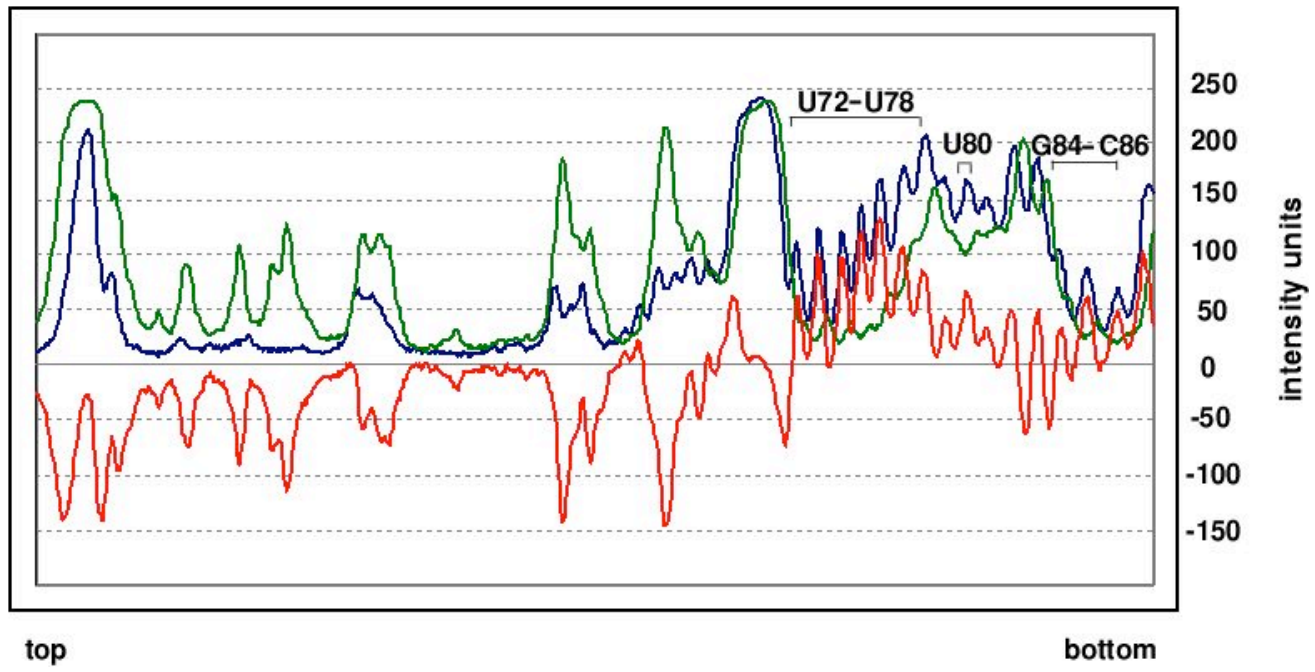

Quantification for Fig. 4-21B, right panel, lanes 5-8 (between nucleotides 58-87 of U1 snRNA)

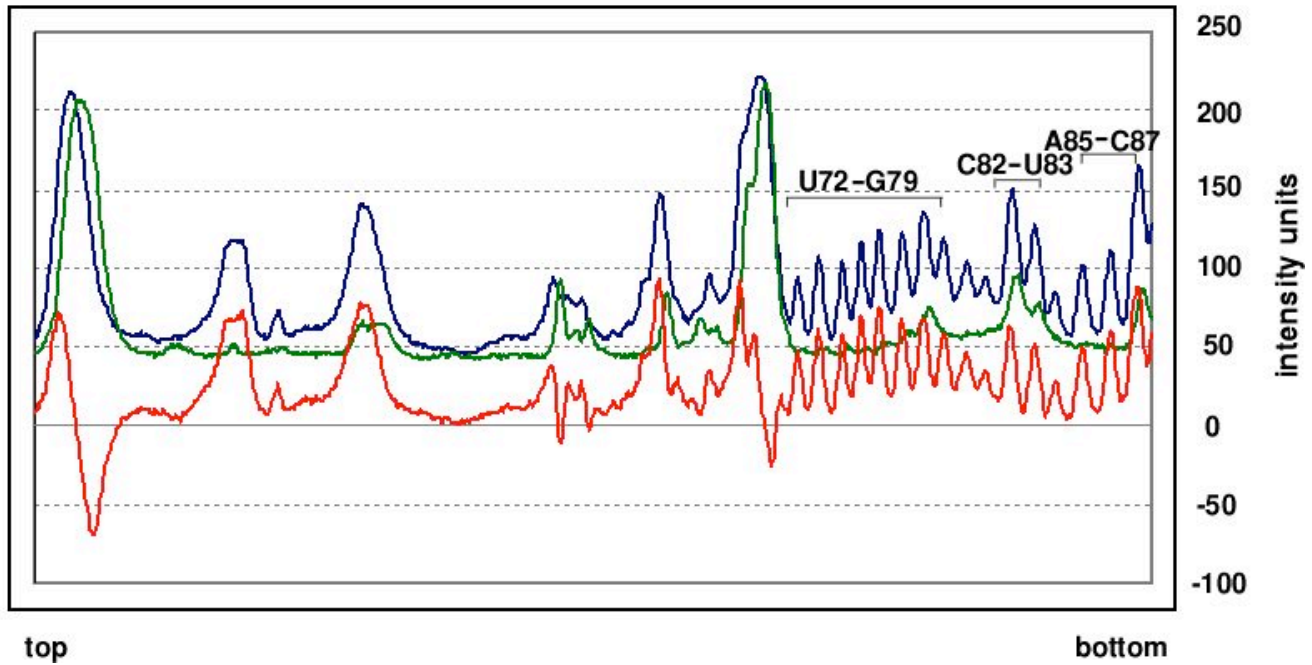


Quantification for Fig. 4-21C, left panel, lanes 1-4 (between nucleotides 88-126 of U1 SnRNA)

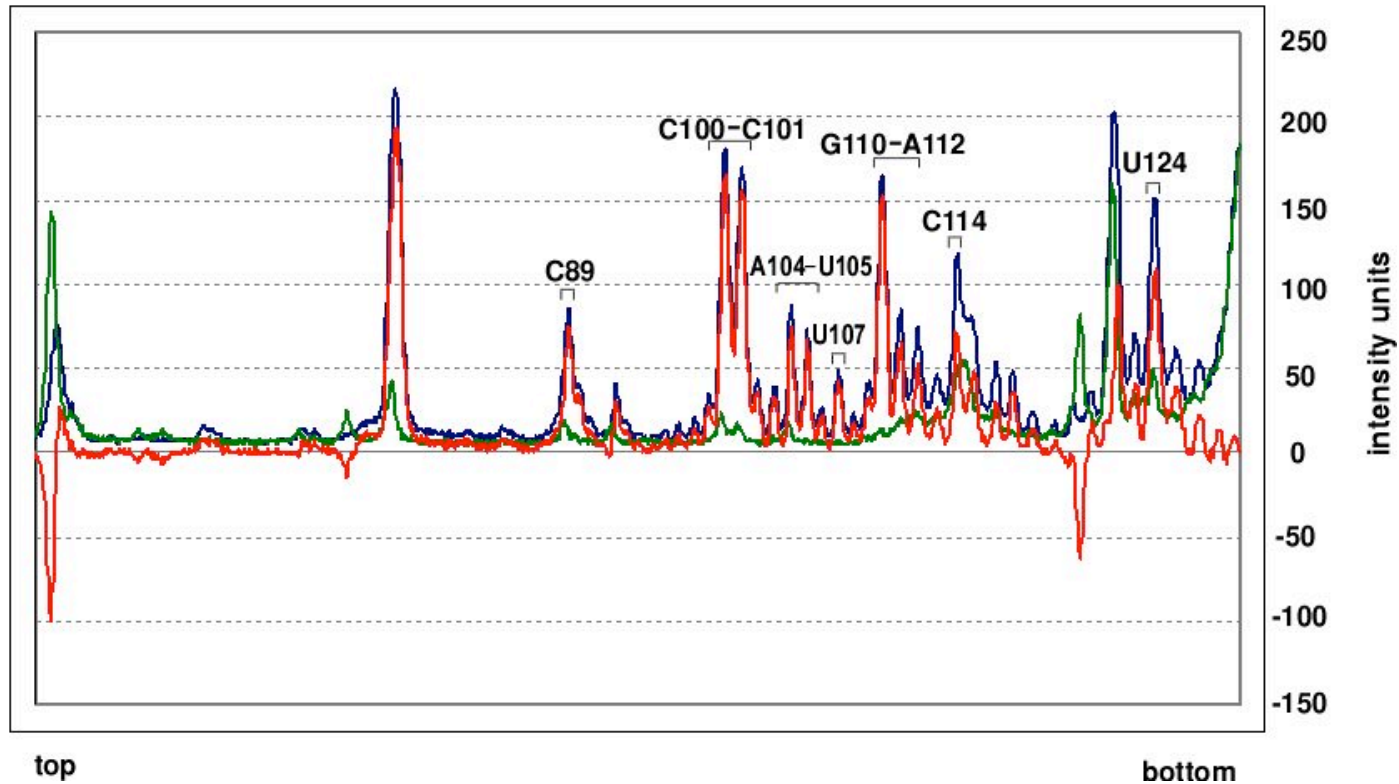

Quantification for Fig. 4-21C, right panel, lanes 5-8 (between nucleotides 88-126 of $\underline{\text { U1 snRNA) }}$

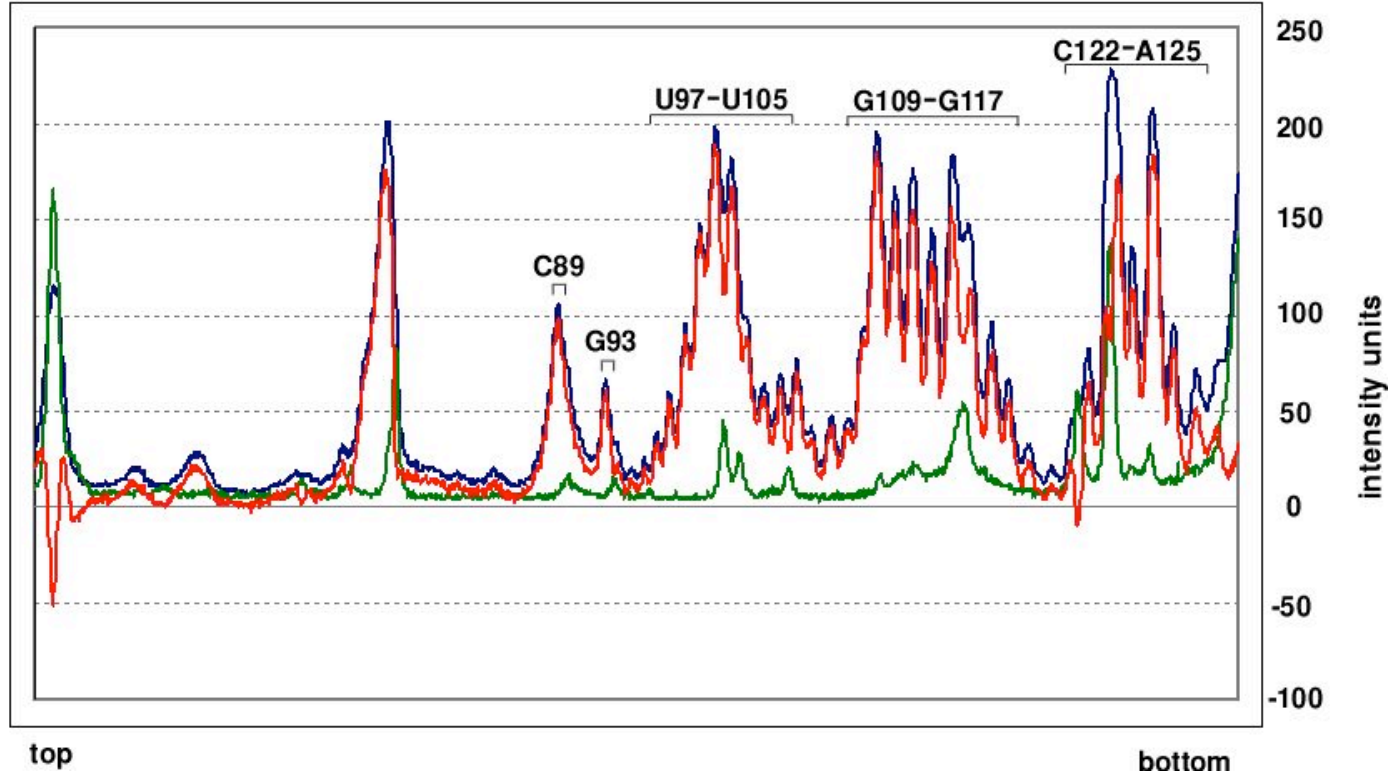




\section{DISCUSSION}

In this work, the molecular mechanisms of splice site pairing, the cross-intron communication of the intron ends and the spatial organization of the early spliceosomal complexes have been studied. The organization of the U2 snRNP relative to the functional sites of the pre-mRNA and U1 in early spliceosomal complexes (E and A) was investigated by analyzing the RNA proximities of $\mathrm{U} 2$ with respect to the pre-mRNA and U1. Therefore, the site-directed hydroxyl radical probing method was used where the hydroxyl radical probe Fe-BABE was attached to U2 snRNA. For this purpose, we have established the two-step reconstitution/complementation system where the endogeneous U2 was depleted and the in vitro reconstituted U2 was provided to the system. U2 is the only snRNA of which internal modifications (pseudouridines and 2'-O-methylations) are required for splicing. In order to reconstitute functional Fe-BABE modified U2 snRNPs in vitro, we investigated the role and requirement of modifications of U2 snRNAs in the first part of this thesis work. The three pseudourines and five 2'-O-methylations but not the $\mathrm{m}_{3} \mathrm{G}$ cap were found to be required for E complex formation and splicing. The results of the first part facilitated the study performed in the second part.

In the second part, the chimaeric U2 RNAs containing required modifications and the Fe$\mathrm{BABE}$ at the $5^{\prime}$ end (since $\mathrm{m}_{3} \mathrm{G}$ cap is not essential for splicing) were generated and used in in vitro reconstitution system. By site-directed hydroxyl radical probing, it was shown that the polypyrimidine tract/3' ss, anchoring site, $5^{\prime}$ ss and $5^{\prime}$ exon of the pre-mRNA and U1 snRNA are in close proximity to the functionally important 5' end of U2 and also to one another already in E complex. Similar cleavage patters were observed in A complex indicating that the spatial organization of $\mathrm{U} 1$ relative to $\mathrm{U} 2$ remains largely unchanged during A complex formation. Mapping of U1 snRNA cleavages onto the U1 snRNA and $\mathrm{U} 1$ snRNP 3D structures revealed a distinct orientation of $\mathrm{U} 2$ relative to $\mathrm{U} 1$ already in $\mathrm{E}$ complex. According to this data, the 5' end of U1 RNA could also be placed on the U1 snRNP 3D structure. 


\subsection{Internal modifications of U2 snRNA}

\subsubsection{The three pseudouridines and five 2'-O-methylations at the $5^{\prime}$ end of U2 snRNA are required for $\mathbf{E}$ complex formation and splicing in vitro}

In this work, it is shown that efficient pre-mRNA splicing in vitro is dependent on the three pseudouridines and the five 2'-O-methyl groups within the first 24 nucleotides of $\mathrm{U} 2$ snRNA. In contrast, neither the $\mathrm{m}_{3} \mathrm{G}$ cap nor internal modifications downstream of the nucleotide A24 are required. Moreover, it is shown here that the internal modifications at the 5 ' end of U2 snRNA are not required for 17S U2 snRNP formation in vitro (see also 5.1.5). Strikingly, all internal modifications required for splicing are also demonstrated to be essential for the ATP-independent formation of spliceosomal E complexes. The data thus corroborate previous observations, indicating that U2 snRNP is functionally associated with the pre-mRNA already in the E complex (Das et al., 2000), and show for the first time that internal modifications within the first 24 nucleotides of U2 snRNA are required for this functional interaction.

Our analysis of the contribution of individual modifications to splicing allowed us to clearly distinguish between the effects of pseudouridines and 2'-O-methylations. When individual pseudouridines at positions 6,7 and 15 of U2 snRNA were replaced by uridines, residual E complex formation and splicing was observed. However, substitution of all pseudouridines by uridines resulted in a complete loss of splicing and $\mathrm{E}$ complex formation (Fig. 4-8 and 4-10B). These results thus provide evidence for a cumulative effect of pseudouridines on E complex formation and splicing. In contrast, four out of the five 2'-O-methylations within the 5'-terminal 24 nucleotides of U2 snRNA were absolutely required for E complex formation and splicing; only deletion of the 2'-Omethyl at G10 was not completely detrimental to splicing (Fig. 4-8 and 4-10).

The results obtained in this study with U2 snRNPs reconstituted in HeLa nuclear extract are different from those observed with Xenopus oocytes (Yu et al., 1998) where the 
pseudouridines were found to be required for the assembly of a 17S U2 snRNP particle. In a following study, they suggested a role for the pseudouridines in and near the branchsite recognition region of the $\mathrm{U} 2$ snRNA for $\mathrm{U} 2$ in splicing and U2 assembly in Xenopus oocytes (Zhou and Yu, 2004). However, it is shown here that a U2 transcript which lacks all the modifications could support the formation of a 17S U2 snRNP successfully and the modifications are required at the stage of integration of U2 snRNP into the E complex. This difference could be due to species-specific differences. There may be some modifications which are absolutely essential for some species and are not essential for others. In addition, there could be differential requirements for the assembly of $17 \mathrm{~S} \mathrm{U} 2 \mathrm{snRNP}$ in vivo versus in vitro.

It was shown by NMR studies that the pseudouridine in U2 snRNA nearly opposite the branch site in $S$. cerevisiae induces a dramatically altered architectural landscape compared with that of its unmodified counterpart (Newby and Greenbaum, 2001; Newby and Greenbaum, 2002). They proposed that the $\Psi$-induced structure places the nucleophile in an accessible position for the first step of splicing. Interestingly, yeast can survive without this particular pseudouridine in its U2 snRNA (Behm-Ansmant et al., 2003; Ma et al., 2003). Biochemical and NMR analyses showed that there is no evidence for improved binding affinity or specificity of p14 or p14-SF3b155 complex for a branchpoint helix containing a pseudouridine-modified human U2 snRNA (Spadaccini et al., 2006). This indicates that there is no specific recognition of a bulged-out branchpoint adenosine. This is in consistent with our finding that the pseudouridines within the branchpoint recognition region of $\mathrm{U} 2$ snRNA are not required for $\mathrm{U} 2$ function in splicing.

Our finding that as many as eight modifications within a short stretch of 24 nucleotides of U2 snRNA are either essential or contribute significantly to $\mathrm{U} 2$ function is quite surprising considering that post-transcriptional modifications in many RNA molecules often have no significant effect on their function, at least not when tested in vitro (for review see Charette and Gray, 2000). Some cases, where modifications have been documented to be required for RNA function are known, however. For example, posttranscriptional modifications in the primer $\mathrm{RNA}_{3}^{\mathrm{Lys}}$ are required for initiation and 
elongation of HIV1 reverse transcription (Isel et al., 1993). While it is thought that the initiation of the reverse transcriptase with the priming complex is affected (Isel et al., 1996), the contribution of individual modified residues of $\mathrm{tRNA}_{3}{ }^{\mathrm{Lys}}$ to the functional interaction with the reverse transcriptase remains to be investigated. Another example is the selective translational activation of stored maternal mRNAs during early maturation of Xenopus oocytes. Here 2'-O-methylation of the first two bases, i.e. the synthesis of a cap II structure on dormant maternal mRNAs, was shown to be required for translational activation (Kuge et al., 1998; Kuge and Richter, 1995). The exact function of the two methyl groups in this activation process is not yet understood. Finally, modified nucleotides that are clustered in the peptidyl transferase center of the $23 \mathrm{~S}$ and $28 \mathrm{~S}$ rRNAs of the large subunits of $E$. coli and yeast ribosomes, respectively, also appear to be required for efficient translational activity of the ribosome (Green and Noller, 1996; King et al., 2003). The effects of individual modified residues appear to be primarily cumulative ones; only a single pseudouridine residue in the peptidyltransferase center of yeast 28S rRNA was found to contribute substantially on its own to translational efficiency (King et al., 2003).

\subsubsection{The $\mathrm{m}_{3} \mathrm{G}$ cap is not required for $\mathrm{U} 2$ function in splicing}

Data presented here regarding the function of the U2 snRNA's $5^{\prime} \mathrm{m}_{3} \mathrm{G}$-cap, indicates that the cap does not play a differential role in the function/assembly of the major spliceosomal U snRNAs (i.e., U1, U2, U4, and U5). In all cases, the cap is dispensable for their activity in splicing and also for their assembly in vitro (see Introduction). We note that the results obtained with U2 snRNPs reconstituted in HeLa nuclear extract, differ somewhat from those observed with Xenopus oocytes (Yu et al., 1998; Zhou and $\mathrm{Yu}, 2004)$. In the latter experiments, to some extent the $\mathrm{m}_{3} \mathrm{G}$ cap structure, was found to be critical for the assembly in the nucleus of a stable 17S U2 snRNP particle. This could either be due to species-specific differences or to differential requirements of $17 \mathrm{~S}$ U2 snRNP assembly in vivo versus in vitro. 


\subsubsection{The modifications are not required for the association of $17 \mathrm{~S} \mathrm{U} 2$-specific proteins}

Glycerol gradient centrifugation and immunoprecipitation showed that functional 17S U2 snRNP could be reconstituted from in vitro transcribed U2 RNAs which contain none of the modifications. Both fully modified and unmodified U2 snRNAs were precipitated with anti-Sm and anti-B" antibodies, indicating that 12S U2 snRNP formation does not depend on modifications. Both RNAs were precipitated by SF3a66 and SF3b155 antibodies. Since SF3a66 and SF3b155 are components of highly stable SF3a and SF3b protein complexes, respectively, it is highly likely that all subunits of SF3a and SF3b are present. Furthermore, both Hela U2 snRNA and U2 transcript were precipitated with antibodies against SPF30/SMNrp, SPF31 and hPrp5 indicating that U2 snRNA modifications are not required for the formation of intact 17S U2 snRNPs.

It was reported that the SF3b49 protein crosslinked to the nucleotides Am1 and Um2 of U2 snRNA in native 17S U2 snRNP particles (Dybkov et al., 2006). SF3b49 also crosslinked to these nucleotides A1 and U2 when they lack the 2'-O-methyl groups indicating that the modifications of $\mathrm{U} 2$ are not required for the interaction of the SF3b proteins with U2 snRNA during 17S U2 snRNP assembly. This is consisitent with our finding that the U2 transcript lacking all the modifications can successfully form the $17 \mathrm{~S}$ U2 snRNP.

All these findings indicate that the modifications are not required for the association of 17S U2-specific proteins. However, there may be more subtle RNA-protein interactions which were not discovered yet. The modifications may be required for the stability or the conformation of RNA rather than its direct interaction with the proteins. 


\subsubsection{The role of modifications in $\mathbf{E}$ complex formation and splicing}

Why might pseudouridines and 2'-O-methylations in the 5'-terminal region of U2 snRNA be required for $\mathrm{U} 2$ snRNP function in E complex formation and splicing? One of the few well-established roles of pseudouridine is that it stabilizes the conformation of RNA by base stacking, with an approximately additive effect on stability when multiple pseudouridines are present (Meroueh et al., 2000), and by coordinating a structural water molecule between its additional hydrogen bond donor at $\mathrm{N} 1-\mathrm{H}$ and the phosphate backbone (Arnez and Steitz, 1994). Similarly, 2'-O-methylation is a powerful biological means to stabilize an RNA helix (for review see Horvath et al., 1998). Thus, one explanation would be that both requirements are a reflection of the necessity for a stabilized U2 5' stem loop structure during E complex formation.

An NMR study which compares the structures of the conserved U2 snRNA stem I domains from yeast and human showed that stability, rather than structure, is a factor of divergence of wobble pair identity and the presence of nucleotide modifications (Dipali Sashital and Samuel Butcher, personal communication). This may suggest that the modifications in the $5^{\prime}$ end of U2 snRNA are required for the stability of the U2 $5^{\prime}$ stem loop during U2 snRNP's integration to the E complex.

It was shown recently that pseudouridine substitution revealed a requirement for backbone flexibility at a particular position within the U7 Sm site, providing in vivo biochemical evidence that an unusual $\mathrm{C}^{\prime}$-endo conformation is necessary for assembly of the Sm ring (Kolev and Steitz, 2006). This shows that the backbone conformation of a particular nucleotide is crucial for the in vivo assembly of an RNA-protein complex. More generally, this provides support for the idea that the evolutionary pressure that maintains pseudouridine modifications at conserved positions within many important cellular RNAs (including snRNAs, rRNAs, tRNAs) reflects a requirement -either during assembly or functioning- for rigidity of the sugar-phosphate backbone at certain sites. This also indicates that the pseudouridines in snRNAs may be required to obtain the 
rigidity of the backbone at certain positions which could be crucial for assembly or interaction with other snRNAs or spliceosomal proteins.

In addition to stabilizing RNA structure, modifications could also play a role in RNAprotein interactions and thus in this way be of functional importance for either U2 snRNP structure or E complex assembly. However, several observations do not support a structural role for modifications in the architecture of U2 snRNP. First, modifications were not required for in vitro assembly of a 17S U2 snRNP particle, and their absence had no detectable effect on the association pattern of most U2 snRNP specific proteins with the U2 snRNA, as evidenced by immunoprecipitation analyses (Fig. 4-11). Second, although a number of protein-RNA crosslinks between U2-specific proteins and the $5^{\prime}$ region of U2 snRNA in purified HeLa 17S U2 snRNPs were observed, these crosslinks were not found to be dependent on the presence of modifications when U2 snRNPs were reconstituted in our two-step in vitro system (Dybkov et al., 2006). While these arguments are not decisive and we cannot rigorously exclude the possibility that U2 snRNA modifications play a role in fine tuning RNA-protein interactions within the $17 \mathrm{~S}$ U2 snRNP, the idea that modified nucleotides contribute functionally first at the time of E complex formation is favoured. It is therefore interesting to investigate how U2 snRNP communicates with U1 snRNP and/or other essential factors in the E complex and whether 5'-terminal U2 modifications facilitate RNA-RNA or protein-RNA interactions between U2 snRNP and other E complex components which is partly the second part of this work. These interactions could also involve components of the U4/U6.U5 tri-snRNP complex, as the latter has been reported to contribute to recognition of the 5 ' splice site at an early step of spliceosome assembly in an ATP-dependent manner (Maroney et al., 2000). 


\subsection{Hydroxyl radical probing in $E$ and A complexes}

Having established the in vitro reconstitution of a functional U2 snRNP containing the required modifications paved the way for analyzing the spatial organization of the U2 snRNP relative to the pre-mRNA and $\mathrm{U} 1$ in spliceosomal $\mathrm{E}$ and A complexes and understanding the mechanisms of splice site pairing. The fact that the $\mathrm{m}_{3} \mathrm{G}$ cap of $\mathrm{U} 2$ snRNA is not required for $\mathrm{U} 2$ function in splicing allowed us to attach the Fe-BABE to the 5 ' end of U2 snRNA for site-directed hydroxyl radical probing. Additionally, the 5' end of U2 snRNA is functionally important while during the catalytic activation of the spliceosome, the U6 snRNA engages in base pairing interactions with the 5 ' end of the U2 snRNA, and the resulting U2/U6 snRNA structure is thought to form the catalytic center of the spliceosome and thus be directly involved in catalysis. After having shown that the Fe-BABE modified U2 snRNP supported splicing, the hydroxyl radical probing in $\mathrm{E}$ and $\mathrm{A}$ complexes were performed.

\subsubsection{Structural aspects of the E complex}

The RNA neighbourhood was examined in early spliceosomal complexes by site-directed hydroxyl radical footprinting with a Fe-BABE probe at the $5^{\prime}$ end of U2 snRNA. In the spliceosomal E complex we find, within close distance, regions of the pre-mRNA of functional importance for the assembly of splicesomes and the splicing reaction per se. This study thus provides a direct evidence for the close spatial association of U2 snRNP with the E complex previously deduced from biochemical evidence (Das et al., 2000) and provide a wealth of detailed information regarding the structural organization of the $E$ complex.

Of the regions of the pre-mRNA hit by hydroxyl radicals, the polypyrimidine tract and the extreme $3^{\prime}$ end of exon 1 are among those showing the strongest cleavages (regions R4 and R2, respectively; Fig. 4-19D). They must therefore be exceptionally close to the 5 ' end of U2 snRNA. Previous RNA proximity data obtained by attaching Fe-BABE to the pre-mRNA (Kent and MacMillan, 2002), showed that the nucleotide at position -6 
relative to the branchpoint, and also the $3^{\prime}$ splice site, are near the $5^{\prime}$ end of the intron (including the 5' splice site), already in the E complex. These data thus indicated that the pre-mRNA's functional sites (i.e., the 5' splice site, BPS, and 3' splice site) are spatially pre-organized in the E complex. Consistent with these results, our data demonstrate that nucleotides immediately bordering these functional sites are in close proximity. Thus, they further delineate additional constraints on the relative orientation of these RNA elements in the E complex.

To confirm that the observed cleavages are due solely to the presence of E complexes and not other spliceosomal complexes, we performed hydroxyl radical probing with MINX pre-mRNA lacking the branchpoint sequence (BPS), which can undergo E complex, but not A complex formation (Das et al, 2000). Significantly, an essentially identical cleavage pattern was observed with this mutant (data not shown) indicating that the observed cleavages are due to E complexes but no other complex.

It is shown in this study that the cleavages on pre-mRNA in E complex are dependent on the 5' splice site by using a 5' ss-deleted pre-mRNA in E complex experiments. There was no E complex forming on native gels indicating that $\mathrm{U} 1$ does not bind to the premRNA in the absence of the $5^{\prime}$ splice site. There were no cleavages on pre-mRNA showing that U2 is not associated (data not shown). This shows that when U1 is not bound, U2 snRNP can not interact with the pre-mRNA. This suggests that it is U1 snRNP which mediates U2 to associate with the pre-mRNA in E complex.

Data presented here firmly place the $5^{\prime}$ end of the U2 snRNA within the 3D space where functional sites of the pre-mRNA are concentrated. Both the $5^{\prime}$ and $3^{\prime}$ splice sites are close to the 5' end of U2 snRNA, as nucleotides neighbouring them are hit by hydroxyl radicals. The same holds for the polypyrimidine tract, which connects the 3 ' splice site and the BPS, and is known to be bound by U2AF65 (Banerjee et al., 2003; Singh et al., 2000; Zamore et al., 1992). Recent data indicate that the U2AF65 interaction leads to bending of the polypyrimidine tract such that the 3' splice site becomes spatially juxtaposed to the branchpoint (Kent et al., 2003). 
The anchoring site, which is an important spliceosome assembly element, is also positioned close to the $5^{\prime}$ end of U2 snRNA already at the stage of E complex formation (Fig. 4-19A and 4-19D). The anchoring site (AS) is contacted in the A complex by a number of U2-associated proteins including SF3a120, SF3a66, SF3a60, SF3b155, SF3b145 and SF3b49, which thereby help to tether the U2 snRNP to the BPS in the A complex (Gozani et al., 1996). Whether these proteins contact the AS in E complexes isolated under mild conditions (i.e. at low salt) has not been investigated; indeed there is generally a paucity of crosslinking data regarding pre-mRNA contacts in E complexes containing the U2 snRNP. Thus, it is not clear whether components of the U2 snRNP directly contact the pre-mRNA at this stage. The 5' end of U2 is positioned very near to a portion of the AS and this spatial organization appears to be relatively fixed, with no major change detected upon formation of the A complex. Interestingly, the very 5 ' end of the U2 snRNA (i.e., positions 1, 2 and 6), is contacted by SF3b49, both in isolated 17S U2 snRNPs and after U2 incorporation into the A complex (Dybkov et al., 2006). In the A complex, SF3b49 has also been shown to contact the AS at a position one nucleotide downstream of G132, the most strongly cleaved nucleotide in this region. Thus it is conceivable that it also plays an important role in juxtapositioning the 5 ' end of U2 near the anchoring site already in the E complex. Alternatively or additionally, U2 may be held in a position near the AS via interaction with U2AF65 bound to the nearby polypyrimidine tract (Gozani et al., 1998). At any rate, our data suggest that the U2 snRNA is poised for its subsequent base pairing interaction with the BPS during A complex formation, already in the E complex.

The uridines in the polypyrimidine tract were hit by hydroxyl radicals indicating that the binding of U2AF65 did not protect the ribose backbone from the cleavage. It was shown before that the modification of the uracils by hydrazine which opens the pyrimidine ring or by ethylnitrosourea (ENU) which modifies phosphates, did not interfere with the binding of U2AF65 (Singh et al., 2000). More recently, structural basis for polypyrimidine tract recognition by $\mathrm{U} 2 \mathrm{AF} 65$ was determined by the X-ray structure of the U2AF65 RNA binding domain bound to a polypyrimidine tract composed of seven uridines at $2.5 \AA$ resolution (Sickmier et al., 2006). The structure revelas that U2AF65 
recognizes uridines through a network of hydrogen bond interactions with the base edges. This shows that the U2AF65 does not protect the backbone which makes it available for the attack from hydroxyl radicals.

Curiously, nucleotides in exon 1 between nucleotides $\mathrm{C} 18-\mathrm{C} 22$ which are located some 36 nucleotides from the $5^{\prime}$ splice site are also positioned close to the $5^{\prime}$ end of U2 snRNA. As the U1 snRNP is known to interact with the cap binding proteins bound to the $\mathrm{m}^{7} \mathrm{G}$ cap at the 5' end of the pre-mRNA (Lewis et al., 1996), it is conceivable that this interaction "bends" exon 1 such that its 5 ' end is located closer to the 5' splice site. This would in turn place nucleotides in exon 1 closer to the BPS and 3' splice site, and also the 5 ' end of U2. Indeed, our data are consistent with previous cross-linking studies which demonstrated that U2AF65 contacts an equivalent region in exon 1 (Chiara et al., 1996).

It was shown before that, in E complex, SR proteins are located on exon 1. SR protein 20 and 30 were shown to be crosslinked to $\mathrm{E}^{-26}$ (nucleotide 32 ) and $\mathrm{E}^{-31}$ (nucleotide 27) of exon 1 (Chiara et al, 1996). In these parts of exon 1, we have not observed any cleavages. This may indicate that these regions are protected by SR proteins and therefore can not be cleaved by hydroxyl radicals. Chiara et al. (1996) has also shown that no SR proteins were crosslinked to $\mathrm{E}^{-3}$ (nucleotide 55) and $\mathrm{E}^{-15}$ (nucleotide 43). We have observed cleavages on these regions confirming that they are not protected by proteins. U2AF65 also crosslinks to $\mathrm{E}^{-31}$ (nucleotide 27) in E complex (much less compared to the crosslink of U2AF65 to the polypyrimidine tract) (Chiara et al, 1996). The 5' end of U2 is in close proximity to the polypyrimidine tract where U2AF65 binds and to the nucleotide 22 of exon 1. This indicates that the polypyrimidine tract and the region around nucleotide 22 are in proximity to each other. This may arise from the folding over of the pre-mRNA in such a way that these two regions are close to each other. This is compatible with the finding of U2AF65 crosslinking to both the polypyrimidine tract and the $\mathrm{E}^{-31}$ (nucleotide 27) above. 


\subsubsection{Close spatial relationship of the U1 and U2 snRNPs}

The U1 snRNP is a central component of both the E and A complex, interacting with the 5' splice site via U1 snRNA base pairing. The observed cleavages in the vicinity of the 5' splice site prompted us to examine whether the $5^{\prime}$ end of the U2 snRNA is also in close proximity to the U1 snRNP. Hydroxyl radical probing was performed with E and A complexes and the U1 snRNA was analysed.

Multiple cleavages were found in distinct regions of the U1 snRNA in both E and A complexes (Figs. 4-21 and 4-22A), confirming that U1 and $\mathrm{U} 2$ are in close proximity at the earliest stage of spliceosome assembly and may even contact one another. Indeed, the relative spatial organization between $\mathrm{U} 1$ and the $5^{\prime}$ end of $\mathrm{U} 2$ does not change significantly during A complex formation, further suggesting a direct, spatially fixed interaction. Communication between U1 and U2 within spliceosomal complexes is likely mediated directly by the U2-associated, DEAD-box protein hPrp5 (Xu et al., 2004), and/or indirectly by members of the SR protein family (Boukis et al., 2004; Fu and Maniatis, 1992). The fact that a functional 5' splice site is required for $\mathrm{E}$ complex formation, but not the BPS (data not shown; Das et al., 2000), suggests that U2 snRNP assists in joining/pairing the ends of the intron by interacting on one side with the U1 snRNP at the 5' splice site, and on the other side with U2AF65 at the polypyrimidine tract and/or directly through SF3a/b protein interactions with the anchoring site (see above).

Recent studies have provided evidence that U1 and U2 snRNPs can form a di-snRNP complex in the absence of pre-mRNA at least in yeast (Xu et al., 2004). However, when we performed hydroxyl radical probing under conditions excluding the incorporation of Fe-BABE U2 snRNPs into spliceosomal complexes (e.g. when pre-mRNA was omitted), no U1 cleavages above background were detected. This suggests that in HeLa nuclear extract the vast majority of U2 snRNPs do not form a complex with U1 snRNPs (at least under the conditions employed in these studies). Alternatively, U1 and U2 may interact in the absence of the pre-mRNA, but their spatial orientation differs from that in the $\mathrm{E}$ and A complex, such that the $5^{\prime}$ end of U2 is not located near the U1 snRNP. 
The U1 cleavage pattern is not random, but rather cleavages are limited to selected regions of the molecule, suggesting that $\mathrm{U} 1$ and $\mathrm{U} 2$ are oriented in a specific manner. Alternatively, the remaining regions of the U1 snRNA may generally not be accessible to hydroxyl radicals due to the presence of U1 snRNP proteins. U1 $70 \mathrm{~K}$ was shown to be crosslinked to nucleotides 28 and 30 of U1 RNA (Urlaub et al., 2000) which are not cleaved by hydroxyl radicals probably showing the protection of nucleotides via U1 70K protein (Fig. 4-22A). There were no cleavages observed on the 5' half of the stem loop II where the U1A protein contacts.

Significantly, no cleavages above background were observed on the U1 snRNA when the pre-mRNA was omitted (Fig. 4-21D), confirming that they are dependent on the formation of spliceosomal complexes. This indicates that U1 RNA is not in close proximity to $\mathrm{U} 2$ in the absence of pre-mRNA. These two snRNPs come close to each other only in the presence of the pre-mRNA. Consequently, U1 and U2 snRNPs interact with the pre-mRNA simultaneously and are located in proximity in $\mathrm{E}$ and A complexes. This also shows that, in our system, the interaction between U1 and U2 snRNPs is dramatically stabilized by the presence of the pre-mRNA. Finally, U1 and U2 snRNPs are present in nuclear extract as single entities and interact with pre-mRNA simultaneously as single entities.

We have shown that the cleavages on pre-mRNA in E complex are dependent on the 5' splice site by using a 5' splice site-deleted pre-mRNA in E complex experiments. There was no E complex forming on native gels indicating that $\mathrm{U} 1$ does not bind to the premRNA in the absence of the 5 ' splice site. There were no cleavages on pre-mRNA showing that U2 snRNP is not associated (see 5.2.1). Additionally, there were no cleavages on U1 RNA in the absence of the 5' splice site (not shown). This shows that U1 snRNP is required for U2 to associate with the pre-mRNA. Both U1 and U2 snRNPs do not associate with the pre-mRNA in the absence of the $5^{\prime}$ splice site. U1 snRNP must be associating with the $5^{\prime}$ splice site for U2 to interact with both pre-mRNA and U1. It was reported before that the association of a $65 \mathrm{kDa}$ protein (probably U2AF65 as stated by authors) with pre-mRNA (either wild type or $\triangle \mathrm{BPS}$ [branchpoint sequence-deleted]) is 
dependent on the integrity of U1 snRNP (Khellil et al., 1991). They have shown that when the first 15 nucleotides of U1 snRNA are deleted, U2AF65 can not be crosslinked to the pre-mRNA. This indicates that the presence of U1 snRNP bound to the 5 ' splice site is a prerequisite for both U2AF65 and U2 snRNP to associate with the pre-mRNA. The fact that a functional 5' splice site is required, but not the branchpoint, suggests that U2 snRNP assists in joining/pairing the ends of the intron by interacting on one side with U1 snRNP at the $5^{\prime}$ splice site and on the other side with U2AF65 at the polypyrimidine tract. The first interaction may be mediated by Prp5 (Xu et al., 2004), and the second by SF3b155 (Gozani et al., 1998), with details unknown. Regardless of the molecular details, the intimate U1-U2 communication demonstrated here is at the heart of the E i.e. the commitment complex formation.

\subsubsection{Mapping the cleavage data onto the 3D model of U1 snRNA}

The asymmetrically distributed cleavage patterns are associated with stems I, II, and III and are widely separated on the secondary structure of U1 snRNA (Fig. 4-22A). We therefore mapped the cleavages to the protein-free three-dimensional model proposed for U1 snRNA (Krol et al., 1990). This model posits a four-way junction with coaxial stacking of helices I and II and helices H and III. Assuming ideal helices, the cleaved regions mapping to each coaxial helix, i.e. stems I/II and H/III, would be separated by approximately one helix turn (Fig. 4-22B) and thus would be located on one side of the coaxial helices. In fact, when we colour the regions on the 3D model, it becomes immediately apparent, that all of them are oriented in such a way, that they can face a single point source of hydroxyl radicals (Fig. 4-22B). This suggests that the 5 ' end of U2 is located on one side of the U1 snRNP in early spliceosomal complexes.

\subsubsection{Mapping the cleavage data onto the 3D model of U1 snRNP}

The cleavage data of U1 snRNA was then mapped onto the 3D model of U1 snRNP to broaden our understanding about the U1 and U2 snRNP communication in E complex. 
The 3D model of human U1 snRNP was described by single-particle electron cryomicroscopy at $10 \AA$ resolution (Stark et al., 2001). The reconstruction revealed a doughnut-shaped central element that accommodates the seven Sm proteins common to all snRNPs, supporting a proposed model of circular Sm protein arrangement (Fig. 423A). By taking earlier biochemical results into account, the authors assigned the remaining density of the map to the other known components of U1 snRNP. The 5' end of U1 snRNA was removed to ease the determination of the structure.

The classical "frontal" view of the U1 model is shown at the left of Fig. 4-23A, where the position of the Sm protein ring (highlighted green) and other U1 snRNP proteins (e.g., U1-70K and U1-A) are indicated, together with the U1 snRNA (dark blue). When Stark and co-workers tried to accommodate the U1 snRNA model in the U1 snRNP density, while reconstructing the U1 snRNP by cryo-EM (Stark et al., 2001), they had to (i) bend the stem I/II coaxial stacking helix into a crescent and (ii) rotate the whole of stem III in the direction of stem II. Strikingly, when we map our cleavage data onto this modified RNA structure in the U1 snRNP reconstruction, the separate regions are brought closer together (Fig. 4-23B). Moreover, RNA regions not hit are either at the back of the structure, not within the line-of-sight of the 5 ' end of U2 snRNA, or they are simply occluded by proteins. As the largest distance between cleavages, those on the coaxial stem I/II, still spans some $50 \AA$, the U2 snRNP must indeed be very close to U1 snRNP, considering a migration distance of hydroxyl radicals of $\sim 20 \AA$ and the length of the spacer arm $(\sim 10 \AA)$. While this is a very crude estimate of distances, it nevertheless demonstrates the closeness of the U1 and U2 snRNPs, and suggests that room for relative movement is rather limited. Unexpectedly, the U2 snRNP interaction domain is located on the back of the well-known U1 snRNP structure.

The hits on the $5^{\prime}$ end of U1 snRNA allow for an unequivocal placement of this structural element, which protrudes from the $\mathrm{H}$ helix next to the four-way junction (Fig. 4-23). In principle, it could be aligned along the rim of the Sm ring in direction of stem I. In this position it would be shielded by the $\mathrm{U} 170 \mathrm{~K}$ protein. Clearly, the demonstration of accessibility to hydroxyl radicals precludes this orientation. In contrast, the alternative 
orientation across the face of the Sm ring (Stark et al., 2001) is fully consistent with the data presented here. Thus, if stem I (U1 70K protein), stem II (U1 A protein) and stem III were placed at the corners of a roughly equilateral triangle, then the 5 ' end of U1 snRNA, protruding from helix $\mathrm{H}$, would be located next to the side joining stems I and III, slightly displaced below the plane of the triangle.

Mapping of the U1 snRNA cleavages onto the U1 snRNA and U1 snRNP 3D structural models provided valuable information as to the orientation of U1 relative to the $5^{\prime}$ end of U2. The distribution of cleavages on the U1 snRNA in these 3D models confirmed that there is a defined orientation of $\mathrm{U} 1$ and $\mathrm{U} 2$; that is the $5^{\prime}$ end of $\mathrm{U} 2$ appears to be located on a specific "side" of the U1 snRNP, which for historical reasons we have designated as the "back" of the particle (Fig. 4-23).

Our cleavage data also help to more precisely localize the position of the $5^{\prime}$ end of U1 within the U1 snRNP. As only limited experimental data was available, including immunolabeling with anti- $\mathrm{m}_{3} \mathrm{G}$ antibodies followed by EM, previously it had proven difficult to precisely localize the $5^{\prime}$ end of the U1 snRNA within the U1 snRNP. Data presented here clearly indicate that the 5 ' end of $\mathrm{U} 1$ is located on the same "side" of the particle as other regions of U1 hit by hydroxyl radicals (i.e., the "back" side).

Furthermore, our data also are consistent with the formation of a base paired U1/5'ss helix. That is, when cleaved nucleotides at the pre-mRNA's 5' splice site and those in the 5' splice site interacting region of U1 are mapped onto a double-stranded RNA helix, cleaved nucleotides of both RNA species could potentially be hit by a single point source of hydroxyl radicals.

When the $5^{\prime}$ splice site/U1 snRNA interaction is taken as a regular A helix, then the premRNA strand would be facing the Sm ring, since the U1 snRNA strand faces the 5' end of U2 snRNA. This orientation is fully consistent with crosslinks between the pre-mRNA and Sm proteins observed in the homologous yeast commitment complex, CC1 (Zhang and Rosbash, 1999). In that complex, the U1 70K protein was further found to contact 
exon 1 sequences upstream of the 5' splice site. Consistently, the U1 70K protein would be available for contacts to exon 1 in the model presented here.

\subsubsection{The potential structural changes accompanying the $E$ to A complex transition}

During the E to A transition, the loosely associated U2 snRNP becomes stably associated with the pre-mRNA, engaging in a base pairing interaction with the branchpoint sequence (BPS). Aside from the establishment of additional U2 contacts with the pre-mRNA, it is not unlikely that this step might also be accompanied by $3 \mathrm{D}$ spatial rearrangements involving U2. We did not, however, detect much change in the spatial relationship between $\mathrm{U} 1$ and $\mathrm{U} 2$ in the $\mathrm{A}$ versus $\mathrm{E}$ complex, indicating that the apparent interaction/positioning of these particles is relatively "fixed" (Fig. 4-22A). Likewise global rearrangements in U2 relative to the pre-mRNA were not observed; the cleavage pattern in the anchoring site was nearly identical in both the E and A complex, and it varied only slightly in other regions of the pre-mRNA (with the notable exception of the central region of exon 1). Nonetheless, we did observe some clear differences in the premRNA cleavage pattern between these two spliceosomal complexes (Fig. 4-20C). For example, cleavages in the $5^{\prime}$ exon were completely lost or reduced, whereas moderate increases in cleavages at the $5^{\prime}$ splice site and BPS/PPT were observed. This suggests that stabilization of the pre-mRNA/U2 interaction during A complex formation is indeed accompanied by small rearrangements in the organization of the $5^{\prime}$ end of $\mathrm{U} 2$ relative to the pre-mRNA.

Alternatively, many of the observed changes in the pre-mRNA cleavage pattern could be due to alterations in the accessibility of the pre-mRNA's backbone due to recruitment or loss of spliceosomal proteins (i.e. local RNP remodelling events). For example, concomitant with A complex formation, U2AF65 becomes less tightly bound to the polypyrimidine tract (Bennett et al., 1992; Champion-Arnaud et al., 1995; Chiara et al., 1997; Michaud and Reed, 1993), and SF1/mBBP is released (Chiara et al., 1996; MacMillan et al., 1994). These events could potentially bring about the observed 
differential accessibilities of the BPS and the polypyrimidine tract to hydroxyl radicals in the E versus A complex. For that reason U2 may be approaching the branchpoint and causing these weak cleavages to occur all the way up to the branchpoint (A155) in A complex and shifting the cleavages in the polypyrimidine tract upstream (Fig. 4-20C). The shifting of the strong cleavages at the $5^{\prime}$ splice site from the $3^{\prime}$ end of exon 1 in E complex to the $5^{\prime}$ end of intron in A complex may be the result of the repositioning of U2 snRNA. The difference of the cleavage pattern at the $3^{\prime}$ splice site in E and A complexes may arise from a similar reason. The fact that the weak cleavages on intron in E complex were not observed in A complex may occur because of the rearrangement of the proteins.

Likewise, crosslinking studies in the yeast commitment complex (i.e., the equivalent of the mammalian E complex) indicate that the 5' splice site and neighbouring regions are dense with U1 snRNP protein contacts (Zhang and Rosbash, 1999). Thus, alterations in one or more of these pre-mRNA-protein contacts could also potentially contribute to the differences observed in the $5^{\prime}$ splice site cleavage pattern. Interestingly, in A complex, almost all exon 1 is inaccessible to the hydroxyl radicals. This may arise from the relatively distal location of exon 1 from the $5^{\prime}$ end of $\mathrm{U} 2$ or the protection of exon 1 by proteins. It was shown before that SRP20 and SRP30 proteins crosslink to the pre-mRNA in B complex (Staknis and Reed, 1994). It is likely that the SR proteins remain bound to the pre-mRNA throughout the spliceosome assembly. Thus, it appears that SR proteins or some other spliceosomal proteins may be protecting the exon 1 in A complex. In both complexes, the 5' splice site is base paired to the 5' end of U1 snRNA. Since this does not change position with respect to the $5^{\prime}$ end of U2 snRNA, the changing pattern on the premRNA must reflect a change in protection by differential protein binding which refelects a remodelling event.

The SF3a and SF3b components UV crosslink to the anchoring sequence in A complex but not in E complex (Gozani et al., 1996; Gozani et al., 1998). However, the cleavage pattern on the anchoring sequence in both complexes were almost identical. This RNAprotein remodelling event does not appear to involve dramatic RNA movements, at least when seen from the vantage point of the 5 ' end of U2 snRNA. Alternatively, the proteins 
may cover the anchoring site thus rendering the RNA invisible to hydroxyl radicals. Interesting however, is the crosslink of SF3b49 (Gozani et al., 1996) to one nucleotide downstream of G132. Independently, this protein was found crosslinked to the 5' end of U2 snRNA (positions 1, 2, and 6) in native 17S U2 snRNP, with no changes in crosslinking pattern in the A complex (Dybkov et al., 2006). This early established static proximity between the $5^{\prime}$ end of U2 snRNA and the pre-mRNA, is thus likely mediated by SF3b49. The whole constellation at this position could be likened to a hinge at G132, downstream of which the RNA-protein remodelling events take place by a "touch-down" or "close-in" of the pre-mRNA anchoring site onto the surface presented by SF3a and SF3b (Gozani et al., 1996), resulting ultimately in the U2 snRNA/branchpoint interaction. The SF3b49 brings together the 5' end of U2 snRNA and the G132 at the anchoring region of the pre-mRNA. These findings nicely match with the data presented here that G132 was cleaved by hydroxyl radicals generated from Fe-BABE at the $5^{\prime}$ end of U2 showing that it is in close proximity with the $5^{\prime}$ end of U2 snRNA. Interestingly, both SF3a and SF3b are part of the U11/U12 di-snRNP (Will and Lührmann, 2005). In a recent $3 \mathrm{D}$ reconstruction by $\mathrm{EM}$ of this particle, the putative path of the anchoring site was traced on the surface of the particle (Golas et al., 2005).

The similarity of the situation that the important structural elements (splice sites and the polypyrimidine tract) are in close proximity with the $5^{\prime}$ end of U2 snRNA in E and A complexes also may show the two sequential events taking place during spliceosome assembly. Firstly, the simultaneous binding of U1 and U2 for E and A complex formation occurs. Secondly, the binding of tri-snRNP to this prespliceosome takes place.

In summary, protein-RNA remodelling events appear to be responsible for most of the shifting cleavage patterns observed in the E to A complex transition. Though this is a likely explanation, we cannot exclude the movement of parts. Nevertheless, from the proximity data presented it can be concluded that the gross overall 3D arrangement of functional RNA segments the A complex is similar to that in the E complex. However, a repositioning takes place among the components of the early complex during $\mathrm{E}$ to $\mathrm{A}$ complex transition. 


\subsubsection{Interactions among the components of the A complex}

After having demonstrated that the $5^{\prime}$ end of $\mathrm{U} 2$ is in close proximity with the functional sites of the pre-mRNA and the U1 snRNA, we combined these results with the previous biochemical data from others in order to obtain a more global picture.

In A complex, when Fe-BABE is placed in the centre of a circle and the cleavages are located within the effective range of diameter, the branchpoint is placed in close proximity to the $5^{\prime}$ splice site facilitating the first step of catalysis (Fig. 5-1). It was shown before that p14 crosslinks to the branch point (Query et al., 1996) and interacts directly with SF3b155 (Will et al., 2001). SF3b proteins 145, 49, 155 UV-crosslinks to the anchoring region and SF3b155 also crosslinks to the downstream of the branch point (Gozani et al., 1996). U2AF35 is known to interact with AG dinucleotide at the 3' splice site (Wu et al., 1999) and U2AF65 interacts with the polypyrimidine tract (Zamore et al., 1992) and associates with SF3b155 (Gozani et al., 1998) (see schematically in Fig. 5-1).

When these findings were united with the results of the hydroxyl radical probing data presented in this work, we come across to interesting matches (Fig. 5-1). SF3b49 was shown to be crosslinked to both $5^{\prime}$ end of U2 and to one nucleotide downstream from nucleotide G132 at anchoring sequence which was cleaved by hydroxyl radicals generated from Fe-BABE showing that it is in close proximity to the 5 ' end of U2. The SF3b proteins crosslink to various sites on the pre-mRNA and SF3b155 interacts with the U2AF65 (Gozani et al., 1998). The polypyrimidine tract all the way down to the branch point and 3 ' splice site were cleaved simultaneously showing their proximity to each other and to the $5^{\prime}$ end of U2. This is compatible with the previous finding that U2AF65 bends the polypyrimidine tract to bring the 3' splice site and branch region close together (Kent et al., 2003). The SF3b155-U2AF65-p14 seems to organize the 3' end of the intron. It is nicely seen in the model (Fig. 5-1) that the SF3b protein complex tethers U2 snRNP to the branchpoint and structures the $3^{\prime}$ end of intron. U2 plays an important role here bringing together the ends of intron in early steps, communicating not only with 3' splice site and branch point but also with 5' splice site and U1 RNA. 


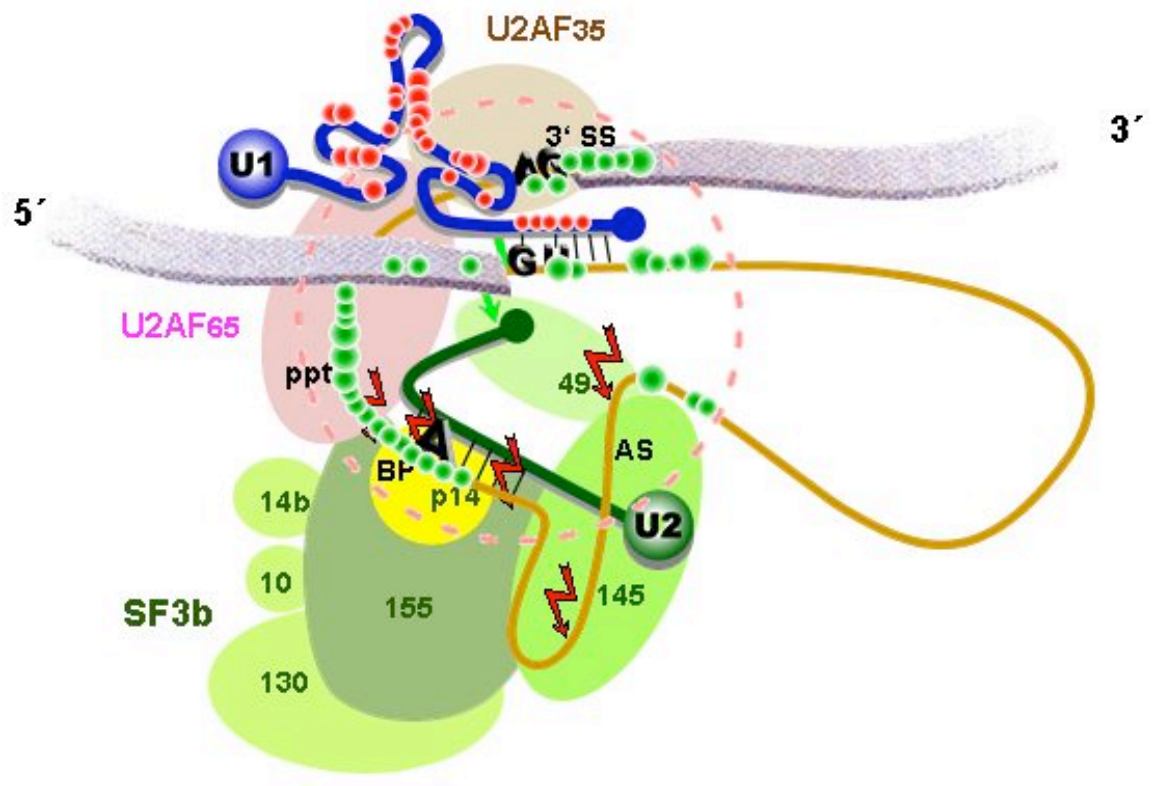

Figure 5-1: The model of A complex which is obtained by combining the hydroxyl radical probing data of the present work and the previous biochemical data from others (Dybkov et al., 2006; Gozani et al., 1996). The exons and introns are shown with gray solid bars and thin yellow line, respectively. The cleavages on the pre-mRNA and U1 snRNA are displayed with green and red dots, respectively. U2AF65, U2AF35 and SF3b components are shown. The crosslinks of SF3b155, SF3b145, SF3b49 and p14 to the pre-mRNA are demonstrated with red arrows while the crosslink of SF3b49 to the 5' end of U2 snRNA is shown by green arrow. U1 snRNA and U2 snRNA are shown with blue and green, respectively.

This close interaction of the 5 ' end of $\mathrm{U} 2$ with the U1 snRNA raises the question whether this is a direct RNA-RNA interaction or a protein mediates this communication. The results obtained in this work showed that the $5^{\prime}$ end of U2 is in close proximity to the U1 snRNA pairing the ends of the intron. Additionally, some protein-protein interactions may help bringing together the intron ends. We have shown here that the close interaction of $\mathrm{U} 1$ and $\mathrm{U} 2$ does not exist in the absence of the pre-mRNA. Their interaction depends on a spliceosomal complex formation. This is different from the situation in minor spliceosome where U11/U12 di-snRNP exists in the nuclear extract and binds to the pre- 
mRNA as a single entity. We have shown that the association of U2 with the pre-mRNA is dependent on $\mathrm{U} 1$ binding by deleting the 5' splice site. It was demonstrated before that the depletion of $\mathrm{U} 1$ impairs the stable binding of $\mathrm{U} 2$ to the branch site (Barabino et al., 1990). However, a di-snRNP among U1 and U2 snRNPs as in the case of U11/U12 disnRNP was not observed in this study. As shown here, the $5^{\prime}$ end of U2 snRNA and the U1 snRNA are in close proximity indicating that the RNA-RNA interaction is fixed already in E complex and maintained in A complex. A number of factors, most likely SR proteins, may facilitate this interaction. In yeast, the presence of U2 in the commitment complex has not been shown. Yeast introns have very conserved splice site and branch point sequences on very short introns (50-500 bp) whereas metazoans have degenerate splice site and branchpoint sequences on long introns (100 bp-10 kb). Alternative splicing which is not observed in yeast is a process which is observed in higher eukaryotes where particles or factors other than U1 snRNP are needed to determine the correct splice sites. The ends of the metazoan introns may need to be identified by U1 and U2 snRNPs already in the very early step while the ends of the short yeast introns may be determined easily by only U1 snRNP. Additionally, yeast U1 snRNP particle is much larger with more proteins compared to human U1 snRNP. This large U1 snRNP particle may be more capable to determine both splice sites of yeast introns. In yeast, a mutation that distrupts stable base pairing between U1 snRNA and the 5' splice site allows low levels of ATP-independent U2 snRNP binding (Liao et al., 1992). This finding indicates that the conserved 5' splice site and U1 base pairing is sufficient to define the correct splice sites. Whether U2 snRNP is normally associated with the commitment complex remains to be determined. In metazoan introns with degenerate splice sites and branch point sequences, $\mathrm{U} 1$ and U2 snRNPs need to be present and bridge the intron ends, definitely via RNARNA interaction and probably also with helper protein/s for correct splice site recognition and pairing. 


\subsubsection{Conserved early spatial organization of snRNPs in the major and minor spliceosome}

The close spatial organization of the 5 ' end of $\mathrm{U} 2$ both with $\mathrm{U} 1$ and functional sites of the pre-mRNA suggests similarities in the general structural organization of U2- and U12type pre-spliceosomes. Assembly of the minor spliceosome is largely homologous to the major U2-type spliceosome, with the notable exception that the U11 and U12 snRNPs form a highly stable di-snRNP and thus interact with the pre-mRNA as a pre-formed complex (Wassarman and Steitz, 1992). U11 and U12 interact with the 5' splice site and BPS, respectively, in a cooperative manner and their close association ensures that the functional sites of the pre-mRNA involved in the first step of splicing are "bridged" already at the earliest step of minor spliceosome assembly (Frilander and Steitz, 1999). To date, it has not been possible to detect an ATP-independent minor spliceosomal complex analogous to the E complex (Frilander and Steitz, 1999). Nevertheless, the fact that the U1 and U2 snRNPs are both functionally present in the E complex, coupled with previous studies showing that $\mathrm{U} 1$ and $\mathrm{U} 2$ snRNPs are associated in extracts (Mattaj et al., 1986), raises the possibility that the initial steps in major and minor spliceosome assembly are more similar than previously thought.

The close association demonstrated here for U1 and U2 snRNPs in both the E and A complexes, resembles to the tight association of U11 and U12 snRNPs in the minor splicesome. The fact that the spatial relationship of U1-U2 snRNP does not change dramatically upon A complex formation (Fig. 4-22A) is evidence for the similarity of the U1-U2 to the U11/U12 interaction. Thus, the U1 and U2 snRNPs may form a molecular bridge between the ends of the intron, much like the U11/U12 di-snRNP. This suggests that $\mathrm{U} 1$ and $\mathrm{U} 2$ snRNPs acts as a single molecular entity to perform the higher order functions as in the case of U11/U12 di-snRNP. Our data indicate that the U1 and U2 snRNPs are also in very close proximity and likely contact each other in early spliceosomal complexes. 
Recent studies indicate that the $5^{\prime}$ end of the U12 snRNA not only base pairs with the BPS, but also contacts the penultimate nucleotide of the $5^{\prime}$ exon in early spliceosomal complexes (Frilander and Meng, 2005). It was demonstrated that, in minor spliceosomes, the 5 ' end of U12 RNA crosslinked to the -2 nucleotide of exon 1 in the very early step before the addition of tri-snRNP (Frilander and Meng, 2005). They have reported that the 5 ' end of U12 snRNA is also in proximity to the branchpoint in minor A complex. Thus, the $5^{\prime}$ and $3^{\prime}$ ends of U12-type introns are in close proximity to the $5^{\prime}$ end of U12 and to each other in the minor pre-spliceosome, similar to the situation with U2 in the U2-type pre-spliceosome. This is consistent with the proximities presented in this study indicating the structural similarity among the components of the early complexes in both spliceosomes.

Indeed, the findings in this study fit nicely into the cryoelectron microscopy structure of U11/U12 snRNPs (Golas et al., 2005). They have shown that SF3b49, p14 and SF3b155 are located in close proximity to each other as it is observed with the site-directed hydroxyl radical probing data in this study. U11/U12 di-snRNP has only a few specific proteins but it contains all seven subunits of SF3b protein complex (Will and Lührmann, 2005). The presence of this protein complex in both $18 \mathrm{~S} \mathrm{U11/U12} \mathrm{di-snRNP}$ and 17S U2 indicates that many aspects of branch site and intron recognition are conserved in both spliceosomes. In addition, SF3b can be the key player in organizing the molecular bridge connecting the $5^{\prime}$ and $3^{\prime}$ ends of the intron during the early steps of spliceosome assembly.

\subsubsection{Pre-organization of $U 2$ and its impact on subsequent assembly steps}

The 3D organization of the functional sites of the pre-mRNA and the 5 ' end of U2 may remain essentially unchanged upon incorporation of the U4/U6.U5 tri-snRNP during the next step of spliceosome assembly (i.e., B complex formation). Although Fe-BABE was tethered to the $5^{\prime}$ terminal nucleotide of U2, our data suggest that nucleotides 11-20 of human U2 that form a catalytically important U2/U6 helix after incorporation of the 
U4/U6.U5 tri-snRNP into the spliceosome might also be located not far from the 5' splice site and the branch point, which react during the first step of splicing. Thus, a major rearrangement in the $5^{\prime}$ end of $U 2$ relative to the reactive functionalities of the pre-mRNA might not be required to generate catalytically active spliceosomes in the subsequent steps leading to the first step of splicing. Furthermore, our data are consistent with the idea that at least part of the 3D interaction interface (i.e., involving U2) that mediates trisnRNP addition is established already during the early steps of spliceosome assembly.

\subsection{Outlook}

In the first part of this work, the roles of individual modified nucleotides of HeLa U2 snRNA in pre-mRNA splicing are investigated. It is shown that the three pseudouridines and five 2'-O-methyl groups within the first 20 nucleotides of U2 snRNA, but not the $\mathrm{m}_{3} \mathrm{G}$ cap, are required for efficient pre-mRNA splicing. The in vitro assembly of $17 \mathrm{~S} \mathrm{U} 2$ snRNPs is not dependent on the presence of modified U2 residues. However, individual internal modifications are required for the formation of the ATP-independent early spliceosomal E complex. The data presented in this work strongly suggest that modifications within the first 20 nucleotides of $\mathrm{U} 2$ play an important role in facilitating the interaction of U2 with U1 snRNP and/or other factors within the E complex. It will be of interest to determine in the future the structure of U2 stem loop I with or without modifications by using a technique like NMR. This will help to understand whether the presence of modifications facilitates the correct 3D structure of stem I in addition to increasing the stability. The possible presence of RNA-protein interactions between the U2 stem loop I and the splicing factors present in E complex like U2AF65, mBBP/SF1 can be analyzed to learn whether the modifications are playing a role in these kinds of interactions to recruit the U2 snRNP to E complex.

The demonstration in the first part, that functionally active U2 snRNPs are reconstituted in vitro from chimaeric U2 snRNAs containing the required modifications, paved the way for the site-directed hydroxyl radical probing studies in the the second part of this study. 
We have used the site-directed hydroxyl radical probing to learn more about the the molecular mechanisms of splice site pairing and the 3D architecture of early spliceosomal complexes. The hydroxyl radical generator, Fe-BABE, was attached to the $5^{\prime}$ end of U2 snRNA. In E complexes, hydroxyl radical cleaved nucleotides are detected in the polypyrimidine tract, 3' splice site, anchoring site, 5' splice site and the 5' exon of the premRNA, demonstrating that these regions are in close proximity to the functionally important $5^{\prime}$ end of U2 and also to one another. The U1 snRNA is also cleaved, and mapping of these cleavages onto the U1 snRNA and U1 snRNP 3D structures revealed a distinct orientation of $\mathrm{U} 2$ relative to $\mathrm{U} 1$. Thus, already in the E complex, the $\mathrm{U} 2$ and $\mathrm{U} 1$ snRNPs are in close proximity, and 'bridge" the 5' and 3' ends of intron. Similar cleavage patterns are observed in A complexes, indicating that the spatial organization of U1 relative to U2 remains largely unchanged during A complex formation. Thus, they may form a molecular bridge between the ends of the intron, much like the U11/U12 disnRNP. It will be of great interest in the future to tether the Fe-BABE to different sites of U2 snRNA and map the RNA proximities in all spliceosomal complexes to gain insight into the 3D architecture of the complexes relative to U2. Additionally, Fe-BABE can be tethered to other snRNAs and to the pre-mRNA or even to proteins in order to investigate the proximities of RNAs in different spliceosomal complexes and steps of splicing reaction to learn more about the spatial organization of splicing elements. This will deepen our understanding of the spliceosome assembly and splicing in 3D.

The results of this work will also pave the way for further studies by including FRET (Fluorescence Resonance Electron Transfer) method in which a fluorophore is attached to different RNAs and proteins and the interactions among them is analyzed in vivo. 


\section{BIBLIOGRAPHY}

Abovich, N., and Rosbash, M. (1997). Cross-intron bridging interactions in the yeast commitment complex are conserved in mammals. Cell 89, 403-412.

Abu Dayyeh, B.K., Quan, T.K., Castro, M., and Ruby, S.W. (2002). Probing interactions between the U2 small nuclear ribonucleoprotein and the DEAD-box protein, Prp5. J. Biol. Chem. 277, 20221-20233.

Achsel, T., Brahms, H., Kastner, B., Bachi, A., Wilm, M., and Lührmann, R. (1999). A doughnutshaped heteromer of human Sm-like proteins binds to the 3'-end of U6 snRNA, thereby facilitating U4/U6 duplex formation in vitro. EMBO J. 18, 5789-5802.

Arenas, J.E., and Abelson, J.N. (1997). Prp43: An RNA helicase-like factor involved in spliceosome disassembly. Proc. Natl. Acad. Sci. USA 94, 11798-11802.

Arnez, J.G., and Steitz, T.A. (1994). Crystal structure of unmodified tRNA(Gln) complexed with glutaminyl-tRNA synthetase and ATP suggests a possible role for pseudo-uridines in stabilization of RNA structure. Biochemistry 33, 7560-7567.

Auffinger, P., and Westhof, E. (1998). Effects of pseudouridylation on tRNA hydration and dynamics: a theoretical approach, Vol Chapter 6 (Washington D.C. ASM Press).

Bach, M., Bringmann, P., and Lührmann, R. (1990). Purification of small nuclear ribonucleoprotein particles with antibodies against modified nucleosides of small nuclear RNAs. Methods Enzymol. 181, 232-257.

Banerjee, H., Rahn, A., Davis, W., and Singh, R. (2003). Sex lethal and U2 small nuclear ribonucleoprotein auxiliary factor (U2AF65) recognize polypyrimidine tracts using multiple modes of binding. RNA 9, 88-99. 
Barabino, S.M., Blencowe, B.J., Ryder, U., Sproat, B.S., and Lamond, A.I. (1990). Targeted snRNP depletion reveals an additional role for mammalian U1 snRNP in spliceosome assembly. Cell 63, 293-302.

Behm-Ansmant, I., Urban, A., Ma, X., Yu, Y.T., Motorin, Y., and Branlant, C. (2003). The Saccharomyces cerevisiae U2 snRNA-pseudouridine-synthase Pus7p is a novel multisitemultisubstrate RNA:Psi-synthase also acting on tRNAs. RNA 9, 1371-1382.

Behrens, S.E., and Lührmann, R. (1991). Immunoaffinity purification of a [U4/U6.U5] tri-snRNP from human cells. Genes Dev. 5, 1439-1452.

Behrens, S.E., Tyc, K., Kastner, B., Reichelt, J., and Lührmann, R. (1993). Small nuclear ribonucleoprotein (RNP) U2 contains numerous additional proteins and has a bipartite RNP structure under splicing conditions. Mol. Cell. Biol. 13, 307-319.

Benecke, H., Lührmann, R., and Will, C.L. (2005). The U11/U12 snRNP 65K protein acts as a molecular bridge, binding the U12 snRNA and U11-59K protein. EMBO J. 24, 3057-3069.

Bennett, M., Michaud, S., Kingston, J., and Reed, R. (1992). Protein components specifically associated with prespliceosome and spliceosome complexes. Genes Dev. 6, 1986-2000.

Berget, S.M. (1995). Exon recognition in vertebrate splicing. J. Biol. Chem. 270, 2411-2414.

Berglund, J.A., Chua, K., Abovich, N., Reed, R., and Rosbash, M. (1997). The splicing factor BBP interacts specifically with the pre-mRNA branchpoint sequence UACUAAC. Cell 89,781 787.

Berglund, J.A., Fleming, M.L., and Rosbash, M. (1998). The KH domain of the branchpoint sequence binding protein determines specificity for the pre-mRNA branchpoint sequence. RNA 4, 998-1006.

Birney, E., Kumar, S., and Krainer, A.R. (1993). Analysis of the RNA-recognition motif and RS and RGG domains: conservation in metazoan pre-mRNA splicing factors. Nucleic Acids. Res. 21, 5803-5816. 
Black, D.L. (2003). Mechanisms of alternative pre-messenger RNA splicing. Annu. Rev. Biochem. 72, 291-336.

Black, D.L., and Pinto, A.L. (1989). U5 small nuclear ribonucleoprotein: RNA structure analysis and ATP-dependent interaction with U4/U6. Mol. Cell. Biol. 9, 3350-3359.

Boukis, L.A., Liu, N., Furuyama, S., and Bruzik, J.P. (2004). Ser/Arg-rich protein-mediated communication between U1 and U2 small nuclear ribonucleoprotein particles. J. Biol. Chem. 279, 29647-29653.

Bradford, M.M. (1976). A rapid and sensitive method for the quantitation of microgram quantities of protein utilizing the principle of protein-dye binding. Anal. Biochem. 72, 248-254.

Branlant, C., Krol, A., Ebel, J.P., Lazar, E., Haendler, B., and Jacob, M. (1982). U2 RNA shares a structural domain with U1, U4, and U5 RNAs. EMBO J. 1, 1259-1265.

Brow, D.A. (2002). Allosteric cascade of spliceosome activation. Annu. Rev. Genet. 36, 333-360.

Burge, C.B., Tuschl, T., and Sharp, P.A. (1999). Splicing of Precursors to mRNAs by the Spliceosomes, In The RNA World II, Gesteland, R.F., Cech, T.R., \& Atkins, J.F., ed. (Cold Spring Harbor, NY. Cold Spring Harbor Laboratory Press), pp. 525-560.

Cartegni, L., Chew, S.L., and Krainer, A.R. (2002). Listening to silence and understanding nonsense: exonic mutations that affect splicing. Nat. Rev. Genet. 3, 285-298.

Champion-Arnaud, P., Gozani, O., Palandjian, L., and Reed, R. (1995). Accumulation of a novel spliceosomal complex on pre-mRNAs containing branch site mutations. Mol. Cell. Biol. 15, $5750-5756$.

Champion-Arnaud, P., and Reed, R. (1994). The prespliceosome components SAP 49 and SAP 145 interact in a complex implicated in tethering U2 snRNP to the branch site. Genes Dev. 8, 1974-1983. 
Charette, M., and Gray, M.W. (2000). Pseudouridine in RNA: what, where, how, and why. IUBMB Life 49, 341-351.

Chen, J.Y., Stands, L., Staley, J.P., Jackups, R.R., Jr., Latus, L. J., and Chang, T.H. (2001). Specific alterations of U1-C protein or U1 small nuclear RNA can eliminate the requirement of Prp28p, an essential DEAD box splicing factor. Mol. Cell 7, 227-232.

Chew, S.L., Liu, H.X., Mayeda, A., and Krainer, A.R. (1999). Evidence for the function of an exonic splicing enhancer after the first catalytic step of pre-mRNA splicing. Proc. Natl. Acad. Sci. USA 96, 10655-10660.

Chiara, M.D., Champion-Arnaud, P., Buvoli, M., Nadal-Ginard, B., and Reed, R. (1994). Specific protein-protein interactions between the essential mammalian spliceosome-associated proteins SAP 61 and SAP 114. Proc. Natl. Acad. Sci. USA 91, 6403-6407.

Chiara, M.D., Gozani, O., Bennett, M., Champion-Arnaud, P., Palandjian, L., and Reed, R. (1996). Identification of proteins that interact with exon sequences, splice sites, and the branchpoint sequence during each stage of spliceosome assembly. Mol. Cell. Biol. 16, 33173326.

Chiara, M.D., Palandjian, L., Feld Kramer, R., and Reed, R. (1997). Evidence that U5 snRNP recognizes the 3 ' splice site for catalytic step II in mammals. EMBO J. 16, 4746-4759.

Crispino, J.D., Blencowe, B.J., and Sharp, P.A. (1994). Complementation by SR proteins of premRNA splicing reactions depleted of U1 snRNP. Science 265, 1866-1869.

Culver, G.M., and Noller, H.F. (2000). Directed hydroxyl radical probing of RNA from iron(II) tethered to proteins in ribonucleoprotein complexes. Methods Enzymol. 318, 461-475.

Das, R., and Reed, R. (1999). Resolution of the mammalian E complex and the ATP-dependent spliceosomal complexes on native agarose mini-gels. RNA 5, 1504-1508.

Das, R., and Reed, R. (1999). Resolution of the mammalian E complex and the ATP-dependent spliceosomal complexes on native agarose mini-gels. RNA 5, 1504-1508. 
Das, R., Zhou, Z., and Reed, R. (2000). Functional association of U2 snRNP with the ATPindependent spliceosomal complex E. Mol. Cell 5, 779-787.

Davanloo, P., Rosenberg, A.H., Dunn, J.J., and Studier, F.W. (1984). Cloning and expression of the gene for bacteriophage T7 RNA polymerase. Proc. Natl. Acad. Sci. USA 81, 2035-2039.

DeRiemer, L.H., and Meares, C.F. (1981). Synthesis of mono- and dinucleotide photoaffinity probes of ribonucleic acid polymerase. Biochemistry 20, 1606-1612.

Dignam, J.D., Lebovitz, R.M., and Roeder, R.G. (1983). Accurate transcription initiation by RNA polymerase II in a soluble extract from isolated mammalian nuclei. Nucleic Acids Res. 11, 14751489.

Duckett, D.R., Murchie, A.I., and Lilley, D.M. (1995). The global folding of four-way helical junctions in RNA, including that in U1 snRNA. Cell 83, 1027-1036.

Dybkov, O., Will, C.L., Deckert, J., Behzadnia, N., Hartmuth, K., and Lührmann, R. (2006). U2 snRNA-protein contacts in purified human 17S U2 snRNPs and in spliceosomal A and B complexes. Mol. Cell. Biol. 26, 2803-2816.

Fabrizio, P., McPheeters, D.S., and Abelson, J. (1989). In vitro assembly of yeast U6 snRNP: a functional assay. Genes Dev. 3, 2137-2150.

Fenton, H.J.H. (1894). Oxidation of tartaric acid in presence of iron. J. Chem. Soc. 65, 899-910.

Fleckner, J., Zhang, M., Valcarcel, J., and Green, M.R. (1997). U2AF65 recruits a novel human DEAD box protein required for the U2 snRNP-branchpoint interaction. Genes Dev. 11, 18641872 .

Forch, P., Merendino, L., Martinez, C., and Valcarcel, J. (2003). U2 small nuclear ribonucleoprotein particle (snRNP) auxiliary factor of $65 \mathrm{kDa}$, U2AF65, can promote U1 snRNP recruitment to $5^{\prime}$ splice sites. Biochem. J. 372, 235-240. 
Friedmann, O.M. (1961). Colorimetric Estimation of Nitrogen Mustard in Aqueous Media. Analytical Chemistry 33, 906-910.

Frilander, M.J., and Meng, X. (2005). Proximity of the U12 snRNA with both the 5' splice site and the branch point during early stages of spliceosome assembly. Mol. Cell. Biol. 25, 48134825.

Frilander, M.J., and Steitz, J.A. (1999). Initial recognition of U12-dependent introns requires both U11/5' splice-site and U12/branchpoint interactions. Genes Dev. 13, 851-863.

Frilander, M.J., and Steitz, J.A. (2001). Dynamic exchanges of RNA interactions leading to catalytic core formation in the U12-dependent spliceosome. Mol. Cell 7, 217-226.

Fu, X.D., and Maniatis, T. (1992). The 35-kDa mammalian splicing factor SC35 mediates specific interactions between U1 and U2 small nuclear ribonucleoprotein particles at the 3 ' splice site. Proc. Natl. Acad. Sci. USA 89, 1725-1729.

Golas, M.M., Sander, B., Will, C.L., Lührmann, R., and Stark, H. (2003). Molecular architecture of the multiprotein splicing factor SF3b. Science 300, 980-984.

Golas, M.M., Sander, B., Will, C.L., Lührmann, R., and Stark, H. (2005). Major conformational change in the complex SF3b upon integration into the spliceosomal U11/U12 di-snRNP as revealed by electron cryomicroscopy. Mol. Cell 17, 869-883.

Gozani, O., Feld, R., and Reed, R. (1996). Evidence that sequence-independent binding of highly conserved U2 snRNP proteins upstream of the branch site is required for assembly of spliceosomal complex A. Genes Dev. 10, 233-243.

Gozani, O., Potashkin, J., and Reed, R. (1998). A potential role for U2AF-SAP 155 interactions in recruiting U2 snRNP to the branch site. Mol. Cell. Biol. 18, 4752-4760.

Graveley, B.R. (2000). Sorting out the complexity of SR protein functions. RNA 6, 1197-1211. 
Green, R., and Noller, H.F. (1996). In vitro complementation analysis localizes 23S rRNA posttranscriptional modifications that are required for Escherichia coli $50 \mathrm{~S}$ ribosomal subunit assembly and function. RNA 2, 1011-1021.

Greiner, D.P., Miyake, R., Moran, J.K., Jones, A.D., Negishi, T., Ishihama, A., and Meares, C.F. (1997). Synthesis of the protein cutting reagent iron (S)-1-(p-bromoacetamidobenzyl) ethylenediaminetetraacetate and conjugation to cysteine side chains. Bioconjug. Chem 8, 44-48.

Grosjean, H., Sprinzl, M., and Steinberg, S. (1995). Posttranscriptionally modified nucleosides in transfer RNA: their locations and frequencies. Biochimie 77, 139-141.

Gu, J., Patton, J.R., Shimba, S., and Reddy, R. (1996). Localization of modified nucleotides in Schizosaccharomyces pombe spliceosomal small nuclear RNAs: modified nucleotides are clustered in functionally important regions. RNA 2, 909-918.

Guo, N., and Kawamoto, S. (2000). An intronic downstream enhancer promotes 3' splice site usage of a neural cell-specific exon. J. Biol. Chem. 275, 33641-33649.

Haber, F. and Weiss, J. (1934). The catalytic decomposition of hydrogen proxide by iron salts. Proc. Roy. Soc. London 147, 332-351.

Hartmuth, K., Raker, V.A., Huber, J., Branlant, C., and Lührmann, R. (1999). An unusual chemical reactivity of Sm site adenosines strongly correlates with proper assembly of core $\mathrm{U}$ snRNP particles. J. Mol. Biol. 285, 133-147.

Hartmuth, K., Urlaub, H., Vornlocher, H.P., Will, C.L., Gentzel, M., Wilm, M., and Lührmann, R. (2002). Protein composition of human prespliceosomes isolated by a tobramycin affinityselection method. Proc. Natl. Acad. Sci. USA 99, 16719-16724.

Hastings, M.L., and Krainer, A.R. (2001). Functions of SR proteins in the U12-dependent AT-AC pre-mRNA splicing pathway. RNA 7, 471-482.

Hausner, T.P., Giglio, L.M., and Weiner, A.M. (1990). Evidence for base-pairing between mammalian U2 and U6 small nuclear ribonucleoprotein particles. Genes Dev. 4, 2146-2156. 
Heinrichs, V., Bach, M., Winkelmann, G., and Lührmann, R. (1990). U1-specific protein C needed for efficient complex formation of U1 snRNP with a 5' splice site. Science 247, 69-72.

Hermann, H., Fabrizio, P., Raker, V. A., Foulaki, K., Hornig, H., Brahms, H., and Lührmann, R. (1995). snRNP Sm proteins share two evolutionarily conserved sequence motifs which are involved in Sm protein-protein interactions. EMBO J. 14, 2076-2088.

Horvath, G.V., Pettko-Szandtner, A., Nikovics, K., Bilgin, M., Boulton, M., Davies, J. W., Gutierrez, C., and Dudits, D. (1998). Prediction of functional regions of the maize streak virus replication- associated proteins by protein-protein interaction analysis. Plant Mol. Biol. 38, 699712.

Ingelfinger, D., Arndt-Jovin, D.J., Lührmann, R., and Achsel, T. (2002). The human LSm1-7 proteins colocalize with the mRNA-degrading enzymes Dep1/2 and Xrnl in distinct cytoplasmic foci. RNA 8, 1489-1501.

Isel, C., Lanchy, J.M., Le Grice, S.F., Ehresmann, C., Ehresmann, B., and Marquet, R. (1996). Specific initiation and switch to elongation of human immunodeficiency virus type 1 reverse transcription require the post-transcriptional modifications of primer tRNA3Lys. EMBO J. 15, 917-924.

Isel, C., Marquet, R., Keith, G., Ehresmann, C., and Ehresmann, B. (1993). Modified nucleotides of tRNA(3Lys) modulate primer/template loop-loop interaction in the initiation complex of HIV1 reverse transcription. J. Biol. Chem. 268, 25269-25272.

Izaurralde, E., and Mattaj, I.W. (1992). Transport of RNA between nucleus and cytoplasm. Semin. Cell Biol. 3, 279-288.

Izquierdo, J.M., and Valcarcel, J. (2006). A simple principle to explain the evolution of premRNA splicing. Genes Dev. 20, 1679-1684.

Jacobson, M.R., Rhoadhouse, M. and Pederson, T. (1993). U2 small nuclear RNA 3'end formation is directed by a critical internal structure distinct from the processing site. Mol. Cell. Biol. 13, 1119-1129. 
Jamison, S.F., and Garcia-Blanco, M.A. (1992). An ATP-independent U2 small nuclear ribonucleoprotein particle/precursor mRNA complex requires both splice sites and the polypyrimidine tract. Proc. Natl. Acad. Sci. USA 89, 5482-5486.

Joseph, S., and Noller, H.F. (2000). Directed hydroxyl radical probing using iron(II) tethered to RNA. Methods Enzymol. 318, 175-190.

Jurica, M.S., and Moore, M.J. (2002). Capturing splicing complexes to study structure and mechanism. Methods 28, 336-345.

Kambach, C., Walke, S., Young, R., Avis, J.M., de la Fortelle, E., Raker, V.A., Lührmann, R., Li, J., and Nagai, K. (1999). Crystal structures of two Sm protein complexes and their implications for the assembly of the spliceosomal snRNPs. Cell 96, 375-387.

Kastner, B. (1998). Purification and electron microscopy of spliceosomal snRNPs Springer Lab Manual: RNP Particles, Splicing and Autoimmune Diseases. Johannes Schenkel (Ed.), pp. 95140.

Kastner, B., Kornstadt, U., Bach, M., and Lührmann, R. (1992). Structure of the small nuclear RNP particle U1: identification of the two structural protuberances with RNP-antigens A and 70K. J. Cell Biol. 116, 839-849.

Kastner, B., and Lührmann, R. (1999). Purification of U small nuclear ribonucleoprotein particles. Methods Mol. Biol. 118, 289-298.

Kent, O.A., and MacMillan, A.M. (2002). Early organization of pre-mRNA during spliceosome assembly. Nat. Struct. Biol. 9, 576-581.

Kent, O.A., Reayi, A., Foong, L., Chilibeck, K.A., and MacMillan, A.M. (2003). Structuring of the 3' splice site by U2AF65. J. Biol. Chem. 278, 50572-50577.

Khellil, S., Daugeron, M.C., Alibert, C., Jeanteur, P., Cathala, G., and Brunel, C. (1991). The 5' end domain of U2 snRNA is required to establish the interaction of U2 snRNP with U2 auxiliary factor(s) during mammalian spliceosome assembly. Nucleic Acids Res. 19, 877-884. 
Kielkopf, C.L., Rodionova, N.A., Green, M.R., and Burley, S.K. (2001). A novel peptide recognition mode revealed by the X-ray structure of a core U2AF35/U2AF65 heterodimer. Cell $106,595-605$.

King, T.H., Liu, B., McCully, R.R., and Fournier, M.J. (2003). Ribosome structure and activity are altered in cells lacking snoRNPs that form pseudouridines in the peptidyl transferase center. Mol. Cell 11, 425-435.

Kohtz, J.D., Jamison, S.F., Will, C.L., Zuo, P., Lührmann, R., Garcia-Blanco, M.A., and Manley, J.L. (1994). Protein-protein interactions and 5'-splice-site recognition in mammalian mRNA precursors. Nature (London) 368, 119-124.

Kolev, N.G., and Steitz, J.A. (2006). In vivo assembly of functional U7 snRNP requires RNA backbone flexibility within the Sm-binding site. Nat. Struct. Mol. Biol. 13, 347-353.

Kolossova, I., and Padgett, R.A. (1997). U11 snRNA interacts in vivo with the 5' splice site of U12-dependent (AU-AC) pre-mRNA introns. RNA 3, 227-233.

Kramer, A. (1992). Purification of splicing factor SF1, a heat-stable protein that functions in the assembly of a presplicing complex. Mol. Cell. Biol. 12, 4545-4552.

Kramer, A., Gruter, P., Groning, K., and Kastner, B. (1999). Combined biochemical and electron microscopic analyses reveal the architecture of the mammalian U2 snRNP. J. Cell. Biol. 145, $1355-1368$.

Kramer, A., Mulhauser, F., Wersig, C., Groning, K., and Bilbe, G. (1995). Mammalian splicing factor SF3a120 represents a new member of the SURP family of proteins and is homologous to the essential splicing factor PRP21p of Saccharomyces cerevisiae. RNA 1, 260-272.

Krol, A., Westhof, E., Bach, M., Lührmann, R., Ebel, J.P., and Carbon, P. (1990). Solution structure of human U1 snRNA. Derivation of a possible three- dimensional model. Nucleic Acids Res. 18, 3803-3811. 
Kuge, H., Brownlee, G.G., Gershon, P.D., and Richter, J.D. (1998). Cap ribose methylation of cmos mRNA stimulates translation and oocyte maturation in Xenopus laevis. Nucleic Acids Res. 26, 3208-3214.

Kuge, H., and Richter, J.D. (1995). Cytoplasmic 3' poly(A) addition induces 5' cap ribose methylation: implications for translational control of maternal mRNA. EMBO J. 14, 6301-6310.

Lewis, J.D., Izaurralde, E., Jarmolowski, A., McGuigan, C., and Mattaj, I.W. (1996). A nuclear cap-binding complex facilitates association of U1 snRNP with the cap-proximal 5 ' splice site. Genes Dev. 10, 1683-1698.

Liao, X.C., Colot, H.V., Wang, Y., and Rosbash, M. (1992). Requirements for U2 snRNP addition to yeast pre-mRNA. Nucleic Acids Res. 20, 4237-4245.

Liautard, J.P., Sri-Widada, J., Brunel, C., and Jeanteur, P. (1982). Structural organization of ribonucleoproteins containing small nuclear RNAs from HeLa cells. Proteins interact closely with a similar structural domain of U1, U2, U4 and U5 small nuclear RNAs. J. Mol. Biol. 162, 623643.

Lührmann (1988). SnRNP proteins. In Birnstiel, M.L. (ed.), Structure and function of major and minor small nuclear ribonucleoprotein particles. Springer-Verlag, Berlin, Germany, pp. 100-114

Ma, X., Zhao, X., and Yu, YT. (2003). Pseudouridylation of U2 snRNA in S.cerevisiae is catalyzed by an RNA-independent mechanism. EMBO J. 22, 1889-1897.

MacMillan, A.M., McCaw, P.S., Crispino, J.D., and Sharp, P.A. (1997). SC35-mediated reconstitution of splicing in U2AF-depleted nuclear extract. Proc. Natl. Acad. Sci. USA 94, 133136.

MacMillan, A.M., Query, C.C., Allerson, C.R., Chen, S., Verdine, G.L., and Sharp, P.A. (1994). Dynamic association of proteins with the pre-mRNA branch region. Genes Dev. 8, 3008-3020.

Maden, B.E. (1990). The numerous modified nucleotides in eukaryotic ribosomal RNA. Prog. Nucleic Acid Res. Mol. Biol. 39, 241-303. 
Madhani, H.D., and Guthrie, C. (1992). A novel base-pairing interaction between U2 and U6 snRNAs suggests a mechanism for the catalytic activation of the spliceosome. Cell 71,803-817.

Maroney, P.A., Romfo, C.M., and Nilsen, T.W. (2000). Functional recognition of 5' splice site by U4/U6.U5 tri-snRNP defines a novel ATP-dependent step in early spliceosome assembly. Mol. Cell 6, 317-328.

Massenet S, Mougin, A., Branlant C (1998). Postranscriptional modifications U small nuclear RNAs. Grosjean and Benne ed. Modification and Editing of RNA. Washington DC: ASM Press, pp. 201-229

Mattaj (1988). U snRNP assembly and transport. In Birnstiel, M.L. (ed.), Structure and function of major and minor small nuclear ribonucleoprotein particles. Springer-Verlag, Berlin, Germany.

Mattaj, I.W., Habets, W.J., and van Venrooij, W.J. (1986). Monospecific antibodies reveal details of U2 snRNP structure and interaction between U1 and U2 snRNPs. EMBO J. 5, 997-1002.

Meister, G., and Fischer, U. (2002). Assisted RNP assembly: SMN and PRMT5 complexes cooperate in the formation of spliceosomal UsnRNPs. EMBO J. 21, 5853-5863.

Meroueh, M., Grohar, P.J., Qiu, J., SantaLucia, J., Jr., Scaringe, S.A., and Chow, C.S. (2000). Unique structural and stabilizing roles for the individual pseudouridine residues in the 1920 region of Escherichia coli 23S rRNA. Nucleic Acids Res. 28, 2075-2083.

Michaud, S., and Reed, R. (1991). An ATP-independent complex commits pre-mRNA to the mammalian spliceosome assembly pathway. Genes Dev. 5, 2534-2546.

Michaud, S., and Reed, R. (1993). A functional association between the 5' and 3' splice site is established in the earliest prespliceosome complex (E) in mammals. Genes Dev. 7, 1008-1020.

Milligan, J.F., and Uhlenbeck, O.C. (1989). Synthesis of small RNAs using T7 RNA polymerase. Methods Enzymol 180, 51-62. 
Moore, M.J., Query, C.C., and Sharp, P.A. (1993). Splicing of precursors to mRNA by the spliceosome., In RNA World, Gesteland A. ed. (Cold Spring Harbor, New York. Cold Spring Harbor Labratory Press), pp. 303-357.

Moore, M.J., and Sharp, P.A. (1992). Site-specific modification of pre-mRNA: the 2'-hydroxyl groups at the splice sites. Science 256, 992-997.

Nagai, K., Muto, Y., Pomeranz Krummel, D.A., Kambach, C., Ignjatovic, T., Walke, S., and Kuglstatter, A. (2001). Structure and assembly of the spliceosomal snRNPs. Novartis Medal Lecture. Biochem. Soc. Trans. 29, 15-26.

Nelissen, R.L., Will, C.L., van Venrooij, W.J., and Lührmann, R. (1994). The association of the U1-specific $70 \mathrm{~K}$ and $\mathrm{C}$ proteins with $\mathrm{U} 1$ snRNPs is mediated in part by common $\mathrm{U}$ snRNP proteins. EMBO J. 13, 4113-4125.

Newby, M.I., and Greenbaum, N.L. (2001). A conserved pseudouridine modification in eukaryotic U2 snRNA induces a change in branch-site architecture. RNA 7, 833-845.

Newby, M.I., and Greenbaum, N.L. (2002). Sculpting of the spliceosomal branch site recognition motif by a conserved pseudouridine. Nat. Struct. Biol. 9, 958-965.

Newcomb, L.F., and Noller, H.F. (1999). Directed hydroxyl radical probing of 16S rRNA in the ribosome: spatial proximity of RNA elements of the 3' and 5' domains. RNA 5, 849-855.

Nilsen, T.W. (1998). RNA-RNA interactions in nuclear pre-mRNA splicing, In Simons and Grundber-Manago ed., RNA structure and Function. Cold Spring Harbor Laboratory Press, New York, pp. 279-307.

Nottrott, S., Hartmuth, K., Fabrizio, P., Urlaub, H., Vidovic, I., Ficner, R., and Lührmann, R. (1999). Functional interaction of a novel $15.5 \mathrm{kD}$ [U4/U6.U5] tri-snRNP protein with the 5 ' stemloop of U4 snRNA. EMBO J. 18, 6119-6133. 
O'Day, C.L., Dalbadie-McFarland, G., and Abelson, J. (1996). The Saccharomyces cerevisiae Prp5 protein has RNA-dependent ATPase activity with specificity for U2 small nuclear RNA. J. Biol. Chem. 271, 33261-33267.

Ofengand, J., and Bakin, A. (1997). Mapping to nucleotide resolution of pseudouridine residues in large subunit ribosomal RNAs from representative eukaryotes, prokaryotes, archaebacteria, mitochondria and chloroplasts. J. Mol. Biol. 266, 246-268.

Ofengand, J., Bakin, A., Wrzesinski, J., Nurse, K., and Lane, B. G. (1995). The pseudouridine residues of ribosomal RNA. Biochem. Cell. Biol. 73, 915-924.

Pan, Z.Q., Ge, H., Fu, X.Y., Manley, J.L., and Prives, C. (1989). Oligonucleotide-targeted degradation of U1 and U2 snRNAs reveals differential interactions of simian virus 40 premRNAs with snRNPs. Nucleic Acids Res. 17, 6553-6568.

Parker, R., Siliciano, P.G., and Guthrie, C. (1987). Recognition of the TACTAAC box during mRNA splicing in yeast involves base pairing to the U2-like snRNA. Cell 49, 229-239.

Peled-Zehavi, H., Berglund, J.A., Rosbash, M., and Frankel, A.D. (2001). Recognition of RNA branch point sequences by the KH domain of splicing factor 1 (mammalian branch point binding protein) in a splicing factor complex. Mol. Cell. Biol. 21, 5232-5241.

Pikielny, C.W., Bindereif, A., and Green, M.R. (1989). In vitro reconstitution of snRNPs: a reconstituted U4/U6 snRNP participates in splicing complex formation. Genes Dev. 3, 479-487.

Price, S.R., Evans, P.R., and Nagai, K. (1998). Crystal structure of the spliceosomal U2B"-U2A' protein complex bound to a fragment of U2 small nuclear RNA. Nature 394, 645-650.

Query, C.C., Strobel, S.A., and Sharp, P.A. (1996). Three recognition events at the branch-site adenine. EMBO J. 15, 1392-1402.

Raker, V.A. (2000) Analysis of spliceosomal snRNP core particle assembly in vitro. PhD thesis., Philips University, Marburg. 
Raker, V.A., Hartmuth, K., Kastner, B., and Lührmann, R. (1999). Spliceosomal U snRNP core assembly: Sm proteins assemble onto an Sm site RNA nonanucleotide in a specific and thermodynamically stable manner. Mol. Cell. Biol. 19, 6554-6565.

Raker, V.A., Plessel, G., and Luhrmann, R. (1996). The snRNP core assembly pathway: identification of stable core protein heteromeric complexes and an snRNP subcore particle in vitro. EMBO J: 15, 2256-2269.

Rana, T.M., and Meares, C.F. (1991). Transfer of oxygen from an artificial protease to peptide carbon during proteolysis. Proc: Natl: Acad: Sci: USA 88, 10578-10582.

Reddy, R., and Busch, H. (1988). Small nuclear RNAs: RNA sequences, structure and modifications. In Birnstiel, M.L. (ed.), Structure and function of major and minor small nuclear ribonucleoprotein particles. Springer-Verlag, Berlin, Germany.

Reed, R., and Palandjan, L. (1997). Spliceosome assembly (Oxford, UK: IRL Press).

Rocak, S., and Linder, P. (2004). DEAD-box proteins: the driving forces behind RNA metabolism. Nat. Rev. Mol. Cell. Biol. 5, 232-241.

Ruskin B, Zamore, P., Green MR (1988). A factor, U2AF, is required for U2 snRNP binding and splicing complex assembly. Cell 52(2), 207-219.

Sampson, J.R., Sullivan, F.X., Behlen, L.S., DiRenzo, A.B., and Uhlenbeck, O.C. (1987). Characterization of two RNA-catalyzed RNA cleavage reactions. Cold Spring Harbour Symp. Quant. Biol. 52, 267-275.

Sanford, J.R., Ellis, J., and Caceres, J.F. (2005). Multiple roles of arginine/serine-rich splicing factors in RNA processing. Biochem. Soc. Trans. 33, 443-446.

Sashital, D.G., Cornilescu, G., McManus, C.J., Brow, D.A., and Butcher, S.E. (2004). U2-U6 RNA folding reveals a group II intron-like domain and a four-helix junction. Nat. Struct. Mol. Biol. 11, 1237-1242. 
Sawa, H., and Abelson, J. (1992). Evidence for a base-pairing interaction between U6 small nuclear RNA and 5' splice site during the splicing reaction in yeast. Proc. Natl. Acad. Sci. USA $89,11269-11273$.

Schaal, T.D., and Maniatis, T. (1999). Selection and characterization of pre-mRNA splicing enhancers: identification of novel SR protein-specific enhancer sequences. Mol. Cell. Biol. 19, 1705-1719.

Schneider, C., Will, C.L., Makarova, O.V., Makarov, E.M., and Lührmann, R. (2002). Human U4/U6.U5 and U4atac/U6atac.U5 tri-snRNPs exhibit similar protein compositions. Mol. Cell. Biol. 22, 3219-3229.

Schwer, B. (2001). A new twist on RNA helicases: DExH/D box proteins as RNPases. Nat. Struct. Biol. 8, 113-116.

Schwer, B., and Meszaros, T. (2000). RNA helicase dynamics in pre-mRNA splicing. EMBO J. $19,6582-6591$.

Segault, V., Will, C.L., Sproat, B.S., and Lührmann, R. (1995). In vitro reconstitution of mammalian U2 and U5 snRNPs active in splicing: Sm proteins are functionally interchangeable and are essential for the formation of functional U2 and U5 snRNPs. EMBO J. 14, 4010-4021.

Seraphin, B. (1995). Sm and Sm-like proteins belong to a large family: identification of proteins of the U6 as well as the U1, U2, U4 and U5 snRNPs. EMBO J. 14, 2089-2098.

Sickmier, E.A., Frato, K.E., Shen, H., Paranawithana, S.R., Green, M.R., and Kielkopf, C.L. (2006). Structural basis for polypyrimidine tract recognition by the essential pre-mRNA splicing factor U2AF65. Mol. Cell 23, 49-59.

Siliciano, P.G., and Guthrie, C. (1988). 5' splice site selection in yeast: genetic alterations in basepairing with U1 reveal additional requirements. Genes Dev. 2, 1258-1267. 
Singh, R., Banerjee, H., and Green, M.R. (2000). Differential recognition of the polypyrimidinetract by the general splicing factor U2AF65 and the splicing repressor sex-lethal. RNA 6, 901911.

Spadaccini, R., Reidt, U., Dybkov, O., Will, C., Frank, R., Stier, G., Corsini, L., Wahl, M.C., Lührmann, R., and Sattler, M. (2006). Biochemical and NMR analyses of an SF3b155-p14U2AF-RNA interaction network involved in branch point definition during pre-mRNA splicing. RNA $12,410-425$.

Staknis, D., and Reed, R. (1994). Direct interactions between pre-mRNA and six U2 small nuclear ribonucleoproteins during spliceosome assembly. Mol. Cell. Biol. 14, 2994-3005.

Staley, J.P., and Guthrie, C. (1998). Mechanical devices of the spliceosome: motors, clocks, springs, and things. Cell 92, 315-326.

Stark, H., Dube, P., Lührmann, R., and Kastner, B. (2001). Arrangement of RNA and proteins in the spliceosomal U1 small nuclear ribonucleoprotein particle. Nature 409, 539-542.

Stevens, S.W., Ryan, D.E., Ge, H.Y., Moore, R.E., Young, M.K., Lee, T.D., and Abelson, J. (2002). Composition and functional characterization of the yeast spliceosomal penta-snRNP. Mol. Cell 9, 31-44.

Sumpter, V., Kahrs, A., Fischer, U., Kornstadt, U., and Lührmann, R. (1992). In vitro reconstitution of U1 and U2 snRNPs from isolated proteins and snRNA. Mol. Biol. Rep. 16, 229240.

Sun, J. S., and Manley, J.L. (1995). A novel U2-U6 snRNA structure is necessary for mammalian mRNA splicing. Genes Dev. 9, 843-854.

Tanackovic, G., and Kramer, A. (2005). Human splicing factor SF3a, but not SF1, is essential for pre-mRNA splicing in vivo. Mol. Biol. Cell 16, 1366-1377.

Tarn, W.Y., and Steitz, J.A. (1996). Highly diverged U4 and U6 small nuclear RNAs required for splicing rare AT-AC introns. Science 273, 1824-1832. 
Udenfriend, S., Stein, S., Bohlen, P., Dairman, W., Leimgruber, W., and Weigele, M. (1972). Fluorescamine: a reagent for assay of amino acids, peptides, proteins, and primary amines in the picomole range. Science 178, 871-872.

Umen, J.G., and Guthrie, C. (1995). The second catalytic step of pre-mRNA splicing. RNA 1, 869-885.

Urlaub, H., Hartmuth, K., Kostka, S., Grelle, G., and Lührmann, R. (2000). A general approach for identification of RNA-protein crosslinking sites within native human spliceosomal snRNPs: Analysis of RNA-protein contacts in native U1 and [U4/U6.U5] snRNPs. J. Biol. Chem. 275 (52), 41458-68

Urlaub, H., Raker, V.A., Kostka, S., and Lührmann, R. (2001). Sm protein-Sm site RNA interactions within the inner ring of the spliceosomal snRNP core structure. EMBO J. 20, 187196.

Valcarcel, J., Gaur, R.K., Singh, R., and Green, M.R. (1996). Interaction of U2AF65 RS region with pre-mRNA branch point and promotion of base pairing with U2 snRNA [corrected]. Science 273, 1706-1709.

van Dam, A., Winkel, I., Zijlstra-Baalbergen, J., Smeenk, R., and Cuypers, H.T. (1989). Cloned human snRNP proteins B and B' differ only in their carboxy-terminal part. EMBO J. 8, 38533860.

Varani, G., and Nagai, K. (1998). RNA recognition by RNP proteins during RNA processing. Annu. Rev. Biophys. Biomol. Struct. 27, 407-445.

Walling, C., Partch, R.E., and Weil, T. (1975). Kinetics of the Decomposition of Hydrogen Peroxide Catalyzed by Ferric Ethylenediaminetetraacetate Complex. Proc. Natl. Acad. Sci. USA $72,140-142$.

Wassarman, D.A., and Steitz, J.A. (1992). Interactions of small nuclear RNA's with precursor messenger RNA during in vitro splicing. Science 257, 1918-1925. 
Wassarman, K.M., and Steitz, J.A. (1992). The low-abundance U11 and U12 small nuclear ribonucleoproteins (snRNPs) interact to form a two-snRNP complex. Mol. Cell. Biol. 12, 12761285.

Wersig, C., and Bindereif, A. (1992). Reconstitution of functional mammalian U4 small nuclear ribonucleoprotein: Sm protein binding is not essential for splicing in vitro. Mol. Cell. Biol. 12, $1460-1468$.

Westhof, E., and Michel, F. (1998). Ribozyme architectural diversity made visible. Science 282, 251-252.

Will, C.L., and Lührmann, R. (2006). Spliceosome structure and function. RNA World. 3rd ed. Cold Spring Harbor Laboratory Press, New York, pp. 369-400

Will, C.L., and Lührmann, R. (2005). Splicing of a rare class of introns by the U12-dependent spliceosome. Biol. Chem. 386, 713-724.

Will, C.L., and Lührmann, R. (1997). Protein functions in pre-mRNA splicing. Curr. Opin. Cell. Biol. 9, 320-328.

Will, C.L., Rumpler, S., Klein Gunnewiek, J., van Venrooij, W.J., and Lührmann, R. (1996). In vitro reconstitution of mammalian U1 snRNPs active in splicing: the U1-C protein enhances the formation of early (E) spliceosomal complexes. Nucleic Acids Res. 24, 4614-4623.

Will, C.L., Schneider, C., Hossbach, M., Urlaub, H., Rauhut, R., Elbashir, S., Tuschl, T., and Lührmann, R. (2004). The human 18S U11/U12 snRNP contains a set of novel proteins not found in the U2-dependent spliceosome. RNA 10, 929-941.

Will, C.L., Schneider, C., MacMillan, A.M., Katopodis, N.F., Neubauer, G., Wilm, M., Lührmann, R., and Query, C.C. (2001). A novel U2 and U11/U12 snRNP protein that associates with the pre-mRNA branch site. EMBO J. 20, 4536-4546.

Will, C.L., Schneider, C., Reed, R., and Lührmann, R. (1999). Identification of both shared and distinct proteins in the major and minor spliceosomes. Science 284, 2003-2005. 
Will, C.L., Urlaub, H., Achsel, T., Gentzel, M., Wilm, M., and Lührmann, R. (2002). Characterization of novel SF3b and 17S U2 snRNP proteins, including a human Prp5p homologue and an SF3b DEAD-box protein. EMBO J. 21, 4978-4988.

Wolff, T., Menssen, R., Hammel, J., and Bindereif, A. (1994). Splicing function of mammalian U6 small nuclear RNA: conserved positions in central domain and helix I are essential during the first and second step of pre-mRNA splicing. Proc. Natl. Acad. Sci. USA 91, 903-907.

Wu, J., and Manley, J.L. (1989). Mammalian pre-mRNA branch site selection by U2 snRNP involves base pairing. Genes Dev. 3, 1553-1561.

Wu, JY., and Maniatis, T. (1993). Specific interactions between proteins implicated in splice site selection and regulated alternative splicing. Cell 75, 1061-1070.

Wu, S., Romfo, C.M., Nilsen, T.W., and Green, M.R. (1999). Functional recognition of the 3' splice site AG by the splicing factor U2AF35. Nature (London) 402, 832-835.

Xu, Y.Z., Newnham, C.M., Kameoka, S., Huang, T., Konarska, M.M., and Query, C.C. (2004). Prp5 bridges U1 and U2 snRNPs and enables stable U2 snRNP association with intron RNA. EMBO J. 23, 376-385.

Yu, Y.T., Shu, M.D., and Steitz, J.A. (1998). Modifications of U2 snRNA are required for snRNP assembly and pre-mRNA splicing. EMBO J. 17, 5783-5795.

Zamore, P.D., Patton, J.G., and Green, M.R. (1992). Cloning and domain structure of the mammalian splicing factor U2AF. Nature 355, 609-614.

Zhang, D., and Rosbash, M. (1999). Identification of eight proteins that cross-link to pre-mRNA in the yeast commitment complex. Genes Dev. 13, 581-592.

Zhou, X., and Yu, Y.T. (2004). Pseudouridines in and near the branch site recognition region of U2 snRNAare required for snRNP biogenesis and pre-mRNA splicing in Xenopus oocytes. RNA 10, 681-690. 
Zhou, Z., Licklider, L.J., Gygi, S.P., and Reed, R. (2002). Comprehensive proteomic analysis of the human spliceosome. Nature 419, 182-185.

Zhuang, Y., and Weiner, A.M. (1986). A compensatory base change in U1 snRNA suppresses a 5 ' splice site mutation. Cell 46, 827-835.

Zillmann, M., Zapp, M.L., and Berget, S.M. (1988). Gel electrophoretic isolation of splicing complexes containing U1 small nuclear ribonucleoprotein particles. Mol. Cell. Biol 8, 814-821. 


\section{APPENDIX}

\section{List of Abbreviations}

$\begin{array}{ll}\text { A } & \text { adenosine } \\ \AA & \text { angstrom } \\ \text { ABE } & \text { aminobenzyl-EDTA } \\ \text { Amp } & \text { ampicilin } \\ \text { APB } & \text { (p)-azidophenacylbromide } \\ \text { APS } & \text { ammoniumperoxidisulphate } \\ \text { AS } & \text { anchoring site (sequence) } \\ \text { ATP } & \text { adenosine-5'-triphosphate } \\ \text { BABE } & \text { bromoacetylbromide-EDTA } \\ \text { BPS } & \text { branchpoint sequence } \\ \text { BSA } & \text { bovine serum albumin } \\ \text { bp } & \text { base pair } \\ \text { cpm } & \text { counts per minute } \\ \text { CTP } & \text { cytidine } \\ { }^{\circ} \mathrm{C} & \text { cacodidine-5'-triphosphate } \\ \text { Ci } & \text { centimeter } \\ \text { CE } & \text { Dalton } \\ \text { Da } & \text { curie } \\ & \end{array}$

DE53 diethyl amino ethyl cellulose 53 


\begin{tabular}{|c|c|}
\hline DNA & deoxynucleic acid \\
\hline dNTPs & deoxynucleotide-5'-triphosphates \\
\hline DMSO & dimethylsulfoxide \\
\hline dpm & desintegrations per minute \\
\hline DTT & 1,4-dithiothreitol \\
\hline DTE & 1,4-dithioerythrol \\
\hline E.coli & Escherischia coli \\
\hline EDTA & ethylendiamine-N,N,N',N'-tetraacetic acid \\
\hline EM & electron microscopy \\
\hline $\mathrm{EtOH}$ & ethanol \\
\hline fmol & femptomole \\
\hline G & guanosine \\
\hline GpppG & diguanosine triphosphate \\
\hline GTP & guanosine-5'-triphosphate \\
\hline $\mathrm{h}$ & hour \\
\hline HEPES & N-2-hydroxyethylpiperazine-N-2-ethane sulfonic acid \\
\hline $\mathrm{kDa}$ & kilodalton \\
\hline 1 & liter \\
\hline$\mu$ & micro \\
\hline $\mathrm{m}$ & methyl \\
\hline $\mathrm{M}$ & molar \\
\hline $\mathrm{m}_{3} \mathrm{G}$ cap & 2,2,7-trimethyl-diguanosine triphosphate $5^{\prime}$ cap \\
\hline$m^{7} G$ cap & 7-monomethyl-diguanosine triphosphate 5 ' cap \\
\hline $\mathrm{Ab}$ & monoclonal antibody \\
\hline & magnesium \\
\hline
\end{tabular}




$\begin{array}{ll}\text { min } & \text { minute } \\ \text { ml } & \text { mililiter } \\ \text { mRNA } & \text { messenger RNA } \\ \text { N } & \\ \text { nM } & \text { any nucleotide } \\ \text { NMR } & \text { nanomolar } \\ \text { NP-40 } & \text { nuclear magnetic resonance } \\ \text { nt } & \text { Nonidet P-40 } \\ \text { nxt } & \text { nucleotide } \\ \text { nuclear extract } \\ \text { OH }\end{array}$




$\begin{array}{ll}\text { snRNA } & \text { small nuclear ribonucleic acid } \\ \text { snRNP } & \text { small nuclear ribonucleoprotein } \\ \text { snoRNP } & \text { small nucleolar ribonucleoprotein } \\ \text { SR } & \text { serine-arginine } \\ \text { ss } & \text { splice site } \\ \text { 3D } & \text { three-dimensional } \\ \text { T } & \text { thymidin } \\ \text { TBE } & \text { tris-borate-EDTA buffer } \\ \text { TCEP } & \text { tris(2-carboxyethyl) phosphine } \\ \text { TEMED } & \text { N,N,N',N'-tetramethylethylenediamine } \\ \text { TPs } & \text { total proteins from HeLa snRNP particles } \\ \text { tRNA } & \text { transfer RNA } \\ & \\ \Psi & \text { pseudouridine } \\ \text { U } & \text { uridine } \\ \text { U snRNP } & \text { uridine-rich small nuclear ribonucleoprotein particle } \\ \text { UTP } & \text { uridine-5'-triphosphate } \\ \text { UV } & \text { ultraviolet } \\ \text { V } & \text { vyrimidine } \\ \text { W } & \text { volume } \\ \text { w/v } & \text { volume per volume } \\ & \\ \text { weight } & \text { weight per volume } \\ & \end{array}$




\section{Acknowledgements}

Firstly, I would like to thank Prof. Dr. Reinhard Lührmann for this interesting topic, for his intellectual stimulation, his support, his advices, fruitful discussions and his interest in this project. I am also grateful to him for giving me the chance to attend international conferences and present my results.

I would like to thank Prof. Dr. Ralf Ficner, Dr. Winfried Kramer and Dr. Markus Hauck for being the members of my examination committee. I am also thankful to Prof. Dr. Reinhard Jahn, Prof. Dr. R. Hardeland and Prof. Dr. Jörg Stühlke for being the members of my external $\mathrm{PhD}$ thesis committee.

I thank Dr. Klaus Hartmuth for his support and help during the course of this work. I also thank him for the paper discussions and the critical reading of my thesis.

Many special thanks to Dr. Berthold Kastner for preparing nice figures for my U1 data, always providing us with schemes, all the U1 discussions and for his continuous help.

I am very much grateful to Dr. Patrizia Fabrizio for all her support and friendship, scientific and non-scientific discussions and helping me whenever I need. I thank her very much for her advices about my future and being with me in my good and bad days.

I am grateful to Dr. Reinhard Rauhut for all his help, support and advices all the time. I thank him for scientific and non-scientific discussions and helping me with the procedure to send my paper.

I would like to thank Dr. Cindy Will for scientific discussions, help with my paper and help for the talks and abstracts of the RNA meetings. I also thank her for the critical reading of my thesis abstract. 
I am very much grateful to Abdullah Yalcin for helping me doing my clonings and showing me the best ways and strategies.

I am grateful to Rebecca Mathew for her close friendship, support, for our coffee breaks and sharing my happiness and also my problems.

I thank to Elif Karagöz very much for her friendship and support and for our cheesesandwich lunches together.

Many thanks to Christian Merz for sharing our small bench together for all these years and being very nice to me when I occupy more space with my huge primer extension gels.

I thank Juliane Moses very much for helping us all the time with our administrative or visa problems and doing her best.

I would like to thank Uschi Drössler and Gertrud Nowak for being so kind, cheerful and helpful all the time. I also thank Peter Kempkes, Thomas Conrad, Kami and Belinda for preparing the nuclear extracts.

I finally would like to thank everybody, all my past and present collegues for the nice working atmosphere in this lab.

Very very special thanks to my parents, my brother and my sister for their continiuos support and help. They always had to miss me because I am far away but they always believed in me and were proud of me.

Most of all, I am very much thankful to my beloved husband Abdullah Yalcin for all his help, interest, trust and ever-lasting love. He always helped me, believed in me and stood beside me. 


\section{Cirriculum Vitae}

\section{PERSONAL INFORMATION}

Name

Surname

Date of birth

Place of birth

Natonality

Gender

EDUCATION

2002-present

2000-2002

1996-2000

1989-1996

1984-1989
Gizem

Dönmez

17.04.1978

Nazilli, Turkey

Turkish

Female graduate study in Department of Cellular Biochemistry

Max Planck Institute of Biophysical Chemistry, Göttingen

Superviser: Prof. Dr. Reinhard Lührmann

MSc International MSc/PhD program of Molecular Biology and

Max Planck Institute of Biophysical Chemistry, Göttingen

Department of Cellular Biochemistry

Superviser: Prof. Dr. Reinhard Lührmann

B.Sc Department of Molecular Biology and Genetics (high honor) Middle East Technical University, Ankara, Turkey

Nazilli Anatolian High School

Beseylul Primary School 


\section{SCHOLARSHIPS}

Max Planck Scholarship (2001-present)

International Msc/PhD program of Molecular Biology scholarship (2000-2001)

Sabanci Group Holding scholarship (1996-2000) due to very high ranking in nationwide university entrance examinations

Turkey Scientific and Technical Research Corporation Scholarship (1996-2000) due to very high ranking in nationwide university entrance examinations

\section{CONFERENCES}

$28^{\text {th }}$ FEBS Meeting

October 2002, Istanbul Turkey

Poster presentation: "Investigation of the modified nucleotides in the 5' end of human U2 snRNA in pre-mRNA splicing"

International symposium: Structure, function and dynamics of RNA-protein complexes September 2003, Göttingen, Germany

Poster presentation: "Investigation of the modified nucleotides in the 5' end of human U2 snRNA in pre-mRNA splicing"

$9^{\text {th }}$ annual meeting of the RNA Society

June 2004, Madison USA

Oral presentation: "Modified nucleotides in the 5' end of the human U2 snRNA are required for early spliceosome (E complex) formation in vitro"

$11^{\text {th }}$ annual meeting of the RNA Society

June 2006, Seattle, Washington, USA 
Oral presentation: "U1 and U2 snRNPs are in close proximity in early spliceosomal complexes as revealed by U2-tethered hydroxyl radical probing"

\section{PUBLICATIONS}

\section{Toyran N, Zorlu F, Dönmez G, Oge K, Severcan F}

Chronic hypoperfusion alters the content and structure of proteins and lipids of rat brain homogenates: a Fourier transform infrared spectroscopy study. Eur Biophys J. 2004 Oct;33(6):549-54

Dönmez G, Hartmuth K, Lührmann R

Modified nucleotides at the 5' end of human U2 snRNA are required for spliceosomal Ecomplex formation RNA. 2004 Dec;10(12):1925-33

Dönmez G, Hartmuth K, Kastner B, Will CL, Lührmann R

The $5^{\prime}$ end of U2 snRNA is in close proximity to reactive groups of the pre-mRNA and to $\mathrm{U} 1$ in early spliceosomal complexes (manuscript submitted). 


\section{Declaration}

I herewith declare that I prepared the $\mathrm{PhD}$ thesis "Investigation of the higher order structure of the spliceosomal RNA network" on my own and with no other sources and aids than those quoted.

Ich versichere, daß ich die vorliegende Arbeit selbständig verfaßt und keine anderen als die angegebenen Quellen und Hilfsmittel benutzt habe.

Die Arbeit hat in gleicher oder ähnlicher Form noch keiner Prüfungsbehörde vorgelegen.

Parts of this thesis were published in:

Dönmez G., Hartmuth K., and Lührmann R. (2004) Modified nucleotides at the 5' end of human U2 snRNA are required for spliceosomal E-complex formation. RNA 10, 1925-33

Dönmez G., Hartmuth K., Kastner B., Will CL., and Lührmann R (2006) The 5' end of $\mathrm{U} 2$ snRNA is in close proximity to U1 and functional sites of the pre-mRNA in early spliceosomal complexes. (manuscript submitted)

Göttingen, December 2006 
